\title{
Learning to Innovate: Learning Regions
}

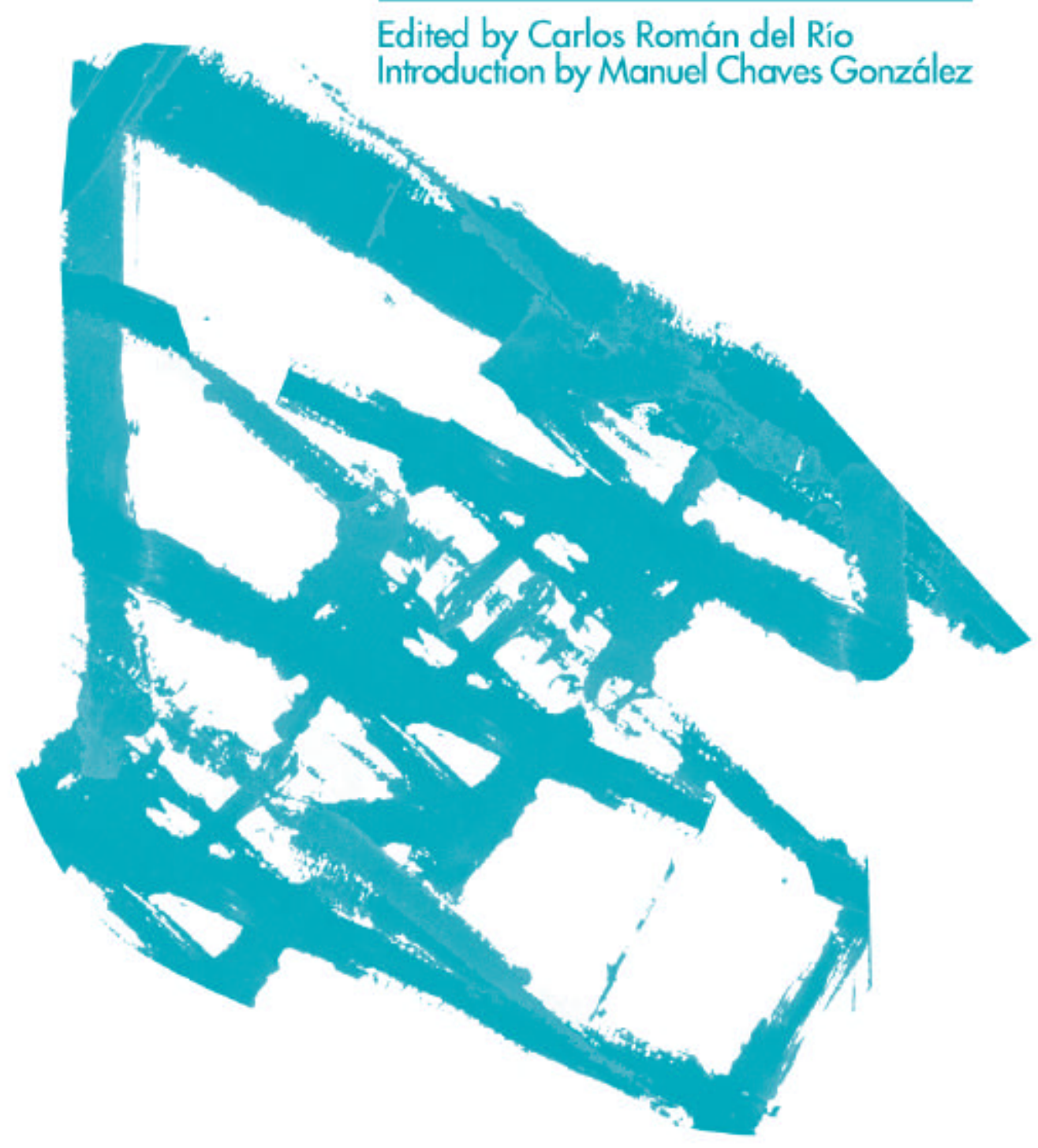

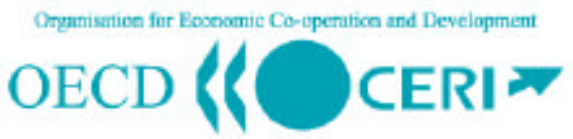

Center for Fdocmional Research and Ienowation

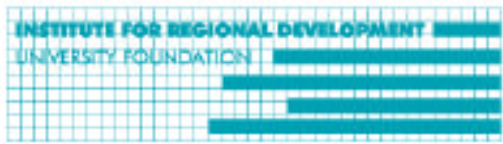

INSTITUTE FOR REGIONAL DEVELOPMENT, 



\section{Learning to Innovate: Learning Regions}

Authors:

Donald Hirsch

Carlos Román del Río

Rafael Camacho Ordóñez

Francisco Alburquerque, Paula Rodríguez, Carlos Román and Raquel Ruiz José María Martín Delgado

Antonio Pascual Acosta

Luis Atienza Serna

Felipe Romera Lubias

Alain Rallet

Thierry Bruhat Consultants

Charles Edquist, François Texier and Nina Widmark

Óscar Villarreal Fernández

INSTITUTE FOR REGIONAL DEVELOPMENT, UNIVERSITY FOUNDATION ORGANISATION FOR ECONOMIC CO-OPERATION AND DEVELOPMENT CENTER FOR EDUCATIONAL RESEARCH AND INNOVATION JUNTA DE ANDALUCÍA

PARQUE TECNOLÓGICO DE ANDALUCÍA 
All rights reserved. No part of this publication may be reproduced, stored in a retrieval system or transmitted in any form or by any means, electronic, mechanical or photocopying, recording, or otherwise without the prior permission of the publishers.

(1) OECD/IDR, 2001

Cover design: Anfora. Grupo de Marketing y Comunicación

Published by: Anfora. Grupo de Marketing y Comunicación

IRD English edition ISBN: 84-86783-32-1 
Learning to Innovate: Learning Regions

Table of Contents

Foreword

Bruno della Chiesa

Introduction

Manuel Chaves González

1. The Learning Region and Cultural Capital:

The Case of the Andalusia Region

Donald Hirsch

2. Learning to Innovate

Carlos Román del Río

3. Economic and Social Development in Andalusia

Rafael Camacho Ordóñez

4. Learning to Innovate: Learning and Cultural Capital Regions

Francisco Alburquerque Llorens, Paula Rodríguez Modroño,

Carlos Román del Río and Raquel Ruiz Crespo

5. Culture as a Basis for Regional Development in Andalusia 129 José María Martín Delgado

6. Indicators for Learning Regions and Cities 135

Antonio Pascual Acosta

7. Sustainable Development and the Environment

Luis Atienza Serna

8. The Influence of Science and Technology Parks on their Surrounding Area: The Andalusia Technology Park

Felipe Romera Lubias

9. The Role of Information and Communication Technology in Local Development: Prospective Analysis of the Case of the Ile de France Region Alain Rallet 
10. Information and Communication Technologies and Regional Development: The Challenges of Creativity and Identity 195 Thierry Bruhat

11. The East Gothia Regional System of Innovation:

A Descriptive Pre-study 205

Charles Edquist, François Texier and Nina Widmark

12. The Role of Culture in Economic and Social Development in Jalisco, México

Óscar Villarreal Fernández 


\section{Foreword}

Organisation for Economic Co-operation and Development

A rapidly growing number of cities and regions in OECD societies and economies are putting learning, education, research and innovation at the heart of their developments strategies, bringing together governments, the private sector and society. The burgeoning interest in learning cities and regions reflects fundamental shifts taking place. They are fast becoming knowledgebased, organised as never before around learning and human skills. Today, these factors are central not only to individual success but also to gaining national, regional and urban economic advantage. Comparative advantage is increasingly dependent on human resources, knowledge creation, and continuous, incremental innovation rather than on access to physical capital and raw materials.

This book contains a synthesis of the presentations made during the conference held in Málaga, Spain, on 30 September and 1 October 1999, as well as the outline document prepared for the seminar by the Andalusian IDR (Instituto de Desarrollo Regional), papers presented in Málaga (including a perspective on the economic and social development in Jalisco, Mexico), and finally 3 papers presented at an earlier seminar. The main topic of discussion at the Málaga conference was "the impact of the cultural capital and knowledge upon social and economic development" of Andalusia as a learning region. The Málaga seminar was part of a larger horizontal OECD project on learning cities and regions organised by CERI (Centre for Educational Research and Innovation) in co-operation with TDS (Territorial Development Service). Other conferences have taken place between 1998 and 2000 in Jena (Germany), the Vienne region (France) ${ }^{\prime}$, the Øresund region (Denmark/Sweden) and the Kent

Where the three additional papers of this report come from. 
Thames-side region (United Kingdom).

This report analyses different approaches to regional development based on knowledge and innovation in Andalusia, with potential applications to similar areas, and on which Professor Carlos Román proposes some theoretical hypothesis. Presentations and discussions focussed on the current situation of the region, analysing its evolution over the last twenty years, and evaluating the policies already implemented in the region. Furthermore, the participants contributed to establishing a diagnosis of the present socio-economic system in order to measure the applicability of policies that would help Andalusia to develop towards a learning region, building up on human, social, cultural and "synergetic" capital.

The Málaga seminar was co-organised by the OECD (CERI and TDS), the Junta de Andalucía (Regional Government) and by the Andalusian Technological Park (Parque Tecnológico de Andalucía), who also hosted the meeting. Professor Carlos Román, Director of IDR, has edited this report with assistance of the OECD Secretariat.

Paris, August 2001

Organisation for Economic Co-operation and Development 


\section{Introduction}

Manuel Chaves González

President of the Andalusian Regional Government

For a few days, Málaga was the forum for debate on the new society we are heading for. The ideas of the experts attending the 'Impact of cultural capital and knowledge on economic and social development' seminar have inevitably prompted a recognition of the transcendental role that new technology will play in configuring future societies and their economic stability.

Today, consolidating Andalusia's economic development is therefore based on an irrefutable premise: that of root-and-branch incorporation into the so-called 'knowledge society'.

Like other areas in the region, Andalusia faces the challenge of having to find its own space in a socially and economically more globalised and interconnected world. The basic instrument for achieving sufficient independence to manage our own future is new technology; the previous step was training our human capital to make use of it. The Andalusian administration is determined to ensure that the highway to technological and computerised development does not end up being off-limits for a significant number of Andalusians.

Today, our Community enjoys a much healthier economic and social situation than it has done historically for consolidating its development and more effectively meeting the challenge. Globalisation and competitiveness are two things that have to be borne in mind when drawing up economic strategies; they are also issues that invite us to see access to new technology and to the popularisation of new information tools as key factors in conquering the new times ahead.

Without this space of our own, the economic benefits that we have built up over the last few years, economic growth and the consolidation of 
social gains will lose momentum, and the Andalusian economy will be in danger of collapsing.

To this end, the Andalusian government has placed special emphasis on promoting a series of measures and incentives designed to improve and facilitate access for Andalusian people and their enterprises to new technology, and to back up this move with the necessary infrastructures to prevent the collapse of the economic transformation that will come from the widespread use of new tools of communications.

The training of human capital in accordance with these objectives and, therefore, the adaptation of training systems together with the structuring of a more socially and economically united civil society in Andalusia will contribute to a better-placed implantation. The vocational training of our young people and entrepreneurs must therefore respond to these new demands.

The adaptation of training structures and the penetration of educational establishments by new technology are now of paramount importance if the investments of enterprises and Public Administrations are not to be wasted. More than at any time in the past, universities must now seek the closest possible relationship between educational offer and the labour market, in the knowledge that the latter is now moving by leaps and bounds towards globalisation via the Internet. Because the new society sees itself as the 'knowledge society', universities must identify the new concept quickly and train new protagonists of this new employment and social revolution.

Moreover, Andalusia's economic and social structure has been changing over the last few years and has become easier to penetrate. This has enabled it to overcome its almost exclusive dependency on the primary production sector, and has boosted the importance of service industries and tourism. The Andalusian economy is now travelling along paths that are both closer to, and more adaptable to, technological innovation. In this context, the Autonomous Administration also has responsibility for promoting research and encouraging its entrepreneurial structure to adapt to using new technology.

An example of this transformation is the new face presented by agriculture in our Community. The primary sector, which continues to be the foundation of Andalusia's economic structure (it produces $11.2 \%$ of GDP), has turned into the region's biggest export industry, and in this respect, the Internet will be the first and main departure point - if it has not become that already. The competitiveness of these enterprises, and their genuine survival in a global market with windows and portals in every home on the planet, will depend on 
their effective access to these systems.

Today, at the dawn of the 21 st century, progress means fluency at surfing the networks that dominate world communications and economic trade; it also means that the maximum extension of new technology must be guaranteed. At the beginning of the 20th century, great minds saw literacy as the challenge that must at all costs be overcome; today, the assimilation of new technology must be articulated in terms no less urgent.

Our Community cannot, and must not, miss this opportunity. Occupation of a recognised place in the knowledge and information society guarantees our future.

Seville, August 2001

Manuel Chaves González

President of the Andalusian Regional Government 



\section{The Learning Region and Cultural Capital: The Case of Andalusia Region}

Donald Hirsch

International Consultant

\section{Introduction}

"But what is a learning region?"

This elementary but unanswered question pervaded the penultimate seminar of a series which, rather than produce a precise set of criteria for certifying or quantifying a region's "learning" qualities, has gone some way to establishing the learning region as a broad paradigm.

There is a natural desire to get beyond the rather vacuous platitudes that undoubtedly permeate this field. So the production of a very preliminary, selective group of indicators for the seminar was helpful. But it also demonstrated the difficulty of giving a precise, functional definition of a learning region. Yet in this seminar and in those that preceded it, participants from regions across Europe have identified common strands and developed key ideas around the factors that can ensure that learning drives a region's economic and social development.

In brief, it is becoming clear what we can and cannot expect to do with the concept of a learning region.

What we can do is:

1) First, identify certain ways in which learning can be a key aspect of a region's development. These include: 
a) Fulfilling conditions, within a region, that are important regardless of the spatial dimension, in the light of globalisation and technological change. So for example the level of worker skills, the ability of its citizens and workers to be flexible and the presence of institutional structures that favour innovation, are agreed now to be central to the success of any nation, region or other locality.

b) Aspects that make the regional or local level of key importance in the success of economies - including networking, the building up of social capital, and the identification of local economic strengths. The notion of industrial/commercial advantage is nothing new. But it becomes more important in the global marketplace where closeness to one's markets is no longer sufficient protection against competition. Moreover the importance of regional or local cultural factors is double-faceted, entailing both culture as a marketable asset in itself, and culture as a way of doing things that can make a vital contribution to comparative advantage now that other factors such as capital and information are more mobile.

2) Second, translate these factors into a series of key attributes that are likely to be necessary elements in a learning region. (The fact that they may not be sufficient prevents them from being used reliably as measures to validate learning regions.) Indicators can help us observe such factors. They include:

- Strong levels of investment in the infrastructure of learning - such as education and training institutions and university research.

- Indicators of innovation, such as the number of patents applied for.

- Indicators of social cohesion, such as low crime and extensive networks.

The commentary on the Málaga seminar below illustrates ways of applying these two aspects of what we can do.

What we cannot do, however, is:

- First, provide a functional definition of a learning region, that distinguishes regions that have and have not achieved this status; or

- Second, pretend that indicators can rank regions by how well they learn. 
In the first place, each region has its own particularities, and learning will play a different role in the development of each one according to its present strengths and weaknesses. A related point is that if learning is a pathway, indicators are more apt to measure how far a region has progressed along it rather than the more important matter of whether it is facing in the right direction. Finally, all regions are in one sense learning regions in that their past and present influence their future. We cannot necessarily tell how effective this learning process will be until after the event. First Century Judea, for example, may have seemed a rather backward place to live, but witnessed a period of theological innovation that was to accelerate its own and the world's learning curves.

\section{What is a region?}

Before proceeding to the substance of the dimensions of learning regions discussed in Málaga, it is worth reflecting on what a region is, a recurring theme at the seminar. At least two distinct concepts can be identified. The commonest use in Europe relates to the EU's official regions, of which Andalusia is one. These bodies typically have several million inhabitants and are the first sub-unit of a country. They may share a cultural identity (more so in some cases than in others - depending on history), but are generally too spread out geographically for daily interactions among their members. A second type of "region", which may also be called a "district", is much smaller and allows closer daily contacts among its inhabitants - Kent Thamesside is one. This distinction is important to the discussion about, for example, social capital which follows: it was postulated that only within "travel to work" areas can the term have real meaning. A complication is that some urban regions such as Greater London share features of both types, while in a partly-urban region such as Oresund it may be possible to create closer daily links between neighbouring urban areas. These differences add to the richness of the analysis of subnational areas engaged in learning, but need to be borne closely in mind.

\section{Three dimensions of regional learning}

In this seminar, in a complex discussion of how regions learn and develop, three particularly strong threads emerged:

- First, the importance of a strategic direction of regional learning, in 
terms of a common set of broad objectives for the region's development.

- Second, the importance of social and institutional relationships in determining the ability of regions to learn and to develop distinctive advantages. Natural resources, capital stocks or other physical advantages are relatively less important than in the past, compared to human interactions.

- Third, the significance of the cultural heritage of a region, which presents an opportunity and a challenge - that of building on the region's past to construct a better future.

Each of these (overlapping) threads creates a dimension in which the features of learning regions can be discussed.

\section{A) Strategic directions}

Andalusia is a poor European region, attempting to develop more rapidly than the rest of Spain and Europe and thus secure a more prosperous future. It has succeeded to some degree in improving its relative position in recent years, with higher growth rates than the rest of Spain and a reversal of a situation of strong net outward migration. In the 1960s and 1970s, under a more centralised regime, the development was based around a clear physical advantage: the region's climate. This was used to promote mass tourism in what had been a poor agriculture-based region. But more recently, there has been a more than diversified strategy. This has been based both around improving the quality of tourism, and promoting a wider range of industries, including those based on new technologies such as audio-visual industries and advanced business sectors. Sustainability has been an important part of this strategy, as has the desire to spread the benefits of development to a wider section of the population.

To varying degrees, regions formulate visions of their own futures, that may have economic, environmental and social aspects. It is a simplification to imagine that everyone in a region will have the same vision, or that a strategy is a static set of objectives rather than an organic, constantly changing set of ambitions. The experience of the previous region to be examined in this seminar series, Oresund, was that it could be hard to define in advance in which economic sectors the best hope for the future lay. Yet at the very least, common factors shaping the destiny of people of the region can be a source of common purpose. In Andalusia, those factors derive from a background of 
agricultural poverty, mass tourism and cultural richness. But making the most of this heritage is not just a matter of good economic planning: the ability to develop social, institutional and cultural strengths will be crucial.

\section{B) Social and institutional relationships}

The dramatic increase over the past two decades in the mobility of both capital and information has changed the nature of comparative advantage. Countries and regions that expect to enjoy a higher standard of living than low-wage parts of the world, where many industrial processes can be replicated, need to have highly productive workers. This in turn relies on constantly "staying ahead" of replicable productive processes by being at the forefront of innovation. This much has been understood for some time now; hence the quest for a more skilled and adaptable workforce. What has emerged in the second half of the 1990s is the importance of local innovation systems, which rely on patterns of human and institutional relationships within particular sectors and regions.

These systems rely first and foremost on productive and open knowledge networks, bringing together the producers and consumers of knowledge. The Andalusia case illustrated both the potential and the pitfalls of these human relationships. The development of the technology park at which the seminar took place epitomised the efforts by a relatively poor and underdeveloped region to use knowledge relationships as a driver of change. It was also clearly a new departure in terms of bringing together public and private institutions. In particular, the creation of such a park fits into a new regional policy that puts a new emphasis on the strengthening of small and medium sized enterprises, which are important drivers of innovation, of networks that link to knowledge from outside the region, and of endogenously generated growth.

But more broadly, for successful knowledge networks to support innovation, everyday contacts between universities and industries need to be constructive throughout a region - not just at cutting-edge business parks. Constructive university-industry contacs are needed across the region. This is not just a matter of finding ways of disseminating scientific "findings" from universities. CERI's work on knowledge production, mediation and use is showing that the three are closely bound up in interactive processes rather than a linear pattern of invention followed by application. So universities and companies must build close relationships built around trust. In the seminar it was stated that universities had contributed to innovation within the region, for example 
through the establishment of Research Result Transfer Offices and Technology Transfer Offices. It also heard examples of how entrepreneurs had helped mobilise regional learning in terms of driving the development of new industries such as the mining of marble. But trust and collaboration between the two clearly had some way to go. The sometimes antagonistic exchanges between local actors made it clear that universities and industry each had its own version of innovation, and sometimes found it easier to collaborate with partners outside the region than across the public-private divide. Part of the task of building a learning region will clearly be to build closer understanding between the two.

That these relationships involve more than just building a scientific knowledge base was illustrated by research findings in the old Laender of Germany comparing knowledge development in districts that have a university with those that do not. Where a university is present, there are clear spinoffs in terms of the quantity of research and development activity, the number of highly qualified employees and the strength of technical professions. But the advantage does not flow through to more patents, innovation or firm births: these seem to depend on activity outside the influence of the university. (In the new German Laender, however, the link did exist, reflecting the less mature state of private institutions).

So while company-university links are important in the factors that stimulate innovation, they are not the only factor. The notions of social capital and institutional capital go wider, putting stress on the knowledge networks that form across organisations and on the trust relationships that are needed to make those networks strong and effective. Here the local dimension comes into play; it was suggested at the seminar that the level at which these trust relationships can be forged is much smaller than a region like Andalusia, and is unlikely to be larger than a travel-to-work district.

Yet while some aspects of social and institutional capital need to be local, the potential for a region-wide contribution should not be dismissed. Andalusia's regional government has set up a "Forum for Andalusia in the New Century" consisting of a debate about the region's future among professionals, intellectuals and ordinary citizens via the Internet. Such discussion can contribute to the strategic vision referred to above, and give a broad "ownership" of this vision which helps build the co-operative relationships implied in "social capital". 


\section{C) Cultural elements}

This seminar paid particular attention to the cultural aspects of learning regions. A number of regions made presentations drawing attention to their cultural heritage. A striking, recurring theme in these presentations was the depiction of certain regions as meeting places of cultures rather than simply as closed, monocultures.

- Andalusia has seen the coming together of many peoples and religions, forming a bridge between Europe and Africa. The Muslim history of the region up until the late fifteenth century, epitomised in the splendid and much-visited Alhambra palace in Granada, sets the region's history apart from the rest of Western Europe. The cultural diversity of this region has often been matched by inter-cultural tolerance.

- Styria in Austria also presented itself as a meeting-place of peoples - again with a history of Christianity meeting Islam, in this case when Turkish peoples spread through the eastern part of Europe. The ending of the cold war period, in which Austria was more isolated as an eastern outpost of the West, once more gives it this role as a crossroads and a mediator between east and west. The University of Graz, for example, is building on its long tradition of helping to educate southeast Europeans.

- Wroclaw in Poland has seen a dramatic movement of peoples in the present century, with the "exchange" of some 250,000 Germans for a similar number of Poles at the end of the Second World War. A city strongly aware of its history, whose thousandth birthday it is celebrating with the millenium, Wroclaw is consciously trying to make culture a centrepiece of regeneration, with the creation of a "cultural stimulation zone".

- The Jalisco region of Mexico identified three key aspects of its regional culture as (i) the influence of the population living outside the region (especially in the United States), whose income helps stimulate family business and who bring back with them aspects of the international culture; (ii) religious tradition and (iii) the role of the family in the centre of the society.

Looked at crudely, the cultural heritage of a region can be a marketable asset. Tourist, craft and various leisure industries can draw on this asset. Tradition may seem an odd commodity to sell at times of rapid change, but it was suggested that it becomes all the more marketable during this period because people want something to cling onto. 
But this, surely, cannot be all there is to the cultural side of learning regions. On its own the Alhambra, like the sun on the Costas, can be seen as more or less a natural resource. Medieval palaces cannot by definition be replicated, so the supply of them in the 21 st century is already given. What can be influenced is not the production of this kind of cultural capital, but how it is used, and how cultural capital in a much broader sense is developed in the future.

This broader sense refers to culture as a way of doing things: "the past as a training institution for the future", as one participant put it. For a region's past to influence its future, it needs to learn to put old strengths to new advantage.

One way of doing so, for the regions mentioned above, is to use the cosmopolitan aspects of one's past to manage a very modern problem: how to reconcile the apparent contradiction between the new localism and the new globalism. This is a matter of finding distinctive local roles within the global economy and society. How good are communities at trading and interacting with outsiders without losing their own identity? The Internet provides tools for both global and local networks. The importance of locally bred innovation within world markets provides a strong motivation to develop them both. Cultural affinity for such a balance may be a vital link.

Another important contribution made by local culture concerns the organisation of social and economic activity. This was shown most clearly in the Jalisco region, where the strength of the family can be turned to good advantage. If local knowledge creation is stimulated by small enterprises bound together internally and with others in the locality through relationships of trust, the family is the world's oldest knowledge creator.

The selection of regions and cities to participate in this seminar and others in the series has been highly arbitrary, so the advantages that they bring to new tasks from old characteristics is bound to be idiosyncratic. But this type of example is an indication of how the historical aspects of one's culture and the new challenges that lie ahead can be connected. In coming together to analyse strengths and project the future, a region's inhabitants should not underestimate the relevance of what lies in their history. 


\section{What can indicators tell us?}

Ambitiously, the OECD Secretariat started to collect some preliminary indicators of learning regions for the present seminar. These helped show as much the limitations of what can be measured as the present state of learning in the regions under discussion.

The model presented is straightforward enough. It sees human capital and social capital as "inputs", with the latter helping to strengthen the former. The "outputs" of economic competitiveness and social cohesion are also relatively easy to conceptualise, as is the proposition that human capital has important social as well as economic benefits, while social capital supports not only social goals but also economic competitiveness. What is difficult, of course, is to put numbers on these four characteristics, in ways that accurately measure region's strengths.

One thing that the evidence shows clearly is that affluence is associated with measurable features of learning, such as educational expenditure, $R \& D$ activity and patent development. Of course, the age-old question around such an association concerns the direction of causality. It seems reasonable, however, to conclude that for a relatively poor region like Andalusia to move ahead, it needs to develop learning characteristics in parallel with economic growth: the former helps make possible the latter, and vice versa.

But to measure the degree to which a region is equipped for "learning" is an altogether more complicated business, which is unlikely in the medium term to involve more than just some "interesting data" on which to reflect, rather than holistic indicators. One possibility would be to look at the extent to which a region "bucks the trend" or outperforms what would be expected of it in some respect, in light of other variables. A simple example concerns patent applications: an OECD analysis of EU regions shows that a cluster of regions have between about zero and 100 applications per million inhabitants, varying roughly in proportion to their GDP per capita. But another group of regions are on a much steeper trend line, rising to over 300 applications per million inhabitants in three well-off regions which are not however the richest. An analysis of outliers of this type is one way in which indicators can guide the examination of learning regions without in themselves giving the results.

Another possibility raised at the seminar is to think of less conventional indicators linked with features of the specified inputs. Social capital is said to be based on networks and on trust. There are many ways of measuring net- 
works, but it is hard to capture their quality simply by counting contacts. Can trust be measured? Perhaps an over-legalistic society is an indicator of the lack of social trust: if one has to fill out many contracts before buying a secondhand car, that is an indicator that local trust is weak. (The author of this seminar report had recently rented a car in the United States, where he was instructed to look carefully for any small scratches and sign a form to certify whether he found any. In Granada after the conference he also rented a car, and noticed a huge dent in the side, but was told by the agent "don't worry, when you return the car just tell them you didn't cause it".) It was suggested that the number of lawyers may be an inverse indicator of social capital. More seriously, crime levels have been taken as significant indicators of the level of social consensus.

It would be highly risky ever to read much into any one such indicator. In Communist Eastern Europe, personal crime levels tended to be very low, but this did not necessarily imply social consensus: individuals tended to defraud the state rather than each other, and had low confidence in the established social order. Yet it may in time be possible to assemble clusters of indicators and look for commonalities in certain places where conditions seem to be the most favourable.

It may even be possible, as suggested in the introduction to this report, to come up with some features that are necessary though not sufficient factors that one would expect to be present in regions that had achieved a learning culture. For example, the region investing at least as much in education and training and in R\&D as one would expect for a region with its particular level of GDP per capita. A similar question could be asked about innovation and networking indicators like patent applications and associative relationships between companies or university-industry links. A third cluster could relate to social relationships and forms of social inclusion, including crime, unemployment and the number of educational under-achievers. Regions that score well in all three clusters could be examined further to see if they provide worthwhile models for others.

\section{Conclusion}

Like a "civilized society" or a "good meal", a learning region is for the moment something that can be aspired to, and used as a reference point, rather than being a label that can be awarded scientifically to certified cases of good practice. The very fact of entering the discussion initiated by the OECD 
can help define and solidify a region's ambitions, and to clarify the role that learning plays in it. It is to be hoped that also there are features of one region that help inspire others, even taking into account the many differences that make wholesale transfer of models from one culture to another impossible.

The experience of Andalusia has in this respect served to underline the potential connectedness between culture and economics, between social intercourse and commercial innovation, between the past and the future. Twenty-five years ago, the expansion of education was seen to a large part as a means of improving the quality of life, and not to be tainted with instrumentalist objectives of raising economic performance. Ten years ago by contrast, the quest for lifelong learning was, in Europe and North America, so oriented towards economic regeneration that social and cultural benefits were generally added as an afterthought to any rationale. At the end of the present century, there is a new understanding of the strong complementarity between socially beneficial learning and economic development. This can still be hard to prove at the macro-economic level. But in the context of regional learning cultures, it is possible to see how a flourishing society supports an innovative economy. This alone is a good reason to go on studying learning regions. 



\section{Learning to Innovate}

Carlos Román del Río

Director, Institute for Regional Development

\section{Determining factors in economic development}

Our preoccupation with establishing which factors are determinants of economic development is as old as economics itself.

It is not just a coincidence that the full title of the seminal work by Adam Smith was "An Enquiry into the Nature and Causes of the Wealth of Nations", in other words, into the economic development of nations.

A great deal of our time is spent studying economic development, but we still find it quite difficult to explain why the process starts in certain areas at certain times, continues at different rates and reaches different levels, encounters different obstacles and produces results that are extremely variable from one country, region or sector of the population to another.

As one might expect, in the course of history many theories explaining the process have been advanced: from precious metals or a whole range of other natural resources - including climate or strategic geographical location to population size or size of territory, i.e. the size of a country's market, not forgetting its openness to the rest of the world or, alternatively, its isolation.

More recently, attention turned to entrepreneurship and more practical aspects, such as the development of business partnerships, the promotion of industry clusters and networks or the existence of an innovation environment.

However, for the past few years, the focus has narrowed down to information and knowledge and how they can be assimilated and learned.

The list of causes has grown steadily longer over the years, so long in 
fact that it has ceased to be of any real practical use most of the time: there are just too many factors that seem to require action. Then again, this is logical enough, since in actual fact everything is in some way related to economic development.

Neo-classical economists, with their proverbial obsession with weighing, quantifying, measuring and modelling everything, tended, as is their wont, to oversimplify the problem. They somewhat cavalierly disregarded anything that was not easily quantifiable and assumed, into the bargain, that economic development could be roughly equated to output growth (which is rather more amenable to measurement). They also assumed that the development equation could simply be extrapolated from the production function. In other words, from a function with only three really relevant variables: land, labour and capital (or, even more simplistically, two: capital and labour). They then established mechanistic cause and effect relationships between the quantities of such variables used and the quantity of end products produced, itself considered as a dependent variable. Any other potential factors were treated as remaining constant, lumped together under the time-honoured ceteribus paribus clause, and were considered exogenous - they even dared to do this with technological change (!) - or were simply filed under the ignominious "residuals" heading.

The most important distinction in the social sciences is not the distinction between quantifiable and non-quantifiable - in the last analysis everything is quantifiable - but between relevant and irrelevant, and fortunately no one now thinks that the only thing that counts is the quantity of factors of production available. Quality, accessibility, space, time, culture, the way in which they can be used and combined, the institutions that shape the context in which resources can be combined, etc., all matter too.

Despite widely divergent geographical, historical, institutional and cultural situations, some elements appear to be common to any economic development process. These are given in the diagram below. 


\section{DETERMINING FACTORS IN ECONOMIC DEVELOPMENT}

\section{KEY ELEMENTS}

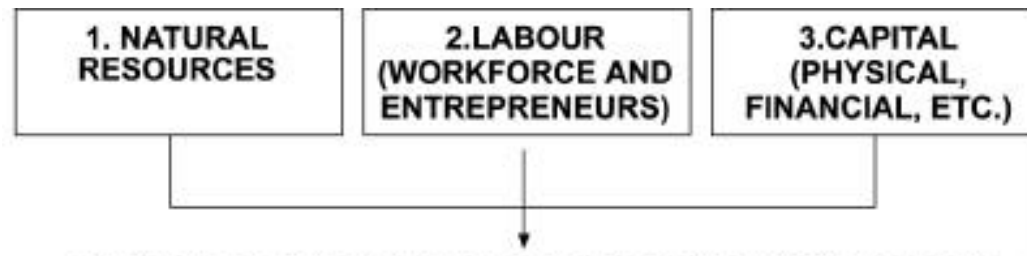

which are combined in Economic Production Units that each:

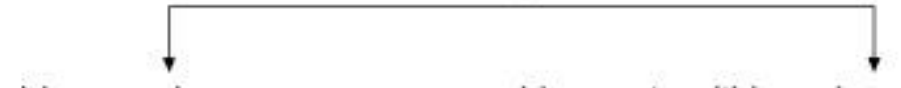

a) have a given

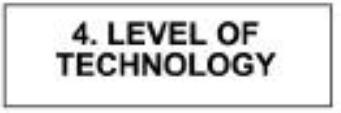

b) operate within a given

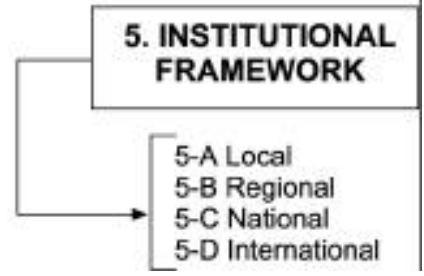

Let me hasten to say the diagram above does not add anything new, nor does it solve our problem, it simply attempts to organise the information that is already available. It is a very "theoretical" diagram, but it does suggest that, instead of ruling one or the other factor out of the equation, it may make more sense to use a mix of all of them in varying combinations, determining the relative importance or exact weight to give to each in the light of the objective, subjective, institutional, geo-strategic and cultural characteristics of each specific economic area. That is to say, in the light of what it is and where it is. Although that would force us to stop using time-honoured models and equations as universally applicable master formulas, whose scientific basis puts them above any ideology. Apart from the implications that this would have for policy considerations, the absence of a single development model could have all sorts of important repercussions. For instance, it would mean that for certain economic areas - cities, regions and even whole countries - the development process might not be so dependent on the quantity and quality of the conventional production resources available - raw materials, energy, plentiful labour (depending on the circumstances the latter, in particular, may be a drawback, not an 
advantage), infrastructure (and, obviously, type of infrastructure, since transport and communications infrastructure are not the same as telecommunications infrastructure) or even on financial capital (think of the oil-producing countries of the Middle East). It might be more dependent on a society's capacity for self-organisation, the acquisition of information, the assimilation of knowledge, its economic management skills and financial structure, on its innovative spirit and a common sense of standards of co-operative behaviour, its willingness to cultivate civic engagement and business partnerships, its success in institution building, attitudes that really promote change, etc. All of these are intangible community assets, which enable communities to develop their own resources, whatever these may be (take for example the countries that received aid under the Marshall Plan after the Second World War), and find markets for what they produce.

Learning to be self-reliant may be much more important than having the resources for it. Of course, every case is unique, but there are many in which economic development depends first and foremost on a society's capacity to learn how to put its economic culture and knowledge to use in acquiring, applying and managing innovative information, so that it can maintain a constant process of balanced economic growth that will actually result in a higher standard of living and quality of life for all of its population.

Consequently, in selecting a specific or ad hoc development strategy (by which I mean designed specifically to suit the characteristics of each individual area), there are two factors - one internal and one external - which are particularly significant. The internal factor is the level of economic and social development already attained (what) and the external element is the extent of connections with the outside world (where).

\section{Globalisation and competitiveness}

Let us begin with the second of these and take a brief look at the way in which the outside world impinges on the design of an internal economic development strategy. Since each case is unique, we will take a real-life example. If we take Andalusia, for instance, the first question we would have to ask is whether the region is part of what we now call the global economy. In Andalusia's case the answer is an unqualified yes. It is part of the European Union, which is the most globalised "economic area" in the world, in contrast to many other regions and countries that are effectively excluded from globalisation, which for our purposes can be defined as: a process of reducing or eli- 
minating barriers to the free movement of (in the following order): ideas, decisions, capital, services, products and factors of production, of which labour is very definitely in last place.

In actual fact, the movement of goods and services has been with us since the very beginnings of economic activity and the internationalisation that we talked about in the 1970 s and 1980s is fairly similar to the globalisation of the 1990s. Similar, but not identical. Not just because the process spread, gained momentum and accelerated dramatically in the nineties, but because it carries new implications which make it both quantitatively and qualitatively different to the economic internationalisation with which we had become familiar.

For instance, the unprecedented development of information technology has given us a totally new medium - electronic telecommunications which have now made possible something that is also totally unprecedented: decisions taken in any part of the world can now come into effect in real time, i.e., they are taken immediately.

Closely related to the above, and as a direct result of it, easier contacts between agents have enabled a very substantial reduction in transaction and tracking costs and in transport costs too, especially when the commodity exchanged is any kind of digitized information.

Furthermore, in contrast to the internationalisation of production that was typical 20 or 30 years ago, when firms in the most developed countries tended to clone (i.e. reproduce down to the last detail) their productive processes in other less developed areas, what usually happens today is that they hive off or break down their processes and site separate stages of production in different locations, with or without outsourcing them. Once again, it was the development of telecommunications that made it possible to organise production and distribution processes in this way. It also explains another major difference, having this time to do with new ways of structuring firms; that rely much more on building networks that vary in composition, form and duration than on establishing rigid hierarchies between central offices and subsidiary establishments. This is not the place to go into the relevance and impact of these changes in strategy or of this new form of "multi-nationalisation", but their importance is obvious.

A further difference to note is the consistently more aggressive attitude of major corporations and international economic institutions in pressurising national governments to abolish protectionist regulations and in lobbying for the deregulation of all markets, particularly capital markets. It seems clear that 
actual and potential flows of north-to-south capital are substantially larger than in the opposite direction and there is no doubt whatsoever that markets are much more globalised than governments are.

Where there is some similarity between the internationalisation of the seventies and the globalisation of the nineties is that both are partial, selective and asymmetric phenomena. Globalisation is partial because, for now at least, "the world is not a single market". According to the World Bank, only 20 per cent of gross world product was generated by international trade in 1998. Added to this, non-monetized activities (personal consumption, payments in kind, etc.) account for a large share of economic activity in underdeveloped countries, with the result that the figures for globalised economic activity are quite a bit lower than generally recognised.

Globalisation is selective because it affects and is concentrated on very specific economic processes operating on a world scale. Most are activities that use high-tech applications in processing and in distribution. They exhibit highly dynamic growth in terms of both production and employment. They add a great deal of value and are key sectors on a worldwide scale.

Moreover, globalisation does not have the same impact on all of the factors of production. As is well documented, 95 per cent of international capital movements are autonomous, i.e. not initiated by the sale of a product or the provision of a service. Are we therefore to assume that we are talking exclusively about hot money or speculation? Perhaps not always, but certainly the deregulation of financial markets has had much more of an impact on shortterm than long-term movements (this is perhaps capitalism at its most speculative). As regards the impact of globalisation on the labour factor, free movement is almost exclusively reserved for highly skilled labour; unskilled labour, as our proposed definition suggests, is the very last to benefit.

Lastly, globalisation is asymmetric through the removal of barriers that has allowed goods to circulate much more freely from north to south than from south to north. Indirect restrictions in the form of non-tariff barriers - ranging from quality, health and environmental controls and specifications to straightforward labelling standards - have also played a part in this. Likewise, the development of new materials has rendered some of the typical products of the south obsolete (synthetic fibres substitute for cotton and wool, fibre optics for copper, and so on for quite a few other primary sector products). All of this helps to explain why there are such striking ad speciem, and hence ad valorem, asymmetries in flows. 
Whatever the case, the main conclusion that all of the foregoing considerations point to is that in a globalised economy the processes of economic growth of its individual constituent areas depend very specifically on how a given area is integrated into the whole. Among other things, this means that in any given area that is itself fully integrated into another larger area, globalisation has a direct, immediate and far-reaching impact: without any protectionist barriers, tariff or otherwise, it is absolutely vital that the area defines a sufficiently differentiated economic profile to enable it to be as competitive as possible in the market segments to which it has access.

Defining such a profile means putting the emphasis on some features, opting for certain types of production rather than others. The logical starting point is with whatever production strengths currently guarantee a minimum market advantage. Not that this implies abandoning any attempt to find new market outlets in the medium to long term. On the contrary, it is important first of all to select specialisations which - because they are based on advanced science and technology and maintain constant innovative tension - will help to consolidate strategic dynamic advantages in the long run. Of course, all of this is a question of degree and time, but connection to a global market requires the definition of a clear production profile. It is not just a question of producing anything at any cost. Those unable to offer some product or service more competitively than their rivals, i.e. those who cannot offer better value for money, will have no place in the global market and will be unable to survive there. This is invariably the case in markets that are not protected by tariff barriers. It also explains why, as the process of globalisation advances, the areas concerned have to meet increasing demands on their competitiveness. Competitive specialisation therefore becomes the key variable in integration and the quality/price or price/performance ratio becomes the surest expression of it. Perhaps, it is also more complicated than that, since improving this ratio depends on a whole series of factors, or rather two sets of such factors: price factors and quality factors. This explains why it is so difficult to break into world markets and why new formulas of public-private sector co-operation are needed now more than ever. The following diagram attempts to illustrate this. 


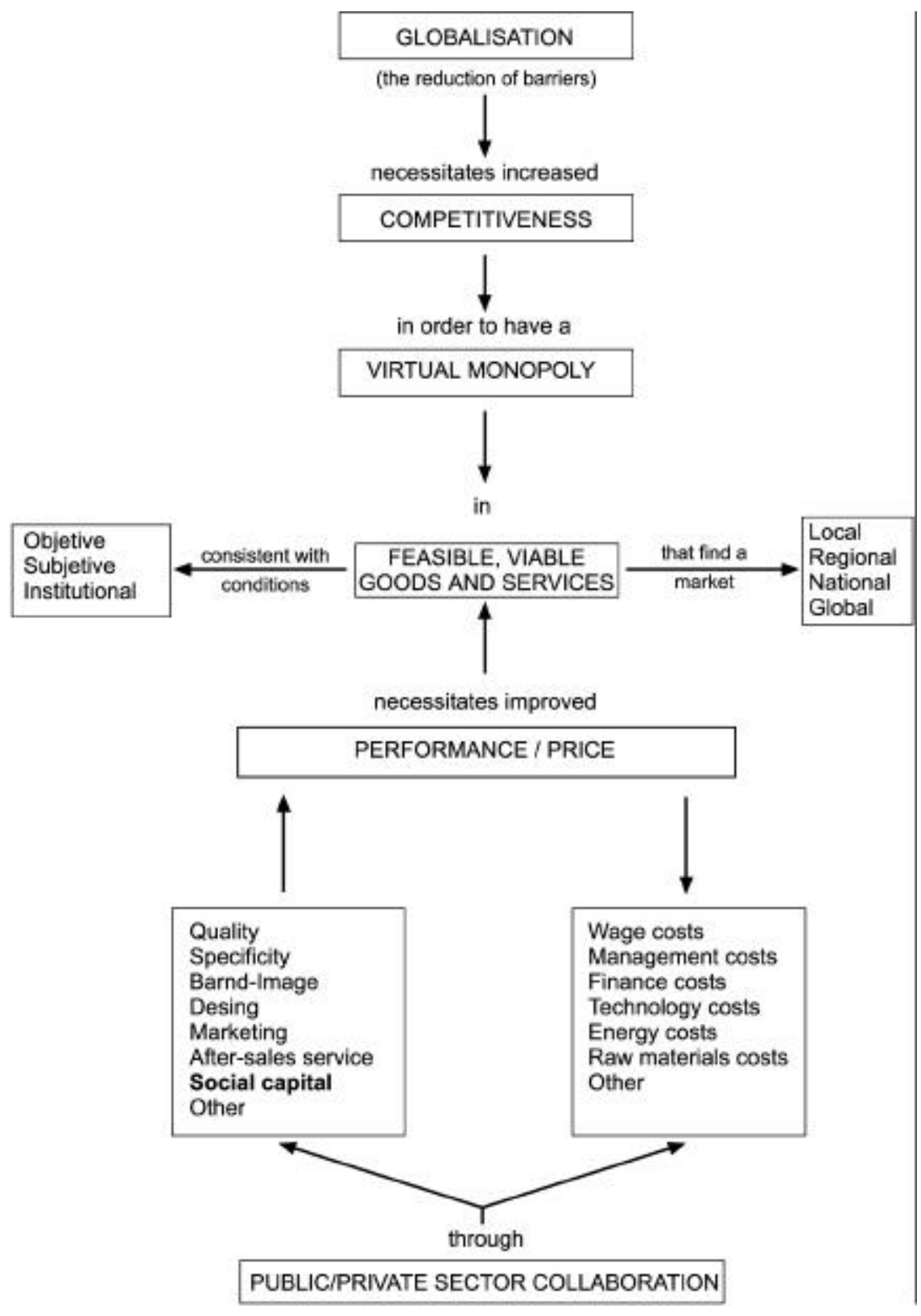


As we have said, the first thing that may force us to re-examine the order of ranking of determining factors in development, and hence to change priorities in selecting these factors for our strategies, is the level of economic development that has already been attained.

For example, there are countries that are unable to improve their price/performance ratio by lowering the wages paid for labour (their wages are so much higher than the going rate in other less developed countries that cutting them would have no significant impact on production costs) or by cutting the costs of the raw materials they use in their specialisations. However, they could improve the ratio by learning to use the information and knowledge available to them to maintain innovative tension and raise productivity, thus constantly improving their strategic position on the markets.

There are quite a few regions in the world and in Europe - Andalusia is potentially one of them - that are an excellent example of just this. Indeed the European Union's current regional policy reflects a new "ERDF strategy" under which programmes designed to improve a region's capacity to acquire and apply innovative information will take priority over those designed to improve traditional transport and communications infrastructure (presumably funding for the latter will be channelled to the new potential member states in Eastern Europe).

Thus, learning to innovate will become the first priority for those areas which:

1. are part of areas that are highly globalised; and

2. have attained a certain level of development.

\section{Social capital}

The main limitation from which some economic areas may suffer in this respect is their weak social infrastructure. Learning to innovate requires a great deal of the best kind of social capital, whose provision thus becomes the cornerstone on which development rests. If no social capital is available, ways of generating it have to be learned.

The problem is that building social capital is not an easy task. To start with, in the traditional scientific literature it is difficult enough to find a properly developed theoretical basis, conceptual framework or comparative methods 
that can be used to define and measure social capital. And, of course, we have no inventory of tried, tested and efficient methods of creating capital.

Indeed, despite the fact that the term "social capital" has been in use for quite a long time now (it was first used by Lydia Judson Hanifan in 1916), it only came into current usage in the social sciences field a few years ago. This is understandable since, although many authors ${ }^{1}$ have written about the concept, it is only recently that it has begun to be widely accepted as a category for analysis. Nevertheless, we are steadily less inclined to agree with Moses Abramovitz, who - in 1986 - claimed that no one knew what social capital was, let alone how to measure it.

We will address both of these issues shortly, but first we have to say that social scientists' reluctance to tackle a subject so far removed from the classical and neo-classical traditions is understandable. Indeed, social capital is, by definition, a collectively owned community asset and for this very reason sits uneasily with the principle of individualism, which to a large extent dominates scientific and therefore economic thinking. As well as this, something that is part of our reality, but is intangible, immaterial, difficult to measure and extremely complex in terms of defining all the causal links it entails, is an excellent candidate to be designated by some letter of the Greek alphabet and added to the conventional researcher's "things-to-do list". Moreover, it is an asset that is so much in a class of its own that, as well as being collectively owned and impossible to ascribe to the individual, it is inalienable. It has a value, not a price. There is no market for it.

Furthermore, social capital, as an economic resource and a factor of production, violates one of the fundamental pillars of marginalist thinking, the law of diminishing returns, since the more use is made of it the greater not only the returns but also the increase in multi-factor productivity, in other words the productivity of all of the other factors of production (e.g. labour and capital) that combine around it.

The foregoing explains why it has taken so long to begin focusing attention on such an "inconvenient" determining factor of economic growth, but that is no excuse for continuing to put off this task. Given that reality is more obstinate than theory - eppur' si muove - it is high time to begin conceptuali-

\footnotetext{
1 Including: Loury, Glenn(1977); Olson, Mancur (1982); Bourdieu, Pierre (1986); Abramovitz, Moses (1986); Coleman, James S. (1987); Gambetta, Diego (1988); Dasgupta, Partha (1988); North, Douglas (1988); Knack, Stephen (1992); Keefer, Philip (1993); Putnam, Robert (1993); Platteau, Jean-Philippe (1994); Solow, Robert (1995); Castells, Manuel (1996); Serageldin, Ismail (1996); Narayan, Deepa (1997); Landabaso, Mikel (1997); Grootaert, Christian (1998); Temple, Jonathan y Paul Johnson (1998); Woolcock, Michael (1998) y Cooke, Philip (2000).
} 
sing and measuring this determining factor of development as an understanding of its mechanisms is crucial in so many cases.

At least for those areas which need to generate or build up social capital so that they can learn to innovate, we propose the following working definition:

\section{SOCIAL CAPITAL}

also known as community, civic, synergetic, relational, intangible, tacit, local, joint, network, etc. capital, and taken to mean the quantitative and qualitative sum of individual human capital, is:

THE CAPACITY OF A GIVEN SOCIAL GROUP TO

1)

\begin{tabular}{|l|l|}
\hline ACQUIRE & \multicolumn{1}{l}{ INFORMATION } \\
\hline Generate & Technical \\
Purchase & Energy-related \\
Lease & Organisational \\
Transfer & Commercial \\
Plagiarise (!), etc. & Financial, etc. \\
\hline
\end{tabular}

- Invention versus innovation

- Information versus knowledge

2)

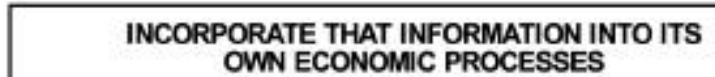
OWN ECONOMIC PROCESSES

Design, production, distribution, post-distribution, redesign processes

and

3)

MANAGE THOSE PROCESSES

which means

TRANSFORMING INFORMATION INTO KNOWLEDGE AND KNOWLEDGE INTO ACTION 
A few comments on the proposed definition are warranted. The first relates to the need to draw a distinction between invention (or discovery) and innovation. While invention is a pre-requisite, it is absolutely no guarantee of genuine innovation. Once an invention has become information, there are many ways it can be accessed, some of them not too complicated, but innovation requires the effective application of an invention to a real productive process and for that to be possible something more than a creative imagination is needed. History is full of inventions and discoveries that have never amounted to anything more than just gadgets, because they were never successfully incorporated into economic processes, for lack of the capacity to take action.

So clear is this distinction between invention and innovation that it would not be going too far to cap Miguel de Unamuno's acerbic "Let them do the inventing!" with a cynical "We'll take care of the innovating" since this is now eminently possible. It may even, under certain conditions, make perfect sense to set aside resources for innovation in preference to invention.

Even more important is the distinction between information and knowledge, as it is the latter that really makes it possible to apply the information acquired to real economic processes, i.e. that enables 1) access to all the available information, 2) selection of relevant information, 3) elimination of irrelevant information, and above all 4) effective use of relevant information, i.e. innovation.

The following table reviews a few of the differences and similarities between information and knowledge. 


\section{INFORMATION}

Facts, data, statistics

Knowing what

Knowing who

Knowing where

Is codified and codifiable

May be codified knowledge

May be tangible

Is explicit

Medium - hard disk (or print out)

Is adquired by reading or listening Is more easily reproduced, transmitted, accessed

\section{KNOWLEDGE}

Abilities, skills, expertise

Knowing why

Knowing how

Knowing for whom

Is not easily codifiable, and once codified it becomes information

May be information that is understood

Is intangible

Is implicit

Medium - human brain

Acquired by learning (individual, collective, ongoing)

Both are present as stocks and as flows

Both are dynamic

Both can memorised

They are necessarily concomitant

Information overload can generate more confusion than information, and knowledge is needed in order to:

a) access all the available information;

b) select relevant information;

c) filter out irrelevant information;

d) apply relevant information. 
Social capital is, therefore, a collective asset or public good that is intangible, unassignable, inalienable and can be built up or destroyed. It is the synergetic sum of individual human capital that helps people learn to innovate. However, for such capital to be available, at least three requirements have to be met:

1.Social agents must interact in accordance with an established code of conduct, whose primary objective is co-operation in the common interest and whose rules may be explicit or implicit but are consensual.

2. The principle on which norms of behaviour are based is trust (Vertrauensprinzip), by virtue of which individual action in the present can be expected to produce a collective result in the future.

3.There must be a public-private institutional structure that facilitates and encourages joint action, provides adequate tools for each operation and applies rewards and sanctions.

These three elements give us a workable enough concept of social capital to be able to see how it manifests in terms of social behaviour, which lends itself to observation.

The goal of effective co-operation among agents, firms, etc. is mutual benefit (specific or otherwise, short term or longer term) and is therefore based on self-interest. It is not ethical but practical in essence: one thing is done so that another will happen. For this very reason, trust is an indispensable requirement, since an actor does something in the hope of obtaining something in exchange. This is conditional, reciprocal trust. Reciprocal because it may be bilateral (I will, if you will) or multilateral (I will, if we will). It is also transitive: if some agents trust other agents who, in turn, trust still other agents, the latter also have the trust of the first agents.

Trust between social agents not only facilitates co-operation and the creation of engagement networks, both present and future, it also increases security and helps maintain innovative tension, reducing uncertainty and risk levels and leaving less room for opportunism and abuse: this, in turn, leads to a reduction in other social costs in addition to economic costs.

The norms that govern behaviour are very diverse in nature and scope. In some cases, they operate as general trading principles and in others 
as specific detailed rules that amount to a virtual code of conduct ${ }^{2}$. They may be explicit or implicit, written or unwritten, and with or without legal force, but they are all set in advance and broadly consensual. The degree of consensus in fact means that rule-breakers face penalties, social or legal.

As regards the third requirement, the creation of social capital requires an institutional framework that is compatible with the nature and functions of the former. It is not enough to have a few intermediary organisations that make contact between economic agents logistically possible; the entire institutional structure must answer to the same principles that inform the social organisation that it is attempting to run in a cohesive manner.

Experience provides more than ample evidence that horizontal networks work better than vertical hierarchies. Perhaps this is an issue that takes us beyond just a strategy for building social capital and into the arena of the political organisation of society (capitalism versus feudalism, democracy versus dictatorship, etc.), but for our immediate purposes there is no doubt whatsoever that the more evenly power is distributed, the easier consensual participation in the decision-making process becomes. Information flows more smoothly between peers; trust is easier between like-minded agents; co-operation encounters less opposition among people who share common interests; and cohesion is much easier to achieve when needs are similar. We could say that homogeneity and compatibility go hand in hand. Once again, the economic structure and the institutional superstructure have to be coherent.

This is the ideal type of social capital that regions and areas that need to learn how to innovate should cultivate. Failing this, it will be difficult for them to acquire information and be able to apply it to their own economic processes. But the existence of social capital can indeed be compared and measured. We can measure absolutely anything that exists, in fact, provided we use the right unit of measurement. This is obviously much easier to do when the particular aspect of reality that interests us can be expressed in "arithmomorphic" terms, but just because something is difficult to measure is no reason to assu-

\footnotetext{
${ }^{2}$ The older the society and the more advanced its stage of development, the more its rules of behaviour tend to be "codified". Its long history and complexity partly explain the need for an established "code of conduct". As one might expect, this has its dialectic correlate in the economic field. Production and distribution technologies are becoming more complex and more established. Indeed, almost every eventuality is provided for; people just have to do what the "code" or checklist prescribes at all times. Production processes are not "jam sessions" and leave little room for improvisation or, it goes without saying, for the creative imagination. The ability to improve solutions is also acquired through long "experience", and is ultimately assimilated into the culture just as is its opposite, with its advantages and disadvantages. That is one of many reasons for some of the differences between northern and southern countries or between "Ford" and "Toyota" cultures.
} 
me that it does not exist ${ }^{3}$.

\section{Associational activity}

\subsection{Associational activity of businesses}

* No. of associations by type (business, professional, unions, etc.)

* No. of co-operatives (and no. of members)

* No. of members of associations (by type)

* No. of meetings per year

* No. of associations by duration (temporary/permanent)

* Average duration

* No. of associations by purpose

* No. of associations by degree of decentralisation of decision-making process

* Degree of homogeneity of businesses and directors (geographical proximity, sector)

* No. of initiatives implemented by associations

* Average no. of initiatives per year implemented by associations

* No. of association federations

* No. of initiatives implemented by federations

* Average no. of initiatives per year implemented by federations

* No. of activities financed by a number of businesses for a common purpose (no association formed)

* No. of advanced service firms

\footnotetext{
${ }^{3}$ How much did Romeo love Juliet? 329? Lambda? Perhaps he didn't love her at all. The truth is that many of our measurements are conventional, i.e. the relationship we establish between the object we are measuring and the unit of measurement we are using is agreed by convention. One obvious convention is to give a pupil that has done very well in an exam $10 / 10$ or an $\mathrm{A}+$.
} 
* Amount of resources shared by type (information, personnel, financial, technology, etc.) by firms belonging to the same association

\subsection{Civic cohesion and co-operation}

* No. of associations (political, cultural, arts, sports, religious, neighbourhood, social welfare, etc.)

* No. of members in these associations (by type)

* No. of hours of involvement per person per year in social activities (family, working meetings, informal meetings, meetings with friends, etc.)

* No. of hours of involvement per person per year in solidarity and cooperative initiatives.

* Composite indicators of social mobility and social polarisation.

* Income distribution indicators (\% GDP, Gini index).

\section{Trust}

\subsection{General trust}

* No. of legal claims on economic grounds

* No. of court cases

* No. of items of lost property handed in and recovered

* No. of offences by type

* No. of mutual aid or solidarity initiatives

* No. of informal norms for civic engagement and reciprocity, classification and strength of instilled values

* General level of trust

\subsection{Trust in government and public institutions}

* Bribery indicator (no. of reported bribery offences and no. of known bribery offences)

* Composite indicator of strength of democratic institutions (independ- 
ence of judiciary, etc.)

* No. of disputes with Public Administration

*Indicator of political and social stability (no. of changes in the executive during the term of the legislature, terrorist activity, political assassination, revolution, coups, union or labour disputes, etc.)

* Political involvement of citizens (voting rate, meetings and political action, no of letters to the Ombudsman and political representatives)

* Indicator of trust in government

\subsection{Access to information}

* No. of newspapers, television and radio broadcasters, telephony and Internet suppliers

* No. of newspaper readers, no. of radios, televisions and personal computers per capita, no. of Internet users

${ }^{*}$ No. of official documents that citizens have access to, ease of access

${ }^{*}$ No. of government initiatives published in Official Bulletins

\section{Public-private institutional framework}

* Administrative efficiency index (average time on administrative formalities and average transaction costs)

* Level of expectation as regards protection of property rights, risk of expropriation and nationalisation and risk of contracts being cancelled by government

* Indicator of judiciary's ability to enforce contracts

* Indicator of trust in the financial system: contract-intensive money (financial assets, excluding cash in circulation)

* No. of forums, conferences and informal meetings between the public and private sectors

* No. of initiatives taken/promoted through consensus between the public and private sectors 
* No. and type of consultations held by the administration with private socio-economic agents on planning, management and assessment of government measures

* Proportion of government budget allocated to subsidies and aid to associations and foundations.

In actual fact, measurement is not the biggest problem that social capital poses. Generating it is the real difficulty. Social capital is an asset that is rooted in social mores. A social group becomes accustomed to organising itself and behaving in a certain way when it has been operating as a group for some time, and the longer it has been operating the more pronounced this tendency is. Although not a sufficient prerequisite in itself, this tendency does go some way to explaining the very wide discrepancies found in the formation of social capital among different groups. The process of formation is slow: social capital is built slowly, destroyed rapidly, and rebuilt very slowly, because the forces at work, either way, are cumulative ones.

In addition, on the issue of who should assume responsibility for the provision of social capital, the highly collective nature of this unique asset would indicate that generating it is also a collective task. Again, it is difficult to establish universal rules, but it is clear that some degree of collaboration between the private sector and government is always necessary. The exact proportions of the mix of various bodies needed in each specific case is a different matter. Probably, societies that have already attained a given level of institutional density require less direct intervention by the public sector, which should act essentially as a strong catalyst for private initiative.

Bearing in mind that, for our immediate purposes, the ultimate objective of the formation of social capital is innovation and that, very frequently, the public sector itself has to learn to innovate just as much or more than the private sector, the agendas will cover a broad spectrum and may include general overall initiatives as well as specific measures. The following are examples of both.

- The creation of an appropriate institutional framework to enable the development of a culture of co-operation between agents with a view to establishing joint objectives, agreements - for a fixed or indefinite duration - and networks between groups of firms: such as establishing mechanisms for exchanging ideas, strategic information, experience and best practices, promoted by public/private intermediate organisations such as transfer bureaux, development agencies, specialised institutes, laboratories, R\&D centres, sub- 
sectoral associations, committees, chambers of commerce, advisory councils, professional associations, foundations, conferences, etc.

- The provision, for groups of firms, of diversified support mechanisms including: financial (start-up aid, sureties and guarantees, risk capital, etc.) and non-financial aid (advice and mentoring, internationalisation, mediation, inventory, guides, etc.) for associations and networks of firms, joint production and marketing projects, initiatives to provide common advanced services and to incorporate information and telecommunications technologies; development and dissemination of indicators of efficiency, excellence and leadership; closer links between university teaching and research programmes and the production environment, in order to help build an efficient science, technology, industry + market system.

- Establishing general guidelines to map a trajectory for innovation processes through the joint development of co-operative plans and programmes that include ex-ante, intermediate and ex-post evaluation.

Having information - and knowing how to apply it - has always been essential, and is even more so for those areas that have already attained a certain level of development and integration into the global economy. Once that economy changes the way it operates and becomes what we now refer to as the "new economy", besides being very necessary factors in economic development, information and knowledge become the absolute "sine qua non" of the entire process ${ }^{4}$.

In the last five years of the 20th century, the economic situation in some of the developed countries was marked by high output growth rates coinciding with high employment rates and low inflation and, at the same time, a reduction in perennial problems with budget and balance of payment deficits. In those countries the most dynamic of the dominant businesses driving (or at least in some way connected to) the new situation have some characteristics in common: the most pertinent is precisely the fact that they were based on the production, dissemination and application of information and knowledge. However, although it seems so at first glance, this was not so much a case of businesses in which the key variable was information - like the high-tech firms

\footnotetext{
${ }^{4}$ Take, for example, the case of Indonesia compared with Papua New Guinea, a country that is totally cut off from the globalisation process and from the information society, where access to drinking water is much more imperative than access to the Internet. It could be argued that knowing where to find water and how to make use of it are, strictly speaking, information and knowledge. That is quite true, but although the concepts are the same, the differences in terms of stocks and flows and in terms of the quantity and quality of the information and knowledge involved are so great that the situations bear no comparison.
} 
that sprang up in the second half of the eighties (microelectronics, information technology, genetic engineering, etc.) - as of the more widespread application of information and its new media in the production of any type of commodity or the provision of any type of service. The ultimate example of this would be the virtual manufacturing firm, which does not directly produce any physical product itself: it organises its entire economic process (production and distribution) on a world-wide scale, hiving off and outsourcing the different stages in the process to locations in the world where the relevant costs are lower; controls the chain of suppliers and customers; and arranges transport of the endproduct to countries where the market for it is best.

Although the above situation reflects our ultimate example, the virtual firm, in the new economy businesses are increasingly being organised on a worldwide scale using information highways and the Internet (from 1995 on) to form business-to-business (B2B), business-to-consumer (B2C), and providerto-provider (P2P) connections and agreements by setting up temporary joint undertakings, exchanging strategic information, connecting databases and datastores, conducting commercial transactions of all kinds, etc.

It is abundantly clear that in addition to a highly developed technological infrastructure and highly skilled human capital, entry into this world requires a high level of social capital. 



\title{
3 Economic and Social Development in Andalusia
}

\author{
Rafael Camacho Ordóñez \\ Ex-Spokesperson of the Andalusian Regional Government
}

To assess the impact of cultural capital and learning - in other words, of knowledge - on the economic and social development of Andalusia, we first need to provide a physical and socio-economic overview of the Autonomous Community.

Andalusia is situated in the south of Europe and measures 87,268 square kilometres, that is to say a little over $12 \%$ of the total area of Spain and $3 \%$ of the area of the European Union. Andalusia's extraordinary geographical position, as Europe's southern gateway and a bridge between two seas, has shaped its historical past and is now plotting its future. Andalusia is an open region criss-crossed by peoples who have engraved on it the complex profiles of a dense and very ancient culture.

With over 7 million inhabitants, Andalusia accounts for almost $20 \%$ of the population of Spain, and is the third most highly populated region in the European Union. Within the framework imposed by its geographical and demographic features, Andalusia has constructed an economic and financial structure based on a Gross Domestic Product (GDP) of 6,311 million euros (10.5 billion pesetas). This gives the region very significant economic influence in the euro zone: of the 151 regions that make up the zone. Andalusia lies 23rd by volume of production.

As for Andalusia's development over the last twenty years, and focusing initially on human capital, the population of Andalusia grew by 800,000 between 1981 and 1996, a rise that accounted for $40 \%$ of the increase in the Spanish population as a whole. Demographic growth has also been accompanied by a change in the migratory flow: the early 1980s witnessed a shift in the migratory movements that had marked earlier periods, and during the inter- 
census period of 1981-1991, there was a positive migratory balance with the rest of Spain of 67,841 people. This trend was maintained in subsequent years.

The last two decades in Andalusia have seen a significant change in the population pyramid: during this time, there has been slow but steady population ageing, and also extraordinary dynamism among people of working age. Furthermore, the Andalusian population is younger than the Spanish population as a whole: under 15 year olds account for almost $23 \%$ of the population, compared with $19.4 \%$ nationally, and under 25 year olds represent $40 \%$, that is to say ten percentage points above the European average.

In the labour market, the working-age population grew by $29.5 \%$ between 1980 and 1997, according to the Encuesta de Población Activa (EPA - Working Population Survey), while it increased in Spain as a whole by $20.5 \%$. Specifically, a total of 837,400 people entered the labour market during this period, and almost $30 \%$ of these did so in Andalusia. This means that the rate of employment stands at an all-time high of $48.7 \%$, almost five points more than in the early 1980 s.

It is worth noting that a large number of women have entered the labour market in the last few years. The female participation rate is currently 2.4 times higher than in 1980: this means that women coming into employment account for $71.9 \%$ of the overall increase in the working population.

Heightened economic expectations naturally explain the increase in the active population to a considerable extent or, to put it in another way, increased expectations are reflected in the creation of jobs. The working population of Andalusia rose by 298,600 between 1980 and 1997, that is to say, by $30.8 \%$ of all new employment in the whole of Spain. Employment rose by $18.9 \%$, almost 11 points more than in all of Spain, and 16.9 points more than in the EU. Employment levels reached a record 2,069,000 in the second half of 1999.

The employment creation process in Andalusia includes the following qualitative factors:

- a significant increase in the outsourcing of employment: $65 \%$ of the working population are currently outsourced in the service sector;

- a substantial increase in the number of working women: the female participation rate increased by 245,180 between 1980 and 1997, and women 
today account for one third of all employed people;

- the prominent role played by the public sector;

- and lastly, a notable rise in education standards: the proportion of the working population with a secondary or university education has almost doubled since 1986, and now accounts for two thirds of the total.

On the down side, the arrival of so many new people on the labour market has led to an increase in the number of people out of work: unemployment has risen from $17.5 \%$ in 1980 to its present rate of $26.06 \%$, according to the most recent EPA, although the situation began to improve in the late 1990s.

To conclude, the positive development in the labour market has led to a major improvement in labour relations, where progress has been made in collective bargaining and in reducing the number of industrial disputes.

Clearly, this qualitative and quantitative advance in employment in Andalusia also derives from a strong economy that has been increasingly capitalised during the last two decades. From the beginning of the 1980s until 1994, the year for which we have the most recent figures, net capital stock ${ }^{1}$ in Andalusia rose by $65 \%$ in real terms, in other words significantly more than the $48.2 \%$ increase registered nationally. The Andalusian economy is now more capitalised than in the early 1980s: specifically, capital stock by unit of Net Added Value was 2.9 in 1980, and 3.2 in 1994.

If we examine the public and private sectors closely, we find that the net public capital stock almost trebled in Andalusia between 1980 and 1994: this increase occurred mainly in productive capital ${ }^{2}$, which doubled during the same period; social expenditure (i.e. mainly education and health) rose by $58.6 \%$. Net capital stock in the private sector rose less in real terms $(51.7 \%)$ than it did in the public sector between 1980 and 1994.

There was therefore an intense process of capital accumulation in Andalusia during this period. In simple terms, per capita capital stock represented $73 \%$ of the national average in 1980 , and rose to $77 \%$ in 1994 : an

\footnotetext{
${ }^{1}$ By net capital stock, we mean the volume of capital being used in the production process at any given moment, that is to say available physical productive assets, excluding depreciation through use and obsolescence (Fundación BBV study on capitalisation and economic growth in the regions during 1955-1995).

${ }^{2}$ In line with the previously mentioned source, public productive capital includes investment in areas such as roads and hydraulic infrastructures, and also infrastructures of bodies that do not belong to the Public Administration (e.g. toll motorways run by concessionaires, airports, basins and other assets belonging to hydrographic companies, and RENFE [Spanish railways] railtrack).
} 
advance, clearly, but evidence that we must all foster the process of capitalising the Andalusian economy.

With regard to developments in the Andalusian economy over the last two decades, attention should be drawn in the first place to the fact that it has gradually adapted to the rhythm at which the international economy has developed, and that it has kept pace with the economic cycle at national and European Union level, particularly during the present decade. Secondly, there has been increasing compatibility between economic growth and low rates of inflation: the latter declined by 15 points between 1980 and 1998, and last year fell to a historic low of $1.1 \%$.

Accordingly, the balance of the last two decades reflects a differential dynamism of the Andalusian economy with regard to its reference economies. Real accumulated growth in the Andalusian economy between 1980 and 1997 came to $63.2 \%$, almost 11 points more than was managed by the Spanish economy as a whole, and 18.5 points more than the European Community. This growth is reflected in the following relative indicators:

- in the early 1980s, Andalusia's GDP was approximately $12 \%$ higher than the Spanish GDP; in 1998, this figure stood at something over $13 \%$. Andalusia contributes $1.1 \%$ to the European Union GDP and, of the 206 European regions, is 19th in terms of affluence;

- levels of affluence per inhabitant have also moved closer together: Gross Added Value per capita in Andalusia was $74.4 \%$ of the national average in the early 1980s; in 1997, it stood at $78.3 \%$. Compared with the EU, GDP per capita in Andalusia has risen from 54\% of the Community average in 1981 to $57 \%$ in 1997.

This convergence in terms of affluence by inhabitant has also been accompanied by a relative increase in the Andalusian population; this has risen by double the national rate. Indeed, if the population of Andalusia had risen at the same rate as the population of Spain as a whole, regional Gross Added Value per capita would have increased by almost ten percentage points since the region became an Autonomous Community, and reached $83.5 \%$ of the national figure.

As far as employment is concerned, the Andalusian economy has grown faster than the Spanish or European economies. For every point of economic growth, employment in Andalusia has risen by 0.34 points, compared with 0.15 points in the Spanish economy and 0.04 points in the European eco- 
nomy.

Economic growth has occurred alongside a dynamic degree of entrepreneurial initiative higher than that registered at national level. Eight times as many commercial enterprises were set up in Andalusia in 1997 as were registered in 1980.

In the field of finance, deposits in banks and savings funds in Andalusia exceeded loans by $44 \%$ in the early 1980 s, but by 1997 , there were $12 \%$ more loans than deposits. Andalusia used to 'export' savings, but the dynamic economy means that savings now have to be found abroad to cover the demand for credit at home.

As for the productive structure of the Andalusian economy, there is first of all a potent tertiary sector (64.1\% of GDP), followed in descending order by the secondary sector (i.e. industry and construction, contributing $24.7 \%$ of GDP), and lastly a primary sector that is still important (11.2\% of GDP) despite a gradual reduction in its contribution to Gross Added Value, and particularly to employment, and which has been reduced to almost half since the beginning of the 1980s.

Production in the primary sector is mainly based on agriculture, and its competitiveness has provided it with clear exporting opportunities: as a result, over a third of agricultural production is bound for international markets, and mainly the European market. The products that underpin this exporting capacity are mainly fruit and vegetables and olive oil: Andalusia is world leader in olive oil.

The competitiveness of the primary sector is the result of intensive modernisation of farms and equipment throughout the last two decades. The high degree of profitability of our farms and greater yield have made it possible to obtain unbeatable quality at good prices. To give just one example, productivity per employee in Andalusia is 30\% higher than in the rest of Spain.

Important areas in the industrial sector include iron and steel processing and chemicals, and the agro-food industry which accounts for almost a third of the total. However, recent movements in the Andalusian industrial sector have been notable for production being reoriented towards segments marked by greater technological content, particularly machinery, electrical and electronic input, and transportation.

Lastly, the service sector is internally characterised by activities linked 
to commerce and tourism: tourism is a strategic sector in the Andalusian economy through its contribution to regional production and its capacity for appealing to other productive sectors via intermediary inputs. Tourism is worth 7,813 million euros ( 1.3 billion pesetas), or $12 \%$ of the Andalusian GDP. These figures reflect the fact that Andalusia is an important international tourist destination: last year, Andalusia welcomed 18 million tourists, of whom over 8 million were foreigners.

Many of the above structural characteristics of the Andalusian economy flow from a process of growing external opening, which registered its most significant landmark in membership of the European Union; this enabled it to access bigger markets, albeit markets that were sometimes more competitive as a result of the process of liberalisation.

An evaluation of this process of opening to the outside is overwhelmingly positive for Andalusia. Since 1986, the Andalusian economy has been able to take advantage of opportunities offered by membership of the European Union to such an extent that its economic performance has outstripped the Spanish and the European economies. With regard to the period under examination, this economic dynamism was reflected in real accumulated growth in GDP in Andalusia of $49.1 \%$ during the period of $1986-98$, that is to say 7.1 points higher than the Spanish economy, and 15 points ahead of the European Union.

It has also been a time of intensive employment creation with Andalusia being one of the European regions with the sharpest increases in employment levels. Between 1986 and 1998, employment in Andalusia rose by $31.1 \%, 9.7$ points higher than the situation nationally and 26.5 points better than the European Union.

However, not only have real variables in the Andalusian economy such as the Gross Domestic Product and employment fared comparatively well, but considerable headway has also been made in terms of nominal stability. For example, from 1986 to last year (1998), inflation in Andalusia fell by 7.9 points (compared with 6.9 points nationally and 1.2 points in the European Union), and at the end of 1998 finished at afore-mentioned historic low of $1.1 \%$, that is to say below the average for countries in the European Union.

From a conjunctural perspective, the Andalusian economy is currently undergoing a period of economic growth, employment growth and low inflation: 1998 concluded with economic and employment growth of $4.3 \%$ and inflation of $1.1 \%$. When compared with data from the European Union, the closest reference region, these figures show that Andalusia has experienced faster eco- 
nomic growth and job creation as well as more effective price control.

Forecasts for 1999 indicate that the Andalusian economy will maintain its good showing, and this in turn means that it will continue to grow faster than the European average. Specifically, it is estimated that this year will see GDP growth of $3.9 \%$, a $3.5 \%$ rise in the employment rate, and inflation below $2 \%$ (inflation is currently four tenths below the national figure: 1.8 as compared with 2.2).

This is how Andalusia is approaching European monetary integration, that is to say membership of the euro, at an appropriate time in economic terms; Andalusia is ready to take advantage of the opportunities that the new currency will generate.

The Andalusian Government has responded to this major objective by drawing up a PLAN DE DESARROLLO REGIONAL DE ANDALUCÍA (PDR Regional Development Plan for Andalusia) 2000-2006 containing a development strategy for Andalusia for the beginning of the next century as follows:

- the PDR sets out an objective: to promote development in Andalusia with a view to achieving real convergence with the European Union;

- it describes the route that must be followed to achieve this objective: that of sustainable competitiveness. It also itemises the priority issues (ten in all) in which interventions will be drawn up;

- it is widely accepted that the last few years have seen major changes, both internally and externally, that have meant the existence of new keys to future development:

1) internally, attention must be drawn to advances that have been made in the availability of infrastructures; the modernisation of productive wherewithal; the training of human capital; and the provision of social support services, making it possible to overcome many of the drawbacks that had historically impeded our development;

2) externally, there has been globalisation of the markets, an acceleration of technological change, and the importance acquired by information in the creation of added value;

- in conclusion, the new key issues to be addressed are fierce competition, unremitting changes, and access to, and management of, information. 
The Andalucía en el Nuevo Siglo (Andalusia in the New Century) Forum was organised by the President of the Government of Andalusia in 1998; it was attended by 200 people from various branches of research and from the economic, social and cultural sectors of our Community, and it published its conclusions in February 1999. The Forum's proposals included 'disseminating and promoting the widespread use of new information and communication technology (ICT) in all social and economic sectors' on the grounds that 'they are now the true driving-forces of change and development in our society... and key factors in preventing the isolation of regions located far from traditional centres of development.'

Other ideas to emerge from the Forum include that 'technological development is the main driving-force of the accumulation of intangible capital', and that 'economic globalisation will generate new opportunities if it is possible to develop a process of accumulating intangible assets at local level. The ability to build up a local concentration of skills, technology, infrastructures and suppliers will create the ingredients of competitive success.'

- The PDR's development strategy places the emphasis on boosting the competitiveness of the Andalusian economy, thereby ensuring its sustainability over time.

- In this context, to be more competitive, there is a need to impact not only on traditional factors of competitiveness, but also on new determinants of competitiveness based on the ability to access, manage and process information as a key to innovation. It is precisely this capacity for innovation that allows us to access, or position ourselves in, continuously changing markets.

- For the proposed strategy to be developed, activities are drawn up under ten headings of intervention, which in turn focus on five key priorities:

1.- Developing new factors of competitiveness, that is to say those linked to the ability to access, assimilate and process information. This involves:

- promoting the dissemination of information and communication technology, for which telecommunication infrastructures and services need to extend throughout Andalusia;

- supporting research and innovation, which involves strengthening the regional system of innovation and its links with the productive system;

- developing the organisational capital of the productive system, that is 
to say the ability to adopt, adapt and manage information in enterprises.

What this means is that Andalusian enterprises that have worked hard to modernise their assets need to move forward in respect of other factors that are essential for them to be able to compete: these include quality, brand image, after-sales service and skills at exporting;

- improving the efficiency of the training scheme so that it ensures that human resource skills meet the requirements of the production system. Only in this way can innovation be transformed into production and employment;

- raising the quality of employment, this being a factor of enterprises competitiveness as well as a contribution to social cohesion.

2.- Complementing the work already done on traditional factors of competitiveness, for example in the transport and energy networks:

- in the field of transport, competition between the railways as the transport of the future, especially because of the opportunities opened up by high-speed travel, and the inter-modality of transport. It is planned to carry on developing the road system at the same time;

- in the field of energy, efforts are concentrated on improving energy efficiency and developing renewable energy.

3.- Consolidating strategic sectors of the Andalusian economy: the agro-food sector and tourism.

\section{4.- Guaranteeing the environmental sustainability of economic} activity, and three areas in particular:

- a balanced use of water (water itself being a limited, strategic resource that must therefore be used efficiently); threat to Andalusia;

- combating erosion and desertification, the greatest environmental

- improving the sustainability of economic processes.

5.- Lastly, consolidating facilities for social cohesion in the field of health and social services, and promoting an inhabitable and integrated urban environment.

The financial scenario includes public expenditure by the 
Government of Andalusia over these last seven years, and which may be cofinanced out of Structural Funds. Total public expenditure comes to 21,525 million euros, that is to say almost 3.6 billion pesetas (3.58 billion, to be precise): this means a Community contribution of approximately 15,000 million euros (2.5 billion pesetas).

In short, the PDR urges that Andalusia should take part in the new revolution involving the information and knowledge society. In the scenario described above, the keys to Andalusia's progress lie in society's capacity to plumb our potential for development, and convert it into the main factor of the competitiveness of our economy.

In this context, it is vital that our productive system should have the ability to find solutions in order to meet the new needs posed by the knowledge and information society, in such a way that it not only overcomes them, but emerges strengthened and in a favourable position. In this way, rigour, flexibility, professionalism and tenacity become key components in this capacity for finding solutions.

It is also important to stress the temperament of Andalusian people as an important asset of our development. Together with the permeability and ability to absorb change and innovation that have characterised us historically, our spirit of openness to the outside and, above all, our spirit of cooperation and our capacity to learn are key characteristics for the future in a context marked by the globalisation of economic and social relations.

Lastly, it should be said that the Andalusian Autonomous Community has historically displayed the capital value of its culture, and is today committed to enriching its cultural and learning capital as key guarantees of innovation, which in turn will undoubtedly be the setting and guarantee of its economic and social development in the 21 st century. 


\section{Learning to Innovate: Learning and Cultural Capital Regions}

Francisco Alburquerque Llorens, Paula Rodríguez Modroño, Carlos Román del Río and Raquel Ruiz Crespo Institute for Regional Development, University Foundation

\section{Introduction}

\section{'Let them invent...' (Miguel de Unamuno)}

'and we will innovate.'

The changes that have taken place over the last years towards a more open, globalised and knowledge-based society are changing the nature of the economic development processes. These are affected, among others, by two main factors: the availability of knowledge resources and the living conditions in each geographical area (Knight, 1995). The new challenge regions are facing is very clear: if they want to take advantage of their knowledge resources, they must create such environments as to raise their value, by establishing conditions for development and ensuring their consolidation. Regions must increase their knowledge about the nature of local resources and focus on those specific features of their environment on which the knowledge-based local activities depend.

Regional development must be less determined by external forces and be planned to a greater extent depending on endogenous factors. Regions need to take initiatives to shape their own future, regulating the development of natural, human and social resources and, at the same time, take as a reference the demands of foreign markets.

The global society in which we live requires the articulation of different forms of knowledge, technologies and skills. Some of the keys to build up the "required learning" process are to use currently existing forces within the regional economy; to choose the best suited technological option linked to the 
regional productive structure; to promote productive activities that are possible (possible in the sense that there must be resources available for their implementation) and feasible (meaning that there is a market inside or outside the region for the final goods or services); and to promote the skills required to connect the different activities and knowledge varieties. And moreover, innovation capacity must be understood as an effective application of new knowledge to new or old regional productive processes.

The availability of natural resources or labour force does not ensure a sustainable development process, and furthermore, investment in research and development in technologically advanced processes is expensive, and sometimes of difficult access to peripheral economies such as Andalusia's. In some cases, it might be more adequate to learn how to innovate, adapting production or management technologies that have been successfully tested somewhere else to local economic processes. The misleading outburst of the Spanish writer and essayist Miguel de Unamuno 'Let them invent' would be thus completed with the cynical proposal 'and we will innovate.'

However, the above mentioned proposal requires that aside of learning to innovate, we must be able to generate and transmit to each and every social agent (public institutions, companies and citizens in general) a new philosophy based on the cross relationship between resources and knowledge. The learning process of innovation is an integrating phenomenon that requires quite a consensus for its effective implementation. The region needs a "social organisation capacity" as a multisided element (of a mainly institutional, social and cultural character) to support a network and to some extent its working. This question is related to the possibility of transforming the achievements of economic growth into solid bases for development.

This document is structured in six main sections. It analyses in chapters II to IV different approaches to endogenous regional development based on knowledge and innovation in order to try to define the essential elements and stages that should characterise the new development strategies for economic areas of similar characteristics to the ones in Andalusia.

In chapters $\mathrm{V}$ and $\mathrm{VI}$, we describe the current situation in the region, analysing its recent evolution and the achievements made over the last twenty years, and making a balance of the advantages and disadvantages in order to make a diagnosis of the socio-economic system and see the possible policies and actions to be applied. The purpose of this analysis is to detect whether Andalusia has the characteristics, value creating factors and capitals that 
define "learning regions." We will analyse in detail if there are in the region those capitals whose importance had been underscored up to now and that are essential for starting up and properly running a development process based on the learning of innovation. We are referring to the social, institutional, cultural, technological and innovation, symbolic, human, psychosocial, civic, cognitive and synergetic capital.

Finally, we will list some of the sectors that show a greater potential, and therefore, the ones on which it should be insisted in the application of the innovation learning process: agribusiness, tourism, environmental goods and services, renewable energies, audio-visual industry and advanced business services.

\section{Andalusia in a globalised economy}

Globalisation has become a central feature in the world economy, which is not only the sign of our times, but also of our space. For many reasons, this globalisation brings regionalisation back to life (Castells, 1997) and stimulates the attention to the challenges of the territorial productive systems (OECD, 1993). Growing integration of economic activities at European scale has made regions depend more on the international context. Thus, they must be prepared to compete in the global economy and to set up co-operation networks among the regional institutions and region-based companies. Therefore, regions and towns do not blur but rather become integrated into international networks that connect their most dynamic sectors (Cooke and Morgan, 1993).

In this new global context, the concentration of resources in a territory, far from being an alternative to spatial scattering, becomes the main basis for the participation of regional economies in a global network. In fact, regions and networks are interdependent elements within the new spatial mosaic of global innovation. Within this context, globalisation does not have a levelling impact of universal processes, on the contrary, it is the calculated synthesis of cultural diversity in the form of differentiated regional innovation skills and logics.

In the "global village," the economic development of each of the areas that make it up depends, essentially, on the way the region is positioned within its context, and therefore, only those regional strategies that take into account the international dimension will have chances to succeed (Román, 1999). In order to protect ourselves from the threats of globalisation and to take advan- 
tage of the opportunities it presents, we must be able to offer some products and services with a better quality/price ratio than that of our competitors. Quality depends on factors such as usefulness, specificity, brand image, design, marketing, post-sale services and environment, while price depends on labour, management, financial, technological, energy, raw material costs, etc. Every area must therefore have its own profile, its effective differentiation within the international economy. However, this competitive specialisation, the key variable to the way each region is positioned in the global market, requires first a definition of a clear productive profile and the adoption of an active and very specific economic development policy.

Up to now, Andalusia has not been able to draft a new development strategy fully based neither on its objective, subjective and institutional conditions nor being able to draw its attention on the conditions imposed by the process of globalisation. In recent history, there have been failures and successes that have been differently valued; however, there has been no definition on where we are going and how to get there. There have been many changes of direction that, although always entailing some risk, at this moment they are especially dangerous, since globalisation has become an essential feature of the world's economy and, therefore, the context where we find ourselves requires a strategy which is compatible with the new circumstances.

Globalisation of society, economy and knowledge has also increased the importance of regional resources of a cultural and organisational nature as a source of competitive advantages. Regions must therefore increase their knowledge on their potential resources, what they do have and what they do not, and focus on the specific characteristics of their environment, on which knowledge-based activities depend. Under these conditions development requires the improvement of human and organisational skills and the creation of a social and cultural environment that leads to innovation, learning, creativity and change.

'To weave this tissue' is not an easy task; however, if we want goods and services as well as information flows to move through, it is essential to connect and articulate the elements that make it up.

Thus, the first thing we need is a new approach to regional development: new meaning that we must pay grater attention than ever before to the international dimension; regional because we must take into account the current state of the productive forces in each territory, outlining the own economic profile depending on them; and global because it must promote the 
specialisation in productions for which a market exists anywhere over the world.

In order to achieve the productive specialisation level required by globalisation in the economic world where we live, we must focus our attention on those activities in which we have some initial advantage and that have possibilities to become competitive at world scale. That is, goods and services for whose production or provision we have raw materials, technological capacity, human, social and cultural capital, organisational and management skills, production and distribution experience, etc.

The implementation of this model requires as a priority a territorial approach of economic development based on the accumulation of knowledge and on innovation. This alternative, although difficult to introduce in Andalusia due to its starting position, is the only one that will enable us to enter in a competitive way the European Union and world markets.

As a summary, the fundamental agenda of a learning region must include:

1) To learn

2) To use what has been learned to apply innovations to economic processes.

\section{Learning to innovate}

Over the last two decades, innovation -understood in such a wide sense that it affects products, processes and company organisation, as well as society and institutions- has earned an increasingly relevant role in economic development models. During the last years, a new trend of economic thought that has been labelled as "neo-Schumpeterian," has contributed to improve our knowledge on technological change and innovation (Dosi et al., 1988; Freeman 1994). Contemporary capitalism is explained as an evolutionary process driven by technical and organisational innovation, in which companies are facing greater uncertainty and instability levels than those acknowledged in neo-classical theory, and in which not only the market, but also social institutions play an important role. This school of thought emphasises two essential aspects of innovation: its interactive character, and the fact that social capital has a decisive influence on the innovation process.

Despite the apparent simplicity of describing innovation as an interac- 
tive process, it is only over the last decade that it has begun to be considered seriously in economic theory and corporate practice. As Kevin Morgan wrote, this argument arose as a critique of the linear models of innovation in which innovation was a mere result of a technology-push or market-pull pressures that caused the sequence research-marketing. These linear models showed important failures, such as the absence of feedback processes and the exclusion of many types of knowledge. The lack of feedback between R\&D centres or departments and consumers prevents the acquisition of required and essential information on the practical results of research.

The second mistake, which still occurs in most western countries, is a consequence of an elitist conception that overestimates scientific knowledge and disregards "lower" types of knowledge such as engineering or production know-how. According to Richard V. Knight (1995), the concept of knowledge must be enlarged to include regional knowledge of an informal nature, such as knowledge about the environment or the social-cultural characteristics of the milieu, which give to it a special and unique value (health and social services, agriculture and viticulture, graphic arts, cuisine, music and dances, popular uses and feasts, sports, fashion and design, education and training, monuments and historical heritage). Therefore, knowledge-based resources are very varied and must be identified and assessed in order to be promoted and exported later on.

Regions must build their development on the knowledge of their own resources and not by trying to compete in new areas that are not compatible with their culture. Knowledge-based development depends on the creation of the conditions that lead to a creative and innovative application of the region's resources and on the establishment of synergies among the different kinds and levels of knowledge.

Innovation must be an interactive process among firms and research centres, among the different departments within the firm, among producers and business clients, and among companies and the wider institutional milieu. This process should be viewed as an interactive learning process in which a wide scope of institutional factors intervenes.

The second argument on the effects of social capital in innovation is closely related to the first one. Social capital includes all those elements that build up the social organisation: networks, rules, institutional practices, social conventions and confidence relationships that facilitate co-ordination and cooperation for mutual benefit. Social capital increases the profits of investments 
in physical and human capital and is already valued as an essential factor for economic development (Putnam, 1993).

These two arguments have paved the way for the current debate on the nature of today's capitalism as a learning economy. One of the main thesis defended by this group defines knowledge as the main strategic resource and learning as the most important feature of modern capitalism (Lundvall, 1994). Due to the speed of innovations, know-how has become the essential resource for companies in order to apply innovations to their products and processes. Like trust, however, know-how can not be treated as a commodity, because although some components of the know-how can be sold in the way of licenses, other components remain tacit and cannot be removed from their social and human context. Therefore, the labour market is the most important market for learning and transferring know-how, and furthermore, many key elements of tacit knowledge are collective ones.

These arguments on know-how and tacit knowledge are part of a wider thesis on the role of intangible and invisible factors (knowledge, skills, abilities, capacities, organisational culture) in economic development (Doeringer and Terkla, 1994; Freeman, 1994). Despite of the fact that those factors are difficult to measure, there is enough empirical evidence to separate those ways of organisation and social conventions that facilitate innovation and learning. We will see three different examples drawn from different levels of aggregation.

At the regional or national level, some of the criteria to assess innovation capacity are: the level of expenditure in science and technology; the stock of social capital that facilitates the collaboration between companies and research centres or between financial institutions and industries; and the existence of intermediate institutions working as learning laboratories for companies and industries, such as it is the case in Germany and Japan where there are quite a few such institutions (Lundvall, 1992; Nelson, 1993).

At the interfirm level, the better results of the Japanese toyotist model as compared to the fordist model are well known. One of the key elements that now explains the greater innovation capacity of the toyotist model is its effective joint problem solving system and interactive learning with synergistic effects that lead to continuous improvements in product price, quality, distribution, design and manufacturing.

At the level of the firm, innovative companies share some key features: horizontal information channels between their $R \& D$, manufacturing and 
marketing departments or networks; decentralised learning procedures and practices open to multiple information channels, both internal (employees) and external (especially clients, suppliers and competitors). However, the ongoing improvement process by means of interactive learning and problem-solving (kaizen) requires a labour force that is actively committed to the company. Only within this social context can we understand two of the main characteristics of Japanese companies, their use of the factory as a laboratory and decentralised learning (Freeman, 1988; Sabel, 1994).

In recent years, several economists (Cooke and Morgan, 1994; Camagni, 1991; Amin and Thrift, 1995; Maskell and Malmberg, 1997; Storper, 1992 and 1995) have tried to apply some of the insights of the "neoSchumpeterian" evolutionary economic theory, especially those related to innovation, learning and the role of institutions in regional development models. According to Storper, the region has currently assumed a central role in the development of capitalism, (partially) due to untraded interdependencies such as the labour market, regional agreements, rules and values, public or semi-public institutions. Thus, Storper follows the same line as Lundvall, for whom the tacit knowledge of a collective nature is tightly linked to its human and social context.

According to Patel and Pavitt (1991), physical proximity facilitates the integration of multidisciplinary knowledge, which is tacit and thus "personembodied" rather than "information-embodied," also facilitating the speed required in decision-making to confront uncertainty. Therefore, globalisation and localisation (or regional specialisation) are no longer considered excluding factors but complementary elements of a common process (Cantwell, 1995).

A low per capita income and a high unemployment rate are nothing else but symptoms of a low development capacity caused by the absence of physical infrastructures, a qualified workforce and $R \& D$ activities. However, the invisible factors are as important as the physical capital (Doeringer y Terkla, 1990; OECD, 1993). The less developed regions usually lack sufficient social capital -invisible factors such as the institutional capacity, the political structure and the attitude to look for joint solutions to common problems. Thus, the establishment of $R \& D$ centres is not a sufficient condition to achieve regional development, since in addition it is necessary to link this supply to local or regional demand. The most important factor in regional innovation is the degree of interaction between R\&D units and the region's companies. As early as 1988, the European Commission stated that the quality of this link or connection and the presence of local synergy were the key elements to promote a regional deve- 
lopment based on innovation.

The problem on the demand side is even more difficult to solve than supply problems because it entails the modification of companies' internal practices, as well as the promotion of at least three types of competence (Morgan, 1997). The first one is the technological competence, that is, a company's ability to apply technologies that are suited to their needs. The second one is the entrepreneurial competence, that is, the ability to integrate relevant technologies into the company's strategy. And finally, the learning ability which consists in structuring organisational practices in such a way as to enable the acquisition of information on changing markets, new technologies and innovative management and organisational structures. In order to solve this problem we must take into account that companies are more open to knowledge coming from its close environment, especially other companies, no matter if they are clients, suppliers or competitors. That is why it is so important to institutionalise the channels through which we want to make information flow.

Another approach that also relates the phenomenon of economic development to social capital is the one suggested by Sergio Boisier (1999). It originates from Harrod-Domar's thesis with the addition of new factors other than the ones considered in the traditional approach to regional development (in which investment and technology are the determining factors of economic growth and development). According to this approach, in a territory it is possible to find different forms of capital that, once articulated with each other, should produce development. Such articulation would be the result of giving value to the most important form of capital that can be found in a community: the synergy capital, meaning the social capacity to promote joint actions aimed at collectively and democratically accepted purposes, with the well known result of obtaining in this way a final product that is greater than the sum of the components.

Boisier identifies nine forms of capital whose configuration determines the development of regions. They are: economic, institutional, cultural, symbolic, human, psychosocial, social, civic, and cognitive capital.

Focusing on the factors with an invisible character, in the case of institutional capital, the region and its institutions must concentrate on solving aspects such as the capacity to act, quick decision making, organisational flexibility, malleability, potentiality, and especially, organisational intelligence, not forgetting an essential aspect which is inter-organisational relations.

Cultural capital - defined as the heritage of traditions, values and 
beliefs, language, social relations, varieties of production and material and immaterial products - has a definite influence on the development process of regions, both from the economic standpoint - with the creation of new market segments that are increasingly demanded by society - and from the perspective of the collective attitudes towards work, leisure, saving, risk, co-operation or competition.

Promoting the symbolic capital of a region implies using the power of public speaking for the task of region building, that is, to mobilise dormant social energies, generate self-references, and even to build corporate territorial images which are essential for today's international concurrence.

Regarding the human capital, generally much emphasis is placed in the generation of knowledge by means of education, research and development. However, some authors like Vetter and Fuentes (1991) have claimed the importance of investments in human capital by means of health and internal migration.

The psychosocial and the social capitals are defined in terms of trust. Trust in the community and in its development potential, and trust as a component of a human capital that enables the members of a given society to trust each other and to co-operate in making up new groups and associations. The civic capital builds up in the region as democratic political practices consolidate, as the concern for the res publica spreads, as a clear trend towards associationism in the public and the private sphere appears and as civic commitment networks develop.

Finally, and as far as the cognitive capital is concerned, a great part of it has an exogenous character, due to the concentration of the scientific and technological research capacity in great transnational corporations. It is well known that the articulations between the parent company and its branches, and the acquisition of machinery and equipment are very frequent modalities of know-how transference to the periphery.

However, the acknowledgement of the increasingly exogenous character of state-of-the-art scientific and technological know-how cannot be an excuse for not trying to develop an endogenous knowledge from a double perspective: the one that relates to local culture and traditions, and the one creating state-of-the-art know-how in technologies that are closely linked to the region's production system. This issue relates directly with the existence and excellence of a regional science-technology-industry (+market) system. 
The working of the synergy capital is not an automatic process; it requires an impelling actor, and that actor cannot be other than the government of the corresponding territory. According to Boisier's opinion, new tasks must be included in the practice of regional governments in order to introduce into them the capacity of mobilising invisible factors.

Therefore, it is necessary to stimulate a collective innovation learning process; to define a strategy adapted both to the resources and to the needs of the region and based on strengthening the dialogue between the public and the private sector; and to design jointly the set of actions in the field of technological innovation and development required to play competitively in a globalised economy. The key regional agents (private companies, public entities and intermediary institutions working in technology transfer and in training) have to assume that the push to increase regional productivity and competitiveness must come from the region itself, which leads us to the existing networks and to their capacity to set up new ones, or its equivalent, to their availability to collaborate for mutual benefit.

\section{Endogenous development and social-cultural capital}

The changes that have occurred in economic, technical and social conditions over the most recent years have led to an increasing awareness on the need to act on several fronts that traditionally had barely been taken into consideration at the regional level. Among others, we can mention: the use and adaptation of the most recent technological innovations; the definition of the role to be played by services in regional development; the creation of more favourable conditions for the starting up and consolidation of new businesses; the problems related to business and white-collar worker training; the entry of regional companies into new markets; and the funding problems and possible new capital-risk formulas (Wadley, 1986).

Regional policy, without waiving its redistribution aims (both of income and of activity), must place now a much greater emphasis than before on favouring each region's own growth capacities, whenever this is compatible with the achievement of the highest possible efficiency in terms of productivity and competitiveness (Cuadrado, 1988).

Among the different existing development models, those included in the theory of endogenous development emphasise the use of each region's growth potentials and the implementation of those measures and instruments 
that can make the productive system more efficient. In contrast to other models, the central core of the endogenous development model underlines the local character of some development factors, linking it very directly with the territory and its conditions, which implies an increase of the specificity of regional development policies, as opposed to the almost universal applicability defended by neo-classical models. And this applies not only to the availability of natural resources, but to a set of factors that are relevant for development, such as workforce qualification, organisational and managerial experience, social and institutional structures, etc., all of which are decisive for a region to be capable of innovating, transferring resources from old activities to new ones, substituting old products and markets by new ones and, in conclusion, making structural changes.

The regional development model proposed in this paper emphasises the promotion of a development which is in agreement with local resources and capacities and which - being essential the elements of globality (attention to any market) and sustainability (environmental self-discipline) - contributes to create the necessary climate for the process to gain its own momentum. Furthermore, this model must be characterised by the predominance of middle and long-term strategies over short-term techniques; by anticipating the future rather than merely "fire shooting" as problems arise; by choosing the technological option (high or intermediate) that matches best the regional productive tissue; and by focusing towards the selective promotion of possible and feasible productive activities (Román, 1995).

Public investment is a fundamental element for building a true domestic market, for its insertion into the European Union and into the "information society". Hereto, it is essential that policy actions implemented by the nation's different government levels and the different public administrations are established in a coherent way and are properly co-ordinated.

However, the most important element in order to start a regional development process based on the accumulation of knowledge lies in the need to design and apply interventionist measures under an active collaboration and co-operation between the public and private sectors. A climate of dialogue and social stability is required, leading to complex co-operation of the Administration-Companies-Universities-Financial Institutions kind to support the establishment of proactive centres that are necessary for development.

In the case of Andalusia, it is necessary to promote a positive external image based on its quality of life. Hereto, the quality of its natural environment, 
its cultural diversity and its historic and monumental heritage are important factors for attracting business investments and job creation; Andalusia must also show a positive image as a place to work, produce and invest. For this purpose it counts on a privileged position, a crossroads of communications and cultures, integrated in Europe and open to the Mediterranean and Africa.

However, in order to make a diagnosis of the endogenous development possibilities and the possible actions and policies to be applied, it is first necessary to make a balance of the advantages and disadvantages a certain region presents.

\section{Historical evolution and current position of the Andalusian region}

Logically, the current situation of the Andalusian economy results from very different factors. Firstly, its peculiar geo-strategic position, but also historical factors such as the role assigned to Andalucia by the Spanish development model over the last thirty years ${ }^{1}$, the recent political-administrative transformation of the Spanish State, leading to the creation of the State of the Autonomies, and the ulterior integration of Spain into the European Union.

Andalusia is Europe's southernmost region. From the geographical point of view, it is a peripheral area; however, in terms of economic development the institutional and economic transformations it has undergone over the last 20 years have given the region an important push forwards, and have placed it in a position which is qualitatively different and with great expansion chances in the mid and long term. This favourable evolution of Andalusian economy can be explained by the incorporation of technical developments to productive activities (responsible for $85 \%$ of Andalusia's growth). This change has taken place thanks to the financial support obtained from the European Union (Andalusia receives 320 pesetas for every 100 it contributes to the Union's budget) and the intervention of the regional and national public sector to increase the capital stock and public services; as well as to an important capturing of foreign investments and to the adaptation capacity of the private sector in the face of the European integration process.

${ }^{1}$ Historical inequalities in development levels caused important differences regarding the amount of infrastructures (transport, energy, telecommunications and environment) and human capital (know-how and workforce qualification), which are essential elements for an effective production. 


\subsection{Territory and population}

In the current globalisation context, the territory acquires an even more relevant role in terms of the fundamental objectives of development, well being and cohesion. Andalusia can move from being a peripheral area to define a new function within Europe and become a significant element in the space of a globalised economy; it must define and strengthen its role in this new world, especially in Europe and in the Mediterranean area. In order to take the maximum advantage of its pure economic rent, it is a top priority to sustain and accelerate the convergence process with the other European regions and a greater implication of the Andalusian Government in European entities and relationship networks is required.

Andalusia's southern border consists of $812 \mathrm{~km}$ of coastline, both on the Mediterranean Sea and on the Atlantic Ocean. There are several mountain ranges on its northern border that spread over most of the region and are the natural frontier between Southern and Central Spain. The Portuguese Algarve is on its western border whereas on the east it connects with the other Mediterranean regions. The challenges Andalusia is facing require a promotion of economic and social integration relationships between Andalusia's Mediterranean coastline and the Maghreb countries, as well as fostering a new co-operation model among European Mediterranean regions, and favouring an effective approach to the Latin American countries in terms of co-operation for development, economic and trade relations, and cultural and educational relationships.

Spain is made up of 17 regions. Andalusia is the largest one in terms of population (18\% of Spain's population) and the second largest one in total surface ( $17 \%$ of Spain's total). In relation to Europe, it accounts for $3 \%$ of its surface and $2 \%$ of its population. Furthermore, it is a region with a constant demographic growth and its population pyramid is wider in its lower steps thanks to a birth rate above that of the other regions and to positive migration balances over the last 10 years. It is the European region with the youngest demographic structure, which has a clear impact on the situation of the labour market and on its productive structure relative capacity to match job supply and demand. This factor, which shows the potential of the region, requires an important effort for its adequate solution. 


\begin{tabular}{|c|c|c|c|c|c|}
\hline & \multicolumn{3}{|c|}{1996} & \multirow[t]{2}{*}{ Total 1998} & \multirow[t]{2}{*}{ Density 1998} \\
\hline & Men & Women & Total & & \\
\hline Andalusia & $3,559,436$ & $3,675,437$ & $7,234,873$ & $7,236,459$ & 82.61 \\
\hline Almeria & 250,552 & 251,209 & 501,761 & 505,448 & 57.60 \\
\hline Cádiz & 548,263 & 557,499 & $1,105,762$ & $1,107,484$ & 148.86 \\
\hline Cordova & 372,249 & 389,152 & 761,401 & 767,175 & 55.71 \\
\hline Granada & 395,509 & 412,544 & 808,053 & 801,177 & 63.35 \\
\hline Huelva & 224,776 & 229,959 & 454,735 & 453,958 & 44.82 \\
\hline Jaén & 319,859 & 328,692 & 648,551 & 645,792 & 47.85 \\
\hline Málaga & 611,750 & 637,540 & $1,249,290$ & $1,240,580$ & 169.80 \\
\hline Seville & 836,478 & 868,842 & $1,705,320$ & $1.714,845$ & 122.17 \\
\hline Spain & $19,399,549$ & $20,269,845$ & $39,669,394$ & $39,852,651$ & - \\
\hline
\end{tabular}

\begin{tabular}{|c|c|c|c|c|c|c|c|c|}
\hline & $\begin{array}{c}\text { Marriage } \\
\text { rate }\end{array}$ & $\begin{array}{c}\text { Birth } \\
\text { rate }\end{array}$ & $\begin{array}{c}\text { Death } \\
\text { rate }\end{array}$ & $\begin{array}{c}\text { Children } \\
\text { death } \\
\text { rate }\end{array}$ & $\begin{array}{l}\text { Veg. } \\
\text { growth }\end{array}$ & $\begin{array}{l}\text { Inmigra- } \\
\text { tion }\end{array}$ & $\begin{array}{l}\text { Emigra- } \\
\text { tion }\end{array}$ & $\begin{array}{c}\text { Net } \\
\text { migration }\end{array}$ \\
\hline Andalusia & 5.047 & 10.843 & 8.149 & 4.649 & 2.694 & 11.31 & 11.77 & -0.45 \\
\hline Almeria & 5.518 & 12.072 & 8.338 & 5.293 & 3.734 & 15.33 & 13.71 & 1.62 \\
\hline Cádiz & 5.019 & 10.935 & 7.456 & 4.185 & 3.479 & 10.27 & 12.20 & -1.93 \\
\hline Cordova & 5.074 & 10.656 & 8.717 & 5.181 & 1.939 & 9.41 & 9.50 & -0.09 \\
\hline Granada & 5.099 & 11.216 & 8.596 & 5.878 & 2.620 & 13.07 & 13.94 & -0.86 \\
\hline Huelva & 4.804 & 10.308 & 9.057 & 3.018 & 1.251 & 9.20 & 9.78 & -0.58 \\
\hline Jaén & 4.848 & 11.156 & 8.727 & 3.929 & 2.429 & 8.82 & 11.62 & -2.80 \\
\hline Málaga & 4.714 & 10.230 & 7.932 & 5.203 & 2.298 & 12.46 & 11.78 & 0.68 \\
\hline Seville & 5.282 & 10.821 & 7.782 & 4.225 & 3.039 & 11.56 & 11,47 & 0.09 \\
\hline Spain (1) & 5.118 & 9.270 & 8.830 & 5.492 & 0.440 & - & - & - \\
\hline \multicolumn{9}{|c|}{ Source: IEA. INE. MNP (1) 1995 Data } \\
\hline \multicolumn{9}{|c|}{ 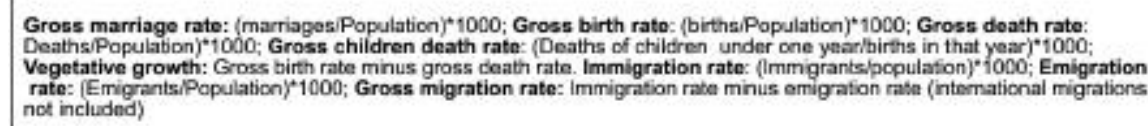 } \\
\hline
\end{tabular}


Another aspect to highlight is the diversity of territory, landscape, ecosystems and climates in Andalusia. We have a clear example in the few kilometres that separate the snow-capped mountains of Sierra Nevada from the Mediterranean climate coast of Granada or from the desert climate of Almería. This diversity between coastal and continental areas, or between the western and eastern provinces has important implications of all kind and has an important potential for sectors such as tourism and agriculture, since it increases the variety of supply and of possible productions.

Finally, there is a clear awareness in Andalusia of the fact that the environmental elements will also define the spatial competitiveness levels, and so the environmental policy becomes a basic element to increase the chances of territorial development. The Andalusian Protected Natural Area Network (RENPA) - created in 1989 - is a pioneer initiative in Spain thanks to which the protected surface in Andalusia accounts for $49.5 \%$ of the total national protected surface. The 85 protected areas account for almost $18 \%$ of Andalusia's total surface. Natural Resources Organisation Plans and Use and Management Guiding plans have been drafted to catalogue and plan all Protected Natural Areas. Furthermore, the Institute for Regional Development has performed the preliminary studies for the drafting of the Sustainable Development Plan of the Los Alcornocales Natural Park (Cádiz-Málaga), and has also supervised the drafting of the Sustainable Development Plan of Sierra Mágina (Jaén). These initiatives are contributing to change the old traditional perspective of local populations that viewed the establishment of protected natural areas as an obstacle for their development.

Since 1989, 676,000 hectares have been reforested. The importance of environmental activities in the region has become obvious with an ongoing improvement of the endowment of environmental infrastructures (water purification, waste treatment, soil protection, coastline protection and air pollution control stations).

\subsection{Historic evolution}

If we make a historical balance of the socio-economic weight of Andalusia, we can state that the current situation is totally new. In the 18th century Andalusia accounted for one fourth of the national income and was in first position among the Spanish regions. It started the 19th century in that same position, the first iron and textile works were opened in Andalusia, which became the entry gate of the industrial revolution to Spain. All this seemed to prom- 
ise a brilliant industrial future.

Because of a complex set of reasons, all these expectations were frus trated and Andalusia entered a long decadence process, in which the end of 19th century depression marked the transition to the "subordinated" take-off of Andalusian economy in the 20th century.

The historical inequalities in Andalusia's development level are the source of the important differences existing at the beginning of the 1980s regarding the amount of cumulative production factors, and their existence is closely related to the economic development level and process of Andalusia.

As a necessary condition to achieve an average development level, Andalusia had to modernise and restructure many economic activities -especially in the fields of agriculture and industry- in order to increase regional competitiveness. These changes should go together with an important investment effort, both by public and by private agents, to reduce the differences existing in essential aspects such as the endowment of infrastructures (transport, energy, telecommunications and environment), human capital (know-how and workforce qualification) and technological capital.

Since the second half of the 1980s a constant growth process has taken place which is only interrupted by the 1992-93 world crisis; its main characteristics being (Osuna, 1999):

- Andalusian GDP grows above the national average, however, its relative weight within the Spanish total (13.4\%) almost does not change over these years.

- Growth of per capita GDP, though it still accounts for only $72 \%$ of the national average and $57 \%$ of the European average.

- Growth of investments, especially public investment and foreign private investment.

- Growth of employment, however the capacity to create stable employment remains very weak. 


\begin{tabular}{|c|c|c|}
\hline & Economicgrowth\% & Employmentgrowth\% \\
\hline Andalusia & $70.2 \%$ & $24 \%$ \\
\hline Spain & $85.1 \%$ & $12 \%$ \\
\hline European Union & $48.9 \%$ & $3.2 \%$ \\
\hline
\end{tabular}

We should also list some aspects worth underlining, such as the consolidation of certain non-typical food-farming productions (extra-early, subtropical, flower, biological, etc.); the starting up of economic activities with good future perspectives in world markets (especially in the machinery and equipment subsector linked to high technology); the remarkable improvement in infrastructures (transports, communications and telecommunications); the emergence of some specific subsectors with an unquestionable qualitative weight (renewable energies, environmental goods and services, audio-visual industry); and finally, the change of the social attitude towards innovation, to which the Andalusian society is increasingly more open.

The economic development and the efficiency of the productive system rely on a series of factors that are essential to achieve and maintain economic growth in the mid and long term. They are basically production factors whose main feature is that they are cumulative, such as physical capital, human capital, technological capital, social capital, and generation of knowledge.

Over the last 20 years important investments have been made in economic and social infrastructures, and technological and human capital. This effort to create the necessary conditions to achieve higher growth rates has received the economic support of national and community regional policies. These policies have been featured to a great extent by their focus on aggregate demand factors. Both national and community institutions have emphasised the alleviation of the differences in the amount of productive factors as an instrument to reduce interregional inequalities in terms of productivity. A main role has been played by training and public provision of infrastructures. 


\subsection{Infrastructures to support productive activity}

Since the constitution of the Regional Government of Andalusia (1982), networks and plans at regional scale have been outlined and designed to confront the needs and priorities. They have been shaped in the form of specific projects due to the important financial effort made, to a great extent, thanks to the investments coming from the EU Structural Funds. All this has meant a remarkable improvement of Andalusian position within the international context and in the region's articulation with other European regions. However, if we compare Andalusia with the national and European averages, we can see that there are still differences, although smaller than before, in the presence of infrastructures, and especially in its internal articulation.

\subsubsection{Transport infrastructures}

Its geographical characteristics place Andalusia in the southern tip of the European continent. This makes transport infrastructures play a different role in Andalusia than the one in other regions. Firstly, the road and railway networks play a cohesive role for its territory. Secondly, harbours and airports play a strategic role for the economic development of the region due to its important function in import and export of goods, in the arrival of tourists and in the mobility for business reasons.

The time required to travel to the main economic centres in Spain and Europe has decreased sharply, and two strategic connections have been established with the outside, one with the centre of Spain, and the other with the Mediterranean regions (the latter is especially important because it connects the eastern part of Andalusia with an area that is experiencing a great development: the Mediterranean arch). The number and length of motorways and dual carriageways has undergone an important growth (from $229 \mathrm{~km}$ in 1985 to $1,699 \mathrm{~km}$ in 1997), and furthermore, a great part of the road network has been improved, the number of motor vehicles has doubled and the first Spanish high speed railway line has been built between Seville and Madrid.

The long Andalusian coastline on the Atlantic and the Mediterranean explains the importance of its harbour system. The Andalusian community has an important port system, with nine large commercial harbours, 17 fishing ports and 20 marinas. Among the harbours the most important one is the harbour in the Bay of Algeciras, between the Atlantic and the Mediterranean which ranks first in Spain for freight and passengers and is one of the most important ones 
of the Mediterranean, especially in the intercontinental traffic of containers.

There is a good airport infrastructure with 6 of them, with a total traffic of more than 10 million passengers in 1997; more than $60 \%$ of them in international flights. Most of the air traffic is linked to tourism; this places the airport of Málaga, the most important tourist destination on the Andalusian coast, in first position in passenger traffic in Andalusia.

However, it is necessary to complete the modernisation of international connection infrastructures in Andalusia, promoting the transeuropean role of its harbours, airports, communication networks and energy networks, as well as reinforcing the role of Andalusian networks in connecting the Atlantic arch with the Mediterranean arch, and speeding up the studies and projects to build a bridge/tunnel connection between Europe and Northern Africa.

\subsubsection{Energy infrastructures}

The situation of the Andalusian energy sector is similar to the general one in Spain. It is highly dependent on oil and there is a scarcity of conventional energy resources. There are storage and transformation facilities both for oil and natural gas. As far as energy use facilities there is a great variety of them, conventional thermal power stations, co-generation power stations, hydroelectric ones, windmill parks and photovoltaic power stations. We should underline the increasing role of renewable energies, especially windmill parks, and the effort currently made in the promotion of solar energy (Andalusia has $23 \%$ of all national solar panels).

Regarding the energy transport and distribution network, the most important feature is the ongoing growth of the gas network, which was started in 1988 with the Huelva-Sevilla gas pipeline. Later this has been enlarged with the building of the Sevilla-Madrid pipeline and the extension of the distribution towards the cities located in the east of Andalusia, except for Almería. It must be underlined that the Maghreb-Europe gas pipeline went into operation at the end of 1996.

\subsubsection{Telecommunication infrastructures}

The transformations undergone by telecommunication networks have improved the accessibility of areas of the Andalusian inland. This sector has 
experienced a remarkable progress, especially the introduction of optic fibre networks and the digitalisation of telecommunication plants (for example, the construction of the international telecommunications centre and teleport in Sevilla). The modern telecommunications network required by business activities has led to the establishment of telecommunication services between the two technological and business parks existing in the region (Málaga Technological Park and Tecnopolis of Seville). Large and middle sized urban areas have a service level similar to the national one, while the conditions in the tourist towns are equivalent to the ones in the most advanced European countries.

\begin{tabular}{|l|c|c|}
\hline \multicolumn{2}{|c|}{ TABLE 4, EVOLUTION OF TELECOMUNICATION } \\
INFRASTRUCTURE IN ANDALUSIA
\end{tabular}

\subsection{Productive sectors}

The sectorial productive structure in Andalusia shows a strong tertiary sector, a somehow reduced industrial sector and an important share of construction, while the primary sector keeps a significant weight. 


\section{CHART 1: EVOLUTION OF THE COMPOSITION OF THE GVA IN ANDALUSIA}

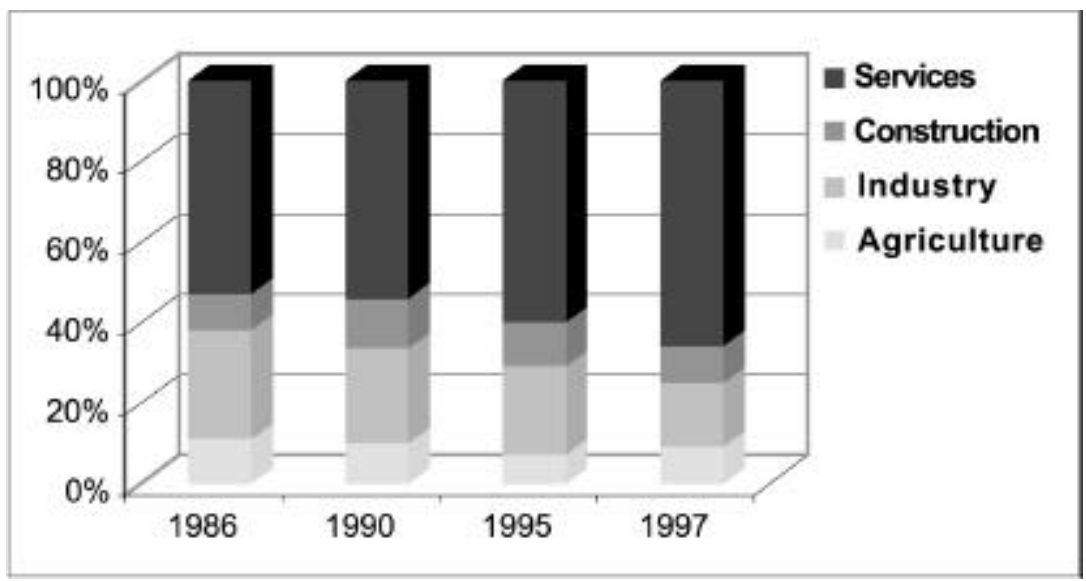

Source: Regional Ministry of Economy and Treasury, Government of Andalusia

The most outstanding factor is the growth of the foreign orientation of the Andalusian economy since the entry into the European Union. This incorporation enabled the release of the exporting potential in several sectors, such as the food-farming industry, and the generation of a competitive pressure on the economy that has acted as an important stimulus. The degree of outward orientation, measured as the percentage of exports and imports on the gross value-added at factor cost (GVAfc) has grown by more than $40 \%$ between 1988 (19.1\%) and 1997 (26.9\%).

Andalusia's trade balance experienced a historic surplus of almost 138,000 million pesetas in 1998. This indicator shows the quick internationalisation and the greater competitiveness of the Andalusian economy. In the last six years exports have more than doubled (105.6\% growth) and imports have grown by $72 \%$. However, Andalusian exports still account for little more than $8.5 \%$ of Spain's total exports over the last decade. 


\section{CHART 2: ANDALUSIAN EXPORTS BY ECONOMIC SECTORS, 1997}

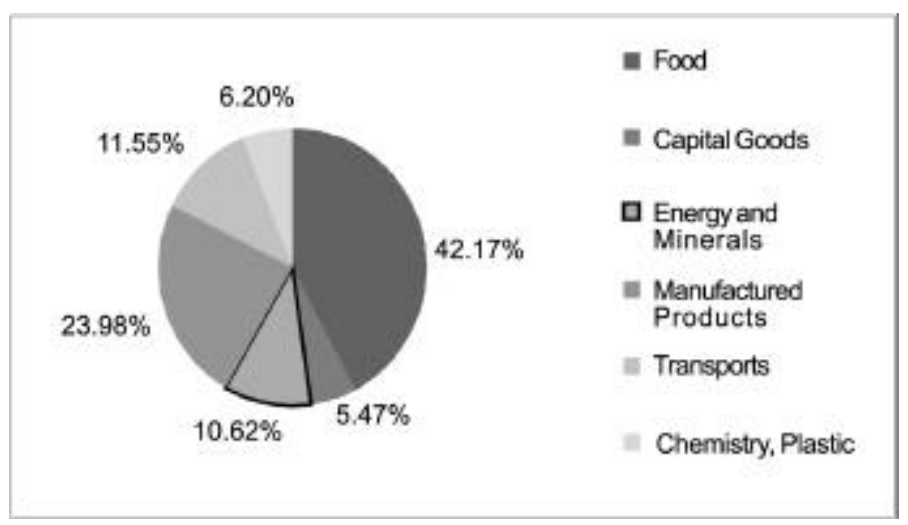

Source: Regional Ministry of Economy and Treasury. Government of Andalusia

\subsubsection{The farming sector}

The Andalusian farming sector has a remarkable dual structure. On the one hand, there are modern and competitive farming units with the financial capacity to undertake an important restructuring and to reach foreign markets, on the other, there are either small farms with few resources or the traditional large landed properties. The contribution of the farming sector to the Andalusian GDP ranges between $7 \%$ and $9 \%$ as compared to 3-4\% in Spain. The food-farming industry accounts for some $30 \%$ of the total. The Andalusian economy as a whole accounts for $13-14 \%$ of Spain's economy, which compared to the relative weight of the Andalusian farming production in the Spanish total (24-29\%), shows the considerable importance of the farming sector in our country. The food-farming sector represents more than $20 \%$ of the farm sector population, half of which corresponds to the production stage.

\subsubsection{The industrial sector}

The Andalusian industry has a quite small relative weight as compared to the rest of Spain and to the European Union. In 1997, its contribution to 
regional production and employment accounted only to $16,5 \%$ of the GVAfC and $12.5 \%$ of the employment. The relative weight of the Andalusian industry in Spain's total is just 9\%. Despite of production growth (in 1988 the regional industry had a $4.5 \%$ GVA growth rate with 25,000 new jobs), a certain specialisation in the extraction and food-farming sectors, the development of modern sectors with a strong endogenous component, and an important presence of companies in sectors with a high value-added and greater technological complexity (especially in metal transformation), the industrialisation level is still very low and focuses on the earlier transformation stages.

As we can see in table 5, in Andalusia there is a clear production specialisation, as compared to the rest of Spain, in food, drinks, tobacco and extraction activities, while there is a lower relative development in areas with a higher technological component. However, the changes experienced over the last years aim at a reorientation of production towards segments with a higher technological component, especially machinery, electric and electronic material, and transport means, which have doubled their contribution to the industrial GVA.

\begin{tabular}{|l|r|r|r|r|r|r|}
\hline \multicolumn{7}{|c|}{ TABLE 5. EVOLUTION OF INDUSTRIAL GVA IN ANDALUSIA AND } \\
SPAIN, $1985-95$ \\
\hline
\end{tabular}




\subsubsection{The service sector}

In the service sector, despite the significant increase of business services, the tertiarisation of the economy is more linked to commerce, non-sales related services, and especially to tourism. Advanced business services have not shown in Andalusia the level of dynamism that can be detected in other developed economies, where services to production have widely developed due to the intermediate demand, especially industrial one.

Commerce accounts for $13 \%$ of the regional GVA, it generates more than $13 \%$ of the employment and includes 107,525 commercial companies. Retail commerce accounts for almost $90 \%$ of all stores and $70 \%$ of the employment in the Andalusian commercial distribution sector. One of the main problems retailers are increasingly facing is the quick expansion of the large commercial surfaces in the main Andalusian cities due to the entry of women in the labour market and changes in the urban way of life.

The important role of the tourist sector in Andalusia is shown both by its contribution to Andalusian GDP, $10.8 \%(14.6 \%$ if we include indirect effects), and by its job generation capacity, with 124,100 employees in 1998. The current trend is clearly expansive, evidenced by the fact that in 1997 tourism grew some $8.7 \%$, well above the national $4.5 \%$ average.

\section{The consolidation process of a "Learning region": the case of Andalusia}

In 1998, the Andalusian economy has experienced a $4.3 \%$ growth rate, which is 0.5 and 1.4 points above the ones experienced in Spain and the European Union, respectively. This growth rate, which almost equalled the one in the previous year (4.5\%), is part of an expansion cycle that started in 1994. The strength of this growth is evidenced by the fact that for the third consecutive year all productive sectors contributed positively to the growth of the regional GDP with higher growth rates in the non-farming sectors. In fact, in 1998, $89 \%$ of the Andalusian economic growth came from non-farming sectors.

However, it is much more important to focus our attention on how growth takes place rather than on how much it accounts for. This statement should be taken into account in the study of any economic development process. Especially when the subject matter is to assess the possibilities of an economic area to become a learning region, which is the case here. Below we 
will introduce some considerations on the nature and characteristics of the development process of the Andalusian economy. To start with, it is an economy that grows not so much because of its own capacity to generate economic activity, but rather because it benefits from a favourable external economic situation and/or public investments; that is, the motor of growth depends, not exclusively, but mainly, on external factors to the region. Second, there seems to be some difficulty in solving or overcoming many of the structural problems that strangle the regional economy during these expansion stages. In fact, if we compare Andalusia with its European neighbours, this is a region with a lower economic development, as shown both by its per capita GDP (57.4\% of the community average in 1996, below that of Spain $78.7 \%$ ) and especially by the high volume of unemployed population. In 1997 the unemployment rate in the Andalusian economy was 32\% (European Commission, 1999) ranking second among the regions with highest unemployment rates, only behind the Island of Reunion.

It is clear that the links with the external environment are increasingly higher. The progressive integration of an economy into another one, it is itself neither good nor bad, it all depends on the way this insertion takes place, the position held - or it is possible to hold -, the tasks and functions that are performed, the dependency - or interdependency - relations that are established. In conclusion, it depends on the strength or vulnerability of the economy that is integrating. All this requires improving the position of the Andalusian economy to make it more competitive, which necessarily entails a transformation of its productive structure by articulating its economic tissue in order to reduce a dependency that in any case is too high.

What can a weak economy - with evident backwardness and placed in the periphery - do? Until now, Andalusian development has basically focused on improving the stock of physical capital, enlarging its infrastructures to improve the connection with the outside, adapting to foreign market demands and technological forces. It is now time to design and implement a new regional development strategy, that pays more attention to endogenous potential factors, as well as to the invisible knowledge-based resources that can generate innovation processes, such as social, cultural, human, institutional, civic and cognitive capital.

The importance of the advantages with a cultural and organisational character is reinforced by society's globalisation. The knowledge market is increasingly becoming globalised. Due to much faster international communications, productive activities become more distant from its cognitive basis, 
which increases, instead of reducing, the importance of regional resources in terms of knowledge and core competence, making them an important source of comparative advantages (Knight, 1996). The knowledge of the own resources becomes thus the strategic resource of regions and their main economic and institutional basis for the future.

Therefore, a new development strategy is necessary, based on the knowledge of the region and rooted in local culture and traditions and in the creation of technological know-how linked to the own production structure. This latter aspect is closely related to the existence and quality of a regional science and technology system.

\subsection{The Science - Technology - Industry + Market System}

One of the essential aspects to achieve the development of innovation processes in the regional sphere is the articulation of the Science - Technology - Industry + Market System.

In order to explain the inclusion of the last element of the chain we must consider that the ultimate aim of research and technological development is the application of innovations in the production system to make it more competitive. To achieve this, either companies conduct research or universities and other research institutions or centres transfer the results of their research to the market.

The scientific work of universities and R\&D Centres must result in successful products in the market in order to obtain interesting economic results. This is only possible if research bodies conduct R\&D projects aimed at meeting industries' needs, and these results are effectively transferred to the production system. In some cases, as we mentioned in our starting hypothesis, the innovation process is independent from the origin of the technology. In fact, there are many development models based on technology import and transfer. The 4th R\&D Framework Programme of the European Union, within the Specific Programme for the Dissemination and Optimisation of Research Results, Technological Development and Demonstration (INNOVATION Programme), established as general objective of the programme to 'promote transnational and transectoral transfer of innovations, regardless of their origin, and especially, to make better known the community $R \& D$ activities and their results.' 
The loop that must close the chain is feedback. The market must "send" to the Science, through the Industry - Technology line information on the results of the discovery, in order for this to be corrected, reoriented, discarded, etc. This is an additional reason that explains the need to bring closer R\&D and production structures.

Andalusia possesses a series of positive factors that can become the key resources in the regional learning process. Among them, the large amount of interface structures ${ }^{2}$, which are responsible for technology dissemination (9.7\% of Spain's total), or the enormous amount of university students in a great variety of academic fields $(277,250$ in the 9 Andalusian Universities in the $1998 / 99$ academic year, $20.3 \%$ of the Spanish total) ${ }^{3}$.

Over the last years, and thanks to the Andalusian Research Plan, the number of people holding a Ph.D. has doubled and Andalusia has 1,640 consolidated R\&D groups. The start of the 2nd Andalusian Research Plan (199497), with a total investment of 141,000 million pesetas, has extended the scope of action since it includes scientific research, technical development, innovation and technology transfer and puts more emphasis on the industrial applicability of results. This last element is especially important, because otherwise, we could overestimate the importance of these research groups. In fact, many of them are nothing else but an alternative way of obtaining some kind of additional funding from the administration, mainly for Social Sciences University Departments. It is evident that the relation of their activity with technical innovation is quite weak.

At the national level, total $R \& D$ expenditure is much lower than the one existing in other EU countries. In 1996, total R\&D expenditure in Spain accounted for $0.87 \%$ of the GDP at market prices, as compared to $2.28 \%$ in Germany, $2.32 \%$ in France or $1.94 \%$ in the United Kingdom (INE, 1998). According to the most recent available data, total internal $R \& D$ expenditure in Andalusia accounted for 63,000 million pesetas in 1996. This figure, which places Andalusia in third position after Madrid (213,000 million pesetas) and Catalonia $(136,000$ million pesetas), does not seem as high if we consider that it represents a mere $0.5 \%$ of the Andalusian GDP.

However, although the evolution of investment in Spanish companies

\footnotetext{
${ }^{2}$ Interface structures work as promotors of the relations between technological supply and demand, both at public and at private level, thus making the innovation market more dynamic. This is the case of the OTRIs (Research Results Transfer Offices).

${ }^{3}$ Commission: "Andalusia a technologically advanced society". Working paper of the Forum Andalusia in the New Century. Regional Government of Andalusia. February 1999.
} 
has been rising over the last 20 years, the percentage of innovative companies is still very low. According to the COTEC Foundation (1998), Spanish companies have not based their expansion strategy on innovation, since only $11 \%$ of them do innovate, as compared to $25 \%$ in the EU. The most recent data on technological innovation in Andalusia show that in 1996 total expenditure in innovation by companies accounted for 38,000 million pesetas (from which 8,000 million by companies with less than 20 employees). This figure represents just $4.8 \%$ of the national total. This is due to the fact that Andalusian private companies hardly do any $R \& D$, either because they do not do any at all, or because they are branches of larger companies whose $R \& D$ centres are outside of this region. Only $14 \%$ of Andalusian employers invest in R\&D and only $31.7 \%$ manufacture or sell new products.

The comparison between both ratios in Andalusia and Spain $(9,8 \%$ in R\&D vs. $4.8 \%$ in corporate innovation) evidences an unbalanced regional innovation system, with a clear predominance of $R \& D$ done in an environment that is not connected to the corporate sector (mainly with a public character). Thus, the Andalusian research, although matching in many aspects the national one, is very weakly articulated regarding production.

The Andalusian Science-Technology-Industry(+Market) System is characterised by a high geographical (Sevilla, Cádiz and Granada) and sectoral (machinery manufacturing, automobile, shipbuilding, aerospatial and foodfarming industry) concentration, which in the future can impact on an economic development marked by its de-articulation. To make this situation even more difficult, to the scarce technological diversification we must add the reduced average size of Andalusian companies (96.1\% are micro-enterprises, with less than 10 employees, and $61 \%$ do not have employees at all) which makes it even more complicate to finance the high costs of technological investments.

To all the above we must add an employer's attitude that is, traditionally, little inclined to modernisation (scarce introduction of advanced production and management systems and low levels of business technology transfer), and very reluctant to collaborate with universities and research centres, and even more with other companies (lack of business associations for sectoral research).

However, and although very slowly, over the last years we can see in Andalusia a trend to incorporate factors that contribute to generate a new innovation culture, supported to a great extent by the consolidation of new information technologies. We are referring to the actions that are taking place in 
terms of professional education and vocational training, in the creation of business co-operation networks, joint use of resources, exchange of experiences, etc.

In order for these actions to mature within the society, it is necessary to count on an innovation-favourable environment. In the case of Andalusia we can find certain elements that facilitate technological innovation processes: telecommunication infrastructures, business innovation centres, technological parks and company incubators.

\subsubsection{Telecommunications}

Since 1990, Andalusia has experienced an important growth in terms of telecommunications, resulting from the expansion dynamics of the sector itself and helped by the political decision of establishing industrial grounds with a very good technological infrastructure, the technological parks (Real, 1995). For the "information society" to develop, it is necessary to have platforms capable of providing access to advanced types of information and communication. Information technologies, telecommunication infrastructures and services, either traditional or cellular networks, are necessary technologies for this purpose.

Andalusia has been one of the first Autonomous Communities in Spain to establish telematic networks, especially within the academic and scientific community. The RICA (Computer Scientific Network of Andalusia) network was established in early 1985, as an initiative of the Directorate General of Universities of the regional government. Currently, the RICA network provides interconnection services to the Andalusian scientific community, universities, public research centres and other entities involved in R\&D activities by means of a series of access points located along the region's territory'. The Scientific Computer Centre in Andalusia (CICA) was one of the four centres that participated in the first full connection from Spain to the Internet in 1990.

\subsubsection{Business innovation centres}

\section{a) Technological Parks}

${ }^{4}$ Regional Development Plan of Andalusia 2000-2006. Regional Ministry of Economy and Treasury. Regional Government of Andalusia. 
The Technological Park of Andalusia (PTA) was opened in 1992, within the worldwide process of establishing technological parks in which to articulate both research and the regions' production needs, and through which to participate as world dissemination centres of the technology generated in them. The corporate purpose of the public company Parque Tecnológico de Andalucía, S.A. focuses on the attraction and settlement within the park of companies and entities working in research, innovation and development or singular production of applied technology.

The peculiar productive characteristics of Málaga determine that the objective of the PTA focuses in the development of the communication technologies sector (in an environment with a high quality of life) and the ulterior dissemination of those technologies to its geographical environment -as an industrialisation and economic unifying element- and to the outside -helping companies to enter international markets.

As of 31 December 1998 the number of companies located in the PTA was 101 , employing 1,705 people and with a total sales figure of 32,761 million pesetas. Among the business services currently provided in the PTA there are: rental of education classrooms and meeting rooms, consulting services, commercial counselling and services, technology dissemination and transfer services, specialised and high tech level training, laboratories, health services, nursery, etc.

The Scientific and Technological Park of La Cartuja, called Sevilla Tecnópolis since 1996, was started as a project to reuse part of the site of the 1992 Universal Exposition held in Sevilla. In May 1999, Sevilla Tecnópolis had 7,493 employees in 147 companies and 13 that were in the process to be established. This area was devoted to a scientific-technological park to perform applied research articulated with the needs of the regional production system, serving as a channel to project regional innovation abroad.

\section{b) Business and innovation centre network}

The Business and Innovation Centre Network (BIC) and the Linkage Centre Network have been working in Andalusia for several years. These two networks have been created by the European Commission, under the initiatives of the Directorate General in charge of regional cohesion policies (DG XVI) and the DG XIII, in charge of innovation and valuation of results obtained from research and information society (telecommunications, markets and technolo- 
gies). Considering that their roles are complementary, the joint work takes advantage of possible synergies of their collaboration.

BICs are local and regional development instruments. Their general objective is to contribute to the regeneration and development of the region's local potential by means of giving support to the creation of new companies based on innovation and technology. BICs perform this task by supplying and integrating a support and service package to these companies: detection systems of innovative ideas, entrepreneurs and companies with a good development potential; counselling for business plans, marketing, organisation international co-operation, innovation and technology; supply of space to these companies, working as company incubators, as well as mediation with public authorities to gain access to funding and SMEs support programmes.

Usually, BICs maintain a direct contact with the local socio-economic environment and serve as nexus between it and the companies they house. BICs are non-profit business centres and are financed through consortiums made up by public and private entities. Networking at European level is ensured by means of the European BIC network, a non-profit organisation, with its head office in Brussels, that supplies them with information and counselling for topics related to transnational co-operation, exchange of information, experiences and good practices, organisation models and interregional co-operation.

The Innovation Relay Centres (IRC) were created in 1995 within the Innovation Programme of the European Union to promote transnational technological collaboration. Their fundamental objective is to promote the transfer of results and technologies according to the needs of the local industry. IRCs give counselling to SMEs in technology transfers, both external and internal, facilitating to SMEs the access to new technologies and innovations. Furthermore, IRCs provide counselling to companies so that they can participate in EU research and technological development programmes.

The Southern Europe-Andalusia Relay Centre (CESEAND) brings together the main actors involved in the technological and industrial innovation process in the Andalusian Autonomous Community. The consortium is coordinated by the Institute for the Promotion of Andalusia, and includes also the Directorate General of Universities and Results (which groups the 10 Research Result Transfer Offices existing in Andalusia), the Andalusian Institute of Technology and the Institute for Regional Development.

The main tasks of the Relay centre are: a) to make an inventory of the 
regional technological resources; b) to promote technology transfers between research centres and companies; and c) to give counselling in European Union technological projects.

\subsubsection{Research transfer}

The Spanish scientific policy has tried over the last years, on the one hand, to improve the technological innovation processes strengthening the relationships between research groups and companies, directing them towards the most promising fields, and, on the other, to promote business research in Spain.

The OTRI-OTT Network (Research Result Transfer Offices and Technology Transfer Offices) was started in 1989 within the National R\&D Plan as an instrument to promote the participation of companies in scientific tasks, to articulate the Science-Technology-Industry + Market System and to introduce more dynamism in the scientific environment. Each University has its own OTRI which is in charge of detecting which research can be interesting for the industry and helping in contract negotiation between researchers and companies. Since 1996, non-profit research entities can create their own result transfer offices financed by the Inter-ministry Science and Technology Commission and registered as such. In 1995, the total income of OTRIs at national level was 35,000 million pesetas, from which 18,500 came for companies (COTEC, 1998).

Although the OTRIs resulted from a decision of the national administration, their regional incardination have made of them essential elements for the technological dissemination of the results produced by Andalusian universities. That is why regional authorities have promoted this figure by means of the creation of a Centre Network included in the Innovation Relay Centre Network.

The following table shows the transfer of research results from the universities and research centres existing in Andalusia to the region's companies during 1998 with a total of 459 contracts. 


\begin{tabular}{|l|c|c|c|}
\hline \multicolumn{3}{|c|}{ TABLE 6. RESEARCH RESULT TRANSFER IN ANDALUSIA } \\
\hline UNIVERSITIES & $\begin{array}{c}\text { PATENTS APPLIED } \\
1997 / 98\end{array}$ & $\begin{array}{c}\text { R\&D CONTRACTS WITH } \\
\text { COMPANIES (1998) }\end{array}$ & $\begin{array}{c}\text { RESEARCH GROUPS } \\
\text { (1997) }\end{array}$ \\
\hline Almeria & 1 & 42 & 59 \\
\hline Cádiz & 6 & 21 & 118 \\
\hline Cordova & 3 & 8 & 163 \\
\hline Granada & 12 & 158 & 330 \\
\hline Huelva & 0 & 19 & 43 \\
\hline Jaén & 1 & 7 & 46 \\
\hline Málaga & 15 & 46 & 194 \\
\hline Seville & 26 & $113 *$ & 930 \\
\hline CSIC & 14 & 45 & 1,478 \\
\hline TOTAL & 78 & 459 & 95 \\
\hline Total number of contracts with companies, separated data not available \\
\hline $\begin{array}{l}\text { Source: Made by the IRD with data from the OTRI-OTT Network and the Regional } \\
\text { Ministry of Education and Science, Regional Government of Andalusia }\end{array}$ \\
\hline
\end{tabular}

As it was mentioned above, R\&D expenditure in Andalusia accounts for only $0.5 \%$ of the GDP as compared to the national $0.87 \%$ and $2 \%$ in the European Union. The lack of an industrial tissue with R\&D capacity hinders enormously technological development in the region. Technological development is the main source of invisible capital accumulation (technological knowhow, human resources and organisational capacity), and therefore, the most competitive sectors and companies in the modern economy are also the ones that allocate greater resources to technological innovation processes.

If we analyse the stages of the technology transfer process over the last two decades, we can see three well differentiated stages: a first stage, corresponding to the first half of the 1980s, in which the developed countries transferred (or better said, moved) the assembly or "packing" of their production process; a second stage, between 1985 and 1990, in which manufacturing was transferred while the design stage and the R\&D activities were carefully hidden, and a third stage in this current years, that broke away from the previous trends, in that companies transfer their $R \& D$ centres to where the market is, but not depending on the needs of local production structures. The paradigm is Japan, which had 280 research centres abroad in 1995 (45\% in the United States and 35\% in Europe).

In the case of Andalusia we can say that there is still a long way to go 
in the evolution process of scientific research. It is essential to complete the Science-Technology-Industry+Market System (both at regional level, and connecting it to the national and community system) or, what would be the same, to end the process Autonomy-Institutionalisation-Integration (+Market), and overcome the incomplete institutionalisation stage which Andalusia is undergoing.

An interesting line for $R \& D$ policies would be to establish the selectivity-priority equation. It is not about promoting technological hypermarkets, but rather about reaching a high level of specificity. The Andalusian technological complex must be connected and integrated - not exclusively but significantly within its economic environment. Attention must be paid to the priority character of the technological needs of its productive structure, also, and especial importance must be given to the promotion of complete, possible and feasible economic processes and activities. All the above must be done with an important effort aimed at identifying more precisely the different local production systems in Andalusia, in order to detect productive and management innovation needs required by each of them, and so, be able to design specific suitable measures (Alburquerque, 1997).

The Andalusian productive tissue cannot just be an additional link of a supranational chain, nor be defined in a generic or aggregate way for the whole territory, but right on the contrary, the R\&D policy strategy must focus on solving those technological problems raised by the activity lines or product types in which we can expect a virtual monopoly, a market segment, either in Andalusia or abroad.

\subsection{The Business tissue}

According to the Central Business Directory of the INE, at the beginning of 1988 there were 352,776 companies in Andalusia ranking second among the Spanish Autonomous Communities, behind Catalonia, accounting for $14.3 \%$ of all the ones existing in Spain. During 1998, 15,756 new companies were created in Andalusia, $14.4 \%$ of the Spanish total figure. The capital stock subscribed by these companies has reached a record figure of 99,000 million pesetas, $70 \%$ more than in 1997. During 1998, 16,411 workplaces opened in Andalusia, creating 52,361 new jobs, most of them $(43,271)$ in new workplaces; however, as it was mentioned above, most of these companies are still very small. 
In an increasingly globalised economy, Andalusian companies show little export vocation. The provincial market is the main destination of their products and services. The importance of the Andalusian internal market is quite significant, and hence, our emphasis on underlining the strengthening of local production systems as a basis to support a solid innovation capacity and in this way undergo the learning process that uses as a reference competitiveness in foreign markets (Alburquerque, 1997).

As table 7 shows, the main destination of Andalusian exports is the European Union, with a global trade balance.

\begin{tabular}{|l|c|c|c|}
\hline \multicolumn{5}{|c|}{ TABLE 7. IMPORTS AND EXPORTS OF ANDALUSIA ACCORDING TO ORIGIN AND } \\
\hline DESTINATION. 1998 (MFillion pesetas) (1)
\end{tabular}




\subsection{Social and institutional capital}

For all that we have said, it seems to be clear that one of the major challenges the less developed regions are facing is to create innovation means within their territory. Under the term innovation mean ${ }^{5}$ we understand a specific production and management set based on a social organisation which, in general, shares a culture and certain instrumental objectives aimed at generating new know-how, new processes and new products. Regions must increase their social capital to be able to learn to innovate, breaking down the institutional inertia of the private and public sector, promoting networks (made up by interdependent nodes and links, but without a geographical centre in the traditional sense) and business associations, and channelling resources to the regional needs.

Collaboration and joint action of the public and private sectors in aspects such as provision of social, physical and financial capital, and the creation of business, institutional and social environments is essential in order to design an appropriate regional development strategy (Román, 1999). In the current context of market globalisation, the capacity of institutions and companies to invest in research and development, education and training, information, co-operation and, in general, in intangible elements is a determining factor. It is both necessary to work in the middle and long term and to react quickly to present conditions and opportunities (European Commission, 1995).

Public-private co-operation must take place, among others, in the field of the supply of social and institutional capital, physical capital (general infrastructures, transport, communication and telecommunication systems, industrial ground, commercial surfaces and offices) and financial capital (capital-risk, mutual guarantee societies, etc.).

One of the most recent examples in trying to promote social capital formation in Andalusia by the regional government is the Forum Andalusia in the New Century, that has consisted in a collective debate process in which professionals, intellectuals of many different areas and citizens (invited to take part in the discussions through the Internet) have discussed the region's problems, possible mid-term solutions and future strategies.

The debate has been organised around fundamental questions (employment, culture and social progress, human resources, business com-

\footnotetext{
${ }^{5}$ The concept "innovation mean" applied to technical-industrial development appeared in the early 1980s in a series of exchanges between Peter Hall, Phillip Aydallot and Manuel Castells.
} 
petitiveness, education and ongoing training, etc.) that required a joint change, innovation and imagination effort in the Andalusian society.

The degree of involvement of the society in its region's development is a crucial element of social capital. Among the many forms of social involvement, participation in elections is the one that shows best the awareness of the population of the importance of getting involved, by means of their vote, in public life.

\begin{tabular}{|l|c|c|}
\hline \multicolumn{2}{|c|}{ TABLE 8. PARTICIPATION IN THE EL ECTIONS TO THE EUROPEAN PARLIAMENT } \\
HELD ON JUNE 13 TH 1999 \\
\hline ELECTORS & \% PARTICIPATION \\
\hline Almeria & $5,774,900$ & 64.63 \\
\hline Cádiz & 392,183 & 66.38 \\
\hline Cordova & 862,111 & 59.53 \\
\hline Granada & 605,813 & 71.21 \\
\hline Huelva & 673,298 & 66.45 \\
\hline Jaén & 364,881 & 65.77 \\
\hline Málaga & 515,621 & 72.37 \\
\hline Seville & 986,073 & 60.82 \\
\hline Spain & $1,374,920$ & 63.06 \\
\hline Source: Ministry of Internal Affairs & 64.38 \\
\hline
\end{tabular}

On the other hand, the complaints and consults presented to the Ombudsman are significant regarding the concern for improving the relation between administration and society. 
CHART 3: EVOLUTION OF THE CONSULTS AND COMPLAINTS TO THE ANDALUSIAN OMBUDSMAN

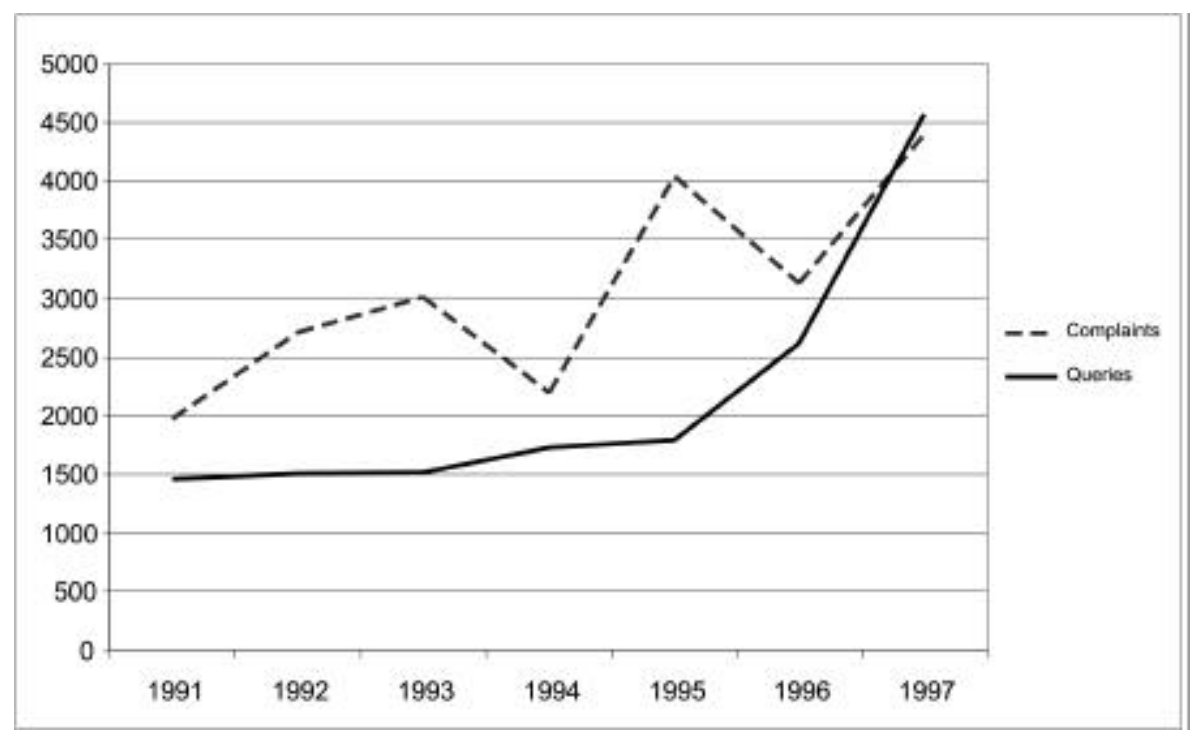

Source: Andalusian Ombudsman. Report to the Parliament.

A further indicator proposed by the OECD to measure the social capital is the number of offences, since this shows the citizens' awareness regarding social rules. 


\begin{tabular}{|l|c|c|}
\hline \multicolumn{3}{|c|}{ TABLE 9. OFFENCES ACCORDING TO THEIR NATURE. 1996} \\
\hline & ANDALUSIA & SPAIN \\
\hline Against the outer security of the nation & & 38 \\
\hline Against the inner security of the nation & 932 & 3,711 \\
\hline Forgery & 469 & 2,633 \\
\hline Against the Justice Administration & 1,099 & 4,006 \\
\hline $\begin{array}{l}\text { Breech of traffic laws, against public health } \\
\text { and the environment }\end{array}$ & 6,077 & 31,208 \\
\hline $\begin{array}{l}\text { Committed by public servants while } \\
\text { performing their work }\end{array}$ & 80 & 341 \\
\hline Against people & 825 & 3,853 \\
\hline Against honesty & 139 & 931 \\
\hline Against honour & 4 & 31 \\
\hline Against marital status of people & 2 & 13 \\
\hline Against freedom and safety & 497 & 2,548 \\
\hline Against property & 11,292 & 49,642 \\
\hline Sanctionable negligence & 165 & 1,007 \\
\hline Special laws & 72 & 1,083 \\
\hline Offences treated jointly & 2,310 & 8,139 \\
\hline No data & 68 & 1,600 \\
\hline Total & 24,031 & 110,844 \\
\hline Source: INE. Judicial statistics of Spain & & \\
\hline
\end{tabular}

Regarding the constitution of business environments, the promotion and dissemination of strategic information, the business co-operation and the promotion of networks and clusters are essential. The Enterprises Skills Network Programme, promoted by the European Union with ERDF Funds and the Andalusia Innovation Network are examples of business co-operation and the use of new technologies by Andalusian companies. The Andalusia Innovation Network is integrated by one hundred Andalusian companies with innovation capacity and concern with the purpose of promoting and disseminating the principles and culture of innovation, quality and ongoing improvement.

An essential aspect in the construction of business networks is the use of information and communication technologies. The use of the Internet in Spain started in 1993, but it was not until 1998 when most of the companies now present in the Internet entered it. This offers new perspectives for the 
international development of the Andalusian business tissue ${ }^{6}$.

\begin{tabular}{|l|c|}
\hline \multicolumn{2}{|c|}{ TABLE 10. INTERNET SUPPLIERS } \\
\hline & NUMBER OF SUPPLIERS \\
\hline Almeria & 6 \\
\hline Cádiz & 8 \\
\hline Cordova & 3 \\
\hline Granada & 10 \\
\hline Huelva & 0 \\
\hline Jaén & 2 \\
\hline Málaga & 17 \\
\hline Seville & 21 \\
\hline TOTAL ANDALUSIA & $\mathbf{6 7}$ \\
\hline Source: ES-NIC Register & \\
\hline
\end{tabular}

\section{TABLE 11. DISTRIBUTION OF POPULATION WITH ACCESS TO THE INTERNET, 1998}

\begin{tabular}{|l|c|c|c|}
\hline & $\begin{array}{c}\text { Population with } \\
\text { access }\end{array}$ & \multicolumn{2}{|c|}{$\begin{array}{c}\text { \% of population with access with } \\
\text { respect to: }\end{array}$} \\
\cline { 2 - 4 } & Thousands & Total population & $\begin{array}{c}\text { Population with } \\
\text { access in Spain }\end{array}$ \\
\hline Andalusia & 325 & 5.29 & 11.83 \\
\hline Spain & 2,747 & 7.96 & 100 \\
\hline Source: AIMC & \multicolumn{3}{|l}{} \\
\hline
\end{tabular}

From the endogenous development perspective, special importance is given to the dynamism of companies, generally SMEs, determined by the employers with initiative and information; to the supply of the regional labour market, where the presence of a qualified workforce and the social incitement to innovation are decisive; to the communication and innovation networks in the area; to the on-site or relatively close available services; to the white-collar workers capable of performing business management; and to the spatial structure, that is, to what could be classified as the urban and natural environment (Cuadrado, 1998).

${ }^{6}$ Study "Electronic commerce between companies and consumers in Internet in Spain", issued by the Spanish Association of Electronic Commerce (AEDE). 
Focusing on business dynamism, it is necessary to note that innovation is in the core of the entrepreneurial spirit; almost all new companies start with an innovative action, at least as compared to its competitors. Later on, and in order to survive or grow, companies must constantly innovate even if it is in a progressive way. However, technical improvement alone is not enough to ensure success. Innovation means also to anticipate market needs, to offer additional quality or services, to organise in an effective way, and to control time periods and costs.

Although implicitly most business organisations have a certain capacity to capture, create and manage know-how, and to change and adapt to new market demands, the level reached by most of them is not sufficient. The characteristics of the type of learning that occurs in those cases, according to Tejedor and Aguirre (1998) are:

- It is unconscious, thus limiting its future potential development.

- The "thinking" and "doing" tasks are separated with the subsequent slowness and high assimilation costs.

- Generative learning is therefore possible only in some organisation levels, dooming the rest of the workforce to doing what others decide or to improving only in an operative way, within the established action frameworks.

- Learning takes place slowly and as a reaction to changes in the environment.

On the other hand, we must highlight that the training level of employers and managers in Andalusian companies is comparatively lower than the one in other European countries, especially in the specific aspects of their position. Under these circumstances managers' experience plays a key role that to some extent makes up for their training deficits in management skills. However, in the middle term, experience could not be enough to confront management areas such as planning, control, human resources or technological innovation. However, it is also possible to remedy those training deficits with external counselling?

Regarding management styles in Andalusian companies, in general they hinder the drafting of strategies capable of exploiting the opportunities

\footnotetext{
${ }^{7}$ Regional Development Plan of Andalusia 2000-2006. Regional Ministry of Economy and Treasury, Government of Andalusia, 1999
} 
opened in the company's environment, causing business strategies to have an essentially defensive character. An indicator for this is the high number of companies that export only in response to specific orders.

The public sector must be aware of the role SMEs play in the productive organisation in each region. The regional economic dynamism is increasingly understood as the ability of regional activities to compete in international markets. Hereto, the availability of a close SME network facilitates externalisation and outsourcing, approaching regional production methods to new organisation techniques which, although started by large companies, are spreading to the smaller ones, just as in the case of "just in time". Therefore, SMEs must be stimulated not only because their own dynamism, but also as a defined strategic element because of the needs of regional factories of large companies.

The proliferation of agreements with other companies to develop joint projects and generate business networks are phenomena that aim at increasing organisational size maintaining a relatively reduced technical size. Here is when the weaknesses of the Andalusian productive tissue show up, since the difficulties resulting from its size are not balanced by a business co-operation approach. Despite of the growing trend towards associationism, still during the mid 1990 s, only $25 \%$ of Andalusian companies maintained some kind of cooperation agreement with other companies.

Since 1993, the regional government has been developing a social concert formula to agree public policy proposals with the main social and economic agents. Among them: the Agreement for the Economic and Social Development of Andalusia (1993/94), the Covenant for Employment and Productive Activity (1995/96), the Covenant for the Employment and Economic Development of Andalusia (1997/98) and, currently in force, the Agreement for Social Concertation in Andalusia.

According to the monitoring data of the Covenant for the Employment and Economic Development of Andalusia (1997), the business activity promotion policies have resulted in the following figures for the 1997-98 period: private initiative investments of 635,523 million pesetas in 9,921 companies have been induced, 29,685 jobs have been created and 109,033 jobs have been maintained, and for this purpose there has been a public expenditure accounting for 51,544 million pesetas.

Next we present the specific results of the actions included in the Business Activity Promotion Programme developed by the regional administration during 1997 and 1998. 


\begin{tabular}{|l|r|r|r|r|r|}
\hline \multicolumn{5}{|c|}{ TABLE 12. PROMOTION OF BUSINESS ACTIVITIES } \\
\hline \multicolumn{1}{|c|}{ ACTIONS } & $\begin{array}{c}\text { PUBLIC } \\
\text { EXPENDITURE } \\
\text { (Mill. Ptas.) }\end{array}$ & \multicolumn{2}{|c|}{ JOBS } & $\begin{array}{c}\text { INVESTMENT } \\
\text { GENERATED } \\
\text { (Mill. Ptas.) }\end{array}$ & $\begin{array}{c}\text { NUMBER OF } \\
\text { COMPANIES }\end{array}$ \\
\hline & & Created & Maintained & & \\
\hline $\begin{array}{l}\text { 1. Business Modernisation } \\
\text { Actions }\end{array}$ & 41,792 & 14,796 & 57,255 & 416,244 & 3,302 \\
\hline $\begin{array}{l}1.1 \text { Modemisation of the } \\
\text { industrial tissue }\end{array}$ & 6,549 & 902 & 10,173 & 51,688 & 52 \\
\hline $\begin{array}{l}1.2 \text { Improvement of business } \\
\text { compefitiveness factors }\end{array}$ & 3,518 & 380 & 14,488 & 14,093 & 761 \\
\hline $\begin{array}{l}1.3 \text { Creation and improvement } \\
\text { of productive tissue }\end{array}$ & 18,473 & 6,943 & 22,483 & 105,714 & 1,410 \\
\hline $\begin{array}{l}1.4 \text { Incentives to business } \\
\text { investments }\end{array}$ & 13,252 & 6,571 & 10,081 & 244,750 & 979 \\
\hline $\begin{array}{l}\text { 2. Financial instruments to } \\
\text { create and maintain } \\
\text { companies }\end{array}$ & 9,752 & 14,889 & 51,808 & 219,279 & 6,719 \\
\hline $\begin{array}{l}\text { 2.1 Agreement Andalusian } \\
\text { Government-Financial Entities }\end{array}$ & 8,972 & 14,889 & 51,808 & 206,304 & 6,719 \\
\hline 2.2 Mutual Guarantee System & 780 & - & - & 12,975 & - \\
\hline TOTAL & 51,544 & 29,685 & 109,033 & 635,623 & 9,921 \\
\hline Source: Regional Ministry of Economy and Treasury. Government of Andalusia \\
\hline
\end{tabular}

If the objective is for Andalusia to take a qualitative step forward, it is essential to start up an Integral Technological Development Strategic Plan, with a particular emphasis on:

1. Giving incentives to the use by businesses of research made in Universities and Public Research Bodies. Research in Andalusian scientific centres and institutions (with 1,640 research groups in 1998) has a small impact on regional business conditions. The paradox is that in some cases these results are used by industrial groups of more developed countries.

2. Centring around regional companies industrial growth and diversification, emphasising on development lines with a strong growth potential.

3. Promoting synergies among the different actors in the science-technology-industry system and improving it also in the two Andalusian Technological Parks, as well as promoting and advising technology transfers.

4. Promoting the constitution of new companies. 
5. Giving advice to SMEs in national and EU technological programmes, in addition to facilitating their access to key infrastructures and offering financial products with a special interest to promote new projects.

\subsection{Human capital}

Culture and knowledge are key instruments for social construction of regions and for their sustainable development. Therefore, learning has become one of the essential instruments to take into account, and not only within the traditional education system, but also in the generation of new formulas of knowledge acquisition.

\subsubsection{Education and ongoing training}

Human capital is essential for the development of a territory for two basic reasons: a) education and training contribute to the generation and adoption of new technologies; and b) education has clear impacts on productivity.

When Andalusia, once it was constituted as an Autonomous Community, received the policy-making powers in education in 1993, it was in a situation of deficits and inequalities as compared to Spain's average. This was shown by an $11.5 \%$ illiteracy rate as compared to a $6.15 \%$ national average. Almost half of the Andalusian population (48.5\%) lacked the minimum adequate qualification to enter the labour market, as compared to the national $28.4 \%$ average. Furthermore, schooling data in secondary and university education (that is, the non-compulsory education in the Spanish education system) were quite below to the theoretical ones according to the relative weight of the Andalusian population in those age groups.

In order to confront that starting situation, the regional government allocated an important part of its financial resources to this area with very positive results. The illiteracy rate has dropped to less than one half, the percentage of population with secondary and university education has increased by 20 points, and an important effort has been made in the construction and fitting of schools. In addition, the average number of years of schooling in the employed population in Andalusia has increased progressively, following the national trends (from 5.66 years in 1981 to 6.61 in 1991). 


\begin{tabular}{|l|c|}
\hline \begin{tabular}{|l|} 
TABLE 13. NUMBER OF STUDENTS IN ANDALUSIA BROKEN DOWN BY \\
EDUTIONAL LEVEL AND TYPE OF SCHOOL. 1997-98 ACADEMIC YEAR
\end{tabular} & 174,143 \\
\hline Secondary Education (old academic system) & 92,953 \\
\hline Vocational Secondary Education & 371,894 \\
\hline Mandatory Secondary Education (new academic system) & 45,683 \\
\hline Secondary Education (new academic system) & 22,224 \\
\hline Vocational Training & 2,269 \\
\hline Social Guarantee & \\
\hline Universities & 176,543 \\
\hline University Faculties & 32,054 \\
\hline Technical University Faculties & 19,370 \\
\hline Technical University Schools & 39,005 \\
\hline University Schools & \\
\hline Specific Education Systems: & 28,263 \\
\hline Music Conservatories & 2,128 \\
\hline Dance Conservatories & 402 \\
\hline Drama Schools & 22,737 \\
\hline Official Language Schools & 4,338 \\
\hline Applied Arts/Trade Schools & \\
\hline Source: Regional Ministry of Education and Science & \\
\hline & \\
\hline
\end{tabular}

The transformation has been especially relevant in the university education system. Andalusia has now 10 universities, aside of the International University of Andalusia. In the last years, the Specialisation Portfolio has increased substantially, with 118 different degrees. The teaching staff and the teaching support staff has increased from 18,685 to 20,154 persons. Over the last 10 years the proportion of Andalusian youth between ages 18 and 25 studying at Andalusian universities has risen from $10 \%$ to $25 \%$.

Notwithstanding the considerable growth of the university system, this is not yet adapted to the requirements of the production system and of society. The type of education emphasises the academic and expert aspects rather than the technical and professional ones; this lack of balance hinders the entry of students into the labour market. There is a surplus of degrees in certain fields that do not find a job. Only $18 \%$ of university registrations take place in Technical Faculties and Technical University Schools, and only $9,2 \%$ of total 
registrations are made in those fields that are more closely linked to the requirements of the productive tissue. Furthermore, Andalusian universities are scattered, weakly connected and lack a sufficient degree of specialisation, giving too much attention to natural sciences to the detriment of physical technologies.

On the other hand, it is necessary to note other initiatives that, although they are in their early stages, have a great social interest, such as the establishment of new teaching modalities, for example the Consortium for Open and Remote Education "Fernando de los Ríos", or the concern of the regional administration for integrating Information and Communication Technologies into the educational system in order to prevent a new type of "illiteracy" among those citizens without access to advanced communication networks. This is the purpose of the Averroes Network, the Educational Telematic Network of Andalusia, that uses structural funds to support the introduction of network infrastructures, computers, modems and Internet access in children, primary, secondary, special and adult education centres.

All the levels of the education system must be connected to ongoing training, both for youth and for other citizens, with a perspective of exchanging experts and facilities and enabling a greater access to postgraduate education.

In the case of the employed population is where we can detect best the training needs and misfunctions between the education system and the production system. The evolution of the characteristics of the working population according to their education level over the 1986-1998 period shows the sharp increase in training levels. 


\begin{tabular}{|c|c|c|c|c|c|c|}
\hline & \multicolumn{3}{|c|}{1986} & \multicolumn{3}{|c|}{1998} \\
\hline & $\begin{array}{c}\text { \%Secondary } \\
\text { Studies }\end{array}$ & \begin{tabular}{|c|} 
\% Technical \\
Studies
\end{tabular} & $\begin{array}{c}\% \text { University } \\
\text { Studies }\end{array}$ & $\begin{array}{c}\text { \% Secondary } \\
\text { Studies }\end{array}$ & \begin{tabular}{|c|} 
\% Technical \\
Studies
\end{tabular} & $\begin{array}{l}\text { \% University } \\
\text { Studies }\end{array}$ \\
\hline AGRICULTURE & 10.24 & 0.72 & 0.94 & 30.59 & 5.23 & 1.86 \\
\hline Men & 9.58 & 0.70 & 1.06 & 29.82 & 5.44 & 2.05 \\
\hline Women & 15.42 & 0.95 & 0.00 & 33.25 & 4.49 & 1.18 \\
\hline INDUSTRY & 20.87 & 4.20 & 3.63 & 38.12 & 17.25 & 7.52 \\
\hline Men & 18.49 & 4.82 & 3.94 & 37.54 & 17.37 & 7.51 \\
\hline Women & 32.98 & 1.01 & 2.02 & 40.71 & 16.72 & 7.56 \\
\hline CONSTRUCTION & 13.21 & 1.92 & 2.80 & 34.30 & 9.49 & 4.05 \\
\hline Men & 12.91 & 1.59 & 2.66 & 34.19 & 9.08 & 3.45 \\
\hline Women & 30.23 & 21.40 & 10.70 & 37.48 & 21.61 & 21.72 \\
\hline SERVICES & 26.03 & 2.32 & 15.05 & 36.62 & 13.39 & 22.99 \\
\hline Men & 26.47 & 2.33 & 14.14 & 38.82 & 13.02 & 20.64 \\
\hline Women & 25.26 & 2.29 & 16.66 & 33.51 & 13.92 & 26.30 \\
\hline TOTAL & 21.01 & 2.26 & 9.41 & 35.80 & 12.44 & 16.30 \\
\hline Men & 19.57 & 2.30 & 7.98 & 36.62 & 12.01 & 13.34 \\
\hline Women & 25.26 & 2.14 & 13.62 & 34.06 & 13.36 & 22.60 \\
\hline ce: INE & & & & & & \\
\hline
\end{tabular}

However, the education level of entrepreneurs and managers in Andalusian companies is comparatively lower than the one in several European countries, especially in the aspects related to their position. Around $70 \%$ of the companies are managed by their founders or heirs and only $25 \%$ of managers have a university education, and most of them concentrate in the larger companies. 


\section{CHART 4: EDUCATIONAL LEVEL OF ANDALUSIAN ENTREPRENEURS}

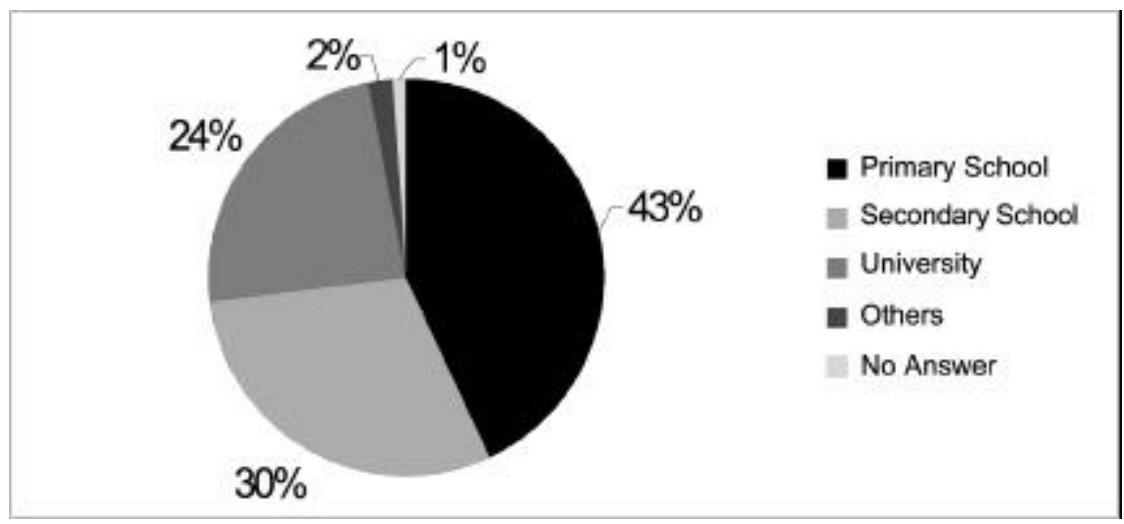

Source: Díez de Castro, E.P. et al. (95) "The enterprise in Andalusia"

\subsubsection{Labour market and employment}

As in the two previous years, during 1988 employment grew in Andalusia above the national average (4.33\% as compared to $3.45 \%$ ). It is necessary to highlight the general growth in all production sectors, the greater relative dynamism of the private sector in job creation, the higher increase of the male working population and of those above 25 years of age, and finally, a more favourable evolution in the groups with higher education levels. 


\begin{tabular}{|l|c|c|c|}
\hline \multicolumn{4}{|c|}{ TABLE 15. INDICATORS OF THE LABOUR MARKET } \\
IN ANDALUSIA AND SPAIN \\
\hline & Numbers (thousands) & Proportion in Spain's total \\
\hline & 1998 & 1986 & 1998 \\
\hline POPULATION & 7,234 & 17.65 & 18.24 \\
\hline ACTIVE POPULATION & 2,779 & 15.56 & 17.08 \\
\hline Men & 1,740 & 16.69 & 17.60 \\
\hline Women & 1.040 & 13.11 & 16.30 \\
\hline UNEMPLOYED POPULATION & 819 & 22.22 & 26.74 \\
\hline Men & 407 & 27.44 & 29.80 \\
\hline Women & 412 & 14.54 & 24.30 \\
\hline Farming & 156 & 63.06 & 69.01 \\
\hline Non-farming & 663 & 17.81 & 23.38 \\
\hline Without previous employment & 196 & 18.26 & 25.91 \\
\hline Men & 72 & 21.36 & 26.35 \\
\hline Women & 124 & 15.34 & 25.64 \\
\hline EMPLOYED POPULATION & 1,961 & 13.82 & 14.85 \\
\hline Men & 1,333 & 14.60 & 15.65 \\
\hline Women & 628 & 11.92 & 13.40 \\
\hline FARMING & 252 & 16.97 & 23.76 \\
\hline Men & 196 & 20.11 & 24.71 \\
\hline Women & 57 & 7.63 & 20.98 \\
\hline NON-FARMING & 1,709 & 13.12 & 14.07 \\
\hline Men & 1,137 & 13.39 & 14.72 \\
\hline Women & 572 & 12.49 & 12.94 \\
\hline Source: INE (EPA) & \multicolumn{3}{|}{} \\
\hline
\end{tabular}

However, unemployment is still the greatest problem of the Andalusian economy. In 1998 the unemployment rate represented $29.4 \%$ of the active population, with a greater incidence in women (39.6\%) than in men $(23.4 \%)$. However, we should make clear that there are three reasons that explain better this higher Andalusian unemployment rate as compared to the national or European averages. First, the traditional weakness of its productive basis, that historically has not been able to generate a volume of jobs according to its demographic potential. Production has grown by more than $60 \%$ between 1977 and 1997, but the employment only by $11.6 \%$ which evidences the important growth of productivity, whose progression has focused on the sectors with a higher degree of outward opening, the farming and the industrial sectors. These increases have caused a constant decrease in their workforce needs.

The Andalusian farming sector has operated in 1997 with 50\% less jobs than those existing in 1977, while the level of industrial employment has dropped by $25 \%$ over those years. The service sector has experienced an extraordinarily dynamic evolution, with a $65 \%$ increase in its number of jobs. We should mention that although in Andalusia the net job creation rate has been fairly small (0.6\% average yearly growth between 1977 and 1997), a significant fact is that from all jobs created in Spain $(382,000)$, more than one half 
of them took place in Andalusia.

A second factor that explains the increase of the unemployment rate in Andalusia is the spectacular growth of the Andalusian population during the last 20 years (36.1\% increase with a $1.6 \%$ cumulative yearly growth rate), doubling the national average.

The third reason that explains the growth of the unemployment rate is the important increase of women's participation in the labour market, $69 \%$ of the active population's growth has been caused by the incorporation of 596,000 women. The employed population in Andalusia has increased by 206,700 women, which represents a 3.3\% cumulative yearly growth rate. However, the labour situation of women at the end of the 20th century is not comparable to that of men: the female activity rate is very low (35.2\% in 1998); the unemployment rate is much higher (39.6\% in 1998); the amount of temporary contracts (98.5\% of all women's contracts in 1998) and irregular employment affects them more and, at the same time, their average salary is lower than that of men. There is also a predominance of contracts with a higher precariousness index in women contracts: $20.4 \%$ of temporary contracts of women are part-time, and $47.9 \%$ are eventual ${ }^{8}$ ones.

\subsection{Cultural capital}

The quality of the environment and the infrastructures, the knowledge on the regional cultural and natural resources and the region's image are gaining a growing importance in the regional development process. Especially, the activities based on knowledge are the ones that are most influenced by these cultural conditions.

\subsubsection{Cultural heritage}

All nations make of their cultural heritage an identity sign to construct their collective awareness, for their social cohesion, to define and make unique their image and to use it as an economic asset. It is well known that Andalusia has an extraordinary historical heritage, built over many centuries in which the creativity of Andalusian artists - a very special case is that of painters - has

${ }^{8}$ Report on the social and labour situation of women in Andalusia". Technical Department of the Secretariate of Women of CCOO-Andalusia, Seville, 1999. 
contributed with expressions and works of a great quality. Currently, it still has artists in all forms of artistic expressions that keep on increasing this historic heritage. At the same tyme, the expressions of a popular culture have been and still are very valuable in that they have been preserved and maintained over centuries and even reach, as in the case of flamenco, unique expressions that enjoy world-wide appreciation. Andalusian sociability forms themselves,and its leisure culture, shared by other Mediterranean societies, are also part of this heritage.

The valuation of this cultural heritage, its preservation, and the support to this living culture cannot be conditioned to a mere tourist attraction, but rather extended in order to contribute to the strengthening of this identity sign of all Andalusians by means of their appreciation and legitimate satisfaction of being part of the tradition produced by all of it. Public authorities must undertake planned and defined actions to enable this cultural heritage to be enlarged, better known, and adequately protected and disseminated, as well as promote its usefulness as an innovation and wealth element. The 2nd Cultural Goods Plan, which is to a great extent a response to these needs must have a realistic fund allocation for its implementation.

\begin{tabular}{|c|c|c|c|c|c|c|c|c|c|}
\hline Monuments & \begin{tabular}{|c|} 
Almeria \\
164 \\
\end{tabular} & $\frac{\text { Cádiz }}{163}$ & \begin{tabular}{|c|} 
Cordova \\
155 \\
\end{tabular} & \begin{tabular}{c|} 
Granada \\
207
\end{tabular} & $\frac{\text { Huelva }}{58}$ & $\begin{array}{l}\text { Jaén } \\
243\end{array}$ & $\begin{array}{c}\text { Málaga } \\
147\end{array}$ & $\begin{array}{c}\text { Seville } \\
237\end{array}$ & $\begin{array}{c}\text { Total } \\
1,374\end{array}$ \\
\hline $\begin{array}{l}\text { Historic } \\
\text { Areas }\end{array}$ & 1 & 18 & 7 & 10 & 8 & 10 & 7 & 10 & 71 \\
\hline $\begin{array}{l}\text { Archaeolo- } \\
\text { gical Areas }\end{array}$ & 8 & 1 & 3 & 5 & 3 & 1 & 12 & 9 & 42 \\
\hline $\begin{array}{l}\text { Historic } \\
\text { Sites }\end{array}$ & - & - & 1 & 1 & 1 & 1 & 2 & - & 6 \\
\hline $\begin{array}{l}\text { Historic } \\
\text { Gardens }\end{array}$ & - & - & 2 & 6 & - & - & 3 & 2 & 13 \\
\hline TOTAL & 173 & 182 & 168 & 229 & 70 & 255 & 171 & 258 & 1,506 \\
\hline
\end{tabular}


CHART 5: YEARLY EVOLUTION OF VISITORS TO MONUMENTAL AREAS IN ANDALUSIA 1991/97

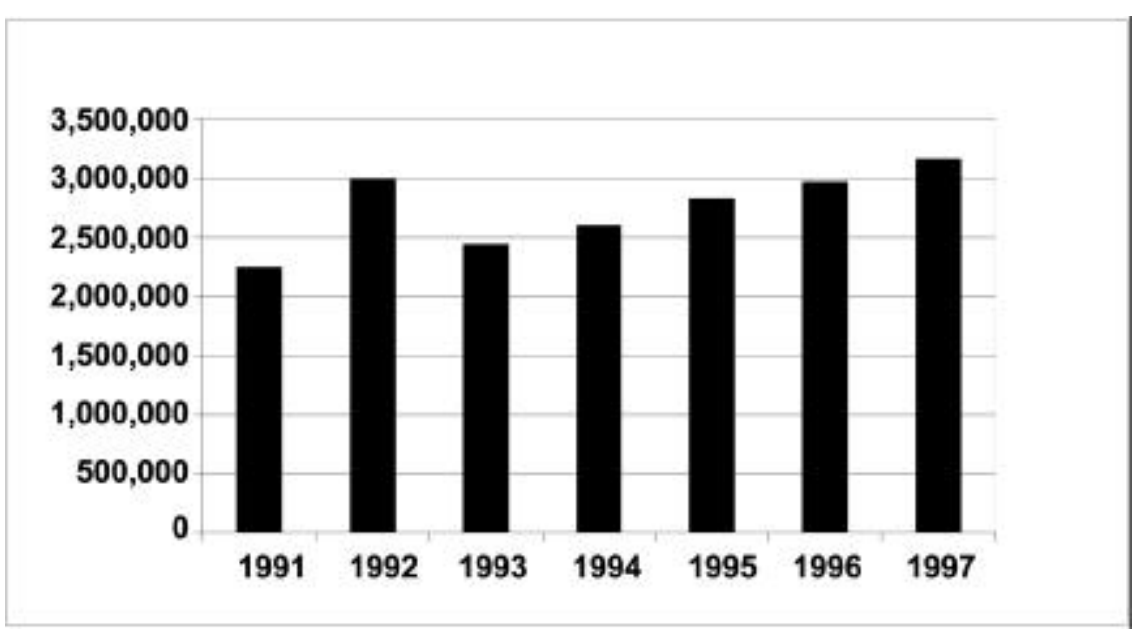

Source: Regional Ministry of Culture

\begin{tabular}{|l|c|c|c|}
\hline \multicolumn{4}{|c|}{ TABLE 17. ACTIVITY OF CINEMAS. 1995} \\
\hline & Cinemas & Films (*) & Audience \\
\hline Andalusia & 234 & 2,120 & $7,735,585$ \\
\hline Spain & 2,090 & 16,278 & $94,637,993$ \\
\hline $\begin{array}{l}\text { Source: Regional Ministry of Culture } \\
\text { (*) Sum of all different films shown in each province }\end{array}$ \\
\hline
\end{tabular}


CHART 6: YEARLY EVOLUTION OF THE NUMBER OF LIBRARY USERS OF PUBLIC PROVINCIAL LIBRARIES AND OF THE LIBRARY OF ANDALUSIA. 19911998

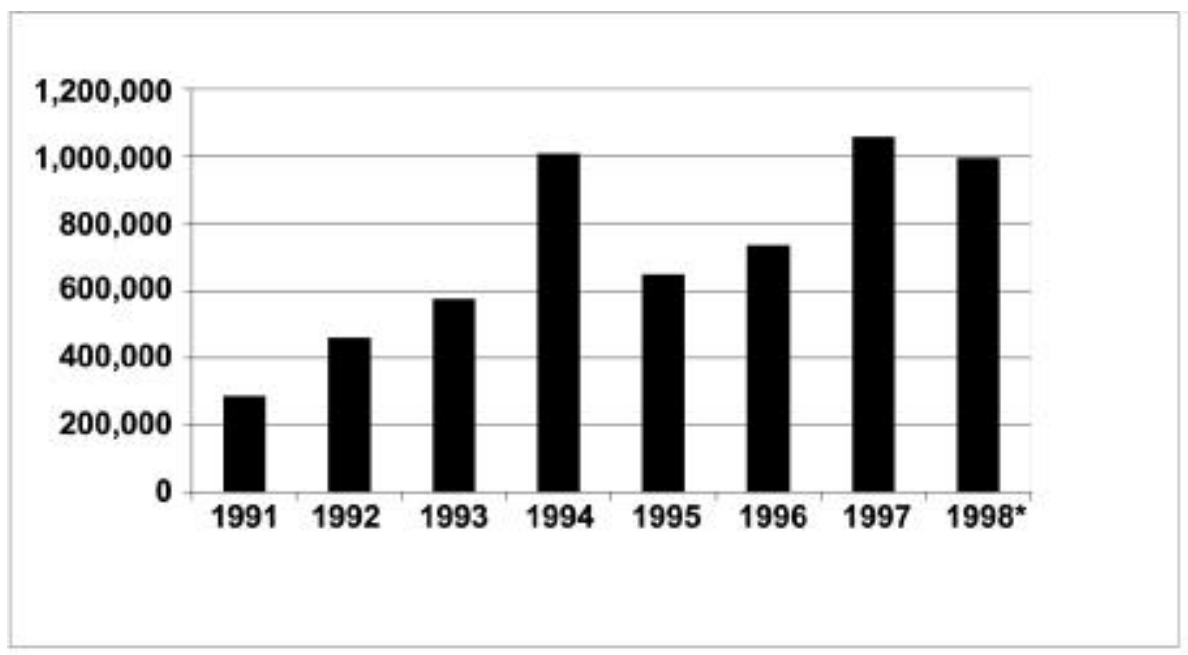

$\left.{ }^{*}\right)$ The decrease of number of users in 1998 is due to the fact that in this year, the Public Libraries of El Puerto de Santa María, Moguer and Antequera are not considered as provincial libraries but as municipal ones. Source: Regional Ministry of Culture.

\subsubsection{Health care and social policy}

Public Health Care is essential not only to ensure social equity and cohesion and to favour social equality, but also because of its important contribution to wealth and employment, to the territorial economic balance, to maintaining and improving the productivity of the human capital and of the technological and information systems development among other purposes.

The health sector plays an important role in the Andalusian economy, absorbing one third of the total budget of the Autonomous Community. During the first stage after the health care policy-making powers were transferred to the Andalusian Government, the actions focused on resource planning and on achieving a levelling of services and facilities, as well as on developing the economic and organisational framework in order to undertake the reform of the health system later. 
In the following stage, the health policy focused on implementing the reform and the extension of the health system to cover all citizens, developing most of the primary health care system, its integration into networks and the increase of the number of hospital beds (however, in 1997 the public and private hospital bed rate per 1,000 inhabitants was 3.04, almost one point below the national average). At the same time the mental health system reform was undertaken and the Andalusian Health Care Service was developed.

In recent years, a transformation of previously existing structures took place with a gradual integration of hospital resources into the public hospital network and the levelling of territorial inequalities through the development of a territorialised primary health care network. Currently, there are 255 basic health care areas in Andalusia that have been reconverted, covering more than $70 \%$ of the population.

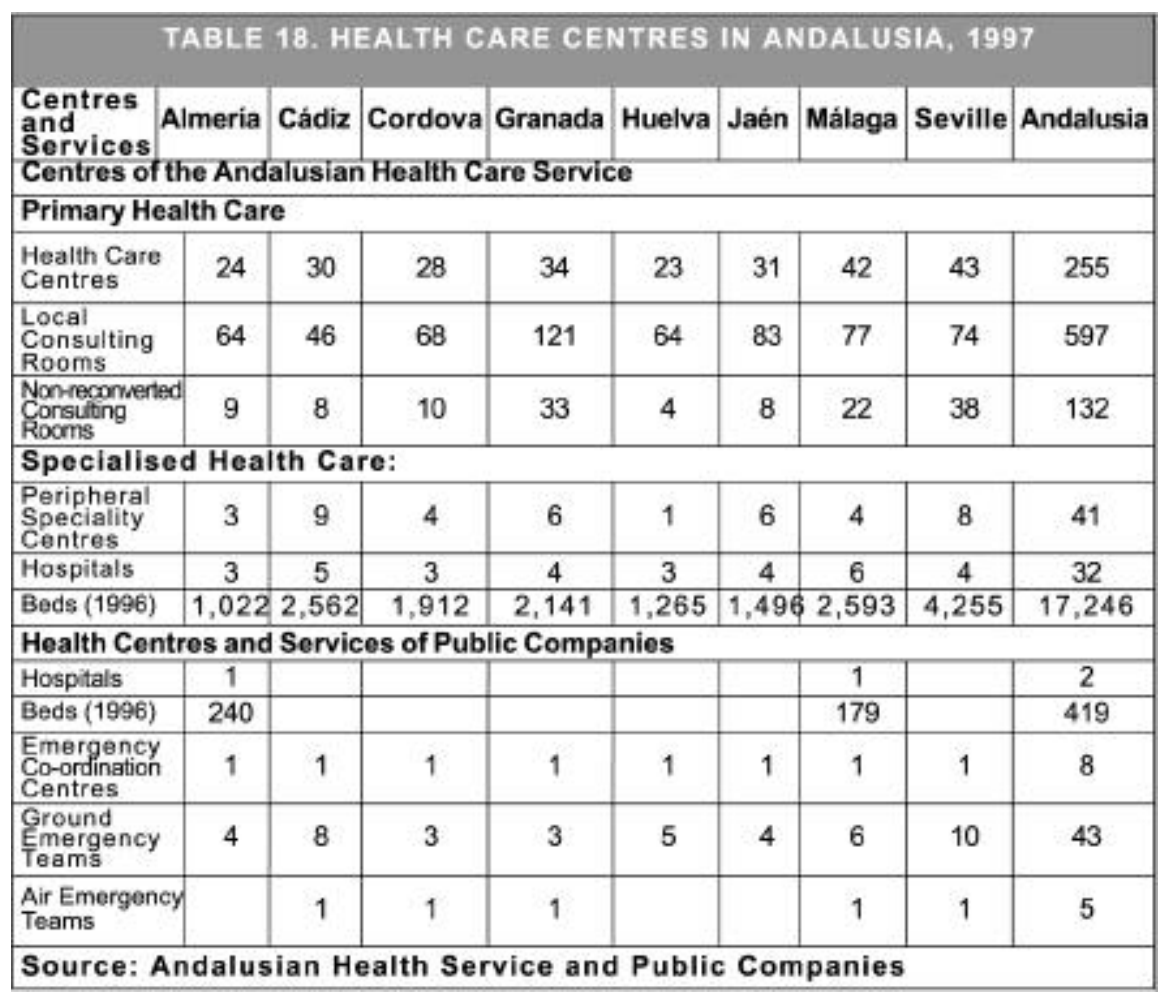


As far as human resources are concerned, there are 78,000 workers in the Public Health Care System, thus contributing to the development of a sustained employment policy.

Regarding Social Policies, in 1999 the budget of the Andalusian Government for social services reached 82,700 million pesetas, an $11.7 \%$ increase since 1997. There are currently 192 social work areas in Andalusia, and 665 social work units that cover almost all Andalusian municipalities. However, implantation and coverage are still insufficient.

Social assistance in Andalusia is divided into two large groups: a) community social services for all the population; and b) specialised social services, focused on special groups that require specific actions. The latter ones are scarcer and with a lower fund allocation.

Social innovation is an essential tool for the transformation and reinforcement of social and economic integration, in which foundations and nongovernmental organisations (NGOs) can play a determinant role. One of the identifying features of advanced societies is the high degree of social awareness of their citizens and, resulting from it, the existence of a high number of volunteers and non-profit entities that provide assistance services, thus complementing the public sector. NGOs and foundations provide services that no one provides or that are deficiently provided, making up for this deficit, or they provide these services in a competitive way enabling users to improve their choosing capacity.

The Bill of the Law of Volunteers in Andalusia, which is currently being passed through the Andalusian Parliament, intends to acknowledge, promote and ensure citizen's voluntary work through non-profit entities in the areas of social services, health care, environment, sports and leisure. Furthermore, since the Law of Foundations came into force (1994) in Spain (and also in Andalusia) the scope of donors has been enlarged and the collaboration resources between the public and the private sectors have been promoted. This has contributed to strengthen the role of foundations and to ensure their survival. 


\begin{tabular}{|c|c|c|c|c|c|c|c|c|c|}
\hline & Almeria & Cádiz & Cordova & Jaén & Granada & Huelva & Málaga & Seville & Andalusia \\
\hline IASS*-Charity & 8 & 99 & 85 & 43 & 38 & 14 & 23 & 129 & 439 \\
\hline LASS ${ }^{\circ}$ tabour & 3 & 1 & & & & 1 & 1 & 3 & 9 \\
\hline \begin{tabular}{|l|} 
Education \\
\end{tabular} & 2 & 33 & 49 & 14 & 34 & 11 & 35 & 56 & 234 \\
\hline Culture & & 2 & 5 & & 3 & 1 & 4 & 10 & 25 \\
\hline Total & 13 & 135 & 139 & 57 & 75 & 27 & 63 & 198 & 707 \\
\hline Source: & $-I P D$ & epor & & & & lusi & Institu & of So & Services \\
\hline
\end{tabular}

\section{Emerging activity sectors}

A sustained development process requires a regional strategy oriented towards the specialisation in goods and services for whose production and provision there are raw materials, technological capacity, human capital, organisational and managerial skills, production and distribution experience, etc. (Román, 1999). Competitive introduction of regional spaces in an increasingly globalised international economy makes it necessary to define more clearly the own economic profile than ever before. It is necessary that world markets acquire the image that Andalusia "is specialised" in the production of environmental goods and services, audio-visual production or renewable energies, for example.

The process must start by those areas in which the current state of production forces guarantees a minimum "spatial rent", which does not mean giving up the search, in the mid and long term, of new market segments. Right on the opposite, it is necessary to select specialisations that in the long run contribute to consolidate dynamic strategic advantages resting on a high level of scientific-technical development and with constant innovation possibilities.

Within the general production lines with a greater potential in the Andalusian region - agribusiness, leisure industries, environmental goods and services, renewable energies, audio-visual industry, high technology linked to the provision of advanced services - there are specific activities in which it is possible to deploy competitive advantages based on product quality and specificity, use, efficiency, design, brand and image; in the existence of adequate marketing channels and effective post-sale services, in the reliability to fulfil the commitments made, etc. More precisely, we can speak about six basic production lines: agribusiness, tourism, environmental industry, renewable energies, audio-visual industry and advanced business services. 


\subsection{Agribusiness}

The specific weight of the Andalusian primary sector is very important. Despite of this, many of its possibilities are not yet completely used up. Land quality in a great part of the regional surface, climate and natural resources, existence of companies with a long production tradition and a good position in export markets, a good technological level in some of them, etc. entail competitive advantages (for example, the possibility of placing in European markets non-typical products such as extra-early, subtropical, flower and biological crops) that the sector is already making good use of. However, for the sector as a whole, a deep reorganisation is necessary, both in terms of the design and implementation of its economic policy and of its microeconomic dimension (in production, management and distribution). Both must contribute to stop the value-added drain and, at the same time ensure an income growth within a sustainable rural and urban development framework.

The scope of possible actions is very wide and ranges from public intervention in the fields of infrastructures, irrigation, training, promotion of business concentration and co-operation (especially for marketing), etc., to the introduction of new technologies in traditional production, in the design of new products to increase the degree of diversification (natural and biological food, food with a high fibre content, new juices, and many others) and differentiation (brands, "appelations d'origine"), in industrial transformation, in business management (normalisation of production processes, quality, time periods and prices), in the establishment of marketing networks, in promotion abroad, etc. It would be a total waste not to undertake the modernisation of an activity with such a long tradition, high importance and growth potential as this one.

The availability of resources, together with the absorption capacity of extended markets, must be the great stimulus to overcome the well known problems of atomisation, little R\&D investment, low average technological level, lack of experts in some productions, low degree of computerisation, weak marketing channels, dependence of foreign companies, etc. that currently strangle the development of many Andalusian food-farming industries.

\subsection{Tourism}

Tourism is one of the most important economic activities in Andalusia. Tourism has undergone two well-differentiated stages over the last decade. The first stage that goes from the late eighties to the early nineties was fea- 
tured by the competition with other tourist destinations, in a situation of exhaustion of the massive, low price tourism model. On the opposite, since the early nineties, tourist activities have shown a clear recovery, caused to some extent by the improvement of the tourist products and services offered in Andalusia.

Andalusia is part of economic, social, political and cultural ecosystems, in which the synergy between tradition and modernity, between stability and change, is essential. Environmental and historic circumstances in Andalusia have shaped a type of society and culture that made up a huge cultural heritage (archaeological, historic, architectural, artistic, anthropological, etc.) that can be the source of wealth and jobs by means of highly specialised and high quality sustainable tourism.

Furthermore, this historic heritage with a great quality and quantity is scattered all over the territory. This facilitates the implementation of policies and programmes with a strategic character in specific geographical areas, local communities, etc. that can have a strong impact on the establishment of actions tending to re-establish the social balance. This implies understanding the historic heritage not only as a resource for social cohesion, but as a potential wealth generation resource.

The forecasts on tourism growth at international scale are very favourable, according to the World Tourism Organisation. It is estimated that the number of international tourists will increase by $4.3 \%$ per year (3.1\% in Europe) until 2002 , while tourism revenues will grow by $4.7 \%$. In the face of this panorama, and considering that the introduction of the Euro will stimulate traveller movements throughout the European Union, Andalusia must maintain its leadership position at world scale.

Since 1993, tourist activities in Andalusia have been continuously improving its market share. The figures speak for themselves: In 1998, 18.1 million tourists came to Andalusia with 29.2 million overnight stays. The contribution of tourism to the regional economy accounted this same year for $14.6 \%$ of Andalusia's GDP (including indirect effects) and employed 124,100 people, that is, $16 \%$ of all the employment in this sector in Spain (IDR, 1999).

Furthermore, tourism is the fundamental motor for many local economies, taking into consideration its impacts on many other chained activities that could be overseen. In this sense we must underline aspects such as its pulling effects on the textile industry, agriculture, fisheries, food-farming industry, handicrafts, commerce and transports, construction, and so on. The impact caused by tourist demand on production during 1997 has been estimated in 
1.56 billion pesetas, from which 1.12 billion were generated by the Andalusian economy to meet the direct needs of tourists.

However, the pulling effect of tourism as income and employment generating activity goes beyond the mere examination of tourist accounting, and reaches variables that are basic in order to understand what has happened in a sector that had everything in its favour, and that to some extent has become one of the most problematic ones. Lack of control in real estate development and the lack of infrastructures are some of the most urgent problems (Román, 1999).

These problems require urgent attention, with the background of past experiences and the perspective of future scenarios. The recovery of the sector requires first of all, the environmental reparation, which is probably the differentiation factor that can contribute most to improve market competitiveness. However, it is also necessary to spread the use of information highways for product marketing. And of course, it is necessary to start up creative imagination to diversify the supply adding to the traditional products new varieties in the fields of sport, adventure, environmental, historic, cultural, scientific, health and residential tourism.

\subsection{The Environmental industry}

A set of new industries is appearing, and in certain cases consolidating at world scale. Their production focuses on the correction of the impacts of socio-economic activities on the environment, and even on the revaluation of the environment. In 1998, 238 companies performing environmental activities were registered in Andalusia, with a total revenue of some 100,000 million pesetas and more than 19,000 workers.

The Andalusian environmental sector is made up basically by SMEs, since more than $72 \%$ of the companies have less than 50 employees. There are four preferred action environmental protection subsectors in Andalusia, both due to the number of industries and to expectations of the sector's agents: Water Management, Waste Management, Energy Saving and Efficiency Activities (Renewable Energies) and Environmental Consulting Activities. The service sector alone accounts for more than $75 \%$ of the supply of the Andalusian environmental sector.

The high diversification and current fragmentation of the sector deter- 
mine entry barriers that are still small, offering entry and business opportunities to a larger number of agents. Furthermore, the environmental goods and service industry in Andalusia presents better cost-effectiveness ratios than other economy sectors.

\begin{tabular}{|c|c|c|c|c|c|}
\hline Sector & $\begin{array}{l}\text { Economic cos } \\
\text { effectivenes }\end{array}$ & $\begin{array}{l}\text { inancial cost- } \\
\text { iffectiveness }\end{array}$ & Acid test & $\begin{array}{c}\text { Running } \\
\text { capital }\end{array}$ & $\begin{array}{l}\text { Financial } \\
\text { autonomy }\end{array}$ \\
\hline $\begin{array}{l}\text { Agriculture, stockbreeding, } \\
\text { hunting and foresty }\end{array}$ & $3.77 \%$ & $4.59 \%$ & 0.85 & 1.13 & 0.22 \\
\hline Marufacturing industies & $6.7 \%$ & $9.21 \%$ & 0.76 & 1.16 & 0.54 \\
\hline $\begin{array}{l}\text { Production and distribution of } \\
\text { energy, gas and water }\end{array}$ & $4.20 \%$ & $5.19 \%$ & 0.83 & 0.85 & 0.62 \\
\hline Constuction & $3.46 \%$ & $7.74 \%$ & 0.89 & 1.41 & 0.41 \\
\hline Commerce & $5.84 \%$ & $12.18 \%$ & 0.63 & 1.07 & 0.30 \\
\hline EMMRONMENTAL & $5.14 \%$ & $17.14 \%$ & 1.08 & 1.31 & 0.57 \\
\hline $\begin{array}{l}\text { LeadingENMRONENTAL } \\
\text { companies }\end{array}$ & $17.08 \%$ & $44.01 \%$ & 1.08 & 1.24 & 0.57 \\
\hline
\end{tabular}

The production of environmental goods and the provision of environmental services make up an economic subsector that, aside of being closely related to the two previous ones, has an important and expanding demand that, to a great extent, could be supplied from Andalusia. Competition is harsh because many companies are already working and have developed a technology that puts them in an initially advantageous situation. However, that advantage is not comparable to the one existing in other sectors in which the train has definitely been missed. In the case of the environmental goods and services, the distance can be still made up, and the good's or service's own nature enable the search for spaces in which it is still possible to be efficient and competitive.

It is still possible to design and manufacture equipment, for example for control of air pollution (sensors, meters, catalysts, etc.); or sea, river and urban water pollution through the construction of desalination and purification plants, etc. Also for erosion prevention (in the inland and on coastline), treatment of solid non-hazardous waste (urban, industrial, agriculture, bio-sanitary) or dangerous waste (nuclear). This can be done in terms of storage or in the performance of recycling and derived activities. Finally, there is also a chance of providing consulting and counselling services, either on the reduction of the environmental equipment deficit or the valuing of areas with an ecological interest, or even in product or process engineering. All these require the training of technicians and experts in environmental impact assessment and studies. 


\subsection{Renewable energies}

The situation is similar in many aspects. Potential demand is enormous and the existing supply is clearly insufficient. Current energy use rates are unsustainable, and although there are different forecasts on the exhaustion of conventional energies, their final extinction is not challenged. The energy we are currently using is, by definition, not renewable, and must therefore not only be saved, but also replaced by another of a different nature, with less limits in its availability (functional or spatial) and less aggressive environmental impact levels.

Currently, the marginality threshold of alternative energies to oil is at the level of oil barrel prices, but the current situation cannot last forever, and it will have to be changed by the possible, but not probable, discovery of radically new sources of energy, by the conversion of renewable energies into feasible sources, by energy saving or by a combination of all the above.

For Andalusia both research and eventual production of renewable energies are activities that deserve a special attention. Firstly, because of the geostrategic position of the region. This is a spatial rent that could be used thanks to the competitive advantage that means having available resources that are not present in other more developed areas (it seems more reasonable to set up a solar energy power plant in Almería rather than in Stockholm; a windmill power plant in Tarifa rather than in Brussels; a sea wave power plant in Huelva rather than in Luxembourg; or a biomass power plant in Jaén rather than in Bonn). As opposed to other productions, Andalusia has here some business experience that does not imply an important technological gap with other countries, and that cannot be wasted.

On the other hand, and aside of its contribution to reducing the region's energy deficit, these are activities with a great pulling effect on other industrial subsectors. Just to mention an example, the promotion of bioclimatic architecture would favour the development of regional technology and industries in a set of very diversified production lines with a high value-added (thermal insulation, thermal solar glass windows, water micro-sprinklers, intelligent regulation systems, solar panels, thermal accumulation materials, etc.).

Of course, it would be necessary to analyse effective resources and opportunities; the most feasible application (electric power generation using agricultural waste, for example); economic feasibility; financial, institutional or even political barriers, etc. All this requires an important research effort, whose positive results will not be immediate, but they are certain, and essential for 
Andalusia to incorporate into its productive tissue a manifold of highly dynamic strategic activities, in competitive and cost-effective conditions.

\subsection{The Audio-visual industry}

Culture, aside of being an important regional development factor as a community value that affects all actions, can be also considered as an economic sector. Cultural companies are part of a wide scope of sectors covering audio-visual industries, performing and plastic arts, preservation of the historic and artistic heritage, content industries and those derived from the expansion of the information society.

An emerging sector that deserves a special attention within the economic development strategy in Andalusia is the audio-visual industry. It is an industry with a high degree of vertical and horizontal integration and with many entry barriers of all kinds; however it deserves to be carefully studied attending to the special existing characteristics both on the demand and on the supply side. Demand is expanding, and probably will keep on expanding. Its high degree of specialisation offers wide spaces in terms of contents, supports and languages, and the Andalusian supply could cover some of them, since an initial critical mass of human capital, technology, companies and institutions is already available. The existence of a regional radio and television company is a further positive factor (as long as it is not intended to make it responsible for the survival of the industry).

\subsection{Advanced business services}

As opposed to the traditional and widespread identification of industrialisation with economic development, the functional and spatial restructuring experienced by the international economy has given to the tertiary sector a role with an increasing importance in advanced industrial country. Without intending to start a debate on what sector should be the predominant one in the economy, if industry or services, it cannot be denied that these have been the ones that have generally created jobs for many years. This is especially true in the advanced business services subsector. This activity is difficult to define, both because of its diversity and because of its dynamism (many advanced services are "advanced" only for a short period of time). In any case, it is clear that these are new, very specialised and highly sophisticated activities. 
Here are some interesting examples:

- Studies and projects: feasibility, investments, financing, placement, civil and industrial engineering, construction, energy, environmental impacts.

- Human resources: selection, training, education.

- Production engineering: industrial design, quality control, R\&D counselling.

- Strategic planning: organisation and management control.

- Market logistics: information, detection, advertising, corporate image, graphic design.

- Computerisation: computer aided design (CAD), computer aided manufacturing (CAM), computer counselling, introduction of systems and networks.

The origin of these new activities results mostly from the above mentioned restructuring of the world's economy, as well as the rise and development of new technologies, to which they are closely linked, and from which they depend. Further features that define advanced services are: high productivity, flexibility and reversibility, high degree of spatial concentration (they are generally located in urban centres of a high relative weight in each country's cities), and one in particular, which at the same time is cause and effect of their rapid growth, their "externality". That is, the possibility of "producing" out of the companies facilities, through the outsourcing of a service that was performed within the company or that did not exist, and "import" it using for its "transport" the new forms of telecommunication.

A further reason for the expansion of advanced business services is its evident positive impact on the activities performed. Cost containment, quality improvement, versatility, reversibility and flexibility (possibility to adapt quickly to the needs of the client company) result finally in the improvement of the production and distribution efficiency, and therefore, of competitiveness.

In the case of Andalusia the convenience of paying special attention to these activities is not due as much to reasons of clear availability of resources, experience, etc. as to reasons of feasibility and opportunity. It is clearly a subsector with a bright future in which it makes sense concentrating investments and improving human capital (for example, by means of their qualification in universities and specialised training centres), and physical capital (for example, 
by means of the connection to the European information highways, financed with structural funds). Both of them have horizontal effects and their improvement will result additionally, in the improvement of the regional production system as a whole.

From an institutional perspective, it is essential to promote the Science-Technology-Industry System, as well as the research centres and the $R \& D$ programmes developed by them, and favour communication channels among economic agents.

All of this must be completed with the establishment of an adequate social environment, both for the stimulus of the business culture and for the creation of satisfactory quality of life components (housing, health, education system, environment, transports, culture, art, citizen security and social stability).

\section{Conclusions}

Over the last twenty years, Andalusia has been able to keep up with and even exceed the general development pace of the Spanish economy. The break has been avoided and it has been able to escape from an underdevelopment situation. However, it has not been possible to design a true regional development strategy jointly by the public and the private sector ${ }^{9}$. There are still some deficits and lacks that require the starting up of structural transformation processes to face the future with more chances to succeed.

1. The importance of improving the social capital must be acknowledged in order to facilitate the building up of networks and associations among all socio-economic agents involved in the development of the Andalusian region.

2. Unemployment is a priority challenge, with an unemployment rate of $29.4 \%$ and a low employment rate.

3. Despite of the progress made in terms of training, there are still important deficits, especially in the upper levels and in technical studies. However, the essential element is the need to connect in an effective way the supply of the education and training system to the needs of the regional productive system and labour market.

${ }^{9}$ The agreement reached with the PDR 2000-2006 can be understood as the beginning of a significant change. 
4. The Andalusian economy maintains a strong dependence and connection with the outside, its productive structure is not sufficiently articulated, and it is necessary to improve its marketing channels and adapt its current production organisation, especially with regard to the industrial and services sectors, and to its capacity to generate value-added.

5. The lack of entrepreneurial tradition and the insufficient domestic savings $(12.4 \%$ of the available income as compared to the $19.6 \%$ national average) to finance the economic development, determine the weakness existing in its productive structure and its too high dependence from abroad.

6. Andalusian companies have a low degree of internationalisation. Andalusia accounts for only $11.3 \%$ of Spain's exports; this figure is below its economic weight (13.4\%).

7. Few infrastructures connect it to the transeuropean transport networks, especially on the coastline and in the area of the Strait of Gibraltar which account for $36 \%$ of the population and $40 \%$ of the GDP of Andalusia.

Therefore, emphasis must be made on the creation of a proactive Andalusia on the basis of an economic culture change, with a more entrepreneurial society and more outward-bound economic tissue. This economic development model aimed at introducing the Andalusian economy in the world's globalised economy requires the starting up of several transformation processes.

Local productive agents (public and private) need a competitive financial sector linked to the development of regional productive activities, by means of instruments, such as the creation of combined financial institutions for venture capital or financial engineering, diversification of Savings Banks, establishment of financial counselling services or local antennas of financial markets.

Innovation stimulating policies, both in the private sector and in Public Administrations are one of the priority axis of economic development policies. In co-ordination with European or national Science and Technology policies it is possible to directly stimulate the accumulation of technological know-how, developing policies focused on the application of technology transfer services, technology lookout services, R\&D technology centres, joint technological projects aimed at solving public needs, and other similar ones.

Programmes aimed at the development of human capital and its adap- 
tation to the remaining regional production resources must be promoted in cooperation with national and European education and training policies. As in the field of technology development, universities should play a central role in this process.

The accumulation of organisational capital is part of the entrepreneurial tradition, and therefore must rely heavily on the private sector. However, the public administration can facilitate this invisible asset accumulation process by increasing its own efficiency, and developing logistic, infrastructure and service systems that would improve the organisational behaviour of the territory as a whole.

It is absolutely necessary to create a critical mass of internationalised economic sectors and a SME Network linked to globalisation. The internationalisation of Andalusian businesses can be achieved by using to the full its integration into the European Union, and by strengthening its economic relationships with its natural foreign markets, Maghreb and Latin America. For this purpose, it is important to draft an economic co-operation strategy with both priority areas. Economic development in both areas means a great market opportunity for the production of goods and services with intermediate technologies, which are the typical ones in Andalusian production structure.

One of the main challenges we are facing in a development strategy for Andalusia within a globalised context is to manufacture and distribute with the most adequate technology in any of the activity lines we have suggested. Competitiveness is the key for survival and success in markets in which tariff barriers, or any other, are relics from the past, if not violations of current regulations.

Furthermore, the choice for the most adequate technology is an especially delicate issue in Andalusia, among other reasons, because of the difficulty of satisfying at the same time the urgent need to create jobs and the need for competitive efficiency. Technological change destroys and creates jobs, the only thing is that the type of jobs it creates is very different from the type of jobs it destroys. The job created is a "different" job: in a different place, in a different moment, under different conditions, with different qualitative and quantitative characteristics. Therefore, an indiscriminate support to high tech companies (in any of the subsectors: electronics, computers, telecommunication, genetic engineering, biotechnology, etc.) just because of their nature can be, sometimes, a total waste. The allocation of subsidies must be absolutely selective and respond to strictly pre-established criteria. Each of the markets we are 
going to serve (domestic and foreign) must be carefully studied in order to decide the most compatible production strategy, in which technology is a main variable, but not the only one.

It is clear that the technology chosen - no matter if it refers to product or to process - cannot be considered, as it was until now, a variable that essentially depends on foreign decisions, right on the contrary, it must be closely linked to the regional productive system, whose demands must meet as a priority. Above the generic subsidies, awarded with the hope of a more than hypothetical ulterior transfer, the expenditure in technology must be aimed at the adoption or adaptation of the already existing formulas that are most adequate to the production processes taking place in Andalusia (that is, to manufacture with high technology); or at developing new technology (that is, to manufacture high technology) whose priority purpose is to solve the technological problems of our own productive system. The full implementation of the Andalusian Research Plan and the consolidation of the Science-TechnologyIndustry + Market System are essential for both purposes.

In conclusion, a development of Andalusia based on knowledge must be a joint learning process organised in a professional way between the public sector and the private sector, and characterised by its clarity, transparency and neutrality. It should not be influenced by sectorial interests, but rather work according to the long-term objectives defined by and among all socio-economic agents involved. This innovation learning process must be necessarily continuous and applied to the region's needs, taking into account the existing basis of resources and improving the different forms of capital.

\section{Bibliography}

Alburquerque F.: Desarrollo económico local y distribución del progreso técnico. CEPAL/ILPES, United Nations, Santiago de Chile, 1997.

Amin A. y Thrift N. "Institutional issues for the European regions: from markets and plans to socioeconomics and powers of association", Econ. \& Soc., 24(1), pages. 41-66, 1995.

Bailly A. S. Maillat D. y Rey M. "Tertiaire moteur et développement régional: le cas des petites et moyennes villes", Revue d'Economie Régionale et Urbaine $5,1984$.

Desarrollo y cooperación en una economía globalizada. Sevilla: University of 
Seville, 1999.

Camagni R. (Ed.) Innovation Networks: Spatial Perspectives. London: Belhaven, 1991.

Cantwell J. "The globalization of technology: what remains of product cycle model?", Cambridge Journal of Economics 19, pages. 155-174, 1995.

Castells M. La Sociedad Red, La Era de la Información. Economía, Sociedad y Cultura Volume I. Madrid: Alianza Editorial, 1997.

Commission "Andalucía una economía competitiva que crea empleo". Working Paper of the Forum Andalusia in the New Century. Junta de Andalucia, February 1999.

Commission "Andalucía una sociedad tecnológicamente avanzada". Working, Paper of the Forum Andalusia in the New Century. Junta de Andalucia, February 1999.

European Commission. Libro Verde de la Innovación. Brussels: European Commission, 1995.

European Commission. Science and Technology for Regional Innovation and Development in Europe. Brussels: European Comission, 1988.

European Commission. Sixth Periodic Report on the social and economic situation and development of the regions of the European Union. Brussels: European Commission, DG XVI, 1999.

Cooke $\mathrm{P}$ y Morgan K. "The network paradigm: new departures in corporate and regional development", Society and Space, 11, pages. 543-564, 1993.

Cooke P. y Morgan K. "The creative milieu: a regional perspective on innovation", in Dodgson M. y Rothwell R. (eds.) The Handbook of Industrial Innovation, pages. 25-32. Aldershot: Edward Elgar, 1994.

COTEC. Informe COTEC 1998. Madrid: Fundación Cotec para la Innovación Tecnológica, 1998.

Cuadrado Roura J. R. "Políticas Regionales: Hacia un nuevo enfoque", Papeles de Economía Española 35, pages 68-95, 1988.

Doeringer P. y Terkla D. "How intangible factors contribute to economic development", World Development 18, pages 1295-1308, 1990. 
Dosi G., Freeman C., Nelson R., Silverberg G. y Soete L. (Eds.) Technical Change and Economic Theory. London: Pinter, 1988.

Freeman C. Technology Policy and Economic Performance. London: Pinter, 1988.

Freeman C. "Critical Survey: the economics of technical change", Cambridge Journal of Economics 18, pages 463-512, 1994.

FUNDANAL: Las Fundaciones y Asociaciones de Andalucía y El Algarve como instrumento de la innovación social en la Unión Europea. Sevilla: Fundación El Monte, 1999.

Gabinete Técnico-Secretaría de la mujer de CCOO-Andalucía. Informe sobre la situación sociolaboral de las mujeres en Andalucía. Sevilla: CCOOAndalucía, 1999.

Garolfi G. Industrializzazione difusa in Lombardia. Milán: F. Angeli, 1983.

Instituto de Desarrollo Regional. Retos Medioambientales y Soluciones Tecnológicas y Empresariales para el Sector Turístico en Andalucía. Sevilla: Instituto de Desarrollo Regional, April 1999.

Knight R. "Knowledge-based Development: Policy and Planning Implications for Cities", Urban Studies, Vol. 32, No. 2, pages 225-260, 1995.

Lafuente A. "Creación de empresas y desarrollo regional", en Economía Industrial, September-October, pages 27-36, 1986.

Lundvall B. A. (Ed.) National Systems of Innovation: Towards a Theory of Innovation and Interactive Learning. London: Pinter, 1992.

Lundvall B. A. (Ed) The learning economy: challenges to economic theory and policy. Copenhaguen: Presentation at the EAEPE Seminar, 1994.

Maskell P. y Malmberg A. "Localised learning and industrial competitiveness", Cambridge Journal of Economics, 1997.

Morgan, Kevin. "The Learning Region: Institutions, Innovation and Regional Renewal", Regional Studies, Vol. 31.5, pages 491-503, 1997.

Nelson R. National Innovation Systems. Oxford: Oxford University Press, 1993.

OECD, Territorial Development and Structural Change: A New Perspective on 
Adjustment and Reform. Paris: OECD, 1993.

Osuna J. L . "Panorama actual de la economía andaluza". Cambio 16, pages 34-36, March 1999.

Pacto por el Empleo y el Desarrollo Económico de Andalucía, 1997. Junta de Andalucía.

Patel P. y Pavitt K. "Large firms in the production of the world's technology: an important case of "non-globalisation", Journal of International Business Studies 22(1), pages 1-21, 1991.

Plan de Desarrollo Regional de Andalucía 2000-2006. Consejería de Economía y Hacienda. Junta de Andalucía.

Putnam R. "The prosperous community: social capital and public life". American Prospect 13, pages. 35-42, 1993.

Real B. "El Mercado de la Innovación en Andalucía". Working Paper of the Department of Applied Economics II. Sevilla: University of de Seville, 1995.

Román C. "Andalucía dentro de su contexto", in Delgado M. y Román C. (eds.) Ocho Análisis de la Economía Andaluza. Sevilla: Instituto de Desarrollo Regional, 1995.

Román C. Una estrategia de desarrollo económico para Andalucía. Sevilla: Instituto de Desarrollo Regional, 1999.

Sabel C. "Learning by monitoring: the institutions of economic development" en Smelser y Swedberg Eds. Handbook of Economic Sociology. Princeton: Princeton University Press, 1994.

Storper M. "The limits to globalization: technology districts and international trade", Economic Geography 68, pages 60-93, 1992.

Storper M. "The resurgence of regional economics, ten years later: the region as a nexus of untraded interdependencies", European Urban \& Regional Studies 2, pages 191-221, 1995.

Tejedor B. y Aguirre A. "Proyecto Logos: investigación relativa a la capacidad de aprender de las empresas españolas", Boletín de Estudios Económicos, Vol. LIII, no 164, pages 231-249, 1998.

Vetter J. y Fuentes R. "Inversión en capital humano e investigación y desarro- 
Ilo", in Estudios Públicos, 4. Santiago de Chile: Centro de Estudios Públicos, 1991.

Von Meyer H. "The Insights of Territorial Indicators", The OECD Observer 210 February/March 1998.

Wadley D. (ed.) Restructuration Régionale: Analyse, Principle d'Action et Prospective. Paris: OECD, 19 


\title{
Culture as a Basis for Regional Development in Andalusia
}

\author{
José María Martín Delgado \\ International University of Andalusia
}

In the context of this seminar on the impact of cultural capital and knowledge on economic and social development, one point that we need to consider is culture as a fundamental factor in regional development, and more specifically for Andalusia as a knowledge, learning and innovation region.

We need to start from the hallmark of our time -- the globalisation of society, the economy and knowledge. There can be no question now of defining any strategy for regional development without reference to the international dimension, to a wider area shared with other regions and governed by the same market forces.

The effect of globalisation has been to standardise behaviour, to set the framework for a single market. The momentum is towards uniform modes of behaviour that generate similar responses to what the market can supply, and ultimately produce more standardised and uniform demand across the global market.

Globalising trends bear down on the particular and the special, in a drive to make everything comply with the rules of a worldwide market.

But the trend is also producing a backlash: local features and characteristics are being re-emphasised, for three reasons:

- as a reassertion of identity in reaction to the homogenising effects of globalisation;

- as a means of highlighting possible competitive advantages over other regions or areas in a market where economic decisions are increasingly unconstrained by frontiers or the local availability of resources; 
- greater emphasis on local features also has a microeconomic basis, since regional exploitation of local resources brings those comparative advantages to the market, either in the end products or in the production process.

This is what Nogue Font has called glocalisation, a term that sums up the dialectic between the global and the local, and claims a singular identity for each factor of production at any given place and time.

We may refer to cultural capital, broadly defined, as the set of distinctive features, spiritual and material, intellectual and actual, that characterise a society or a social group (Mexico City Declaration on Cultural Policies, 6 August 1982), or more narrowly as the set of cultural, material and symbolic goods of a given society.

In opting between these two senses, it appears more appropriate to refer to cultural capital in the second one. At the same time, we need to note that this implies some degree of identification of "development" with "economic growth"; in that context culture becomes instrumental. It is then simply another factor of production, an element that influences development, either empowering or weakening it.

From this standpoint, cultural capital has emerged in recent years as a factor of the utmost importance in economic development.

In terms of production it has been shown that the only way to develop a competitive regional economy, in the face of globalisation and the immense power of supranational markets, is by establishing a model of endogenous development that exploits the area's resources and capabilities, one being its own specific cultural capital.

From another standpoint, however, cultural capital is in itself a wealthgenerating factor. As an essential part of the welfare state, culture has turned into a consumer good.

Use and enjoyment of cultural goods is now a right and aspiration of all citizens, so that exercise of this right must be guaranteed and the cultural demands of the greatest number must be satisfied.

In this way, cultural capital produces three effects of great economic significance:

- the first is that it shapes economic development, determining the sectors or products that yield higher returns and make the local economy more 
competitive;

- the second is that a whole sector springs up around cultural goods and activities to promote their conservation, dissemination and use by citizens, generating wealth and employment;

- in the third place, when rationally maintained and exploited cultural capital is a significant component in social well-being and the quality of life, affecting both the region's inhabitants and people from outside who decide to visit or even settle there.

Andalusia occupies a privileged position here. Located on the warmest fringe of the European Union, it has a wonderful natural environment and extraordinary cultural riches. The accumulation of this cultural capital has shaped its economic development, and should logically shape it still further in the future.

The economic and education policies carried out in Andalusia over the past twenty years have paid due heed to the environment and the area's cultural goods, achieving significant headway. Economic growth, rising per capita incomes, better education and greater social awareness have substantially increased our cultural capital and our standard of living, so that we are genuinely well placed to steer our future more effectively with policies more in line with the times, more sustainable in both material and ideological terms.

Andalusia clearly believes that cultural capital is an asset. Our second cultural plan (Plan de Bienes Culturales) takes an overall approach where the restoration, conservation and dissemination of our historic heritage are compatible with its use and enjoyment by citizens.

That brings out the economic significance of our cultural goods and activities as creators of wealth and employment, co-existing with tourism, which is the first-ranking sector in Andalusia's economy.

While accepting this economic conception of culture, compatible with its ideal values, we are bound to go further still. There is a need to launch more integrated policies to ensure that our cultural capital yields economic and social returns.

Our monuments, historic sites and cultural goods in general need substantial investment for research, restoration, conservation and dissemination, and that means sufficient economic resources to preserve and develop them and allow their use and enjoyment by citizens. 
Such investment, whose "utility" and "profitability" are proven, and not just in economic terms, generates new forms of employment; activities ranging from academic research to public access to culture, involving numerous occupations and large numbers of jobs.

The same is true with creative cultural activity. Around this has sprung up a "cultural industry" that generates wealth, though it has not been given due attention. It is estimated that, leaving aside government spending, a town of half a million people generates a turnover of some Pta 15,000 million per year from access to cultural goods.

It is noteworthy how little systematic research has been conducted on this sector, both stable and massive and largely run by cultural enthusiasts.

We accordingly believe that these components of Andalusia's cultural capital, with vast potential, have not so far been paid sufficiently thorough and forward-looking attention.

In those terms alone, the cultural sector is an extraordinary factor for economic growth. It is one of our expanding sectors, opening the way to fuller exploitation of our difference-based advantages.

But it has other effects that are beneficial for development as well. There is an important intangible effect, as it yields invisible returns that have been significant in building up the idea of community in Andalusia. It is a factor for social cohesion and collective identity, and generates knowledge, intelligence and creative capacity, both in individuals and in society as a whole.

It thus contributes to a knowledge and innovation society, building capabilities that ultimately find expression in productive activity as well.

That is why we say culture is the basis of regional development in Andalusia, because even in its narrowest definition culture is a determinant of economic and social development. When development is equated with economic growth, culture is an essential element in Andalusia's case; and if we take the more modern definitions of culture and development, it is more crucial still.

The United Nations report on human development considers development as a process that increases the effective freedom of those benefiting from it to carry out their particular aims. In this sense, the dimensions of culture extend well beyond economic growth, so that culture is also a desirable end in itself. 
The freedom to define one's own fundamental needs is mediatised via the internationalisation of cultural processes, an outcome of globalisation. Just as in the economic sphere, the "global popular culture" that some are enthusiastically promoting is a threat to cultural specificity. That accounts for the reassertions of identity by groups of people who are turning to their own culture as a shield against this aggression, and mobilising to combat it. "Global culture" corresponds to a particular philosophy of life and to uneven distribution of the benefits of so-called progress as well.

This means that the nature of conflicts is changing. The 1994 report on human development notes that, of the 82 conflicts that occurred across the world in the early 1990s, 79 were within countries; they were conflicts between peoples, not between countries. When we look at what is happening now, we can see that matters are much the same or even worse.

In the same context, we need to change our ideas of culture and development and the relations between them. That is what the World Culture and Development Commission did in its 1996 report, focusing on the form in which various ways of living together affect the extension of possibilities and options open to human beings.

This is no doubt a broader and more human approach, and less of an economist's approach if I may say so, which is seeking to alter policies, and not cultural policies alone.

Do not think that I am raising points that are overly dramatic or philosophical in a discussion about economic and social development. I sincerely believe that the only way of achieving stable and sustainable development in Andalusia is to approach it in precisely this way.

A successful move from the global to the local can only be made by taking express account of cultural values. Scientific and technological knowledge is not, in itself, enough; we need to adapt it creatively to local circumstances and to local culture.

To do that we need to extend the definition of culture to take in more than monuments, writings and performances; we need to extend it to the values and ideals which it conveys; otherwise the vector is divorced from its context and hence from its true meaning.

While it must be recognised that the expansion of tourism has generated wealth from particular cultural goods, these goods must not become mer- 
chandise serving tourism's purposes. Quite the reverse, in fact. What leads a place to be chosen as a tourism destination is its cultural and social pullingpower, so that the key point is the way of life in that place, and that depends on its "culture".

You will of course understand that we are not referring to culture in any tribal sense, as something localised and exclusive. Andalusia is universal principally on account of its culture, or rather "its cultures". I refer to the way of living together that is found in Andalusia, and which has made us what we are.

That is the point from which we need to plan our economic and social development, to help our region advance in line with our ways of life, and making full use of our many comparative advantages.

In that respect we possess cultural capital that will not just allow us to progress, but which compels us to draw returns from it in the economic and social sense. 


\title{
Indicators for Learning Regions and Cities
}

\author{
Antonio Pascual Acosta \\ University of Seville
}

\section{Introduction}

The technological revolution driven chiefly by the extraordinary advances in information and communication technology is bringing substantial change across the world. On the economic side, the new paradigm is finding clear expression in two ways. The first is the improvement in production processes in all branches of activity, leading as in other past periods of intensive technological change to greater "mechanisation" with a corresponding transformation in job typologies as requirements change, and a marked shift towards advanced services and the leisure sector. The second and perhaps more positive effect is the generation of new opportunities for economic development related, more or less directly, to the information and communication society.

With regard to human resources, it seems logical to assume, given current trends, that the requirements of "production", understood not in the conventional mechanistic sense but more broadly as productive knowledge, will in the near future entail increasing numbers of workers trained to collate and manage information.

Innovation and knowledge are the fundamental raw materials for these new industries. That requires far-reaching redesign of individual skills -- a new approach not simply to initial training but also to ongoing training as required by the changing nature of information technology as well as innovation in every aspect and at every level.

This being so, in policy terms the future of regional growth requires government services to promote sustained growth in intelligence, to build a 
modern and competitive production base.

To achieve this aim, government departments must support training and stimulate fundamental research and also, importantly, innovation-related research. But such government action will not in itself be sufficient. All the agents involved in developing the region, such as educational institutions and economic and social players, must embrace the new model of competitive development, based on knowledge and learning. Hence the concept of Learning Cities and Regions.

Devising strategies that will equip a region or city to be a centre of innovation and learning involves fresh demands and challenges for statistics, this being a new and complex area requiring the formulation of models that will allow statistical monitoring.

There is hence a need for an analytical model to help establish the relations between human, social and cultural capital, and the linkage with economic competitiveness. The model must cover inter-relations between as many variables as possible, be applicable to all regions, and in fact help us to judge the effectiveness of the various models of development being pursued. That was the approach that we took in the preparatory meetings, during which we considered the range and reliability of data available and established an initial corpus on which we shall continue to work today.

\section{The case of Andalusia: basic data}

The Autonomous Community of Andalusia has achieved significant economic headway in recent years. Very briefly -- since the position here will be discussed in detail by other speakers -- we may mention the pace of economic growth, especially in terms of convergence. For example, over the reference period 1980-1997 cumulative growth has been $70.2 \%$, compared with $58.1 \%$ for Spain as a whole and $48.9 \%$ for the European Union.

Comparative data on employment are even more significant, showing a rise of $24 \%$, twice the level for the country as a whole and well above the EU level of $3.25 \%$.

Yet these satisfactory results do not reflect one of the fundamental potential strengths of the Andalusian economy, and its chief weakness: the substantial increase in its labour force, and the inability to bring unemployment rates down quickly or significantly enough. There is substantial labour poten- 
tial, and insufficient economic activity to absorb it.

Joblessness in Andalusia does not stem from inadequate growth or failure to generate sufficient employment, as the figures mentioned above demonstrate, but rather from the strong increase in the labour force: a rise of $43.1 \%$ in Andalusia, according to the Labour Force Survey, well above the figure for Spain as a whole, which was only $23.6 \%$ over the same period. As a result, over the last twenty years, except at the start of the period and in the final phase where a significant trend reversal is occurring, unemployment has remained around $30 \%$ of the region's labour force, with a 1998 level of $29.5 \%$.

UNEMPLOYMENT IN ANDALUSIA, 1980-1998 (as a percentage of labour force)



Source: Labour Force Survey (INE).

The reasons underlying this labour force expansion are demographic ones. The population of Andalusia shows higher natural growth than Spain as a whole, while migration movements have reversed, so that from being an area of emigration Andalusia has become a net recipient of immigrants since the early 1980 s.

The age pyramid is predominantly young, especially when compared with other parts of Spain or the European Union. According to data from the 1991 census, $23 \%$ of Andalusia's population is under 15, compared with only 
$19.4 \%$ across Spain, and that state of affairs will continue because, while there is some ageing, the pace is slower than in the other regions. That is a significant asset for Andalusia, as well as a source of significant pressure on the labour market.

All these developments over the past twenty years show headway that is confirmed by data such as gross disposable household income per capita (using Fundación BBV series). In constant terms, at 1986 prices, this indicator has moved from Ptas 515,000 in 1983 to Ptas 679,000 per capita in 1997, the last year for which data are available, giving an increase of $31.8 \%$.

While more conventional macroeconomic indicators are an essential source of information for measuring an area's development properly, we can see that they are clearly insufficient when it comes to gauging a region or city's efforts to enhance its population's skills and its technological position, i.e. the factors that will govern future growth in the area.

As I have mentioned, there is no set of indicators, and no synthetic indicator, that will help us determine whether geographical area $X$ is moving closer to, or away from, the hypothetical ideal of a learning region. But in each particular case there will inevitably be a given number of variables that, taken as a whole, can help us to determine, fairly accurately, whether the area in question exhibits -- or lacks -- the profile of a learning or innovation region.

As a rule, the data collected will relate to R\&D spending, general indicators concerning education and culture, and other more varied indices of technological development.

\section{$\cdot R \& D$ spending}

In 1996 the National Statistics Institute (INE) started to run annual surveys of $R \& D$ and of technological innovation by business. The first focuses on R\&D expenditure by government, business and the institutional sector, while the second gauges innovation in the enterprise sector. Although both surveys cover the whole country, the total spending in each autonomous community is also supplied.

From the R\&D survey, total expenditure on $R \& D$ in Andalusia was Ptas 65, 865 million in 1997, nearly $10 \%$ of the figure for the whole country, and less than its population-based share would be. In that connection, the highest concentration of R\&D spending is found, as was to be expected, in the two most industrially advanced autonomous communities: Madrid and Catalonia 
together account for $53.9 \%$ of the national total.

\section{BREAKDOWN OF R\&D SPENDING IN SPAIN, 1997}

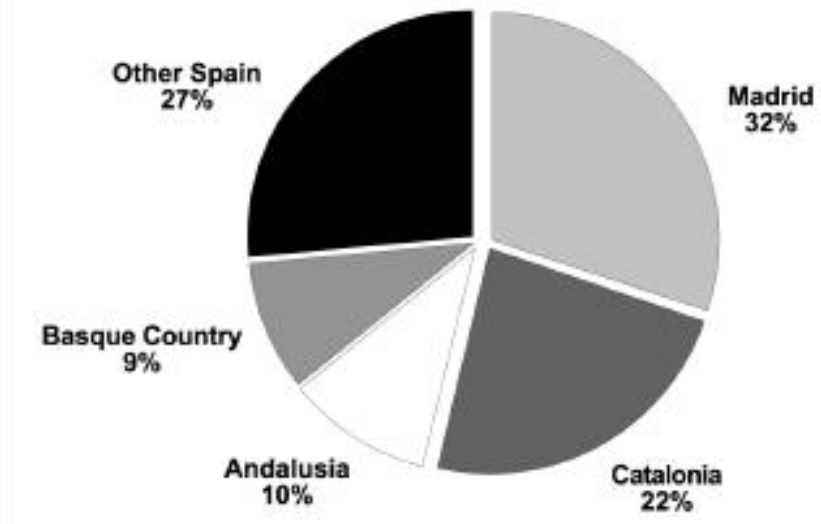

Innovation expenditure by the business enterprise sector totalled Ptas 7,942 million in Andalusia in 1996 (only data available), or 10.6\% of the total for Spain, similar to the proportion of total R\&D spending. Taken together with the other survey, this indicates that $12.1 \%$ of $R \& D$ expenditure in Andalusia is by business, so that the bulk of research there is performed by government and higher education.

We have to bear in mind, nonetheless, that the data from these two surveys are not directly comparable. One gauges the research effort, whereas the innovation survey shows spending by business to improve production processes, extending beyond $R \& D$ expenditure to other items such as the acquisition of innovation embodied in new machinery and plant.

This means that the figure we obtain when omitting the non-comparable portions would be much lower, strengthening the comment that $R \& D$ expenditure by business is very low. But this is a feature common to the other autonomous communities as well, since the figure for Spain, obtained on the same basis, is still lower at $11.2 \%$.

Another means of measuring the research effort in a given region, this time from the standpoint of government alone, is to examine budgeted spending by the autonomous community and its focus. 
Using this approach, Andalusia's 1999 budget allocated a total of Ptas 24,102 million to the seven programmes covered by research policy. The chief objective, as stated in the introductory statement, is to encourage technology transfer, linking scientific research more effectively to the needs of the production system.

The programme allocated the largest share of resources is Teaching and Training with $57.9 \%$ of the total, followed by Farming and Fisheries R\&D and Training with $18.5 \%$, and Scientific Research with $12.7 \%$.

Broadly speaking the budget for these items has been increased by $15 \%$ over the figure for 1998 , which set against the overall increase of $5 \%$ in Andalusia's budget, makes clear that the autonomous government is relying on innovation as a means of securing more competitive economic growth.

Research programmes now account for over $1 \%$ of Andalusia's overall budget, given that the projects concerning the Business Fabric and Industrial Policy are also concerned with innovation, as well as those mentioned above on the research side.

\section{- Other indices of technological development}

Aside from $R \& D$ spending, another possible indicator of a region's technological development, its proximity to a learning society, is the level of computerisation. The most relevant survey available is that run by AIMC, the firm which conducts the general media study (EGM) on Internet users visiting Spanish web sites. To date there have been two such surveys, one in 1996 and the other in 1998, and the findings in both years show an increase in the number of internauts that is greater in Andalusia than across the country as a whole, although the region's share was just 10\% in 1996 and $10.3 \%$ in 1998 . Another indicator, the population with Internet access, shows that in the total for Spain Andalusia contributes $11.83 \%$, or 325,000 people; that figure can be considered high when we note that 1998 saw the start of easier conditions of access for private individuals and small businesses.

A further possible indicator is the number of technology patents issued in the region. Data from the Spanish Patent Office about patent applications in Andalusia show a highly positive trend between 1993 and 1997, which may be taken as reflecting the satisfactory course of technological innovation in the region.

The proportionate increase in Andalusia over this period was $19.6 \%$, 
well above the countrywide figure of just 3.3\% over the same period. The proportion of patent applications in the total for Spain is also moving favourably, from $7.8 \%$ in 1993 to $9 \%$ in 1997 . Andalusia accordingly ranks fourth, after Madrid, Catalonia and the Valencian Community, although considerable leeway still has to be made up to achieve its proper level in terms of population.

\begin{tabular}{|c|c|c|c|c|c|}
\hline \multicolumn{6}{|c|}{ TABLE 1: PATENT APPLICATIONS IN ANDALUSIA AND SPAIN } \\
\hline & \multicolumn{2}{|c|}{1993} & \multicolumn{2}{|c|}{1997} & \multirow{2}{*}{$\begin{array}{l}1993 / 97 \\
\% \text { change }\end{array}$} \\
\hline & Number & $\%$ & Number & $\%$ & \\
\hline Andalusia & 168 & 7.8 & 201 & 9.0 & 19.6 \\
\hline Spain & 2,165 & 100 & 2,236 & 100 & 3.3 \\
\hline
\end{tabular}

\section{- Education and culture indicators}

In recent years the community government has made significant efforts to enhance the cultural and educational infrastructure in Andalusia.

University education has been expanded throughout the last two decades, with student enrolments increasing sharply: for the academic year $1985 / 86$ there were 117,235 enrolments, while ten years later the 1997/98 enrolment was over 260,000 . The main challenge for Andalusian universities at present, as acknowledged in the Economic Plan for Andalusia 2000 (Plan Económico Andalucía Horizonte 2000), is that the instruction provided at universities places more emphasis on academic and disciplinary aspects than on technical and professional ones, while demand for university education is determined more by the social recognition which particular qualifications enjoy than by the needs of the labour market.

In all, Andalusia has ten universities with some 12,500 teaching staff, $16.1 \%$ of the total for Spain. Across the range of qualifications there are currently 405 diploma courses across all ten universities, covering 118 different topics. The increase in supply has naturally been accompanied by a significant increase in teaching, support and research staff, currently over 20,000.

This process, and improvements elsewhere in education, has resulted in a substantial increase in levels of education, directly reflected in the qualifications of the employed population in Andalusia, with an increase in university-level personnel of $108 \%$ between 1986 and 1997, and a still sharper rise, $152 \%$, in those with completed secondary education. 
By contrast, workers with no formal education and those with a primary certificate alone have fallen by around 30\% over the same period. Accordingly, while personnel with secondary and university education represented $33 \%$ of all those in employment in 1986, by 1997 they had become the largest group on the labour market in Andalusia, representing 62\%.

\begin{tabular}{|l|c|c|c|}
\hline \multicolumn{3}{|c|}{ TABLE 2: EDUCATIONAL LEVELS OF PERSONS IN EMPLOYMENT } \\
\hline & $\mathbf{2} \%$ total & \multirow{2}{*}{$\%$ change } \\
\cline { 2 - 4 } & 1986 & 1997 & -29.3 \\
\hline Illiterate, no education & 20.9 & 11.8 & -29.6 \\
\hline Primary education & 46.4 & 26.0 & 152.1 \\
\hline Secondary education & 23.3 & 46.7 & 108.0 \\
\hline University education & 9.4 & 15.6 & 25.7 \\
\hline Total & 100 & 100 & \\
\hline Source: EPA & & & \\
\hline
\end{tabular}

One last indicator that may be noted is the number of research groups operating in Andalusia, principally via the universities and the Research Council (Consejo Superior de Investigaciones Científicas). In the academic year 1992/1993 a total of 1,227 groups were reported, and there was a 33.7\% increase over the following four years to reach 1,641 in the academic year 1996/97.

At the same time, the data show a strong bias towards research in the humanities and social sciences in Andalusian universities. In the academic year 1996/97, projects in these fields accounted for $38 \%$ of the total, while research projects on IT and production technology represented $9 \%$.

\section{New indicators for new circumstances: Learning cities}

We can thus see that the indicators point, in the case of Andalusia, to sustained headway on all matters related to training and learning, a trend that is strengthened by two significant focal points for innovation, the Andalusia Technology Park (PTA) - on whose premises we are meeting today - and Sevilla Tecnópolis on La Cartuja (Charterhouse) Island in Seville, both of which belong to the Asociación de Parques Tecnológicos de España (APTE) and the International Association of Science Parks (IASP). We may also mention certain local production systems in Andalusia - the exemplar being in the marble 
sector in Almería - which are not simply concentrations of firms but make up a more complex production fabric, with strategies for cooperation, development and promoting innovation, and special lines of support and funding for each.

These may broadly be some of the indicators whose trends may enable us to describe Andalusia, and more specifically the Seville and Malaga areas, as learning regions or cities. But as is becoming clear during this session, from a strictly statistical standpoint we need to go one important step further: it is not sufficient to gauge trends in a particular field, we need to establish the relations between one particular variable and others.

We thus need to consider the possibility of a synthetic indicator which would allow us to rank regions in terms of their capacity to innovate and develop, and would assist comparisons across regions. By definition, synthetic indicators are a weighted combination of single indicators. The weighting of individual elements is very closely tied to the particular model of regional development that is being proposed, so it is essential to arrive at a consensus on the relative importance of each individual variable, and establish a series of statistical questions on which we have worked during the preparatory meetings and which are the fundamental topic for this session.

There is already a consensus that indicators such as library consultations or museum visits can help to gauge cultural capital, or that crime rates, ombudsman consultations or participation in voluntary groups can help to determine social capital. But in my opinion, based on experience in Andalusia, other indicators can be considered as well.

In the first place, and since we are basically discussing processes of change and the need for ongoing training, we need to move away from the traditional indicators which reflect the numbers of people obtaining academic certificates or qualifications, which were of use when dealing with relatively uniform and stable systems of education, towards indicators that will inform us of other qualitative aspects such as attitudes to change and readiness to engage in continuing training.

Another indicator could be government attitudes to innovation and the degree of autonomy in R\&D policies. It is important to determine whether the region has the capacity to develop its own innovation policies, and its degree of dependence on national or EU policy, the origin of research funds, and the role that government and institutions perform in innovation. From this standpoint, for instance, we could consider such aspects as the range of qualifications on offer in the education system, the degree of computer use in educa- 
tion, and new experiments promoted by government to enhance services to citizens, among other things.

Innovative behaviour by entrepreneurs could be a further indicator: determining how many businesses are set up by young people, and what kinds. Still in the business sector, it will be of value to determine attitudes to change among workers and unions, so that considerable value will attach to information about training or incorporation of new technology in firms and data about industrial disputes or the degree of cooperation and combined projects among small and medium firms to achieve the scale that enables them to take on joint operations to conduct $R \& D$, enhance product quality or penetrate external markets.

Infrastructure has traditionally been one of the elements selected to gauge development in a region. But the revolution in production and communications technology is radically altering this item's importance, and it is now essential to link it to the capacity to innovate and the region's accessibility -understood not just in terms of geography or of physical propinquity but more as its capacity to relate to other areas. As a result, rather than the traditional distinction between central and peripheral regions, we should start to employ the concept of regions with low, medium or high levels of relations. From this standpoint, partnership should apply not just to firms but also to individuals and regional governments and institutions, research centres, joint marketing initiatives and even transregional voluntary or cultural movements.

Along similar lines, migration movements could be an indicator of regional dynamism, since they reflect real differences between regions, basically in terms of production or job opportunities, as well as a "psychological" difference, in the valuation which citizens place on living conditions there.

Another factor to be borne in mind is the region's attractiveness to outside operators. In a globalised world market, the manner and degree of a particular region's development will depend on its attractions to outside operators who may wish to relocate and manufacture there. A lot of economic research has been done on this subject, but from the standpoint of learning cities and regions we may usefully single out factors such as quality of life for individuals and families, gauged basically in terms of the accessibility and quality of social provision, and matters directly related to production. We also need to consider other factors that are clearly relevant to entrepreneurial activity, such as taxation.

These and other indicators could be combined with those mentioned 
earlier in order to assess learning cities and regions. The condition, however, remains that data must be available, must be reliable and must be uniform. On the last point, substantial headway has been made by adopting the Eurostat framework, although some differences persist and make homogenous comparison difficult. The scope for long-term views, either backwards or forwards, is hampered by the changes that indicators have undergone, due partly to their varying operationality and partly to the evolution of political structures in the regions.

A further important aspect which we must pursue is zoning. As against the traditional three-tier division (national, regional and local levels), new forms of territorial organisation are emerging which do not fit these classifications: the major conurbations, the so-called "travel-to-work" areas, and transnational or interregional structures with a high degree of independence. This raises the need to use other zonal classifications. In the specific case of Andalusia, and its assessment as a learning region, its territorial dimension and current production structure, with a strong tertiary sector, relatively little manufacturing and significant primary activity, lead us to envisage the application of alternative classifications that more faithfully reflect the impact of innovation activities, so that they are not diluted by inclusion in such an extensive and varied territorial entity as Andalusia.

We finally need to consider the question of qualitative information, and the problems involved both in collating it and in making it comparable across regions. Accordingly, from the foundation afforded by the overall picture of the five case studies considered, we need to continue work on formulating and designing the model that will enable us to measure, determine and compare the learning regions. 



\title{
Sustainable Development and the Environment
}

\author{
Luis Atienza Serna \\ Fundación Doñana 21
}

\section{Sustainable development}

Sustainable development, coined little more than twenty-five years ago, has become a significant keyword in economic and political writing. Concerns over the loss of biodiversity, the depletion of non-renewable resources, water and air pollution, the greenhouse effect, damage to the ozone layer, erosion and deforestation have driven the social debate over the sustainability of economic development from the environmental standpoint.

OECD has not remained untouched by this changing view of development. Article 1 of the 1961 Convention establishing the Organization in fact saw sustainable growth as steady GNP growth. In a world of apparently limitless natural resources and inefficient use of manpower, how to increase labour productivity was the key economic concern and the focus of technological innovation.

This focus began to shift in the 1970s, and more markedly in the 1980s. The change was finally consolidated in the 1990s as a result of new social demands, some of them the outcome of deferred environmental bills having to be settled, and the realisation that labour productivity is now very high and manpower is in surplus, and that natural resources are scarcer while the cleaner and more efficient technology available could significantly raise their productivity. It is noteworthy in this respect that OECD has in fact adopted a three-year programme of work designed to present analysis and recommendations on sustainable development to its Ministerial meeting in 2001.

Society seems to be getting free from the "frog syndrome" (FROG, First Raise Our Growth) from which it has been suffering for many years. A 
frog that is sprayed with hot water will leap out of the way to escape death; a frog put into cold water that is then heated up slowly will die, because it does not notice the change in temperature, or only when it is too late. Even so, the significant headway made in some countries in cutting the most perceptible effects of environmental deterioration (cleaning up water, reducing atmospheric emissions, etc.) has lowered social concern in recent years and heightened the danger of a relapse into the frog syndrome.

Since the Brundtland Report of 1987, it has been commonplace to define sustainable development as development that satisfies mankind's needs without jeopardising the capacity of coming generations to satisfy theirs. It means managing renewable resources in line with their capacity for renewal, to manage non-renewable resources in line with the potential of renewable ones to replace them, and limiting waste and emissions to the environment's capacity to absorb them. But that is only a partial definition. Sustainable development must, at one and the same time, be:

- Economically sustainable: compatible with competitiveness in a global economy. While we must seek strict application of the precautionary principle where there is doubt over the consequences of our actions for the environment, we also need to be stricter when it comes to requiring economic viability for proposed alternative courses. Economic development that, while very environment-friendly, is based on a subsidised economy is not sustainable.

- Socially sustainable: development must be harmonious, balanced, and in solidarity with space and time. Poverty and marginalisation are clearly unsustainable. Fundamental factors are investment in human capital and the conception of development as a shared model, requiring that citizens and their social and economic institutions play an active role in designing it, carrying it through and evaluating it.

- Environmentally sustainable: development that does not support present consumption at the cost of future well-being.

Producing a sustainable model of development calls for a global strategy, since some problems extend well beyond national borders, and also requires action at national, regional and local levels. The threats and the potential, both economic and environmental, differ very widely from one area to another. So do the problems, priorities and concerns, as well as each area's contribution to global imbalances and its responsibility for rectifying them. Micro- and macro-environmental approaches must be complementary. 
Sustainable development is not a well-mapped route, but one that needs to be explored. Focusing solely on growth is to behave like the drunken man in the story, who lost his keys on the dark side of the street but looked for them under the lamp because that's where the light was. We are bound to work in conditions of uncertainty and imperfect knowledge, and to shun absolute truth, universal remedies and monolithic doctrine with single theoretical solutions. The lack of scientific certainty is no excuse for inaction. We need to guide ourselves in space and time to reach decisions, rather than define an ideal, abstract model which, however Utopian and far from reality, cannot free us from the business of practical decisions. We cannot become "ecochondriacs", lamenting over lost harmony but unable to do anything about it. We need positive responses, compromises and settlements of clashes of interest, which will help to rejuvenate our economic architecture. We need people to tell us that the route we are taking is the wrong one, because it is unsustainable, but above all we need entrepreneurs, with their projects and initiatives, to open up new routes that will make the aspirations for employment and wellbeing compatible with conservation of the natural heritage. This means investing in human resources via education and training for entrepreneurship and employment.

\section{The environment in Andalusia}

The environment is in comparatively good shape in Andalusia, in relation to other regions in Spain and other EU countries. This is also the autonomous community where the drive for sustainable development has found expression in the most ambitious policy and the most advanced administration of the environment.

The biodiversity and natural area of Andalusia is unparalleled in continental Europe. Eighteen per cent of the area (1.5 million hectares) is included in the Andalusian network of protected natural areas (Red de Espacios Naturales Protegidos de Andalucía -- RENPA), accounting for $60 \%$ of all protected land in Spain. Andalusia has $16 \%$ of the EU landmass designated as special protection areas (SPAs) for birds, even though the total area of Andalusia is just $2.7 \%$ of that of the EU. Out of the 124 types of habitat which the EU considers to be of Community interest in Spain, 76 are represented in Andalusia. It also has 100 of the 165 species of Community interest, great diversity of animal and plant life, and hundreds of exclusive endemic species. Spain has the largest number of species in the EU, and in Andalusia we find 
$73 \%$ of Spanish mammals, $81 \%$ of birds, $82 \%$ of reptiles, $61.5 \%$ of amphibians and $67 \%$ of fish. This diversity is under threat, however, from the deterioration of eco-systems, meaning that $25.5 \%$ of mammals, $11.6 \%$ of birds, $28.2 \%$ of fish and $18.5 \%$ of reptiles are endangered species. UNESCO has designated seven biosphere reserves in Andalusia, covering a total of 650,000 hectares.

Water is not a widely available resource, and is very unevenly distributed in both time and space compared with the average for Spain, which in turn is well above the European average. These climatic conditions underscore the importance of dam capacity and the proportion of irrigation in total water demand ( $77.5 \%$ of consumption) - in sharp contrast with the average for the EU, where irrigation accounts for barely $20 \%$ of consumption.

Water quality is very adversely affected by the low flows and the decade-long neglect of investment in water purification. The backlog has been vigorously tackled in recent years, with very substantial investment in sewage systems so that treatment levels are now approaching those elsewhere.

Soil contamination by nitrates and pesticides is fortunately far from the levels obtaining in Central Europe, although some episodes of higher localised pollution do occur in the more intensive farming areas in the Guadalquivir Valley and the coastal area around Almeria.

Air pollution ( $\mathrm{SO}_{2}, \mathrm{NOx}, \mathrm{NH}_{3}$ and volatile organic compounds) is low or very low, depending on the area, though some local pollution may occur. Acid rain does not occur in Andalusia.

Production of solid urban waste is some $20 \%$ below the EU average. Of this waste, $17 \%$ is still disposed of at non-controlled sites, but this figure has fallen very considerably from the $60 \%$ of some ten years ago. The situation with regard to paper recycling is very satisfactory compared with EU levels, but much less favourable with glass. There is very high coverage with containers for the selective collection of paper and cardboard. Coverage for glass is improving, but is still unsatisfactory.

Erosion, loss of plant cover and indeed desertification, taken together with the water cycle, form one of the most serious environmental problems in Andalusia. Erosion risks are high or extreme across $38 \%$ of the area, and average over another $34 \%$. Woodland area represents $26 \%$ of Andalusia, and the chief threat is fire, though this has not prevented the woodland area of increasing increasing by $24.5 \%$ between 1975 and 1995 . 
The environmental industry in Andalusia is still in its infancy, small in size and without any consolidated structure, and unable to specialise because demand, though growing, is still weak; the sector nonetheless employs 19,000 people and has a turnover of Ptas 100,000 million (Euro 600 million).

One of the pillars in the development model proposed for Andalusia in the 21 st century is environmental sustainability, reflected in enhanced quality of life and a permanent increase in social well-being. The environmental strategy of Andalusia has the following main objectives:

1. Bringing the water system into balance, eliminating shortfalls in supply and treatment, encouraging efficient use of water, in particular through the introduction of modern irrigation methods, and reducing the risks associated with major events, in particular drought and flood;

2. Reducing the risks of deterioration for natural resources, in particular combating deforestation and erosion and preventing and controlling forest fires;

3. Promoting conservation and sustainable use of protected natural areas, integrated in their socio-economic context. Trends in the local authority areas where protected natural areas are located, over the past ten years, indicate that the historical population loss has been halted, and numbers are beginning to rise slightly. Unemployment has fallen more than across Andalusia as a whole, and additionally employment is less sensitive to the economic cycle. Tax and domestic appliance indicators reflect a rise in income and well-being above the average for Andalusia, although the historical leeway has not yet been made up fully.

This environmental strategy is one of the main thrusts for development in Andalusia in the Regional Plan for 2000-2006, to which Euro 3,600 million are being allocated, or $17 \%$ of projected total public expenditure.

\section{The sustainable development plan for Doñana}

Doñana is the flagship of sustainable development in Andalusia and in Spain. The 1994-99 Sustainable Development Plan for Doñana is a highly advanced formulation, for a regional framework, of an integrated strategy to achieve compatibility between development and the natural environment. 
Doñana, covering nearly 300,000 hectares in all, with 110,000 hectares of protected natural areas and 162,000 inhabitants, is a natural area within a densely populated part of Andalucia. It is one of the most valuable ecosystems in Europe, and the largest protected area in Spain. Doñana is a UNESCO biosphere reserve, a special protection area under the Ramsar Convention, a Council of Europe area, and a Human Heritage site.

The clash between development and conservation has been present in Doñana since it was declared a National Park. The spread of irrigated crops, in particular rice and strawberries, brings pressure to bear on the quantity and quality of the most vulnerable element in Doñana's eco-system: water. The conventional model of tourism, based almost exclusively on sun and sand, with housing developments along the coastline to provide holiday centres and second homes for visitors from other regions, plus excursionists, squanders the region's enormous natural and cultural resources and has generated a high environmental impact in exchange for highly seasonal economic activity, making limited contributions to local employment and income.

In 1992 an international panel of experts convened by the Andalusian authorities presented a report on strategies for sustainable socio-economic development in Doñana designed to settle, or at least moderate, the clash between conservation and development.

On this basis, and in line with the fifth EU Environment Programme, the 1994-1999 Sustainable Development Plan for Doñana was drawn up. It received financial backing from the Andalusian authorities, the central government and the European Commission, with investment over the period totalling nearly Ptas 63,000 million (Euro 375 million). The aims were:

- Integrated water management, with investment to tackle the problems of urban supply and irrigation, cutting abstraction from aquifers, and to combat water pollution by means of drainage and treatment networks;

- Consolidation of farming, removing some crops from the most sensitive parts of protected areas, modernising farms and farm infrastructure, supporting the processing and marketing of local products (fruit and vegetables, grapes and wine, olives and olive oil, rice, etc.) and encouraging integrated and environment-friendly agriculture;

- Steering the tourism sector towards a high-quality model more friendly to natural and cultural resources, while at the same time making full use of their contribution to the socio-economic development of the area. The 
aim is to achieve the maximum added value, maximum wealth, from the area's limited reception capacity, with an attractive multi-theme tourism supply embracing the resources available for coastal, nature, cultural, religious, sporting and scientific tourism, capable of drawing in a wide spectrum of more upmarket visitors, with spending power to synergise with other economic sectors, for short and medium-stay visits throughout the year. That entails developing new centres of interest and new facilities, and above all stimulating entrepreneurial capacity and training for local human resources;

- Modernising the highway infrastructure, to improve access and overcome chokepoints, paying particular attention to minimising the environmental impact;

- Upskilling and training as strong pillars to support the gradual change in the area's economic architecture, so that local people become not just observers of change but protagonists as well;

- Exploiting the potential of Doñana as a brand to assist the marketing of local products and services;

- Launching substantial operations to rehabilitate and conserve ecosystems.

The Plan is now in the final stage, and over $80 \%$ completed, in spite of difficulties with some infrastructural investment, due to the environmental vulnerability of the area. It is rather early to draw conclusions because, while projects all had to be launched by December 1999, some may take until 2001 to be carried out. But trends in local socio-economic and well-being indicators are highly positive, above the average trends for Andalusia, although in absolute terms they still remain below the average.

What is changing most in the area -- and this gives us particular satisfaction given the contribution that Fundación Doñana 21 has been able to make -- is local people's perceptions about their own future, the linkage of their economic future to conservation of Doñana's natural heritage, and their involvement as full players in the drive to make high quality, and the natural heritage, the basis for competitiveness, progress and well-being.

The Doñana Sustainable Development Plan was seen in the EU as the first experiment in integrated operations for sustainable development, and was devised as a pilot project with demonstration effects for other parts of Andalusia, Spain and Europe. The Plan is now living up to the expectations 
that were placed on it. Two of the many significant achievements of the Doñana strategy for sustainable development may be singled out:

1. The institutional model for management. The establishment of Fundación Doñana 21, a private non-profit institution, as the agency for sustainable development, backed by representatives of the Government of Andalusia, local savings banks, local authorities, business and trade union bodies and conservationists, together with observers from the European Commission, has supplied management capability but above all has strengthened social involvement and has assisted consensus on operations. Such involvement and consensus have also gained from the several hundred meetings that Fundación Doñana 21 has held with institutional, economic and social players in the region in little over two years' existence, to discuss and plan its operations.

2. The Doñana 21 label, reflecting the high-quality and environmentfriendly approach as basic factors in the competitiveness of the region's economy. By using the Doñana 21 label, local businesses can link their products and services to the image and prestige of the most valuable natural area in Europe. In exchange, businesses make a threefold undertaking: to establish a quality management system and an environmental management system, both complying with ISO standards, and preparing and publishing a plan for ongoing improvement of their environmental performance indicators.

We were aware that a quality mark identified with Doñana had to be stringent, sound, internationally recognised and certified by an independent agency of the highest repute. We accordingly requested AENOR, the Spanish Association for Standards and Certification, to conduct a review and evaluation of compliance with the requirements of our label. We are proud to say that today 46 local firms are already engaged in establishing the Doñana 21 label, and this project is becoming the symbol of sustainable economic development in Doñana. The label is designed to demonstrate that the commitment to quality and nature is within the reach of SMEs, and here we are draw- ing on the drive, energy and open, forward-looking and enterprising attitude of businesses in the area, including micro-firms, which have given the label an exceptional welcome. It is a pioneering initiative, innovative both for Spain and internationally. This is the first label covering quality and environment-friendly rules, and we are convinced that it will show the way for similar initiatives in other outstanding natural areas in Europe.

A new phase is opening up in Doñana, once we have completely over- 
come the spillage into the Guadiamar River following the Aznalcóllar incident, with a commitment to quality and nature that is at the same time a commitment to competitiveness, employment and well-being, and solidarity with future generations. At present we are working on the operational strategy for the period 2000-2006, which involves less investment in infrastructure and facilities, as the most significant shortfalls were tackled in the period 1994-1999, and more resources to shift production processes towards innovation and the environment as factors generating competitiveness, to exploit natural resources in ways compatible with conservation, to encourage new economic activity, and to expand education and training for employment and innovation, because human resources and the natural heritage are the basis for the area's future.

Andalusia has a natural heritage whose wealth and diversity is unparalleled on the European continent and the environmental position is generally satisfactory, though not without problems, in particular related to the water cycle and erosion, and cases of local pollution.

There is clear recognition that this environmental heritage is an economic asset for the future that ties in well with new forms of social demand concerning tourism, agriculture and foodstuffs, and needs to be exploited sustainably to support competitiveness and employment; we are accordingly laying down development and conservation strategies that are pace-setters in international terms, to move from theory to practice in the promotion of a sustainable model of economic, social and environmental development. 



\section{The Influence of Science and Technology Parks on their Surrounding Area: The Andalusia Technology Park}

Felipe Romera Lubias

The Andalusia Technology Park

\section{Introduction}

The first section deals with the changes that information technology has brought to the economic landscape as the millennium draws to a close. It has set off a major crisis in traditional manufacturing, and is responible for the new industrial revolution based on information and knowledge, the emergence of global markets and, above all, the Internet, which is shaping up as the greatest technological-cultural revolution of the past 200 years.

We then analyse the position of small and medium firms in this new landscape and consider how technology parks can be effective infrastructures assisting local economic development, and how the technology park model can find its place in areas that are backward from the economic and technological standpoints.

The final section deals with the pattern of expansion at the Andalusian Technology Park (PTA) in Málaga, Spain.

\section{Information technology}

As we near the end of the 20th century, we can consider the conditions that have quickened the pace of development. The century has seen a substantial increase in life expectancy, due largely to advances in medical science, but it is no doubt information technology (electronics, computers, telecommunications) which has brought about a fundamental change in economic life across the planet and altered the worldwide economic landscape. These tech- 
nologies have revolutionised life, ushering in the new millennium.

Their introduction into economic activity has triggered a significant crisis in traditional manufacturing, and fostered a new industrial revolution, this time knowledge-based. IT has created global markets and, above all, the Internet.

\subsection{The crisis in traditional manufacturing}

Information technology has plunged traditional manufacturing into a major crisis. Incorporating IT in manufacturing has raised productivity in spectacular fashion and greatly cut back employment there. The process of change is by no means over, especially in small and medium firms located in backward areas.

The expansion of information technology, where new generations arrive every three or four years, means that industrial modernisation is a continuous process. It is essential to keep up with the pace of technological change in order to compete in the marketplace.

\subsection{Knowledge-based industry}

Information technology has fostered a new industrial revolution based on knowledge and information. Innovation has become essential in order to compete in the marketplace and the new knowledge-based industries are the strongest ally of innovation.

Software development and advanced IT-based services will be the greatest generators of employment in the early years of the coming millennium.

\subsection{Global markets}

There have always been worldwide markets, but information technology has converted these world markets into global ones. A global market is a world market where decisions are taken in real time.

Little by little, all markets are becoming global ones. As more sectors 
of the economy become involved, they need to raise their own productivity to remain competitive there.

\subsection{The Internet}

The Internet is the paradigm of the development that information technology is generating. Computer science and telecommunications come together there, and of course the Internet is driven by electronics.

The Internet is the most effective tool to compete in global markets and is giving impetus to the new knowledge-based industrial revolution. The Internet as we know it today bears no relation to the Internet that we shall shortly see, and the amount of business transacted there will increase exponentially year by year. Internet will provide access to global markets.

\section{SMEs in the new landscape}

Traditional small and medium firms need to adjust to the new economic landscape and one essential for them is to adjust in technological terms to their new surroundings. Adjustment is no easy matter, especially for SMEs located in backward areas since using technology entails a learning process and the day-to-day efforts required for an SME to survive are so great that in many cases technological adjustment has to take second place.

The secondary importance of technological adjustment for traditional SMEs is a bizarre paradox, since technological adjustment is vital to their survival.

Global markets are both a threat and an opportunity for SMEs. The threat is that other firms which previously did not operate on their local market will compete there, and usually compete with products and services of higher quality and lower cost. In such circumstances, technological adjustment and innovation are the sole means for firms to cope with changes in the market. Raising competitiveness becomes a fundamental objective for the survival of the firm.

But global markets also offer firms the opportunity to operate in the new global landscape, selling their products and services on wider markets. Co-operation between firms in different geographical regions is an excellent 
method of fostering participation in these markets. Over the coming years, the Internet will assist such co-operation and facilitate access to global markets.

In addition, the new knowledge-based industrial revolution is fostering the formation of small IT firms which are already well adjusted to the new landscape and will beyond a doubt be the driving force for economic development in the coming millennium and the greatest generators of new employment. The features of these businesses are small size and high capacity to adjust to change.

\section{Technology Parks as driving forces for economic devel- opment}

The term technology park covers a range of projects diversely named science parks, research parks, technopoles and even technology incubators: in a recent article I proposed giving all these initiatives the name technocells. They are the offspring of information technology and represent the scope of IT to shape a model of economic development, put into practice in the 1980s in advanced regions and now in the 1990s in less advanced areas.

Technocells sprung up in the place where information technology was growing, Silicon Valley, and in twenty years have spread across the world. The table below makes a simplified presentation of the numbers of technology parks (these combine technology, science and research parks and technopoles), technology incubators, and technocells -- the aggregate of the first two. It shows only those projects linked in some form of national or international network, and the data are for end-1997. The significant expansion of technology parks, especially in backward regions, and of incubators (over 10 per cent a year) means that the data are indicative only. 


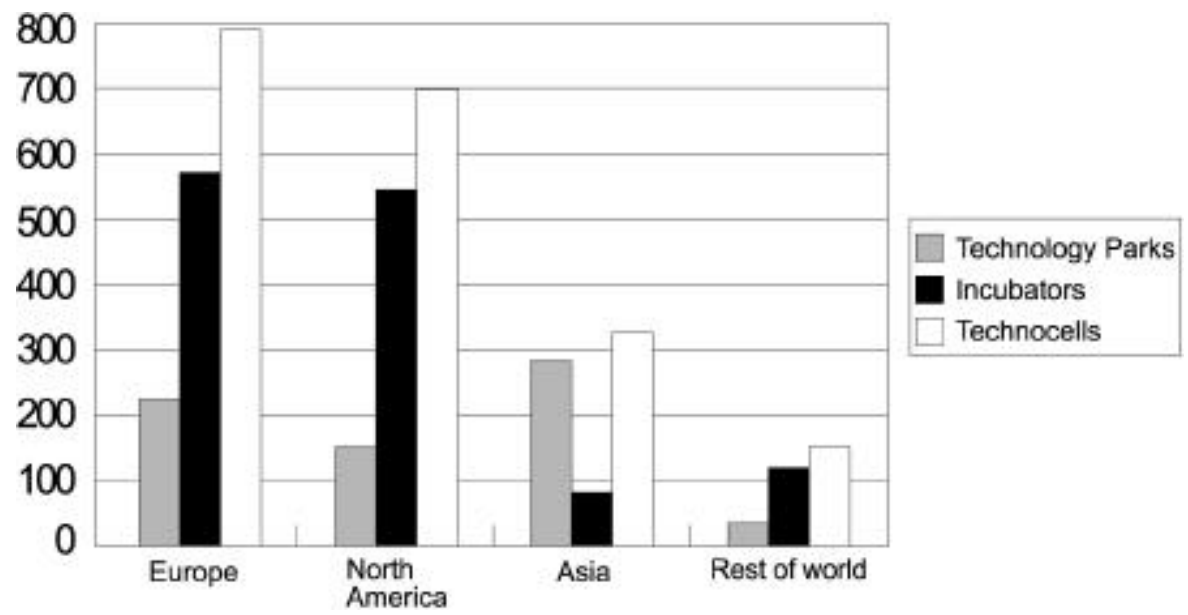

Figure 1: Technology Parks, incubators and technocells in the world

\subsection{Technology Parks and IT}

Information technology has fostered the emergence of technology parks, since it has provided the best tool for promoting business development and technology transfer.

In the design of technology parks, the main focus of attention was on telecommunications infrastructure, especially in backward areas where efficient telecommunications have been a plus factor in encouraging innovative firms to locate there.

In many cases this infrastructure has been a key factor in business development and has fostered growth for the firms located in technology parks.

In addition, while the main activity in a large number of parks has not been information technology, IT has in all cases proved significant for the development of firms in technology parks, and without it the parks would not have come into being.

\subsection{Technology Parks and innovation}

The knowledge-based revolution generated by the expansion of infor- 
mation technology means that entrepreneurial innovation will be an increasing necessity in our economy. The bulk of the products or services that we shall be consuming in four or five years' time have not yet been developed, which is both a great opportunity for new and innovative firms to find new slots in the market and an ongoing challenge to existing firms, for if they fail to speed up the innovation process, creating and marketing new products and services, they may well disappear.

The stimulus that technology parks provide is extremely helpful to the development of innovative businesses. In addition, technology parks are increasingly having to help create new innovative firms in their midst, meaning that in many cases it is essential for technology parks to include a technology incubator to help the formation of new firms, through spinoffs from industry or the academic world. In such cases close co-operation with manufacturing firms in the vicinity, and local universities, is essential.

That is one of the reasons that the notions of technology park and technology incubator are increasingly being combined, and, as mentioned earlier, being termed, in the aggregate, technocells. A technology incubator is the simplest expression of a technology park.

Technology parks are, in addition, an effective means of fostering the dissemination and transfer of technology to traditional sectors in the vicinity of the park. The accumulation of innovative firms in a park turns them into disseminators of technology, and that is how technology parks can be agents in local economic development.

It is in these ways that technology parks can and must assist traditional SMEs in overcoming the paradox of their only secondary interest in the processes of technological adjustment.

\subsection{Technology Parks and global markets}

The appearance of technology parks and global markets almost simultaneously on the economic stage has led to some confusion over the relation between the two. The objectives of the technology parks had not included their firms' participation in global markets, chiefly because the latter were in their infancy. But the way in which technology parks have developed means that they are seen as effective infrastructure in assisting their businesses and the immediate surroundings of the park to compete and enter global markets more 
satisfactorily.

The stimulus provided by technology parks extends to business cooperation. Co-operation of this kind between firms in different regions is the route that will lead firms in business parks to sell their products and services outside their local markets.

\subsection{Technology Parks and the Internet}

The changes that the Internet is going to bring into our lives in the next few years will have a very direct impact on the development and future course of technology parks. Many technologically active firms based in technology parks already use the Internet as a competition-related tool and many technology parks are setting up internal telecommunications networks where the costs of internal communications and connections to the outside are lower than elsewhere.

The idea that technology parks should become Internet connection points within a high-speed global network is a further step in the development of the technology parks themselves.

\subsection{Technology Parks in backward areas}

The technological and economic changes described above lead us to examine the scope for developing technology parks successfully in backward areas. What would a few years back have seemed a paradox (namely, the seeming contradiction of setting up a technology park in an area of low technological development) can be seen as an opportunity, and technology parks in such areas become an instrument that fosters economic development there.

That explains why technology parks have spread extensively throug hout the 1990s in more backward economic areas, including Latin America and China.

Below we describe a practical example of the development model involving a technology park in an economically backward area, the Andalusian Technology Park (PTA) in Málaga, Spain. 


\section{The Andalusia Technology Park}

Andalusia is one of the most extensive regions in Europe, larger than some EU Member countries; it has a low level of both economic and technological development.

The idea of establishing a technology park in the region was launched by Andalusia's Autonomous Government. There were two spurs: the need to give impetus to regional development policy, at a time when the autonomous community had just come into being under Spain's devolution process, and the emerging vogue for technology parks.

Initial research to establish the project's viability was commissioned by the Autonomous Government in 1985, but the decision to go ahead was taken only in late 1988. The Autonomous Government of Andalusia and Málaga Council signed an agreement, as joint promoters, to build the Andalusia Technology Park.

Infrastructure work was launched in 1989 and continued into 1992, and the park was inaugurated in December that year.

The fundamental objective of the Andalusian Technology Park is to ensure that technological development assists the economic expansion of the region, and with that aim in mind the park was designed and developed in four stages, which are described below.

\subsection{Stage I: Establishing the PTA}

The park was established as a high-quality project with advanced infrastructure and services to provide its users with competitive market advantages in terms of image, funding and operating costs.

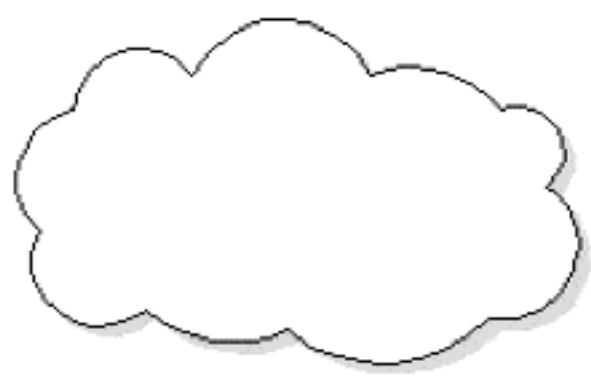


The PTA is located in the city of Málaga, within a metropolitan area with a population of over 1 million where the chief economic activity is tourism. The PTA is $13 \mathrm{~km}$ from the city centre, $7 \mathrm{~km}$ from the university and $6 \mathrm{~km}$ from the international airport. It has a total area of 168 hectares, of which 91 hectares are landscaped, with over 4,000 trees and 150,000 plants and shrubs. The plots reserved for various innovation-related purposes cover a total of 51.4 hectares.

The park has a heliport, three alternative electricity supplies, with a 40 Mva substation, two separate water supply networks and two different optic fibre circuits.

The PTA provides video-conferencing facilities, meeting rooms, teleworking and remote learning centres, management and administration of telecommunication services, restaurants, a creche, banking and travel services, entry control, video surveillance and remote monitoring of premises, e-mail and Internet services (http://www.pta.es) with permanent high-speed connection and cost-free communications, maintenance of shared facilities and upkeep of the landscaped areas.

The park adjoins a 60 hectare reserved area, of which 10 hectares have been purchased to establish an industrial estate related to innovative activity in the park, and also has an agri-food area covering a further 7 hectares.

In addition to basic infrastructure, the PTA has promoted the construction of the following multi-purpose buildings:

The park's Head Office, which houses the management company and is the world headquarters of the International Association of Science Parks; it will shortly also house the Mediterranean office of the International Union for Conservation of Nature and Natural Resources (IUCN). There is a business centre providing video-conferencing facilities, an auditorium, meeting rooms, a restaurant and a computer service centre.

The Kindergarten, which provides creche facilities for the children (up to age three) of people working in the park and its immediate vicinity.

The Health and Safety Centre, which provides accident prevention services and medical attention for those working on the site.

Bic-Euronova, a European business and innovation centre to house innovative initiatives and serve as a business incubator. Firms taking space in 
this building can stay for a maximum of three years.

The Business Centre (the Nido, or Nest, Building), which contains offices which can be rented by innovative firms.

The Auxiliary Industry Technology Centre (CTIA), a combined workshop and office building, with premises for rent or sale.

The Occupational Training Centre for Telecommunications and Information Technology, designed to provide training for staff working in firms in the park and its surroundings; it also houses a vocational training centre.

The Málaga University Building, or Blue Building, houses institutes and research centres attached to Málaga University which are concerned with economic development and have links with firms in the park.

The R\&D10 area comprises six buildings each with $600 \mathrm{~m}^{2}$ of floor space, with firms occupying all or part of a building.

\subsection{Stage II: Attracting innovation to the PTA}

The second stage in developing the PTA was to draw innovative activity into it to provide a technology mass, drawing in high-tech industrial concerns, research and development agencies, universities, laboratories and advanced service providers, and setting up auxiliary industrial and service firms around the park.

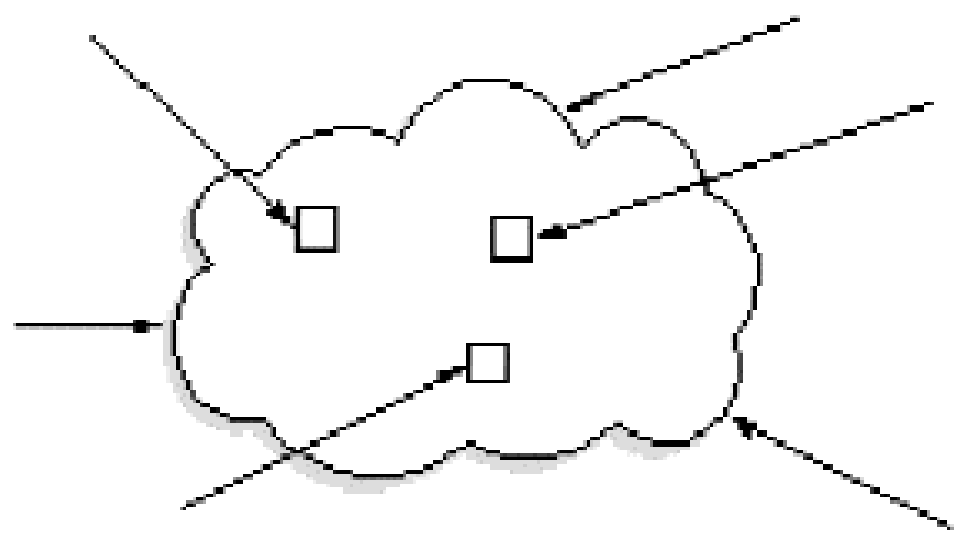


Firms and institutions have chosen to locate in numerous ways since the PTA started operations seven years ago. Practices ranged from renting 15 $\mathrm{m}^{2}$ of fully equipped office space to purchasing a plot of some $100,000 \mathrm{~m}^{2}$ as the site for a major industrial complex.

The range of buildings has also allowed firms and Málaga University to locate in a variety of ways.

The first example is Bic-Euronova, the park's business incubator. It is a prime instrument for business creation and the heart of the PTA. Virtually all business projects have emerged via Bic. It offers business services as well as rented premises in the building it manages. Over its 7 years' operation, occupation has averaged 85 per cent. In October 1999 Bic housed 35 firms, most of them concerned with information technology.

Firms which locate in the Bic building can remain there for a maximum of three years, after which they must move to another part of the PTA. Experience shows that the positive image conveyed by association with the PTA means that, after leaving Bic, firms want to remain in the park; usually, however, they lack sufficient financial capacity to buy a plot and build their own premises. The PTA has accordingly developed other multi-purpose buildings to house businesses.

The Auxiliary Industry Technology Centre (CITA) is a 10,000 $\mathrm{m}^{2}$ building in which twelve firms have been able to locate. It is divided into work-shop and office space, which could be rented or purchased. At present it is fully occupied. Three types of activities are conducted there. One group of firms are involved in developing and manufacturing electronic components and work as subcontractors for the major IT plants in the park, such as Raytheon and Alcatel. The second group comprises major mobile telephone operators such as Amena and Airtel. The third group of firms are in advanced services and software development.

The Business Centre, in the Nido (Nest) Building, was put up to house firms leaving the Bic building, and this has effectively occurred. But the Business Centre has also been used by large multinationals to set up their advanced service centres and software plants. Coritel, Siemens and Telenor Media have done this. The building also contains banking and travel agency facilities. It provides some $8,000 \mathrm{~m}^{2}$ of floor space, all taken up on a rental basis, shared by 37 firms.

The R\&D10 area comprises of six buildings put up on a plot of some 
$7,000 \mathrm{~m}^{2}$. Five of the buildings have $600 \mathrm{~m}^{2}$ of floor space each, and the other $900 \mathrm{~m}^{2}$. Each building has two storeys, and is sold unfitted: the idea was to encourage firms which wanted their own premises to set up in the park at low cost. Half of the eight firms occupying these buildings (the $900 \mathrm{~m}^{2}$ unit was subdivided) came from Bic or the Business Centre, and the others from outside. There is virtually 100 per cent occupation, and information technology businesses predominate.

The Andalusian Development Agency (Instituto de Fomento de Andalucía) is currently putting up a new $2,500 \mathrm{~m}^{2}$ building, on similar lines to Bic and the Business Centre. It will be used as an extension of the incubator and the Business Centre.

Another multi-purpose building where firms can locate is the Málaga University Building, or Blue Building. The firms there have very close links with Málaga University: the building houses eleven university research groups which work with businesses, the Agency for Research Transfer (Oficina de Transferencia de Resultados de Investigación -- OTRI), and new firms emerging from the university under its spin-off programme.

The Head Office is a restored 19th century building which houses the park's management company. A range of services are available there for firms operating in the park, including an auditorium, meeting rooms, video-conferencing facilities and a restaurant. It also houses international agencies, including the world headquarters of the International Association of Science Parks (IASP) and the Mediterranean office of the International Union for Conservation of Nature and Natural Resources (IUCN).

Apart from these shared buildings, the PTA contains another thirteen units belonging to individual concerns. They include the manufacturing sites for Alcatel, Raytheon and Air Liquide, the technology centres run by CETECOM, INDYCCE and the Málaga authorities, production centres for Predan and King Buffets, training centres operated by FORMAN and Telefónica, and the main premises of the emergency health service agency.

Figures 2, 3 and 4 below show how the PTA has developed since its opening in terms of the number of firms, employment and business invoicing. 


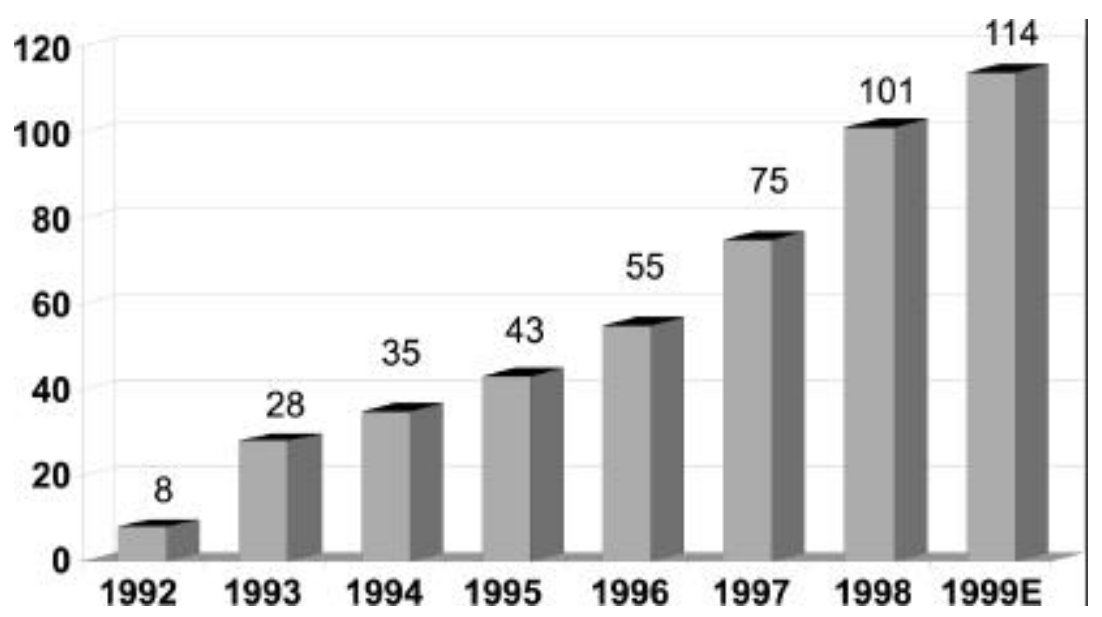

Figure 2: Busnisses established in the PTA

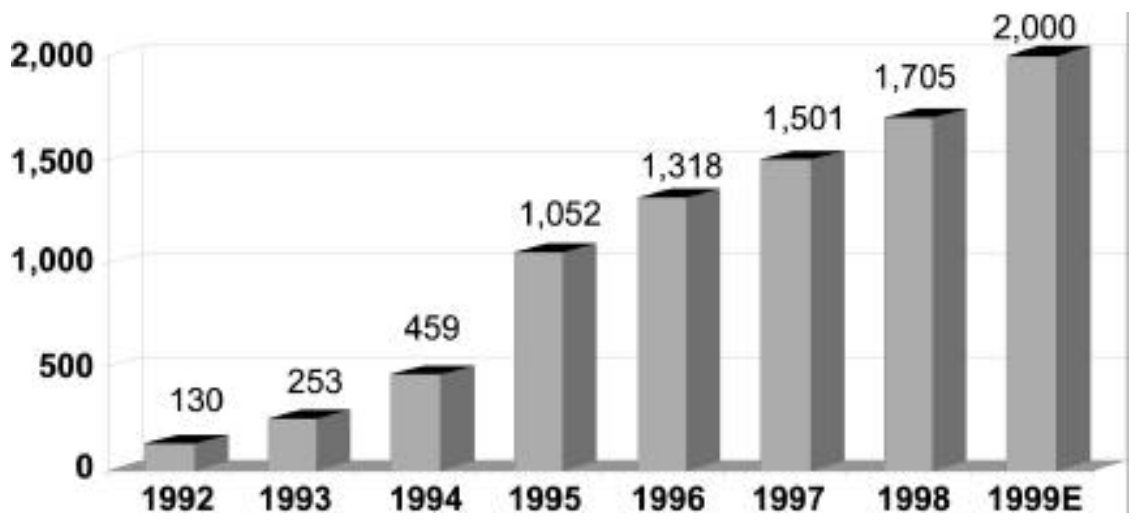

Figure 3: Employment in the PTA 


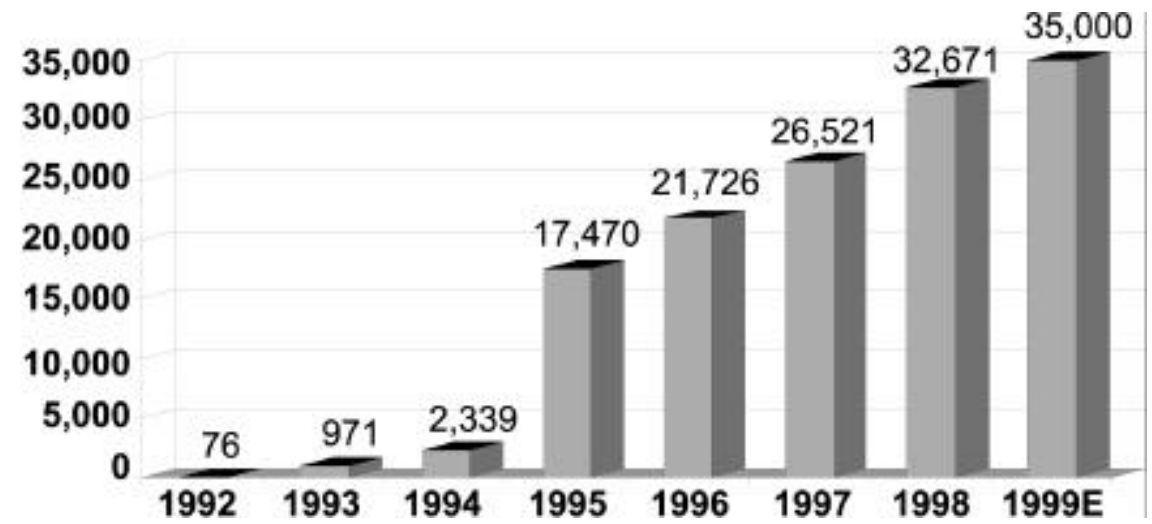

Figure 4: Invoicing by firms in the PTA (million pesetas)

\subsection{Stage III: Dissemination of technology}

The third stage in the development of the PTA is to make use of the technology mass there to:

1. set up new firms;

2. promote industrial development in the region;

3. direct university research towards economic development in the surrounding area;

4. raise standards and competitiveness in the traditional sectors, by establishing technology service centres. 


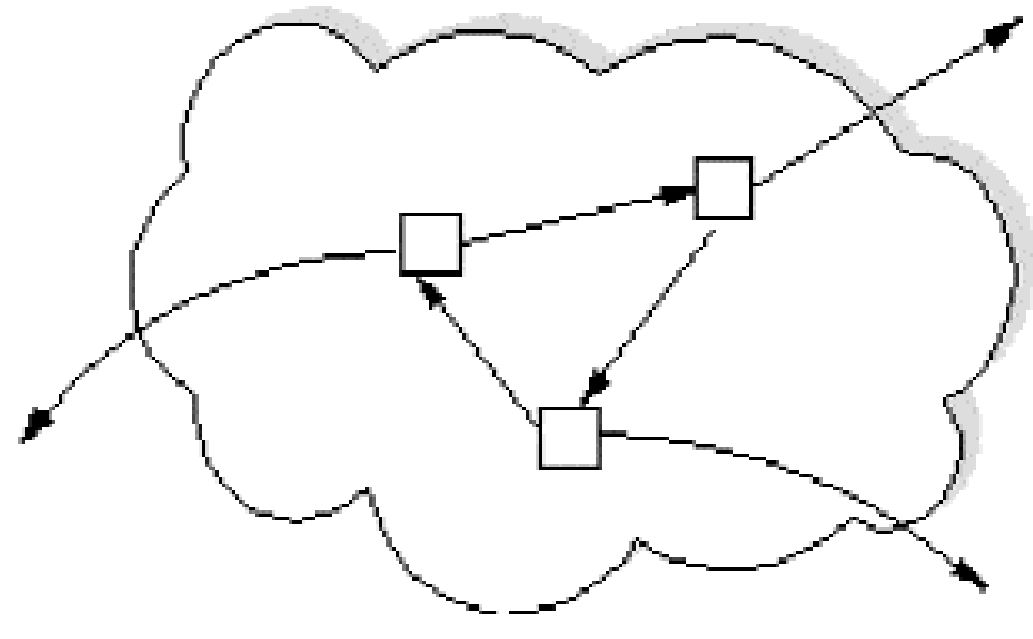

The PTA has proved an effective instrument for the creation of innovative businesses. Over 60 of the firms established in the park were formed there; more importantly, a route has been traced by which the process can expand in coming years. The relations between Málaga University, BicEuronova and the PTA are fundamental to this process. The university's interest in business creation will grow in the next few years with the construction of a new building to serve as a pre-incubator. The aim, in short, is to stimulate the university community to set up businesses, with the university supplying premises and resources. The new firms would be housed in Bic-Euronova and subsequently locate elsewhere in the PTA.

In addition, the model of development followed by Málaga University in the PTA is based on four activities being run in the Blue Building. The first, already noted, is business creation by the university community. The second is the Research Transfer Agency; its presence in the Blue Building has brought a significant increase in recent years in contracts and links between Málaga University and firms in the park and the immediate vicinity. The third feature is the arrival of eleven research groups which secured laboratories within the park via a selective competition. Last, the Blue Building also houses firms with shared interests either with the university (Málaga University has a stake in some of these firms) or with the research groups.

Bic-Euronova has to date been the most effective instrument in the 
PTA's own activity in business creation.

FORMAN, the Occupational Training Centre for Telecommunications and Information Technology, has been one of the park's most effective instruments in disseminating technology in the area, and the park's management company has conducted numerous $R \& D$ training schemes in conjunction with firms in the park and in the immediate vicinity. This goes hand in hand with activities concerned with technology watch, Internet use, and establishing centres for teleworking, distance learning and virtual documentation. The INDYCCE and CETECOM technology centres provide services that have built up strong links with the surrounding area.

\subsection{Stage IV: Co-operation networks}

The objective at this stage is, via technology co-operation networks, to foster the participation of Andalusian firms in global markets through business co-operation.

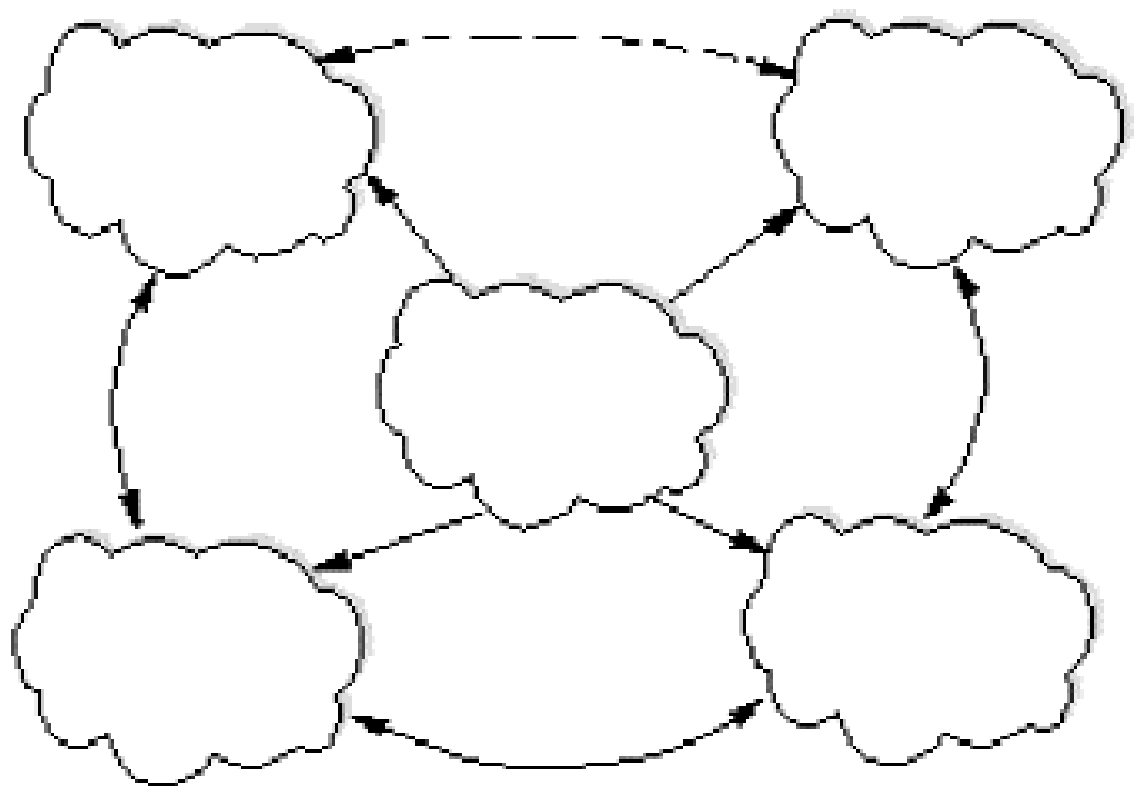


Since its foundation, the management company for the Andalusia Technology Park has taken part in numerous European programmes, of varying levels and kinds, which have helped give impetus to technology transfer and raised the international status of the technology park and the firms established there. Similarly, the PTA has for a number of years taken part in national and international technology networks to build up strong links with other agents (firms, institutions, technology parks, government agencies, etc.) involved in technology transfer. Among these co-operative networks we may mention:

The International Association of Science Parks (IASP), founded in Sophia Antipolis, France, in 1984 to provide an international forum for the parks. It currently has a membership of 206 parks across 45 countries, containing over 40,000 firms and some 1,000 public or private technology $R \& D$ centres.

At the IASP General Assembly in Peking in September 1995, the Andalusian Technology Park was chosen as the Association's headquarters, making it an international reference point in technology and R\&D.

The PTA also belongs to the Association of Science and Technology Parks of Spain (APTE), made up of the country's 16 science and technology parks. They maintain collaborative links and contacts via the Association, established in 1988.

Another means of fostering business co-operation is IDEA, an association set up to promote and develop the PTA, encouraging relations between firms there and others outside. The members are firms with plots in the park, and others which, though not established there, may contribute to its development. Twenty-three outside firms, representing all the leading businesses in Málaga, belong to IDEA.

Business ties have already been established among the membership, in particular the contracting network which the PTA fostered through the creation of the Auxiliary Industry Technology Centre (CTIA), where small firms have set up which subcontract for larger ones such as Alcatel, Raytheon and Fujitsu.

IDEA seeks to stimulate competitiveness in firms in the Andalusian Community through the use of appropriate technology, inter-firm co-operation on technical, manufacturing and commercial matters, looking for shared advantages, complementarity and synergies that will enable firms to enhance their position on more and more global markets. 
Agreements have further been concluded with Oulu Park in Finland, Innotech in Hungary, the Brussels Science Park, the Nanking Park in China and the Santa Fe Park in Argentina, and with the Bolívar Programme, to stimulate relations with firms established there.

\section{Conclusions}

Information technology has transformed the worldwide economic landscape and firms need to adjust to these changes.

Global markets and the Internet are now meeting points in this new landscape for business, and will become increasingly important in the future.

Technology parks are infrastructures contributing to the economic development of their environment and a significant driving force in development itself. The processes of accumulating and disseminating technology are at the heart of their activity, and the parks assist business co-operation to enable firms to interact with global markets.

In addition, technology parks are increasingly relevant in backward economic regions, odd though this may seem at first sight. If firms are economically backward, they do not readily embrace technological advances. The example of the Andalusian Technology Park shows the way towards a new form of economic and technological development in backward regions.

The first stage in the project, establishing the park, calls for political and social initiative and funding to get it off the ground. The second stage, drawing in innovative capacity, has to rely strongly on local potential, rather than attracting firms from outside the region. The third and fourth stages are more complex, since the right approaches and attitudes are needed in the park's environment to launch dissemination and transfers of technology. It is no simple matter to make the environment receptive, but if it can be done, the results will be striking. 


\section{Bibliography}

ROMERA, F. (1998): "De Palo Alto a El Palo", Málaga Digital.

ROMERA, F. (1998): "Technocells". Delivering Innovation, pp. 93-119, IASP.

ROMERA, F. (1998): "Science Parks: The Engine for Growth", Proceedings of the XV IASP Conference on Science and Technology Parks, pp. 570-589, Perth, Australia.

ROMERA, F. (1999): "Tecnoceldas". Gestión de Centros de Desarrollo e Innovación, pp. 17-32, Parque Tecnológico de Andalucía, Málaga.

ROMERA, F. (1999): "El Parque Tecnológico de Andalucía (PTA) como foco del desarrollo regional y de la cooperación interregional". Gestión de Centros de Desarrollo e Innovación, pp. 85-103, Parque Tecnológico de Andalucía, Málaga.

ROMERA, F. (1999): "The Association of Science and Technology Parks of Spain", Proceedings of the IASP European Conference on Science and Technology Parks, pp. 292-298, IASP Málaga. 



\section{The Role of Information and Communication Technology in Local Development: Prospective Analysis of the Case of the lle de France Region}

Alain Rallet

IRIS, Université de Paris Dauphine

\section{Introduction}

In an information economy and society it is natural that information and communication technology (ICT) should become an instrument of local and regional development through information flows, just as transport has long assisted development by means of physical flows -- though the manner in which ICT can become a tool of development is less clear. The aim of this paper is to help clarify this question by examining the situation in the French regions and more particularly the lle de France region, which is one of the world's great metropolitan areas. Some of the conclusions reached will be specific to that region, while others are also applicable to other types of region.

I propose to begin with a brief history of the ICT issue in France (Section 2). I shall next discuss the need to identify the effects of ICT on the location of activities so as to be able to shape a local development policy using ICT as an instrument (Section 3). On that basis I shall then consider the place of ICT in the development of the lle de France region (Section 4).

Given that the effects of the information revolution are more ahead of us than behind us, my analysis is essentially prospective. Using already existing elements as a frame of reference, it offers some policy-relevant conjectures on future developments.

\section{ICT and local authorities in France}

The interest of French local authorities in ICT started in the mid-1980s. 
This was the time when decentralisation gave them powers they would seek to apply to many fields. The same period saw the spread of cable technology and the adoption of the Plan Câble at national level.

Two main stages can be identified: the stage of pioneering and demonstration effects, and the stage of opening-up to competition (Rallet, 1994; Musso and Rallet, 1995).

\subsection{Pioneering and demonstration effects}

First the local authorities, along with households and businesses, went through a phase of discovering the new technologies. They practised them by developing numerous experiments in which ICT was put on display as much as it was used (multimedia centres, etc.).

Local authorities set out to perform two complementary functions. The first was to familiarise the population with these technologies and initiate learning processes. The second was to exhibit a symbol of technological modernity, with ICT symbolising the modern world and also being the way to become part of it.

In this latter context it should be remembered that local authorities had to convey a positive image now that decentralisation had in effect made them competitors. They strove to outdo one another in modernity and adopted demonstrative technological projects. This strategy had positive effects. First, it changed the negative image of certain areas: industrial restructuring areas (Roubaix), rural areas, semi-rural areas (Futuroscope), regions and towns determined to become new eldorados of development (Montpellier, Languedoc-Roussillon), towns and regions with international status (lle de France). Second, it brought local economic and intellectual resources to a development project by mobilising a small nucleus of actors (government, local authority, local representative of the public operator, engineers and researchers in the speciality or heavy users of ICT, firms wishing to enter the networks market and adopting a strategic stance, local associations for technological or cultural outreach, etc.). ICT had the advantage of structuring a small local technocratic society buoyed by the political ambition of a mayor or the president of a regional council.

The demonstration phase is not over and can never be inasmuch as technological progress is constantly creating a new source of demonstration 
effects -- e.g. the Internet replaces the fax. Advertising new technology is an unceasing function. But this is no longer enough to constitute a policy. It is necessary to move on from the symbol to the reality, from the technology showcase to the introduction of development processes based on the use of ICT. This is the present stage.

\subsection{Deregulation and use of ICT as a development tool by local authori- ties}

If local authorities used ICT purely as a showcase for such a long time it was essentially because they had no real power to do otherwise, given France Telecom's monopoly of telecommunications. It was not possible to obtain advantageous pricing conditions for the locality. Furthermore, local negotiations with the regional directorate of the public operator led back very quickly to the national level, with the result that any attempt to establish regional networks through one or more regional agencies was taken over by the national operator. Regional networks were thus a subset of a national operation, as in the case of RENATER.

When the telecommunications sector was opened up to competition, local authorities found they had more scope for equipping their territories with communication infrastructures and services. For one thing, they can now use competition between operators in order to influence the development of infrastructures and secure compliance with a certain number of conditions, being administrators of public property. For another, they are now tempted to become operators themselves (local loops), given that competing operators develop market skimming strategies that may leave aside certain areas and even entire towns.

As yet the telecommunications authority ART (Agence de Régulation des Télécommunications) does not grant a licence to operate a public network to local authorities, deeming that this is not within their field of competence. Recently a court ruling was given against the town of Nancy for attempting to open an optical fibre loop. However, there is a real risk of inequalities between areas, particularly for high-speed networks. This is a problem of area development not resolved by the current definition of universal service, which is restricted to the telephone.

Investment in high-speed networks admittedly represents a risk for local authorities insofar as the returns are uncertain. In the first place there is 
no guarantee that there will be sufficient need for multimedia services in the areas concerned to make the infrastructure cost-effective, which means that it might revert to the status of technological symbol. But most importantly, technology is evolving so rapidly that choices made at time $t$ are liable to be no longer the right ones at time $\mathrm{t}+\mathrm{n}$. No one knows today whether multimedia programmes will be delivered in future by cable or by telephone (with the ADSL technology). A specialised operator can hedge by developing a portfolio of alternative technologies, whereas local authority investment is irreversible.

More generally, the introduction of ICT as a tool of local development is not fundamentally a problem of infrastructure, even though local authorities are instinctively inclined to think it is. It may be a problem of area development policy, as suggested earlier. This, however, could be quite easily resolved with an expanded definition of universal service and also with technological progress, which as it increases the number of alternative technologies (telephone, cable, optical fibre, radio, satellite, etc.) will greatly reduce the areas of uncertainty.

The problem is rather to anticipate economic impacts on the location of activities and populations as a guide to local development policy.

\section{Impact of ICT on the location of activities}

There are three types of ICT impact on the location of activities and jobs, or perhaps it would be truer to say three broad issues related to these impacts. Relocation of activity was the first issue to emerge. It is a subject of public debate, but its implications are limited. The other two are more interesting, although less central to the debate. One is the creation of new activities from the prospects offered by the new means of telecommunication. The second is the impact of telecommunications on the co-ordination of activities already located at a distance.

\subsection{ICT and relocation of activities}

This concerns teleworking (or telecommuting) and relocation. Existing activities and jobs may be relocated through the use of ICT, for the purpose of reducing transport costs, land and building costs or wage costs.

Teleworking and relocation of service activities pose different pro- 
blems.

\section{* Teleworking: limited prospects at present}

To avoid any misunderstanding of the term "teleworking" it is important to distinguish between teleservice provision and distance networking. Teleworking in the strict sense of the term is a method of work organisation that allows tasks formerly performed on-site to be performed off-site. Teleservices imply a market relationship between the service provider and the recipient and thus fall outside the sphere of paid work. Distance networking concerns individuals or units that are already separated geographically and that co-ordinate to perform work together.

These two categories of activities will be discussed later (see 3.3 and 3.4). "Road warriors" are likewise excluded from my definition of teleworking. These workers (sales engineers, maintenance technicians, reps, lorry drivers, certain own-account workers, etc.) were already itinerant before the use of sophisticated communication technologies in their trade. These technologies may change the way they perform their work but they do not change its location.

With regard to teleworking, the question for the future is this. Must we expect a geographical fragmentation of today's collective workplaces?

It is necessary to be very cautious on this point and not confuse technical potentialities with economic and social possibilities. Technically it is possible, and will become increasingly so, to organise and control teleworking thanks to ICT. To do this it will be sufficient to adopt methods of work organization and control, compatible with the geographical remoteness of individuals.

Yet there are a number of economic and social obstacles to the development of teleworking:

- Employee resistance. Employees fear to be too far away from the places of decision-making at a time when employment is very insecure. And, in our societies, the workplace is the essential locus of socialisation.

- Employers themselves are disinclined. As they see it, the immediate disadvantages of teleworking outweigh the hypothetical advantages. They would have to change work patterns and adopt new management methods. There are no obvious advantages in terms of productivity, the argument of saving workspace being valid only for firms located in inner city areas. 
The existence of these obstacles suggests that the development of teleworking (a) must permit the maintenance of a collective workplace (alternation between office and home or the telecentre solution) and (b) allows only limited remoteness. Co-ordination from a distance is possible only if frequent contacts serve to solve the inevitable problems of interaction. The greater the amount of remote co-ordination, the more often, it is necessary to meet.

For this reason, teleworking will develop largely in the geographically limited context of an intra-urban or peri-urban fragmentation of a number of workplaces, on the edges of towns or close to regional transport nodes. In other words, there is not much prospect of developing telework units in peripheral or rural areas. By contrast, the development of teleworking in a central region like lle de France is more credible. It could take the form of employees working part of the time at home or working in telecentres near their homes and close to transport nodes to facilitate mobility.

Home-based working would seem to be reserved for certain occupations already practised partly at home (journalism, consultancy, teaching, publishing) and certain limited categories of employees (persons wishing to work at home for family reasons). It is therefore unlikely to develop on a very large scale.

Telecentres, on the other hand, have a real potential. Surveys show that a number of employers and employees are interested in a workplace location closer to home, which would reduce the expenses and fatigue connected with travel, as well as real estate costs for businesses. But since there is no real incentive today for employers and employees to adopt teleworking, the situation is unlikely to change until such time as the authorities take drastic measures to reduce motor traffic in metropolitan areas. If such measures were taken, this could open up a property market for telecentres, which in theory would concern areas high dwelling and low job density.

* Relocation of service activities: more downsizing than relocation

The late 1980s were to bring the threat of mass relocations of service activities to countries or regions with lower wage costs.

First of all it should be pointed out that relocation is nothing new. Already in the 1970s many Paris-based banks had set up their data processing centres in the provinces and, in the case of decentralised banks like the Crédit Agricole, outside the regional centre. 
Moreover, there are at least two reasons why the prospect of relocation should not be overestimated:

1. Information and communication technologies automate the data capture and processing tasks that are the easiest to shift. In some cases these tasks are passed on to users, as in the case of bank customers who record their transactions and manage their own accounts. Automation and decentralisation of information processing thus make it pointless to relocate low-skilled tasks. Rather than fear that mass data processing activities will be relocated, it is necessary to prepare for their being phased out. The big difference between the service economy at this point and the era of industrial decentralisation is that low-skilled tasks are not likely to be relocated but rather to disappear.

2. Many service activities are not just informational. They are also interactional in the sense that they are characterised by the intensity and frequency of relations between individuals. These activities, which have a high value added, cannot be relocated. On the contrary, they are becoming more and more concentrated. Telecommunications, for example, have helped to make the world's financial flows converge on just a few marketplaces.

The risk of relocation therefore seems confined to certain types of activity, more specifically:

- Activities involving medium-skilled work. This work is more difficult to automate. Moreover, it does not necessitate close interactions inasmuch as it rests on a precise division of tasks. The example most frequently cited is data communications.

- Geographically extensive activities in which time zone differences permit continuous work. This necessarily applies only to intangible activities. Data communications are again frequently cited.

In total, possibilities of service relocation exist, but they have been considerably overestimated. A more important concern is the inevitable reduction of the central staff of the major private and public establishments, and certainly a downsizing of the large workforce assigned to routine data entry and processing. For the lle de France region this is a real challenge, given the overwhelming presence of central government departments and company headquarters. 


\subsection{ICT and the creation of new activities}

The spatial impact of ICT is often discussed in terms of relocation of activities, whereas it is more a question of the activities that can be created as a result of ICT. These activities are of two kinds.

a) Activities directly related to the supply of new information and communication technologies

This concerns the production of hardware, content (server platforms, software, CD-ROMs, video games, etc.) and services (technology and organisation consultancy, installation and maintenance, product distribution, etc.).

These are very buoyant markets with over $10 \%$ annual growth and generating fairly high-skilled jobs. The question of where these activities are going to be located is therefore very important. In this regard, they can be divided into two sub-groups:

- The first comprises activities dependent on an earlier specialisation and/or an R\&D potential in that field. They depend on a complex system of competencies already acquired, actors already installed and a start-up momentum. The location of these activities is highly constrained and confined to a few centres of worldwide importance. Silicon Valley comes to mind, of course, but also a region like lle de France, which has the competencies and R\&D potential to fill specific niches in the new markets (high-speed switching, voice recognition, groupware, computer graphics, etc.). The problem here is already well known. First there has to be a system of financing suited to the development of technological innovations (venture capital, seed money). Second, the $R \& D$ potential has to be given commercial value (the case not only with small businesses but also with big centres like CNET). It is now necessary to reason in terms of the region as a whole with a network of competencies and initiatives, for international prominence is at stake.

- The second sub-group consists of activities less dependent on specialisation and competencies acquired earlier. The majority of service activities fall into this category.

First there are the consultancy activities linked with the dissemination and use of the new technologies (services for speedy installation, advice to users, training, quality hotlines, and so on). Absence of such services hampers the spread of ICT. Their development, which is vital, is a gauge of the ICT momentum of a locality or region. 
Next there are the intermediary services. Contrary to a naïve belief that telecommunications will establish direct contact between suppliers and purchasers or between service providers and users, thus constituting a vast electronic marketplace without middlemen, the new technologies presuppose the presence of intermediaries to make them operate effectively. Access to world information implies that intermediaries collect and process that information so as to present it in a selective and refined form. Human intelligence alone is not enough for this purpose. So one can expect to see a marked growth of functions related to information collection and processing. These are typically central area activities, since they presuppose numerous contacts between client (businesses) and information gatherer. They have been developing very rapidly in Manhattan over the past two or three years.

b) Finally, and linked with the preceding type of activity, there are the fast-developing information publishing services.

Unlike the activities closely linked to technological innovation and having a high R\&D potential, these service activities are not heavily dependent on historic advantages, at least to begin with. Their development depends largely on a local climate that favours the use of information and communication technologies. A "switched-on" township can, through its emphasis on use of the new technologies, encourage the development of these emerging services. The question of their location is still comparatively open, since they are only at the beginning of their development path. But once the services have appeared, the advantages will go to the first mover, since self-reinforcing mechanisms will be established and produce irreversible effects that will make it more difficult for those services to penetrate the markets of towns and regions which have lagged behind at the outset. There are opportunities to be seized here through a proactive local or regional policy.

\subsubsection{Teleservice supply}

Teleservices fall into two categories. There are the services which were formerly delivered on the spot (building surveillance, retailing, teaching) and are now performed from a distance (remote surveillance, teleshopping, distance education, telemedicine). And there are the services that used to be performed in-house and have now been outsourced (secretarial services).

Two points need to be made regarding the location of these services. 
First, a service is never totally dematerialised by ICT. The virtual is not a substitute for the physical, as some like to think, but complementary to it. For example, remote building surveillance presupposes the existence of teams ready to intervene and therefore located not far from the buildings concerned. The same applies to the purchase of material goods: electronic commerce requires physical transport logistics. As for intangible services, many can be performed only on a face-to-face basis (e.g. education, healthcare). The fact that the physical and virtual worlds are complementary has implications for the location of activities. It implies the maintenance of geographical proximity (onsite competencies) and/or ready accessibility of the place where the service is delivered and therefore the existence of good transport facilities. Teleservices are not footloose. This applies both to their production (educational and medical human resources are located in metropolitan areas) and to their distribution (necessity of on-the-spot resources and easy accessibility). It is therefore not so much the location that will change as the nature of what is located there: the service will be designed from a distance and delivered on the spot. As regards service design, central areas will be the natural choice. Where service delivery is concerned, adjustments may be expected. Commercial infrastructures will certainly evolve by concentrating on functions that cannot be performed electronically: recreational activities, for example, will be increasingly associated with shopping, a trend that has already begun.

Second, ICT is making it possible to develop new patterns of spatial organization of services. Service production and consumption can now be separated geographically to some extent, whereas formerly they occurred on the same site. A service is designed and produced centrally, then distributed by mobile agents who deliver it locally themselves or through intermediaries. The new technologies enable these agents to access centralised resources at any time, while remaining in contact with local customers. Yet this does not alter the existing patterns of location as such: the central places remain central and the location of customers does not change. One notable development, however, is that service users no longer need to go to the agency in the nearest town, the agency comes to them. Service distribution, which used to be solely by way of fixed physical infrastructures, will now also be effected through mobile structures underpinned by fixed local bases, rather in the manner that the postman delivers mail from a post office. The mobile part of agency structures can thus be expected to increase. 


\subsection{ICT and the development of distance networking}

Information and communication technologies do more than serve to move activities from one place to another or to underpin new activities. They also serve to develop distance co-ordination between units or individuals already separated geographically. In the latter case, locations are unchanged but the flows between locations intensify and the spatial division of labour may alter -- leading, for example, to greater specialisation of localised units.

The development of distance networking is the most overlooked of the spatial effects of ICT, being the least spectacular since the physical locations do not change. But it is just as important as the others.

From the standpoint of location dynamics, there are two aspects to be considered.

1. By enabling localised activities to increase the possibilities and efficiency of distance co-ordination, ICT will reinforce existing spatial patterns. More particularly, it will increase polarisation, i.e. the concentration of flows between the present economic poles. As an example, the electronization of financial flows has reinforced the position of the world's leading financial centres. The explanation is simple: ICT permits the concentration of flows on the places with the most resources and competencies. In an economy that has been made technically more footloose it is the most developed regions and towns that benefit economically. Here the effect is the same as that produced by lower transport costs: lowering of the physical barriers to movement stimulates competition and benefits the most efficient sites. Geographic concentration increases as communication costs decrease. This effect is counter-intuitive: ICT increases the concentration of activities, whereas one would expect activities to be able to be performed anywhere. There is a disconnection here between the economic effects and the potential technological effects.

Central regions like lle de France should benefit accordingly. Ile de France has a technological and economic potential that will be enhanced by the capacity to develop distance relations with other central areas.

2. The development of distance networking presupposes ready accessibility of the sites co-ordinated in this way. It must be remembered that telecommunications do not replace physical movement. The greater the amount of distance communication, the more the communicators need to meet. Plane or train tickets are often the main item of expenditure in distance co-operation. Telecommunications and rapid transport modes are thus the two complemen- 
tary underpinnings of distance networking. But while telecommunications make it possible theoretically to communicate from any part of the territory, the same does not apply to rapid transport infrastructures, which are highly discriminatory in their coverage. Hence the need to travel induced by the requirements of distance co-ordination lends great value to the points of access to rapid transport networks and especially their nodes. The lle de France region is very favoured in this regard, on both the national and international levels.

Distance networking thus exerts a polarising influence by way of two factors associated with the development of this type of co-ordination through ICT: increased competition between geographic areas due to ease of communication -- competition which benefits those areas with a high concentration of resources and competencies -- and the role played by rapid transport infrastructures in distance co-ordination.

The lle de France region is well placed as regards these two factors and should therefore be one of the areas to benefit most from the development of distance co-ordination.

\section{ICT, location dynamics and development of de lle de France region}

I now propose to consider the effects of ICT on activity location in relation to the two main characteristics of a central region like lle de France:

- the need to strengthen its international position; and

- resolution of the problems connected with its internal spatial organisation.

\subsection{ICT and the international position of Ile de France}

There are three factors that should help to strengthen the international (and national) position of the lle de France region.

First, the region has the resources (research potential, competencies, know-how) necessary for the development of new activities linked with information and communication technologies: production of software and content, provision of teleservices (finance, education, healthcare), technological innovations in hardware. These resources are located in the central area or in spe- 
cialised areas (distribution of $R \& D$ jobs). It is probable that the knowledge underpinning the new activities will not change its location. Even so, these resources have to be mobilised (enhancement of research potential, innovation financing capacity, scope for actors in bureaucratic environments such as education and healthcare, etc.).

Second, the region has the necessary resources for the siting of activities using information and communication technologies. As already emphasised, the more activities become informational and performable from a distance, the more their location will be determined by the factors of co-location: namely, density of the professional community and diversity of the resources on hand. In other words, the more an activity becomes technically footloose, the more its location is economically determined by the competencies that towns and regions offer. Since these competencies are very unevenly distributed, the development of ICT will increase the geographic polarisation of activities. Given the diversity of the resources it offers, the lle de France region is very well placed to benefit from this polarisation effect.

Third, lle de France possesses rapid transport infrastructures, which, in the telecommunications era, constitute an essential factor of location. Possession of these infrastructures is absolutely necessary in order to develop distance co-ordination, which implies frequent travel. And the lle de France region has a good transport network, both in regards its national and international links and where its internal structuring is concerned.

Thus the region is well placed to benefit "naturally" from the development prospects offered by ICT and strengthen its position.

The question then is what could prevent it from doing so. There are no problems with regards to the supply of telecommunication infrastructures and services. Now that the telecommunications sector has been opened up, prices are becoming internationally competitive and a rapid response in terms of capacity (speeds) and services can be given to any request made. Specialised operators cater for the economic actors with telecommunication-intensive needs (e.g. La Défense local loop). As regards to the other actors, the present networks are mostly under-utilised (e.g. the Numéris network of France Telecom).

There are, however, two areas of policy concern:

- Operation of the region's public services (education, healthcare, research) requires high- and medium-speed networks. As in the United 
States, there is a case for an Internet II to relieve the congestion of the present Internet network. This raises the question of the future of the Renater regional networks. But technology is advancing so swiftly that caution should be exercised on the question of investing in new infrastructures (note the very rapid progress in data compression techniques with the arrival of ADSL technology on the market).

- The momentum of activities linked with the new communication technologies depends partly on the ability of local and regional authorities to mobilise stakeholders and facilitate the learning processes. If a township or region shows initiative here, this will undoubtedly favour use of the new technologies and the emergence of new activities. As stated earlier, those communities will have the advantage of being the first movers. There is some uncertainty about which areas of the lle de France region will be the most dynamic.

The region is well placed to benefit from the effects of telecommunications polarisation, provided that it solves the induced transport problems.

There is every reason to expect that the intensive use of telecommunications will result, paradoxically, in increased mobility of individuals. Telecommunications promote mobility both directly and indirectly: directly, because they make mobile workers more mobile and increase the number of telecommuters; indirectly, because they interact with transport (see above). Thus, contrary to the spontaneous impression that telecommunications reduce travel, people's mobility must be expected to increase (just as the development of logistics has increased product flows in the case of just-in-time production). This may cause problems of congestion that limit the polarisation effects induced by telecommunication. In such a situation and if drastic measures were taken to reduce motor traffic, teleworking might develop in collective and possibly shared workplaces located close to residential areas or transport nodes.

\subsection{ICT and intra-regional distribution of activities}

Since $80 \%$ of regional employment is in the tertiary sector, the remarks that follow apply essentially to services. But there are considerations for industry too.

In the case of services, there is every reason to expect a steep reduction in back office personnel (file processing). Despite the fact that computeri- 
sation began more than 20 years ago, this downsizing has not yet taken place, but it will in both the private and public sectors. In the private sector, especially banking, the arrival of competition is making cost cuts essential. French banks, which have lower profit ratios than their foreign counterparts, have embarked on downsizing policies, and mutual insurance companies are likely to do the same. In the public sector, the modernisation programme now under way will ultimately result in staff cuts in central government departments.

The reduction in back office personnel will not necessarily mean an overall decrease in the business and government workforce but certainly a new spatial distribution. In the banking and insurance sector, the first wave of computerisation in the 1960s and 1970s brought the establishment of information processing centres in peripheral areas or even in the provinces, with headquarters remaining in the central area. The staff of these back office units and more generally those of all the support facilities will be cut back and large numbers returned to the central offices, which have seen a steep reduction in their management personnel. At the same time, the workforce share assigned to front office activities, i.e. agency work and telecommuting, will increase. The result will be a workforce distribution less independent of the distribution of population and activities. This could establish a pattern of distributed centralisation (location of certain resources and competencies in the centre, but with a small workforce, and assignment of the larger share of personnel to customer service). The peripheral areas to which functional units were relocated in the 1970s are liable to suffer most because of transport problems.

With regards to industry, we are witnessing increased functional specialisation of space. ICT enables a business to operate as a quasi site when it is geographically spread over several establishments. Functions hitherto performed on the same site will be divided among different locations. This is now the case with distribution centres, which tend to be separated from administrative headquarters. Each function is seeking its optimal location (the headquarters in the central area, the distribution centre close to a transport node), which will be linked to the other locations by telecommunication and thus have the benefit of pooled resources. However, since adjustments between functions imply frequent interactions, the business units have to be not too far apart in distance or else easily accessible. Only then can the whole organization operate as a quasi site. Greater functional specialisation within regions is therefore to be expected, again with attendant problems with regards to transport. 


\section{Conclusion}

A number of conclusions can be reached regarding the role of ICT in local and regional development and the relevant policy settings that would be desirable. The last part of this paper now presents the conclusions applicable to local authorities as a whole, those concerning the lle de France region having been set out earlier.

Authorities need to shift their policy focus from infrastructure supply to support for ICT use and the provision of services to the local economy. The question of infrastructures may arise in the context of area development but it can be resolved through negotiations with private operators or with national and European bodies (definition of universal service content). On the other hand, significant differences between territories may emerge and widen if the authorities concerned do not give the same degree of priority to the development of uses and services. Similarly, the problem of inequality of ICT access relates less to equipment than to uses and learning capacity, less to talk lines than to education.

The impact of ICT on the local economy is too often considered in terms of relocation of existing activities, whereas the major spatial impact of ICT is the creation of new activities. Here too, irreversible differences may develop between territories because of unequal momentum. This point is linked to the previous one: if uses are not encouraged and learning processes supported, there will be no favourable environment for the creation of activities.

With ICT it is possible to achieve a more rational organization of activities and the population and, in particular, to relieve congestion. But it must be remembered that use of ICT necessarily makes people more mobile (more telecommuters and road warriors, more frequent need to travel). Contrary to general expectation, additional problems of transport and congestion may result.

ICT should make it possible to "open up" local development policies. These focus principally on the development of local synergies. But given the greater ease of distance communication and travel, local development policies must also support the capacity of local actors to establish distant connections. Information and communication technologies are creating a new space pattern of societal co-ordination. 


\section{Bibliography}

MUSSO P. (dir.) (1994), Communiquer demain, La Tour d'Aigues, DATAR Éditions de l'Aube.

MUSSO O. and RALLET A. (dir.), Stratégies de communication et territoires, L'Harmattan.

OFFNER J-M. and PUMAIN D. (dir.), Réseaux et territoires, La Tour d'Aigues, Éditions de l'Aube.

RALLET A. (1994), Télécommunications et stratégies de développement local : du rôle des collectivités locales à la politique de la CEE, (in collaboration with E. Négrier), Research report to DATAR, 150 pp., September 1994.

ROWE F. and VELTZ P. (dir.) (1991), Entreprises et territoires en réseaux, Presses de l'École Nationale des Ponts et Chaussées.

SAVY M. and VELTZ P. (dir.) (1995), Économie globale et réinvention du local, La Tour d'Aigues, DATAR - Éditions de l'Aube. 



\section{Information and Communication Technologies and Regional Development: The Challenges of Creativity and Identity}

Thierry Bruhat

Consultant

\section{Introduction}

We shall show how, starting from the example of new French science park strategies, how information and communication technologies (ICTs) can contribute to original territorial policies aimed at promoting creativity and economic and social innovation. These new policies are based on the implementation of learning processes which the towns involved hope will strengthen their territorial identity while upholding their competitive position in the context of globalisation-related trade.

\section{Lyon: promoting intelligence}

On the initiative of its chairman, Raymond Barre, the Lyon urban community published on 25 May 1998 its action plan for a "technology-oriented town". The object of the plan, which extends and expands on a policy launched some 15 years ago, is to involve all scientists, businessmen, and technology-transfer bodies in a collective movement aimed mainly at creating and developing innovative activities. Its declared ambition is to promote poles of excellence for the coming century, but above all it is to help the economic and social system to regain control over scientific and technological development in terms of challenges specific to it. Lastly, and it is a sign of the times, it makes town planning (the setting, infrastructure) subservient to the project and not a precondition thereof. The plan is one of the three components of a global strategy for the development of Lyon in the 3rd millennium, which is called the "town of intelligence". The other two are the development of information and communication technologies (ICTs) and the development of culture. 
This strategic thinking by the town of Lyon derived from the recognition, on the part of its elected representatives, of the difficulties involved in bringing to the fore economic projects of scientific and technological origin which were visible on the international scene, while at the same time mixing in the existing (and very varied) themes and attracting high-level thinkers from outside.

Lyon, town of intelligence, rests on a twofold wager consisting, first, of successfully meshing innovation, culture and ICT so as to nurture original forms of competency polls recognized internationally and, second, enabling people (researchers, entrepreneurs...citizens) rather than institutions to appropriate activity-creating projects. Some of these projects, subsequently supported by the local authorities, will trigger cross-fertilisation processes that will help to structure new competency poles in the metropolitan area.

In the desired interaction, therefore, between economic innovation and culture, it is not just a matter of placing the emphasis on the economic developments expected to derive from ICTs which already exist and will continue to grow but above all of seeing them as furthering the creation of economic, social and cultural activities specific to the possibilities offered by the town of Lyon with a view to creating competency poles.

One of the competency poles to which Lyon has subscribed is that of the sciences and technologies of the living and of health. Lyon is home to the second most important teaching hospital in France. The Hospices Civils de Lyon (HCL) consist of 18 establishments with 7,000 beds. 2,500 doctors and 16,000 non-medical staff work there. The HCL give 850,000 consultations per year and cater for 1.5 million inhabitants ${ }^{1}$. Then again, on the industrial front, the pharmaceuticals sector in Lyon is made up of groups with global strategies which gauge the economic and scientific importance of Lyon by the yardstick of the output of the major research centres and world markets, even if they also see it as a place of origin (the Institut Mérieux founded in 1897 by Marcel Mérieux Bio-Mérieux, Boiron, Aguettant, Lipha...). This particular sector of activity, which accounts for some 10,000 jobs, is in contact with materials, fine chemicals, computer and service companies together forming a sort of nebula of activities.

Everyone senses that the health sector is going to change radically over the coming decades as a result of new practices, new products and the 
widespread use of information systems by all the players in the system. Also, the public/private demarcation is going to move; it may reasonably be expected that the energy (time and money) that people devote to health is going to increase, but that the nature of benefits is going to change. Products and services, for example, are going to develop to the detriment of specific systems of the hospital variety. Already, the facilities management market in health care is expanding and certain logistical and service functions are being contracted out.

What Lyon wants to do is to encourage the development of new health practices and new types of relationships between health-care centres, clinical research activities, $R \& D$ companies and the population. Information and communication technologies are going to be at the heart of this meshing relayed by networks, programmes and services. On the urban front, the civil hospices in the 3rd and 8th arrondissements of Lyon and in Bron provide the urban community of Lyon with an opportunity to give a completely new reality to the "biotic" town concept by demonstrating its scientific, economic, social and urban dimensions. This will not be achieved just by concentrating activities, but by encouraging creativity in all the components of the activities park, from new medical practices to gene therapy, from food safety to environmental technologies, etc. In addition, promoting Lyon's considerable medical heritage, including two museums of the history of medicine, should allow this modernity to be firmly rooted in local culture and history.

As far as implementing this policy goes, the original feature lies in applying a method of project engineering that allows scientific, economic and institutional players to be involved in carrying out various projects: new training and research programmes, start-ups, promotional events, etc. This method embodies a form of learning through action, which concerns all the economic players as well as government officials.

\section{Rennes Atalante, Utopia for $\mathbf{2 0 1 5}$}

Rennes Atalante is one of Europe's best-known science and technology parks. In a town of 350,000 inhabitants, some 4,000 private-sector jobs and nearly 140 firms have been created in the space of 15 years, mainly in information technologies. The science and technology park was conducive to the creation of an industrial environment centred on the Centre Commun d'Etudes sur les Transmissions et les Télécommunications (CCETT). The Centre's specialities, image processing and telecommunications, radio trans- 
missions and on-line services have become the same as those of the park. The development of training courses for telecommunications engineers in schools and at the university (IFSIC) is now really enhancing the park's attractiveness.

Rennes Atalante was set up in 1984 on the basis of the science park model, two such parks existing in France at the time: Sophia Antipolis and the Meylan Zirst near Grenoble. The context has changed, however, and even if the science park has adapted over time, those in charge were anxious to mobilise the local economic and scientific community with the object of identifying a new, prospective strategy ${ }^{2}$ for the next fifteen years.

In terms of information and communication technologies, the Rennes Atalante science park is recognized for its competencies. The object of the research pursued was to use the analytical capacities mobilised to determine the long-term future of the park. Everyone realizes that the activities, which ensured the park's success in the past are not going to guarantee its future. Whether in plant and equipment or services, information and communication technologies are subject to constant waves of innovation. While these sweeping changes all represent opportunities, the options adopted now are going to be decisive as regards the permanence of an attractive and competitive centre for telecommunications activities in Rennes.

Also belonging to the past, however, is the government physical planning policy that allowed the core research equipment to be put in place, on the basis of which the science park developed its main competencies. In a country fond of major technological programmes ("Le colbertisme high tech"3), the management of technological development is going to require striking cultural, organizational and managerial change. It is not, for example, sufficient to announce that the future is going to be in networking equipment and competencies; one also has to say what for and how.

On the basis of these premises, the prospective analysis carried out by Atalante has produced three sets of suggestions for the future.

1. The notion of technological competency parks has to become less technological and more economic, closer to market innovations and the expert-

\footnotetext{
${ }^{2}$ By applying an original method of prospective analysis which has mobilised more than 160 people in eight months. The players involved having identified the emerging range of issues concerning technology-oriented development (i.e. the momentum of scientific, technological and economic creativity at the interface between research, business, higher education and the regions), the method translates these issues into actual projects which give concrete form to this new vision of local development.

${ }^{3}$ E. Cohen, Le colbertisme "high tech", Hachette, 1992.
} 
ise they require. Nowadays, wealth is more to do with intelligence and less with the actual product. These parks ought no longer to represent a concentration of research and higher education activities, but be the result of crossfertilisation processes which will give momentary form to a local, specific and competitive productive pole.

2. While spatial proximity is no longer a discriminating element where work is concerned, the concept of territory still holds good in at least two essential ways. First, the isotropy of work areas made possible by ICTs is going to increase the importance of quality of life in towns and their areas of influence. Nomadism does not seem to have to be a permanent way of life. Second, product innovation requires territories which sustain it through their capacity to bring the players in the corporate "innovation system" 4 into contact and make it more efficient. Where ICTs are concerned, local economies must not see themselves only as consumers of services and equipment, but also as incubators for new applications and new programmes.

3. The success of such strategies is dependent on the acquisition of new individual and collective competencies in such areas as the management of economic and technological information, marketing, mediation between research and business and, above all, entrepreneurship. The latter is a genuine skill, which only comes with experience. Despite having progressed to a remarkable degree, the academic system is not yet equipped to meet this new challenge of training through learning in action.

In view of these considerations, the science park is at present drawing up a project for a new competencies pole aimed at providing companies, researchers and users with a pool of telecommunications and multimedia equipment and services with which to test new economic and social needs. The plan is to include applications in electronic commerce, the developing and testing of new products, the infrastructure needed for multimedia developments and testing, a combination of cordless/terrestrial/satellite resources, a shop window for economic and social experimentation, etc.

It is an international project, which will provide researchers, companies and project promoters with equipment and services on the basis of elements specific to the bodies concerned, whether in terms of availability or cost. This sort of "platform" will require its own running in terms of both equipment and also the design and implementation of service-testing programmes that meet

${ }^{4}$ I.e. all the relationships between the functions of the company and its partners: suppliers, service providers, customers, etc. 
new economic and social needs.

Lastly, in both this example and that of the town of Lyon, one of the conditions governing success is the development of entrepreneurship. For the countries of the European Union, moreover, the development of a culture conducive to entrepreneurship is essential as was recommended by the working party convened by the Commission to discuss the theme of "Innovation, New Activities and Job Creation"5.

\section{The challenges of creativity and territorial identity}

In these two original strategies which assign a new meaning to the "technopolitan" concept, a number of challenges would appear decisive.

1. It is a matter, in the first place, of looking for a territorial economic identity, attaching preference to original forms of development on the basis of a better link between existing competencies (scientific, technological, business) and external competencies. This is neither a return to local development (globalisation being assumed), nor all-out technology, the driving force of the market in regards to innovation being recognised. Rather, it is a quest for an overall territorial identity based on developing the quality of a metropolitan area, not only in terms of its equipment but also the profusion of its projects, the creativity of its inhabitants and the quality of life which, moreover, brings together urban and rural territories.

2. In the expression "information and communication technologies", it is not the term technology that counts, but more especially the notions of information and communication. Technologies, as if it needed repeating, are mainly additional means of action which do not spare the need to think about the ultimate objectives. The multimedia revolution is a revolution in programmes. In both Lyon and Rennes, new programmes are needed to meet new economic, social and cultural needs. This does not mean that the local market is sufficient for their development; it facilitates their incubator and creation phases. It is in these phases that personal interaction is vital, and urban territories make such interaction easier.

3. Towns and local regions are put forward as areas in which these new development processes can take shape. As P. Veltz shows, it is the "rela-

\footnotetext{
${ }^{5}$ See Luxembourg Conference of 18th May 1998, EC-DG XIII.
} 
tional" character of the modern economy that constitutes the most important territorial tie ${ }^{6}$. These forms of development seek to benefit from the meshing and links between the variety of local skills and expertise, and also from their capacity to mobilise outside competencies at local level, which does not mean that the latter are obliged to relocate. In this connection, ICTs are essential.

4. These strategies derive from economic ambitions, on top of which come social, cultural and urban goals. One of the characteristics of the processes described is the mobilisation of cultural and historical resources and of qualities of "urbanness" as assets in developing a competitive position on the international scene. In this respect, the future of local technological development policies must surely lie as much in enhancing the competencies of universities specialising in human sciences as in favouring engineering schools. On the urban front, the programming of new areas in some cases the renewal of existing areas will be designed to promote such developments. Here, the quality of the area will take precedence over its scale.

5. Many of the competencies required to implement these strategies have still to be acquired and the means of acquiring them have yet to be found. On the one hand there is the entrepreneurial culture which has already been discussed, but in its global form ranging from the financial system, to young graduates and ultimately to government decision-makers: one can in fact be an entrepreneur for public projects. Second, there is the need to learn to manage activity-creating projects in an inter-institutional environment. This is what has been called project engineering. Finally, it is necessary to develop market analysis and trade negotiation skills in the above mentioned areas of technological innovation. These skills are lacking; however, the means of acquiring them are not, in the majority of cases, of an academic nature. Learning while being an entrepreneur implies a new institutional framework.

\section{What learning forms for government action?}

Although it now appears to be recognized that it is exchanges of ideas that drive local development, it has been empirically observed that dense exchanges do not happen automatically. While these new strategies are the product of chance movements, proactive policies are nevertheless needed because cross-fertilisation processes do not happen automatically. These poli-

${ }^{6}$ P. Veltz, "Les villes européennes dans l'économie mondiale", in Bagnasco A., Le Galès P. Villes en Europe, La Découverte, 1997, p. 60. 
cies are original.

"Programmed" cross-fertilisation is that which results from the activities of (at least one) player who really puts time and resources into taking advantage of the opportunities for co-operation that are available on a particular site or in a given territory. This means having a bold strategy, the results of which can usually be seen in co-operation projects involving companies, public research and educational establishments and local institutions ${ }^{7}$. In such cases, cross-fertilisation is designed from the outset to create new products as the outcome of exchanges of ideas. It is vital to establish the appraisal criteria at the time of conception. The aim and object is to increase programmed cross-fertilisation on the basis of well chosen incentives and action programmes, the latter being an essential component of "technopolitan" policies. In this area, as in others, the effectiveness of the policies depends on the quality of the management. However, the said management cannot be transposed from either the corporate world or the public domain. It has to be invented. It is a new job. It is reasonable to believe that project engineering methods will form part of these new competencies. Below are outlined some of the characteristics of these new forms of government action.

1. New methods of prospective analysis and strategic planning have to be invented. Is it only public officials who should be expected to produce new visions of future development? It would seem vital that the expertise of all local players be mobilised in formulating a collective ambition and a utopia. The utopian dimension of prospective analysis is essential ${ }^{8}$, determining the actual applicability of any policy. But prospective analysis without strategic guidance serves no purpose. The guidance of manageable action programmes has to take account of the need for these projects to be appropriated by the players involved. Similarly, appraisal of an action is not a matter of controlling a procedure, which is by definition experimental, but of steering it.

2. The very nature of local government action is changing. Its aim must be to facilitate appropriation and learning processes in projects involving people rather than institutions. It is on the degree of freedom of the people in the institutions that these strategies depend, the latter resulting ultimately in inter institutional processes. However, these changes require a very considerable learning effort on the part of government officials in that national and local public and quasi-public institutions nowadays have forms of organisation and

\footnotetext{
${ }^{7}$ See L. Tsipouri and T. Bruhat, report for the Conseil général des Alpes-Maritimes and the EC-DG XIII on a method of evaluating the development of Sophia Antipolis, 1996.

${ }^{8}$ Y. Barel, Prospective et analyse des systèmes, La Documentation Française, 1971, p. 134 et seq.
} 
cultures, which do not prepare them for the new forms of action required to implement these territorial strategies.

3. An area is judged according to its range of competencies, not so much on the basis of its equipment and infrastructure. Competency areas are looked upon by firms as components of the innovation process. And since it is generally known that new activities represent the main source of growth and jobs, the town component of the innovation economy is becoming a vital part of the process of change. Intangible investment is taking precedence over equipment investment; as for policy regarding financial assistance to firms, it seems less suitable, not that the latter refuse it but that they are more interested in receiving assistance in optimising flows and in raising their competency level. Against this background, while some capital equipment is necessary, it is more the sort of equipment that ensures mediation between new and old technologies, new and old forms of training, between research and development, etc.

\section{Conclusion}

While the concept of cross-fertilisation is central to the ambitions of French science and technology parks, it has to be recognized that results have not matched expectations as, moreover, in the other Community countries? This does not invalidate the science park function, however, quite the opposite. In an environment in which the players involved in technological development have multiplied, trade and the relations between companies and the competencies available in their environment are at the heart of the innovation process. Locally, there has to be strategic guidance of all of these systems and forms of expertise. What the researchers, entrepreneurs and government experts mobilised when these strategies were formulated in Lyon and Rennes expect of a "technopolitan" policy is that it should trigger fertilisation processes and projects, channel expertise in the light of emerging projects, inform government decision-makers about the new relationship of capital equipment and space vis-à-vis intangible issues, contribute ex post to the consistency of programmes and initiatives, and further the necessary process of cultural change. In fact, that it should give support to the structuring of a whole process of learning through action, but without organising it. The success of these policies will depend on their capacity to turn scientific, economic and social,

${ }^{9} \mathrm{~T}$. Bruhat, (under the guidance of) "Etude comparative des parcs scientifiques en Europe: enjeux pour une politique communautaire d'innovation", Report for EC-DG XIII, 1995. 
historical and territorial resources into competitive advantages within the context of globalisation. It will also hinge on the affirmation of a territorial identity and on the virtues of creative disorder and entrepreneurship.

\section{Bibliography}

E. Cohen, Le colbertisme "high tech", Hachette, 1992

Conferencia de Luxemburgo, del 18 de mayo de 1998, CE-DG XIII

P. Veltz, "Les villes européennes dans l'économie mondiale", en Bagnasco A., Le Galés P. Villes en Europe, La Découverte, 1997, pg. 60

L. Tsipouri y T. Bruhat, informe para el Conseil général des Alpes-Maritimes y la CE-DG XIII sobre un método de evaluación del desarrollo de Sophia Antipolis, 1996

Y. Barel, Prospective et analyse des sytèmes, La Documentation Française, 1971

T. Bruhat, "Etude comparative des pares scientifiques en Europe: enjeux pour une politique communautaire d'innovation", Informe para la CE-DG XIII, 1995 


\section{The East Gothia Regional System of Innovation: A Descriptive Pre-study}

Charles Edquist, François Texier, and Nina Widmark University of Linköping, Sweden

\section{Introduction}

Studies of the Swedish industrial structure have pointed to severe deficiencies with respect to product innovation (Edquist and McKelvey, 1994, Edquist and Texier, 1996). They show that:

1) So-called R\&D-intensive industrial sectors are crucial for industrial renewal and therefore for economic growth and job creation.

2) Sweden is not specialised in the production of high-tech products ${ }^{1}$ or growth products².

3) This has had some dramatic consequences for growth and employment in Swedish industry, with the loss of 125,000 industrial jobs between 1975 and 1991.

However, the studies mentioned were conducted at national level, and very little is known about product innovation and learning processes at regional levels.

This investigation is the first part of a more comprehensive study entitled "The East Gothia Regional System of Innovation Study". The "systems of

\footnotetext{
${ }^{1}$ Several definitions of high technology can be suggested; the most usual is to follow OECD recommendations and define high-tech sectors as industrial sectors investing more than a certain percentage of their turnover in R\&D activities. This results in the following sectors being classified as high-tech: ISIC 3522 Drugs and Medicine, ISIC 3825 Office and Computing Machinery, ISIC 383 Electric Machinery, ISIC 3845 Aircraft, ISIC 385 Professional Goods.

${ }^{2}$ Edquist and Texier (1996) identified what they called growth products by pointing out those sectors for which value added grew most rapidly in the OECD area as a whole between 1975 and 1991 . They are: ISIC 342 Printing and Publishing, ISIC 3522 Drugs and medicine, ISIC 356 Plastic Products n.e.c., ISIC 3825 Office and Computing Machinery, ISIC 3832 Radio, TV, and Communication Equipment, ISIC 3839 Electric Apparatus, and ISIC 3845 Aircraft. It may be noted that high-tech sectors and growth sectors are largely the same.
} 
innovation" approach focuses on the role of innovation in economic transformation and growth. This theoretical framework stresses the importance of the interdependence of organisations in an institutional context (Edquist, 1997a). The purpose of the project will be to study learning processes related to product innovations in the East Gothia Regional System of Innovation (EG-RIS). The EG-RIS study will have four parts (Edquist, 1996):

- A preliminary descriptive pre-study of the East Gothia region which emphasises variables of relevance for learning related to product innovation (the present study).

- An analysis of the region's competence base.

- Design of a questionnaire and a survey of learning and product innovation in the region.

- An analysis of the data collected and theoretical and policy conclusions.

This paper, which constitutes the first part of the EG-RIS study, focuses on actors, institutions and variables of specific relevance to learning processes and product innovation in East Gothia. It gathers relevant information and provides a general background for understanding learning processes and product innovation in the region. No attempt is made to present new data. The second section describes the structure of the region's manufacturing industry. It emphasises the role of high-technology industries for increasing employment and welfare in East Gothia. It focuses on two issues: R\&D-intensive sectors and level of technical education within firms.

Manufacturing industry accounts for one-fifth of East Gothia's employment. Nearly four-fifths of that employment is in the services sector, which is discussed in the third section. However, only a small part of services is con-sidered, as few data are available. However, there are some important interdependencies between high-tech manufacturing industries and specific services, e.g. consulting, software development and financial services.

The fourth and fifth sections focus on the university as the region's most important producer of knowledge and on other organisations that support product innovation and $R \& D$. The sixth section addresses the issue of regional institutions ${ }^{3}$.

\footnotetext{
${ }^{3}$ Institutions are here defined as "the rules of the game" in the interactions between organisations, as defined by North (1990) or Edquist and Jonsson (1997). They should not be confused with the actors or "players", which are here labelled organisations.
} 
Things are only large or small in comparative terms, so that the East Gothia region must be compared with other entities. For this reason, data on East Gothia presented here are compared with Swedish averages. Two cities, Linköping, where Linköping University is located, and Norrköping, are also specifically investigated. These are the largest cities in East Gothia.

\subsection{East Gothia: an overview}

Before presenting the industrial structure of East Gothia, it is useful to describe the region's general characteristics with respect to population, economic growth, employment, etc., in order to give the reader some background for the following analysis.

East Gothia is Sweden's fifth largest region, with a population of 416,443 in 1996 (SCB, 1996a). The rural population is more or less the same as in the rest of Sweden, at 16-17\% (SCB, 1996b). Linköping and Norrköping are of almost equal size and together account for $61 \%$ of East Gothia's population (SCB, 1996a).

In East Gothia, 173,961 persons were in the workforce in 1994 (SCB, 1994a). The working population can be classified in several ways. Table 1 shows the employment distribution between the private and the public sectors, and table 2 shows the employment distribution among agriculture, industry and services in 1994.

\begin{tabular}{|l|l|c|c|c|}
\hline \multicolumn{5}{|c|}{ TABLE 1: SHARE OF TOTAL EMPLOYMENT IN THE PRIVATE AND } \\
& Sweden & East Gothia & Linköping & Norrköping \\
\hline & $64 \%$ & $63 \%$ & $60 \%$ & $64 \%$ \\
\hline Private sector & $36 \%$ & $37 \%$ & $40 \%$ & $36 \%$ \\
\hline Public sector & Source: SCB, 1996a \\
\hline
\end{tabular}

\begin{tabular}{|c|c|c|c|c|}
\hline & Sweden & East Gothia & Linköping & Norrköping \\
\hline Agriculture & $2 \%$ & $3 \%$ & $2 \%$ & $2 \%$ \\
\hline Industry & $27 \%$ & $31 \%$ & $27 \%$ & $28 \%$ \\
\hline Services & $71 \%$ & $66 \%$ & $71 \%$ & $70 \%$ \\
\hline
\end{tabular}


As table 2 shows, Linköping's public sector employs a somewhat larger share of the working population than is the case for Sweden, East Gothia and Norrköping. This is owing to the presence of such public activities as Linköping University, the University hospital, the defence research organisation (FOA), etc. Table 2 shows that a smaller proportion of East Gothia's population is employed in services than the Swedish average. Linköping and Norrköping are, however, similar to the national average in this respect. Table 3 gives a more detailed breakdown of the working population for Sweden, East Gothia, Linköping and Norrköping.

\begin{tabular}{|l|c|c|c|c|}
\hline \multicolumn{5}{|c|}{ TABLE 3: SHARE OF TOTAL EMPLOYMENT PER INDUSTRIAL } \\
\hline & Sweden & East Gothia & Linköping & Norrköping \\
\hline Agriculture, forestry, etc. & $3 \%$ & $3 \%$ & $2 \%$ & $2 \%$ \\
\hline $\begin{array}{l}\text { Mining, manufacturing, etc. } \\
\text { Energy production, water }\end{array}$ & $19 \%$ & $25 \%$ & $21 \%$ & $22 \%$ \\
\hline Construction & $6 \%$ & $6 \%$ & $6 \%$ & $6 \%$ \\
\hline $\begin{array}{l}\text { Wholesale \& retail trade, } \\
\text { repair, transport, etc. }\end{array}$ & $20 \%$ & $16 \%$ & $15 \%$ & $20 \%$ \\
\hline $\begin{array}{l}\text { Financial intermediation, } \\
\text { real estate, renting, etc }\end{array}$ & $10 \%$ & $9 \%$ & $11 \%$ & $10 \%$ \\
\hline Education; R\&D & $8 \%$ & $8 \%$ & $10 \%$ & $6 \%$ \\
\hline Health \& social work & $21 \%$ & $21 \%$ & $22 \%$ & $21 \%$ \\
\hline $\begin{array}{l}\text { Hotels, restaurants; } \\
\text { social \& personal service } \\
\text { activities, etc. }\end{array}$ & $7 \%$ & $5 \%$ & $5 \%$ & $7 \%$ \\
\hline $\begin{array}{l}\text { Public admin. \& defence, } \\
\text { etc., extraterritorial } \\
\text { organisations and bodies }\end{array}$ & $5 \%$ & $6 \%$ & $7 \%$ & $6 \%$ \\
\hline $\begin{array}{l}\text { Unspecified economic } \\
\text { activities }\end{array}$ & N.A. & $2 \%$ & $1 \%$ & $1 \%$ \\
\hline Source: compilations of http://scb.se/scbeng/swfig/swfg8en.htm and SCB 1994a \\
\hline
\end{tabular}

The three sectors that employ the largest share of the workforce are the same for Sweden, East Gothia, Linköping and Norköping: health/social work, wholesale/retail trade and mining/manufacturing. It is clear, however, that the East Gothia region has a higher proportion of manufacturing/mining than Sweden. (As Table 2 shows, $31 \%$ of East Gothia's workforce is employed in industry as compared to $27 \%$ in Sweden as a whole). Norrköping and Linköping are also above the Swedish average, but less so. As for whole-sale/retail trade, East Gothia and Linköping are well below Sweden and Norrköping.

In January 1997, unemployment in East Gothia was $0.9 \%$ below the Swedish average of $6.9 \%$. Norrköping fell between Sweden and East Gothia with $6.6 \%$ and Linköping ranked lowest with an unemployment rate of only 
$5.6 \%$

Table 4 compares the gross regional product (GRP) per capita of East Gothia, Linköping and Norrköping to the Swedish average for 1990 and 1993. The GRP per capita in East Gothia in 1993 was 7\% below the Swedish average (SCB, 1996c). The GDP/capita in Sweden in 1993 was SEK 165,400 (SCB, 1996b). The only municipality in the region with GDP per capita above the Swedish average in 1993 was Linköping, at $108 \%$ of the national average. Norrköping was rated as the second best municipality with a figure $2 \%$ below the Swedish average. Hence, East Gothia was, in 1993, considerably "poorer" than the Swedish average and Linköping was considerably "richer".

\begin{tabular}{|l|l|c|c|c|}
\hline \multicolumn{5}{|c|}{ TABLE 4: COMPARISON OF THE GROSS REGIONAL PRODUCTS } \\
\hline & Sweden & $\begin{array}{c}\text { East } \\
\text { Gothia }\end{array}$ & Linköping & Norrköping \\
\hline $\begin{array}{l}\text { GRP/capita, 1993 } \\
\text { (current prices, SEK) }\end{array}$ & $\begin{array}{l}100 \% \\
\text { (GDP/cap. 165,400) }\end{array}$ & $93 \%$ & $108 \%$ & $98 \%$ \\
\hline $\begin{array}{l}\text { GRP/capita, 1990 } \\
\text { (current prices, SEK) }\end{array}$ & $\begin{array}{l}100 \% \\
\text { (GDP/cap. 158,900) }\end{array}$ & $92 \%$ & $105 \%$ & $103 \%$ \\
\hline
\end{tabular}

As table 4 shows, compared to the Swedish average, the East Gothia region did not experience any large changes between 1990 and 1993 . However, Linköping improved from 105\% to 108\%, while Norrköping declined from $103 \%$ to $98 \%$. Norrköping's economic activities seem to have been more sensitive to the recession of the early 1990s than East Gothia and Linköping, owing to the industrial and economic structure of the municipality. These issues will be further discussed below.

\section{The industrial structure of East Gothia}

This section describes the industrial structure of East Gothia, Linköping and Norrköping and compares them to the industrial structure of Sweden as a whole. Two databases are used $^{5}$ to show the distribution of employment and value added among five industrial sectors (capital-intensive, R\&D-intensive, knowledge-intensive, labour-intensive and protected). Data on

\footnotetext{
${ }^{4}$ Open unemployment on 31 January 1997, population between 16-64 years old. Source: Länsarbetsnämnden i Östergötlands Län, 28/2 1997.

${ }^{5}$ SCB (1994b) and SCB (1994c).
} 
the level of technical education in the five industrial sectors are also presented. The discussion focuses on the R\&D-intensive sector (or high-tech sector) as product innovation is likely to be more common in that sector than in others. Definitions of the high-tech sector vary somewhat (see note 1 and Appendix 2) but they point largely to the same types of industrial activities.

The share of industrial employment and value added emanating from the R\&D-intensive sector is considerably higher in East Gothia $29 \%$ for employment and $31 \%$ for value added) than in Sweden $(13 \%$ and $17 \%$, respectively). Linköping emerges as a city with a very strong R\&D-intensive sector ( $55 \%$ and $71 \%$, respectively). In general, the region's industrial structure appears to be quite "advanced" in this respect (See tables 6 and 7).

\subsection{Method and definitions}

Two classifications of Swedish manufacturing industry provided by Statistic Sweden (SCB, 1994b) are combined to obtain the OVA (Ohlsson/Vinell/Andersson) database. The first classification is based on the intensity of technically educated people in Swedish manufacturing industry at firm level. The second divides manufacturing industry into five sectors according to the relative use of four factors of production (capital, R\&D technicians, other technicians and white- and blue-collar employees). The two database were designed separately and are independent.

\section{- Level of technical education in Swedish industry}

Andersson et al. (1996) defines engineers (högskoletekniker) as workers with at least one year of university education in engineering. Technicians (tekniker) are defined as all technical workers with a high-school degree ${ }^{6}$. Using this classification, Andersson (1996) defines three categories of firms:

- Class A: a firm belongs to class $A$ if the proportion of technicians and of engineers in the firm's labour force is higher than the Swedish average in the industrial sector to which the firm belongs (see table 5).

\footnotetext{
${ }^{6}$ An implication of Andersson's definition of "engineers" and "technicians" is that firms with a young workforce will tend to be classified as having a more educated workforce than similar companies employing older people, since almost everybody under 30 years of age in Sweden has a high-school education. On the other hand, the broad definition of "technicians" captures older workers with a short technical education.

${ }^{7}$ This definition is somewhat problematic and will be discussed later.
} 
- Class B: either the proportion of technicians or that of engineers in the firm is higher than the Swedish average in the industrial sector to which the firm belongs (see table 5$)^{8}$.

- $\underline{\text { Class } C}$ : the proportions of both technicians and engineers in the firm are lower than the Swedish average in the industrial sector to which the firm belongs (see table 5).

\begin{tabular}{|l|c|c|c|}
\hline \multicolumn{4}{|c|}{$\begin{array}{r}\text { TABLE 5: AVERAGE } \\
1994 \text { AS A PER OF EDUCATION IN INDUSTRIAL SECTORS, }\end{array}$} \\
\hline & Technicians & Engineers & Total \\
\hline Protected sector & 27.9 & 4.2 & 32.1 \\
\hline $\begin{array}{l}\text { Capital-intensive } \\
\text { sector }\end{array}$ & 31.6 & 4.3 & 35.9 \\
\hline $\begin{array}{l}\text { Labour-intensive } \\
\text { sector }\end{array}$ & 43.4 & 9.4 & 52.8 \\
\hline $\begin{array}{l}\text { Knowledge-intensive } \\
\text { sector }\end{array}$ & 50 & 12.2 & 62.2 \\
\hline $\begin{array}{l}\text { R\&D-intensive } \\
\text { sector }\end{array}$ & 53 & 24.3 & 77.3 \\
\hline Manufacturing as a whole & 40 & 9.7 & 49.7 \\
\hline Source: SCB, 1994b. & & & \\
\hline
\end{tabular}

In the following discussion, Class $A$ will be called high education industry ( $\mathrm{HEI})$; Class $\mathrm{B}$, medium education industry (MEI); and Class $\mathrm{C}$, low education industry (LEI).

\section{- The Ohlsson/Vinell Division of Industry}

As mentioned before, the Ohlsson/Vinell approach (Ohlsson/Vinell, 1987) uses the notion of factors of production to classify industry. Within all industrial activities, four factors of production are identified: capital, R\&D technicians, other technicians and white- and blue-collar employees. (The meaning of the term technician is different from that of the other classification). An industry is classified as belonging to a certain sector depending on the factor of production that it predominantly uses. The sectors and their characteristics are listed below ${ }^{10}$.

\footnotetext{
${ }^{8}$ This class does not provide useful information for the purposes of this study and is therefore generally ignored in the following discussion. In later parts of this study, an attempt will be made to divide it into two sub-categories, one focusing on technicians and the other on engineers.

${ }^{9}$ For example, to be classified in class A for the R\&D-intensive sector, a firm has to have more than $77.3 \%$ of engineers and technicians.

${ }^{10}$ The detailed Ohlsson/Vinell classification of industry according to SNI is found in Appendix 2
} 


\section{Capital-intensive sector}

This sector is defined by a high dependency on physical capital. It is characterised by strong links to raw materials which are imported in many cases, and includes parts of food production, along with the pulp, paper, steel and chemical industries.

\section{$\underline{\text { R\&D-intensive sector }}$}

This sector is characterised by a predominance of research and development technicians in the workforce. It includes electronic products in the fields of computer, telecommunication and instruments and production of pharmaceuticals, aircraft and electricity generators.

\section{$\underline{\text { Knowledge-intensive sector }}^{11}$}

The knowledge-intensive sector has a large proportion of technicians (other than R\&D technicians). It consists basically of firms in the engineering and chemical industries and also includes producers of consumer durables, e.g. motor vehicles, many investment products, the shipping industry and manufacture of many input products.

\section{Labour-intensive sector}

The labour-intensive sector principally uses ordinary white- and bluecollar workers. The industries include food production, forestry, manufacture of leather products, shoes, clothes, plastic products, paper packages and certain building materials.

\section{Protected sector}

This last sector is not defined by a certain factor of production but rather by what is produced. It consists of the protected parts of forestry, food production and building materials industry, as well as those of the printing industry.

\subsection{Results}

As pointed out in the introduction, R\&D-intensive sectors, also called

\footnotetext{
11 "Knowledge-intensive" does not here refer to the type of knowledge that is created at universities, but rather to that possessed by technically trained persons, including those with intermediate level training. This distinguishes the knowledge-intensive sector from the R\&D-intensive sector.
} 
high-tech sectors, are central to industrial dynamism and renewal. The following discussion therefore focuses on the R\&D-intensive sector. Each table in this section refers to a figure in Appendix 1. Unless otherwise specified, all data in this section are for the year 1994.

\subsubsection{The industrial structure of East Gothia}

Table 6 shows the share of the workforce in the five sectors of industry for Sweden, East Gothia, Linköping and Norrköping. Table 8 shows the share of value added for the same sectors for Sweden, East Gothia, Linköping and Norrköping. The two complement each other. The first "overestimates" labourintensive industry since it is based on employment figures. The second "overestimates" the capital-intensive sector (see also Figures 1 and 2 in Appendix 1).

Table 6 shows the predominance of employment in R\&D-intensive industries in Linköping. More than $55 \%$ of the that city's industrial workforce were employed in this sector in 1994. East Gothia as a whole also presented a high percentage of employment in this sector, with $29 \%$, as compared to the Swedish average of $13 \%$. Table 7 confirms pattern: Linköping produced $71 \%$ of its industrial value added in the R\&D-intensive sector in that year. East Gothia, with $31 \%$ of its value added in R\&D, was far above the Swedish average of $17 \%$.

\begin{tabular}{|l|c|c|c|c|}
\hline \multicolumn{5}{|c|}{ TABLE 6: DISTRIBUTION OF THE WORKFORCE IN FIVE INDUSTRIAL } \\
SECTORS, 1994(\%). (SEE FIGURE 1 IN APPENDIX 1) \\
\hline & Sweden & East Gothia & Linköping & Norrköping \\
\hline Protected & 22 & 13 & 16 & 14 \\
\hline Labour-intensive & 25 & 18 & 12 & 19 \\
\hline Capital-intensive & 13 & 12 & 1 & 23 \\
\hline Knowledge-intensive & 27 & 28 & 16 & 20 \\
\hline R\&D-intensive & 13 & 29 & 55 & 24 \\
\hline Total industry & 100 & 100 & 100 & 100 \\
\hline Source: SCB, 1994b.
\end{tabular}




\begin{tabular}{|c|c|c|c|c|}
\hline & Sweden & East Gothia & Linköping & Norrköping \\
\hline Protected & 18 & 8 & 9 & 8 \\
\hline Labour -intensive & 19 & 12 & 6 & 16 \\
\hline Capital-intensive & 21 & 20 & 1 & 42 \\
\hline Knowledge-intensive & 25 & 29 & 13 & 17 \\
\hline R\&D-intensive & 17 & 31 & 71 & 17 \\
\hline Total industry & 100 & 100 & 100 & 100 \\
\hline
\end{tabular}

These two tables are a good proxy for the industrial structure of East Gothia in 1994. They show that it was very different from that for Sweden, and notably that it was much more oriented towards R\&D-intensive sectors. The ranking - Linköping, East Gothia, Norrköping, Sweden - is not surprising and recurs throughout this section.

The position of Linköping was largely due to the size of Saab Aircraft which is classified as an R\&D-intensive firm. In 1994, Saab employed 5,856 persons ${ }^{12}$ in Linköping. This amounted to $82 \%$ of Linköping's workforce in the R\&D-intensive sector and to $45 \%$ of its total industrial workforce ${ }^{13}$. Other important employers in Linköping are found in the Mjärdevi Science Park, which has many small firms but also large ones such as Ericsson ${ }^{14}$.

By the end of 1997 , there were about 3,800 persons working in the Mjärdevi science park. Ericsson accounted for 2,350 (1,600 in Ericsson Mobile Telecommunication $A B$ and 750 in Ericsson Radio Systems $A B$ - Application Centre).

Apart from the predominance of the $R \& D$-intensive sector in Linköping, table 6 also shows that Norrköping employed nearly twice as much of its workforce $(23 \%)$ in the capital-intensive sector as the Swedish average $(13 \%)$ or as East Gothia (12\%). Less than $1 \%$ of Linköping's workforce was in this sector. This reflects the absence of process-oriented basic industry in Linköping. The relation between these figures holds for table 7 as well. For Norrköping, $42 \%$ of value added in manufacturing industry came from the capital-intensive sector, compared to $21 \%$ for Sweden, $20 \%$ for East Gothia and $1 \%$ for Linköping. The predominance of the capital-intensive sector in

\footnotetext{
${ }^{12}$ Centre for Innovation and Entrepreneurship (CIE), (1996), pp. 86-89. SAAB has four divisions in Linköping: Saab Aircraft AB, Saab Military Aircraft, Saab Dynamics and Saab Ericsson Space. Saab as a whole had 7,485 employees in 1994 (Saab Årsredovisning, 1995)

${ }^{13}$ Here it should be stressed that although all employees at SAAB do not perform R\&D-related tasks, they are still clas sified as working within the R\&D-intensive industry category.

${ }^{14}$ In Linköping, Ericsson Radio Systems, Application Centre, had 427 employees in 1994 (Ericsson Application Centre Verksamhetsberättelse 1995) and Ericsson Mobile Communication had 580 employees (Feldskog, 1998).
} 
Norrköping was due principally to the paper and paper pulp industry.

When looking at the figures for Linköping in tables 6 and 7, the small size of the "knowledge-intensive" sector may seem surprising. Linköping is a university city and a university produces knowledge. There should therefore be many "knowledge-intensive" firms in the area. However, the term "knowledgeintensive" is partly misleading in that it does not here refer to the type of knowledge that is created at universities, but rather to that possessed by technically trained persons, including those with intermediate-level training. This distinguishes the "knowledge-intensive sector" from the "R\&D-intensive sector".

Linköping's industry also had a predominance of "R\&D-intensive" industry, a sector which depends to a much greater extent on the knowledge created at the university than the so-called "knowledge-intensive" sector. The proximity of the university, both physically and socially, has stimulated Linköping firms to specialise in R\&D-intensive activities, and many firms have been created as spin-offs from activities at the university. Furthermore, this environment has induced high-tech companies to locate in Linköping.

Norrköping was well below the Swedish and the East Gothia averages for knowledge-intensive industry because of its specialisation in process-oriented basic industry.

\subsubsection{Level of technical education in manufacturing industry}

Table 8 shows that $34 \%$ of East Gothia industry was considered as high education industry compared to the Swedish average of $28 \%$, whereas $45 \%$ of the region's industrial workforce was working in low education industry. Linköping was, however, an exception, as $50 \%$ of its industrial workforce was in high education industry and only $27 \%$ in low education industry.

\begin{tabular}{|l|c|c|c|c|}
\hline \multicolumn{5}{|c|}{ TABLE 8: DISTRIBUTION OF WORKFORCE AMONG THE THREE EDUCATION } \\
CLASSES, 1994 (\%). (SEE FIGURE 3 IN APPENDIX 1) \\
\hline & Sweden & East Gothia & Linköping & Norrköping \\
\hline High education industry & 28 & 34 & 50 & 30 \\
\hline Medium education industry & 29 & 22 & 23 & 17 \\
\hline Low education industry & 43 & 45 & 27 & 53 \\
\hline Source: SCB, 1994b.
\end{tabular}

This table shows that, in terms of the workforce's educational level, East Gothia represented a combination of the region's two main cities. East 
Gothia had a more "balanced" structure than either of the two cities whose workforces appeared to have strongly contrasting characteristics in this respect.

Table 9 focuses on the R\&D-intensive sector. It shows that in 1994, $76 \%$ of the workforce in the R\&D-intensive sector worked in a firm in high education industry, but the share was only $6 \%$ in Norrköping, so that the share for East Gothia was $47 \%$. For the share of low education in the R\&D-intensive sector, instead, the figure for Norrköping was $93 \%$, compared to only $3 \%$ for Linköping. The share of East Gothia was 39\%. Accordingly, the R\&D-intensive sector indicates that the difference between Linköping and Norrköping in terms of the workforce's educational level was remarkable. This is, of course, a reflection of the fact that in what is classified as R\&D-intensive industry in Norrköping, the workers mainly carry out non-advanced activities (like assembly). $R \& D$ activities for the company are carried out elsewhere.

\begin{tabular}{|l|c|c|}
\hline \multicolumn{1}{|c|}{ TABLE 9. SHARES OF HIGH AND LOW EDUCATION IN THE R\&D-INTENSIVE } \\
SECTOR. 1994 (\%). (SEE FIGURES 4 AND 5 IN APPENDIX 1)
\end{tabular}

\subsubsection{The relationship between technical education level and sector of activity}

Table 10 shows the share of high education industries (HEI) in the five sectors in 1994, that is, the relationship between the nature of the sector of activity (e.g. protected, labour-intensive, etc.) and the degree of technical education $^{15}$ of those employed in it.

Using Andersson's definition of level of technical education and the OVA database (SCB, 1994b), $28 \%$ of Swedish industry as a whole was constituted by firms classified as having a high education workforce (table 10). This means that the firms' proportion of technicians and engineers in their labour force was higher than the Swedish average (see table 5). Both East Gothia and Norrköping had higher figures, with $34 \%$ and $30 \%$, respectively. However, at $50 \%$, the figure for Linköping was much higher.

\footnotetext{
${ }^{15}$ For definition and discussion of what is meant by "high education", see section 2.1 above.
} 
Table 11, which gives the figures on low education industry, shows the other side of the coin: $27 \%$ of Linköping's, $43 \%$ of Sweden's and $45 \%$ of East Gothia's industry consisted of low education firms. Norrköping's share was almost twice that of Linköping's at 53\%. Again, the educational levels of the workforce differed sharply between Linköping and Norrköping.

\begin{tabular}{|c|c|c|c|c|}
\hline & Sweden & East Gothia & Linkōping & Norrkōping \\
\hline Protected & 24 & 22 & 13 & 16 \\
\hline Labour-intensive & 21 & 27 & 16 & 36 \\
\hline Capital-intensive & 33 & 31 & 0 & 60 \\
\hline Knowledge-intensive & 30 & 30 & 25 & 28 \\
\hline R\&D-intensive & 36 & 47 & 76 & 6 \\
\hline Total industry & 28 & 34 & 50 & 30 \\
\hline
\end{tabular}

TABLE 11: SHARE OF LOW EDUCATION INDUSTRY IN FIVE INDUSTRIAL SECTORS, $1994(\%)$. (SEE FIGURE 5 IN APPENDIX 1)

\begin{tabular}{|l|c|c|c|c|}
\hline & Sweden & East Gothia & Linköping & Norrköping \\
\hline Protected & 47 & 52 & 65 & 57 \\
\hline Labour-intensive & 44 & 34 & 46 & 18 \\
\hline Capital-intensive & 41 & 54 & 0 & 33 \\
\hline Knowledge-intensive & 41 & 49 & 56 & 57 \\
\hline R\&D-intensive & 41 & 39 & 3 & 92 \\
\hline Total industry & 43 & 45 & 27 & 53 \\
\hline Source: SCB, 1994b.
\end{tabular}

\section{- The Knowledge-intensive, protected and labour-intensive sectors}

In knowledge-intensive industry, the share of all workers in high education industries was about the same for all areas (30\% or somewhat less). Linköping had the lowest figure (25\%), both here and for the protected and labour-intensive sectors. Norrköping had a high proportion of workers in the high education part of the labour-intensive sector (36\%) compared to Linköping (16\%), which brings the East Gothia average down to $27 \%$. The Swedish average was $21 \%$.

\section{- The R\&D-intensive sector}

Most striking in table 10 are the figures related to the R\&D-intensive and the capital-intensive sectors. Linköping and Norrköping deviated in the 
R\&D-intensive sector. In $1994,76 \%$ of the workforce in the R\&D-intensive industry worked in firms in high education industry ${ }^{16}$ as compared to the Swedish share of $36 \%$ but also to East Gothia's share of $47 \%$ and that of Norrköping (6\%). Linköping employed about 7,000 workers in R\&D-intensive industry owing to Saab $\left(5,856\right.$ workers $\left.{ }^{17}\right)$, Ericsson $\left(427\right.$ workers $\left.^{18}\right)$ and indirectly to the Technical University (as knowledge/engineer producer) ${ }^{19}$ and the Mjärdevi Science Park. Other large R\&D-intensive firms outside Linköping were Whirlpool and Ericsson in Norrköping, Nokia in Motala and ABB in Finspång .

Table 10 also shows a relation between the education level within firms and the sector of activity; however, the relation is not linear. Some production units classified as R\&D-intensive employ fewer personnel with a high education than others. For Norrköping, $24 \%$ of its industrial workforce (table 6) worked in the R\&D-intensive sector ( $11 \%$ above the Swedish figure). However, only $6 \%$ worked in a high education industry, owing to the presence of production units of R\&D-intensive firms in Norrköping (e.g. Whirlpool and Ericsson). In those firms R\&D is done elsewhere. Table 11 confirms this, showing that $92 \%$ of the R\&D-intensive industry workforce in Norrköping worked in low education industry, compared to only $3 \%$ in Linköping. The highest shares of low education in Linköping's industry were found in the protected sector $(65 \%)$ and in the knowledge-intensive sector (56\%).

In East Gothia, 47\% of the workforce in R\&D-intensive industries worked in high education industries (Table 10). This was $11 \%$ higher than the Swedish average. However, this number is explained by Linköping's dominance; more than a quarter of the industrial workforce in East Gothia was employed in Linköping.

\section{- The capital-intensive sector}

As shown above, high education firms within the R\&D-intensive sector in Norrköping were very scarce.

Table 11 also shows that in Norrköping the workforce with high education was found in the capital-intensive sector. This can be related to the fact

\footnotetext{
${ }^{16}$ It means that most of those employed at SAAB have a high technical education, i.e. SAAB belongs to category $A$ in Section 2.1.

${ }^{17}$ Saab Årsredovisning 1995.

${ }^{18}$ Ericsson Verksamhetsberättelse 1995.

${ }^{19}$ See Section 4 on Linköping University.
} 
that $23 \%$ of the workforce in Norrköping worked in this sector (table 6). For Sweden, only $33 \%$ of the workforce in the capital-intensive sector worked in a high education industry (table 10), i.e. approximately half the figure for Norrköping. For Linköping, these figures are somewhat irrelevant, since fewer than 50 persons worked in the capital-intensive sector.

\subsection{Some conclusions on the industrial structure of East Gothia}

The region of East Gothia has succeeded in positioning itself in industrial sectors with good prospects for economic growth and job creation. As tables 6 and 7 show, East Gothia was well ahead of the Swedish average in the high-tech sector ${ }^{20}$, i.e. in the R\&D-intensive industries, in terms both of employment and value added. As the tables show, East Gothia's position was mainly due to Linköping's excellent performance.

As noted in the introduction, high-tech sectors are regarded as achieving higher economic and employment growth than other sectors. This is reflected in Linköping's gross regional product per capita. As table 5 shows, in 1990 Linköping's gross regional product was $5 \%$ above the Swedish average; in 1993, during the recession, it exceeded the Swedish average by $8 \%$. Linköping's economic structure seems to have survived the economic crisis better than the country, Norrköping and East Gothia. Part of the explanation may lie with the expansion of Linköping University, which will be discussed below.

However, Linköping's performance is largely the result of the activities of Saab Aircraft (in 1995, the total turnover of all of Saab's activities in Linköping was SEK 7,925 million ${ }^{21}$ ). The new Ericsson facility and the rest of Mjärdevi Science Park also contributed to Linköping's high figures for education level and share of production in R\&D-intensive industry.

Linköping's dependence on Saab might be problematic if Saab were to run into serious economic difficulties as a result, for example, of termination of the production of the civilian aircraft Saab 340 and Saab 2000. However, its dependence in this respect has decreased somewhat during recent years, owing to the establishment of other advanced firms in the Mjärdevi Science Park $^{22}$ and elsewhere in the Linköping area. In particular, the two Ericsson firms

${ }^{20}$ Ohlsson/Vinell (1987) uses high-technology industry as a synonym for the R\&D-intensive sector (p. 125).

${ }^{21}$ Affärs Correspondenten, No. 3 Årgång 13, 24 September 1996.

${ }^{22}$ In 1998, there were about 3,800 persons employed in the Mjärdevi Science Park firms. Ericsson accounts for about half of these (Johansson, 1998). 
in Mjärdevi have grown from 1,000 employees in 1994 to 2,350 in 1997. In other parts of East Gothia as well, similar activities have been established or growing, e.g. Nokia in Motala and ABB in Finspång.

\section{Services}

In 1995 , services ${ }^{23}$ accounted for $71 \%$ of total employment in Sweden and manufacturing for $27 \%$ (table 2). The figures are similar for East Gothia, Linköping and Norrköping ${ }^{24}$. It is therefore important to study this sector, although the analysis of services presents several difficulties. One relates to the definition of services. Another is to identify which services are most relevant for studying innovation processes in general and in East Gothia in particular.

This section gives a very brief overview of a part of the services sector with important links to manufacturing industry. First, it identifies the relevant part of the service industry. Next, some preliminary results are presented on the structure of this sector in the East Gothia region.

\subsection{Background}

Defining the service industry has been the topic of a long-standing debate concerned with trying to identify what characterises services, what distinguishes them from manufacturing industries and characterises them specifically and what should be included in the sector (Hauknes, 1996, Illeris, 1996). The aim here is to understand, on the basis of current theoretical thinking on the topic, what kinds of services are most important to product innovation and how they affect regional economic performance.

Important characteristics of services have been emphasised in the literature. The focus is often on the importance of user/producer relationships and their intensity. Illeris (1996:4) describes this relationship in terms of face-toface relationships and highly customised products. Other characteristics are high labour intensity, the irreversibility of the change in the product or the person and the ephemeral nature of the activity (which does not last over time but is carried out over a short period).

\footnotetext{
${ }^{23}$ Services sectors include: Trade; Restaurants, Hotels; Public Transportation, Communication; Bank, Insurance and Consulting; Private and Cultural Services, Education and Research; Health and Medical Care and Public Services.

${ }^{24}$ Source: SCB 1996a, SCB 1994a.
} 
The characteristic described as the user/producer relationship is of particular importance to the present study, since the focus is on those part of the sector which have a visible impact on product innovation in a regional context. User/producer relationships have been pointed out as central elements in systems of innovation, in the work of Lundvall (1992), Nelson (1993) and Edquist (1997). In the context of innovative processes, some service activities are particularly relevant and important. Their interaction with regional manufacturing industry and their ways of interacting are also central to this study.

Measuring any kind of changes in the services sector is a statistician's nightmare. Statistical classifications do exist, however. The most generally accepted classification to date may be Browning and Singelmann's (1978) functional categorisation.

\begin{tabular}{|c|c|c|c|}
\hline \multirow{2}{*}{$\begin{array}{l}\text { Services } \\
\text { sector } \\
\text { Distributive }\end{array}$} & \multirow{2}{*}{$\begin{array}{l}\text { Service industry } \\
\text { Transport and storage } \\
\text { Communication } \\
\text { Wholesale and retail trade }\end{array}$} & \multicolumn{2}{|c|}{ NACE Rev. $1^{25}$} \\
\hline & & \begin{tabular}{l|l} 
\\
1 \\
$G$
\end{tabular} & $\begin{array}{l}60-63 \\
64.2 \\
50-52 \text {, exc. } \\
50.2,50.4 \\
52.7\end{array}$ \\
\hline Producer & $\begin{array}{l}\text { Bank, insurance and other financial services } \\
\text { Real estate } \\
\text { Legal services } \\
\text { Accounting } \\
\text { Engineering and architectural services } \\
\text { Misc. business services }\end{array}$ & $\begin{array}{l}J \\
K \\
K \\
K \\
K\end{array}$ & $\begin{array}{l}65-67 \\
70 \\
74.11 \\
74.12 \\
72-74\end{array}$ \\
\hline Social & $\begin{array}{l}\text { Medical/health services and hospitals } \\
\text { Education } \\
\text { Postal services } \\
\text { Government } \\
\text { Other professional and social services }\end{array}$ & $\begin{array}{l}\mathrm{N} \\
\mathrm{M} \\
\mathrm{I} \\
\mathrm{L}\end{array}$ & $\begin{array}{l}85 \\
80 \\
64.1 \\
75\end{array}$ \\
\hline Personal & $\begin{array}{l}\text { Hotels and restaurants } \\
\text { Repair services } \\
\text { Entertainment and recreation } \\
\text { Other personal services }\end{array}$ & $\begin{array}{l}\mathrm{H} \\
\mathrm{G} \\
\mathrm{O}\end{array}$ & $\begin{array}{l}55 \\
50.2,50.4 \\
52.7 \\
92\end{array}$ \\
\hline
\end{tabular}

The most commonly identified difficulty for assessing the role of services for economic growth and improvement of welfare is the difficulty, or even the

${ }^{25}$ NACE, Nomenclature Générale des Activités Économiques dans les Communautés Européennes, Rev. 1 is the sta tistical classification of economic activity of the European Union. 
impossibility, of measuring productivity in some service industries, at least in terms of labour productivity. In this context, Illeris (1996) identifies two types of service industries. One is dependent on manufacturing activities, the other is not. This classification points to the existence of interdependencies between manufacturing industries and service industries. Productivity growth in manufacturing industries is highly dependent on the efficiency of its relationship to services even though the measurement of this interdependence is highly problematic.

In this report, the focus is on the services sector called "Producer" by Browning and Singelmann because of the intensity of its relationship to manufacturing industries. This is not to deny the relation of other services to manufacturing. However, the strength of the relation and the contribution to productivity growth and product innovation in manufacturing industry is often less visible. (This is not, however, the case for the "Distributive" sector which is very important to the functioning of manufacturing industry, e.g. the relation between production of telecommunications equipment and telephony services, i.e. fixed telephone calls, mobile calls, Internet services and data communications services.) Within the producer services sector, the focus here is on engineering services and financial services, partly because of data availability.

\subsection{Some empirical evidence}

A study of the services sector requires data. Because no reliable databases of services in East Gothia have so far been designed, the services issue is here treated in two ways. First, an attempt is made to measure the role of computer and consulting services in the region using a database established in the report Ideas that really mean business (CIE, 1996).

\subsubsection{High-tech consulting and software development}

CIE (1996) lists 119 high-tech firms ${ }^{26}$ in East Gothia. According to that report, those firms accounted for almost the whole population of high-tech firms in the region in $1995^{27}$. The database includes data on turnover ${ }^{28}$,

\footnotetext{
${ }^{26}$ The definition of high-tech firms is the following: "1- a portion of the budget must be devoted to R\&D, 2- the employees must have a high level of education (Master of Engineering or equivalent), 3- the firm must have a technologybased business idea" (CIE, 1996:v).

${ }^{27}$ Details on the way the list was designed can be found in Ideas that really mean business, (CIE, 1996).

${ }^{28}$ However, as many firms did not provide turnover information, this indicator cannot be used.
} 
employment and type of activity. On the basis of this last indicator, firms are here classified as high-tech manufacturing firms or high-tech service firms. The CIE database indicates that there were 10,299.5 employees in the high-tech manufacturing industry.

\begin{tabular}{|l|c|c|}
\hline \multicolumn{2}{|c|}{$\begin{array}{c}\text { TABLE 13: EMPLOYMENT IN HIGH-TECH MANUFACTURING AND HIGH-TECH } \\
\text { SERVICES IN EAST GOTHIA AND ITS MAJOR CITIES IN 1995 }\end{array}$} \\
\hline & Manufacturing & Services \\
\hline Linköping & $6,769.5$ & 2,176 \\
\hline Norrköping & 881 & 122.5 \\
\hline Motala & 647 & 43 \\
\hline Mjölby & 25 & 9,5 \\
\hline Atvidaberg & 16 & 22 \\
\hline Finspàng & 1,782 & 10.5 \\
\hline Other & 9 & 2,383.5 employees in 82 \\
\hline East Gothla & $10,299.5$ employees in 37 \\
\hline
\end{tabular}

Table 13 shows that of the 119 high-tech firms in East Gothia, which employed 12,513 persons, 37 were classified as manufacturing firms. These firms employed more than 10,000 persons. The 82 firms considered as hightech service firms cover activities like engineering consulting, software development and technical support. They are mainly located in Linköping and particularly in the Mjärdevi Science Park. High-tech service firms in East Gothia employ almost 2,400 persons. Table 14 shows that only 16 high-tech service firms have more than 20 employees.

\begin{tabular}{|c|c|c|c|}
\hline \multicolumn{4}{|c|}{$\begin{array}{l}\text { TABLE 14: SIZE OF HIGH-TECH SERVICE FIRMS IN EAST GOTHIA } \\
\text { (IN 1995) }\end{array}$} \\
\hline $\begin{array}{l}\text { Size of the firm } \\
\text { (number employed) }\end{array}$ & $1-9$ & $10-20$ & $>20$ \\
\hline $\begin{array}{l}\text { Number of firms } \\
\text { in East Gothia }\end{array}$ & 49 & 17 & 16 \\
\hline
\end{tabular}

The structure of the high-tech services sector seems favourable to the development and support of existing larger manufacturing firms. The high growth of Mjärdevi Science Park since its creation in 1984 and the growth of the services sector there show that there is potential for expansion of high-tech service firms in the region.

At this stage of the present pre-study, the services sector raises many 
questions which could usefully be addressed later in the project or in another project.

- What is the origin of the small service firms? University/research/firm spin-off?

-What are the growth prospects of the service firms?

- How big can firms in the services sector be? Stockholm?

- Do they reach a critical mass and then to leave the region for

- What is the intensity of the relationship between the services sector firms and firms in the manufacturing sector?

-What forms does this relationship take?

- Where are manufacturing firms that work with service firms located?

- How big can the high-tech services sector be as compared to the regional manufacturing industry?

- With whom do Mjärdevi service firms interact?

- How much can Mjärdevi Science Park continue to grow?

- Can the Mjärdevi Science Park survive without Ericsson and Saab?

- What is the economic/knowledge-creation relevance of service firms for the region as a whole?

-When do service firms get listed on the stock market?

- How is the listing on the stock market organised?

- How do service firms finance their development?

-What kind of services do banks provide for high-tech service firms?

-What are the relations between banks and firms?

-What is the region's financial structure?

-What is the character and structure of the region's capital market? 


\section{Linköping University}

Linköping University has a great impact on the industrial structure of the East Gothia region. There are many university spin-off firms in Linköping and regular co-operation between the university and large high-tech companies. The university also raises the number of educated persons in the Linköping workforce (table 15). In general, there is not much difference in educational levels between Linköping, Norrköping, East Gothia and Sweden. However, in Linköping 33\% of the labour force has a post-high school education.

\begin{tabular}{|l|c|c|c|}
\hline \multicolumn{3}{|c|}{ TABLE 15: LEVEL OF EDUCATION OF THE TOTAL LABOUR FORCE } \\
\begin{tabular}{|l|c|c|} 
IN EAST GOTHIA, 1993 \\
Level of education 1993
\end{tabular} & $\begin{array}{c}\text { Pre-high } \\
\text { school }\end{array}$ & High school & $\begin{array}{c}\text { Post-high } \\
\text { school }\end{array}$ \\
\hline Linköping & $20 \%$ & $47 \%$ & $33 \%$ \\
\hline Norrköping & $27 \%$ & $51 \%$ & $22 \%$ \\
\hline East Gothia & $26 \%$ & $50 \%$ & $24 \%$ \\
\hline Sweden & $25 \%$ & $50 \%$ & $25 \%$ \\
\hline Source: Lănsstyrelsen i Östergötlands lăn and Lănsstyrelsen i Jönköpings lăn, 1995. \\
\hline
\end{tabular}

Linköping University is expanding fast at the moment. During the last five years the number of undergraduates has increased by $43 \%$. In 1997, 20,000 students were enrolled and there were 155 professors on the staff. The university had 1,200 graduate students and awarded 92 doctorates and 80 licentiates in 1997 (Falklöf, 1998).

Linköping University has large departments and emphasises interdisciplinary studies, both in conventional disciplines and through Tema, an independent interdisciplinary department organised around five themes. The university also has a reputation for being oriented towards engineering and health science, and in fact the Faculty of Technology receives $49 \%$ of total university funding and $51 \%$ of the research and research education funding every year. The Faculty of Arts and Sciences receives $28 \%$ and $18 \%$, respectively, and the Faculty of Health Sciences $23 \%$ and $31 \%$, respectively. Funding for research and research education at the university amounted to SEK 895 million in $1994 / 1995$. This represents $60 \%$ of the university's total funding ${ }^{22}$.

The task of universities is not only to educate and do research. The so-called third task of the university is receiving more and more emphasis. It implies that universities play an important social role, e.g. in industrial de-

${ }^{29}$ Data in this paragraph and the following are taken from Linköping University Activity Report 1994/95. 
velopment through co-operation with industry and other organisations. Such cooperation should foster technology transfer and commercialisation of university research. It facilitates the creation of start-ups and spin-offs from the university.

Table 16 shows that research in the technical faculty in Linköping is financed by Swedish firms to the same extent as Stockholm Royal Institute of Technology $(6.4 \%$ and $6.7 \%$, respectively). However, foreign firms are more involved in the financing of research in Linköping than in Stockholm $(3.4 \%$ and $1.8 \%$, respectively).

\begin{tabular}{|c|c|c|}
\hline & $\begin{array}{c}\text { Linköping Institute of } \\
\text { Technology }(\%)\end{array}$ & $\begin{array}{c}\text { Stockholm Royal Institute of } \\
\text { Technology (\%) }\end{array}$ \\
\hline Swedish firms & 6.4 & 6.7 \\
\hline $\begin{array}{l}\text { Swedish non-profit } \\
\text { organisations }\end{array}$ & 9 & 7.3 \\
\hline $\begin{array}{l}\text { Foreign firms and } \\
\text { organisations }\end{array}$ & 3.4 & 1.8 \\
\hline
\end{tabular}

Linköping University is located in Linköping, but it has a satellite campus in Norrköping. Currently some 1,500 students studying at the Norrköping campus are enrolled in engineering programmes, teacher education for children and youth and a number of programmes at the Faculty of Health Sciences. The university is currently expanding rapidly in Norrköping and offers both undergraduate and research programmes. In 2000, about 5,000 persons will study in Norrköping. Given the effect Linköping University has had on the industrial structure of Linköping, the expansion in Norrköping may be very important in the long run. The emphasis on capital-intensive industry may perhaps come to be balanced with more R\&D-intensive businesses. However, this will not happen for some time, probably only in five to fifteen years.

The following questions are worth exploring in relation to Linköping University and its role in the East Gothia regional system of innovation:

- To what extent and in which fields is university research applicable to industrial needs?

- How do the university and East Gothia industry relate (finance, advice, competence, etc.)? Do firms perceive these relations as important? 
- How significant is industry's involvement in university research?

- Which firms fund university research, and why?

- Are they from the region, from other parts of Sweden or from other countries?

- What areas/disciplines of research receive firm funding? What results do firms expect?

- What is the potential for developing financial and other forms of cooperation between university and industry?

- In what way is the expansion of the Norrköping campus likely to affect the municipality of Norrköping?

\section{Other organisations}

Many organisations in the East Gothia region are involved in product innovation, e.g. Linköping University, firms, regional government, etc. None dedicates itself explicitly to product innovation, although product innovation is related to many of their activities. Since there are so many organisations, it is impossible to present them all. They can be divided into groups according to their main activity (as it relates to product innovation). Some individual organisations within each group are described briefly below.

\subsection{Groups of organisations/networks}

East Gothia organisations can be broadly divided into product innovators and support organisations and further divided as follows.

Product innovators:

- Firms.

- Linköping University.

- FOA.

- Individuals.

Support organisations: 
- Advisory support organisations.

- Financial support organisations.

- Other types of support organisations.

Organisations concerned with innovation in East Gothia collaborate with one another. Co-operation among organisations may take two forms, formal or informal, depending on the type of bonds created among the organisations in the networks that are formed. Such networks have various kinds of rules of conduct and behaviour. Sometimes, one of the organisations participating in the network presides and co-ordinates its activities. Such cooperation networks can take two forms:

- Firm networks.

- Other networks.

Cooperation between organisations concerned with product innovation in East Gothia points to one of the cornerstones of the systems of innovation approach: interdependencies between organisations in the system. According to Edquist's (1997) definition, innovations can be seen as "'new combinations' of elements of existing and/or new knowledge"..$^{30}$ Since knowledge emerges or exists in different parts of the system, actors need to interact while engaging in innovative processes. The existence of frequent cooperation among actors in East Gothia seems to imply that the regional system of innovation is rather coherent, even though it is not possible to evaluate its efficiency.

\subsubsection{Product innovators}

Product innovators are actors that create new products and are mainly firms. Products may also be invented by individuals, but they are disregarded here, unless such individuals are organised as a firm. The present study is concerned with inventions, i.e. innovations that are marketed and thus become new products. As the industrial structure was described in Section 2, the role of firms in the East Gothia innovation system is not returned to here. However, firms will play the central role in the later investigation of co-operation among innovating organisations (through a questionnaire to be addressed to all manu-

\footnotetext{
${ }^{30}$ The definition is based on Schumpeter, but expressed as in Edquist (1997), p. 27.
} 
facturing firms in East Gothia).

\subsubsection{Support organisations}

Support organisations are designed to provide help to firms or projects carried out by several firms/organisations or by individuals. They contribute indirectly to product innovation through their involvement with innovative firms. The help may consist of funding (loans and/or contributions), advice, education or training and other kinds of support. An organisation can be involved in one or all of these activities.

Reasons for offering support vary. Some organisations seek to promote regional growth by supporting potentially successful companies; others may support innovations or foster entrepreneurship. Finally, some aim at facilitating exports from the region.

The following discussion excludes all profit-seeking organisations that supply support, as they constitute parts of the services industry which was briefly discussed in Section 3. However, it is important to recall the crucial importance of service-producing organisations, such as financial institutes, banks and consulting firms.

\section{- Advisory support organisations}

Advisory support activities in East Gothia are mainly performed by publicly financed organisations which seek to strengthen and develop smallscale industry in the region. The idea is that small firms have neither the funds nor the time to collect the information that is useful when planning to expand. Hence, the offer of free advice on a wide range of topics, including taxes, technical issues, EU legislation, export-related topics and contacts, is a way to increase the competitiveness of regional or local firms on international or national markets. Such organisations exist throughout Sweden, but may vary regionally and locally in their structure, the extent and kind of advice offered, etc. They are present at both regional and municipal levels. Examples of organisations performing advisory support activities are ALMI företagspartner, Östsvenska handelskammaren and Nyföretagarcentrum ${ }^{31}$.

\footnotetext{
${ }^{31}$ The organisations are described in more detail in Section 5.1.4.
} 
Education is another kind of support. Seminars, courses and mentorship increase the knowledge base of firms, and this may influence their growth and development prospects. CIE (the Centre for Innovation and Entrepreneurship) at the University of Linköping is an example of an organisation offering educational support.

\section{- Financial support activities}

Financing is another kind of support activity. Funding can be made available to firms or to specific projects, either in the form of loans or as subsidies (or some combination of the two). Such financial support is used to fund projects which are perceived as too risky to receive support from market actors (banks, etc.), but which are considered to have great potential. As with advisory support, financial aid is directed towards small firms, as large firms can afford to finance risky projects themselves. Examples of organisations supplying financial support are ALMI företagspartner, TeknikbroStiftelsen and Tillskottet.

\section{- Other kinds of support organisations}

Apart from advice or funding, there are other ways of indirectly supporting product innovation. One is to create and run science parks. They provide technology-based firms with buildings, an innovative climate created by the proximity to other firms, a relationship with the university and certain types of support for new enterprises (firms may initially obtain lower rent for office space, venture capital, etc.). One example in Linköping is the very successful Mjärdevi Science Park for technology-based firms, and the recently established science park directed towards the medical field, Berzelius, in the same city. In Norrköping, the science park Pro Nova should also be mentioned.

\subsubsection{Cooperation networks}

Whereas there are many support organisations in the East Gothia region, there seem to be considerably fewer co-operation networks. This may be due to the fact that such networks need a person or organisation to preside and administer them. 


\section{- Firm networks}

Firm networks are formed by firms that seek to formalise their cooperation with one another. The reasons for collaboration differ and include general support schemes for mentorship and information exchange and cooperation regarding specific issues (e.g. lobbying). In East Gothia, Stiftelsen för Småföretagsutveckling i Linköping (SMIL) and Kunskapsföretag i Norrköping (KiN) constitute examples of firm networks.

\section{- Other networks}

As already mentioned, a multitude of organisations in East Gothia perform activities related to product innovation, and it is important for each to be informed about the others' activities. Such knowledge increases the likelihood that different actors will co-operate on projects of mutual interest and creates synergy effects related to ideas. It also decreases the risk of two organisations engaging in similar tasks. An example is Produktråd Gothia.

\subsubsection{Individual organisations/networks}

This section briefly describes some organisations/networks active in the East Gothia region. It is not a complete list.

\section{- ALMI företagspartner}

ALMI is a national conglomerate with 22 subsidiaries. The state, more specifically the Ministry of Industry and Commerce (Näringsdepartementet), owns $51 \%$ of each subsidiary. The remainder is owned by the county administrative board (Länsstyrelsen) in the region where the subsidiary in question is located. ALMI's mission is to increase economic growth. It works with all industry branches but limits its efforts to small and medium-sized companies (fewer than 250 employees). The average company supported by ALMI has 10-20 employees.

ALMI's work is carried out in three separate domains: competence, capital and contacts (the three Cs). For the first field, competence, companies can receive detailed strategic advice of the kind described under "Advisory Support Activities". ALMI services should be offered only where no workable 
market solution exists. ALMI employs 15 business consultants to provide these services. Under the second activity, capital, firms can receive ALMI funding in the form of loans (last mortgage loans, topplån). ALMI accepts higher risk on these loans than a bank would, in return for higher interest rates than a bank would apply. Firms that only sell locally cannot receive loans. In its third activity, contacts, ALMI seeks as far as possible to work as a broker, connecting firms with the organisations/institutes/persons most likely to be able to help them.

Activities performed by ALMI that are directed specifically towards product innovation are funded partly by NUTEK (the National Board for Industrial and Technical Development) and partly by Innovationscentrum, a foundation established with money from the wage-earners funds (löntagarfonderna). Firms and persons qualifying for help in the development of a new product can receive "seed capital" of around SEK 70,000 for early-stage support.

- Centre for Innovation and entrepreneurship (CIE) (Centrum för Innovation och Entreprenörskap) and Small Business Development in Linköping (SMIL) (Stiftelsen för Småföretagsutveckling i Linköping)

CIE is an independent unit at Linköping University, which is active in the fields of research, consulting, training and teaching services. It aims to stimulate the growth and development of local technology-based firms and also focuses on entrepreneurship. CIE is closely connected with SMIL, a foundation for developing small-scale business in Linköping. Its objectives are the same as CIE's, with the difference that SMIL is only concerned with small companies. To achieve its goal, SMIL works with a network of entrepreneurs and may help small companies to seek expertise from firms of all sizes and technology areas.

Important CIE and SMIL activities include programmes (e.g. lectures, seminars, mentors, development of business plans, co-operation between participating entrepreneurs) and networking (e.g. lunch clubs, seminars, pubnights, firm associations, European SMIL partners, presentations of spin-off firms, etc.) Consulting is never performed for single firms, only for groups of companies.

CIE and SMIL are financed by NUTEK and also by TeknikbroStiftelsen, the European Union, the Wallenberg Foundation, ALMI företagspartner and the fees firms pay to participate in the programmes. 
CIE/SMIL co-operate with Mjärdevi Science Park AB.

\section{- Gothia Product Council}

The Gothia Product Council consists of one representative from TeknikbroStiftelsen, Gothia BIC (Business and Innovation Centre), the Regional Swedish Invention Association, the Linköping Technical University (a professor), the Innovation Relay Centre (IRC) and two delegates from ALMI. The purpose of the organisation is to evaluate applications from firms which seek to receive "seed capital" from ALMI. The Council also discusses general advice, funding and contacts.

\section{- Innovation Relay Centre}

This is a new organisation founded by NUTEK and DG XIII (EC). There are four IRCs in Sweden. East Gothia falls under the one for Central Sweden, which has its head office in Uppsala. Its mission is to deal with downstream and upstream transmission of technical knowledge. IRC aims at finding practical applications for scientific results and practical problems for research.

\section{· Kommunens näringslivsbolag i Norrköping}

This is a municipal support organisation providing new companies in Norrköping with an advantageous environment when locating in the city. Activities include helping firms to find office space, solving communication issues, establishing contacts between firms and consulting companies, etc.

- Knowledge-intensive firms in Norrköping (KiN) (Kunskapsintensiva företag i Norrköping)

$\mathrm{KiN}$ is located in Norrköping and is a sister organisation to SMIL. 


\section{- Mjärdevi Science Park AB and Berzelius Science Park}

Mjärdevi Science Park $A B$ is a municipal company in Linköping that manages and develops the science park. Around 110 firms are located in the Mjärdevi park, of which a few are large and many are small. The firms employ almost 4,000 persons. It is the largest science park in Northern Europe and one of the fastest-growing in the world in terms of number of jobs. ${ }^{32}$ The aim of Mjärdevi Science Park is to provide facilities for high-tech firms, stimulate co-operation between university and industry, assist $R \& D$, support newly established firms and facilitate technology transfers. Mjärdevi focuses on ITrelated businesses and co-operates with Linköping University, CIE, SMIL and TeknikbroStiftelsen, among others. There is co-operation among firms for research and development.

Firms in Mjärdevi Science Park can benefit from various kinds of economic support. One is an "incubator" programme that provides newly established firms with cheap office space. There are also two financial programmes designed for the firms in Mjärdevi Science Park which make seed capital and venture capital available. The first makes seed capital available as a subsidy (i.e. not requiring repayment) in amounts of SEK 50,000 to SEK 200,000 to firms or persons with a good business idea. Funding is from SAF-LO and Innovationscentrum. The second provides venture capital from TUAB (Teknikparkernas Utvecklingsbolag), which is financed by Atle and SWEDEPARK to support projects leading to new business plans, products or companies based upon research and development carried out at the university. The venture capital is handled by the investment firm Atle.

Berzelius Science Park for medical technology is expected to function more or less like Mjärdevi. Firms in this park will be spin-offs from the Health University and companies drawn to the expected atmosphere of co-operation for research, patenting, etc. The initiators of this project are the County Council of East Gothia (Landstinget i Östergötland), the municipality of Linköping and Linköping University, and it is supported by ALMI, TeknikbroStiftelsen and Mjärdevi Science Park AB, among others.

\section{- Nyföretagarcentra}

The Nyföretagarcentra are foundations financed jointly by regional

${ }^{32}$ Connect, forum for Mjärdevi Science Park, No. 0.5, 1995, reprint from Site Selection magazine, a publication of Conway Data, Inc. The database includes over 12,600 science parks all over the world. 
governments and local industry. They seek to encourage entrepreneurship, increase the survival of new firms, develop networks and broaden local business. Their main activity is providing advice to individuals who wish to start their own company. Nyföretagcentra are located in the main municipalities of the region: Linköping, Norrköping, Motala, Kisa and Vadstena.

The Nyföretagarcentra welcome all lines of industry, although they can only help around half of the applicants. In Norrköping, for example, around one hundred new companies are established every year, and service firms (including IT) and retail/merchant business (handel) account for most of them. Manufacturing only accounts for $11 \%$; a share the board of Norrköping Nyföretagarcentrum would like to increase. Like other support organisations, Nyföretagarcentra strive to support firms which appear to have significant possibilities for growth.

One interesting activity of the Norrköping Nyföretagarcentrum is its Entrepreneur Programme, carried out in co-operation with Pro-Nova. It is concerned with exploiting employee ideas or spin-off ideas emerging from companies in the Nyföretagarcentrum network. The centre also co-operates with ALMI Företagspartner in a product council for patents and it also supports KiN. The centre has 60 established firms involved in this activity, which contribute both money and knowledge. They act as mentors/sponsors (fadderverksamhet)

\section{- $\underline{\text { ProNova }}$}

ProNova was started in 1989 in the same spirit as Mjärdevi Science Park. ProNova brings together firms, research units and education facilities in the IT sector (ProNova, 1998). In 1998, it had 70 firms and 510 employees (Gustafsson, 1998).

\section{- TeknikbroStiftelsen}

TeknikbroStiftelsen in Linköping is a foundation. There are seven such foundations in Sweden, all located in major university cities. Each has its own activity plan and a board composed of representatives from business and the university. TeknikbroStiftelsen in Linköping has received SEK 120 million from the wage-earner funds which it can use until year 2007 (when the funds must be paid back to the state). It supports product renewal and higher levels of technology and productivity in firms through increased contacts between firms 
and the university and between firms and other organisations in order to increase firm competitiveness and create jobs. Among other activities, the foundation provides risk capital to firms for initiating the development of product innovations ("products" here include both tangibles and intangibles, i.e. services), and hence promotes projects that imply new knowledge and new technology for a company.

Risk financing is TeknikbroStiftelsen's most important activity. Since it finances very risky projects, it may apply interest rates that are higher than normal bank rates. However, its conditions are less strict than those offered by private venture capital firms. In addition, TeknikbroStiftelsen is prepared to enter projects much earlier than banks. All lines of industry can receive support, although TeknikbroStiftelsen has so far focused more on electronics than on other sectors. Fund-receiving firms are actively followed by appointing persons connected with TeknikbroStiftelsen to the company's board of directors. TeknikbroStiftelsen also offers advice, contacts, etc. In other words, TeknikbroStiftelsen offers "intelligent capital", i.e. capital and knowledge in combination. TeknikbroStiftelsen is open to cooperation with other organisations and risk capital providers if appropriate.

\subsection{Some preliminary conclusions}

Below is a summary of our findings concerning non-profit organisations related to product innovation in East Gothia:

- The number of support organisations is large at both regional and local level. Hence, it is hard for firms to obtain an overview of what assistance they can expect. The number of support organisations also complicates cooperation among them, thereby creating possible inefficiencies when several organisations undertake the same kind of work. It also decreases the likelihood of synergy effects.

- The number of co-operation networks is small.

- All actors contacted in the course of the present study are interested in co-operation and willing to co-operate with other organisations.

The question of whether the situation in East Gothia resembles or is different from that of the nation as a whole is important. However, an answer requires a systematic comparison to other regions. 


\section{Institutions}

North (1990:1) defines institutions as "...the rules of the game in a society or, more formally, ... the humanly devised constraints that shape human interactions". This definition encompasses regulatory laws, norms of human behaviour, as well as formal or informal relationships among firms or between firms and other kinds of organisations. The fact that institutions affect economic performance is now generally accepted. There is also a relationship between institutions and innovation. Because knowledge originates from different sources, forms of interaction among the sources have to be designed to co-ordinate knowledge creation and diffusion. For present purposes, what is of interest is which institutions affect innovation processes in a region.

A detailed account of the institutional set-up of East Gothia would require a thorough analysis of firms' regional behaviour and that can only be done once the questionnaire has been implemented and detailed case studies have been obtained. However, the presentation of certain some organisations in Section 5 indicates certain patterns related to institutions: ${ }^{33}$

- The organisations usually work with all lines of industry but limit themselves to small and medium-sized firms. It is thought that larger companies (above 250 employees) do not need the help.

- Most efforts are directed towards those firms that are likely to contribute most to economic growth in the East Gothia region. For example, TeknikbroStiftelsen concentrates on financing product innovations that include new knowledge and new technology, mainly in high-tech areas. Behind this strategy is the well-founded belief that product innovations in high-tech areas are an important engine of economic growth and employment creation.

- The organisations also try to work as brokers, connecting firms with the organisations and persons most likely to be able to help them.

- Normally, support organisations try not impede competition or interfere with free markets. Hence, services should be provided where there is no workable market solution.

- Support organisations usually have few rules to decide which firms should receive assistance. Often the decision is largely based on an appreciation of the character of the entrepreneur and similar criteria.

\footnotetext{
${ }^{33}$ The issue of regional institutions will be further studied in later stages of the EG-RIS project.
} 
Questions that may later be asked in relation to institutions are:

- Do firms in East Gothia have important "regional" (institutional) characteristics?

-Why does it matter for firms to be located in East Gothia?

- Is the technological environment specific to East Gothia or can it be found in other regions?

- Why do firms choose East Gothia?

- What institutions are specific to East Gothia and why are they more (less) attractive than in other regions?

\section{Conclusions}

This study shows that the East Gothia region is performing well as compared to Sweden in general. The type of industry being developed and the level of education of the workforce largely augurs well for the region's and particularly for Linköping's future economic growth. Linköping's industrial structure is much more oriented towards high technologies than that of Sweden in general, and $56 \%$ of Linköping's workforce and $71 \%$ of its industrial value added in is found in the R\&D-intensive sector. Linköping University's strategy of specialising in information technology reveals its awareness of potential market growth. However, understanding the interaction between the university and regional industry requires more work. For example, is the university creating new industrial potential or is regional industry driving the university's priorities?

The extension of Linköping University in Norrköping may, in the long run, improve the region's economic performance. Since the university's effect on the region's economy is already clearly visible, a combination of the two cities should help strengthen the region's industrial structure. So far, Norrköping's industrial structure is weak in terms of growth and employment prospects, since its R\&D-intensive industry is largely based on production facilities and a workforce with a low technical education. Such activities can easily be moved to places where production costs are lower. ${ }^{34}$ Moreover, the weight of Saab in the region's industrial structure is a weakness. What would happen to the region if Saab left completely?

\footnotetext{
${ }^{34}$ For example, Ericsson decided in 1997 to move its production plant in Norrköping, employing 2,300 persons.
} 
Does a regional system of innovation exist in East Gothia? This study shows that it does, in the sense that there is a qualified workforce adapted to the needs of the region's industry and that there is close interaction among firms and organisations in the region. The university has been very important for the region's industrial development, as it provides both a competent workforce and state-of-the-art research. However, the intensity of the relationship with regard to R\&D between the university and firms appears to be limited in terms of funding. There is interaction among the actors of the system, but its extent and nature are difficult to evaluate. Some organisations have been designed in order to promote product innovation in the region by offering various kinds of assistance to new or established firms. But what is their direct impact on the region's industry?

Many questions remain to be answered. This report is the first part of a larger study which aims to answer some of the questions.

\section{Bibliography}

\subsection{Articles}

Affärs Correspondenten, No 3 Årgång 13, 24 September 1996

Andersson, E., Klofsten, M., Mikaelsson, A.S., (1996), Swedish University Industry Indicators, Working Paper, Linköping University, Centre for Innovation and Entrepreneurship, Linköping.

Browning, H. and Singelman, J. (1978), The Transformation of the US Labor Force: The Interaction of Industries and Occupation, Politics and Society, vol. 8,1979 , p. 581-509.

CIE, (1996), Ideas That Really Mean Business, An overview of high-tech firms located in the County of Östergötland, Sweden, produced by the Centre for Innovation and Entrepreneurship (CIE) of the Business Relations Office, Linköping University.

Edquist, C. and McKelvey, M. (1995), High R\&D Intensity Without High technology Products: a Swedish Paradox?, to be published in Nielses, Klaus and Johnson, Björn (eds.) Evolution of Institutions, Organizations and Technology, Aldershot: Edward Elgar.

Edquist, C. And Texier, F. (1996), The Growth Pattern of Swedish Industry, in 
Innovation Systems and Competitiveness, Osmo Kuusi (Ed.), Taloustieto Oy Publisher, Helsinki 1996.

Edquist, C. (1996), The East Gothia Regional System of Innovation, Project Description.

Edquist, C. and Johnsson, B., (1997), Institution and Innovation: a Conceptual Discussion, in Systems of Innovation, Technologies, Institutions and Organisations, London, Pinter Publisher, Cassel Academics.

Edquist, C. (ed.) (1997a), Systems of Innovation, Technologies, Institutions and Organisations, London, Pinter Publisher, Cassel Academics.

Edquist, C. (ed.) (1997b), Introduction ibid.

Ericsson Verksamhetsberättelse 1995

Falklöf, L. (1998), Nära 20000 Studenter, in Lite Nytt, Nr 4, 1998.

Hauknes, J. (1996), Innovation in the Service Economy, STEP report, 1996.

Illeris, S. (1996), The Service Economy - a Geographical Approach. John Wiley \& Sons.

Johansson, (1998), CEO of the Mjärdevi Science Park

Kunskapen är inte ärvd utan förvärvad, 1995, Länsstyrelsen i Östergötlands län and Länsstyrelsen i Jönköpings län.

Linköping University Annual Report 1994/95.

Länsstyrelsen 1995 in cooperation with Landstinget, Almi, Östsvenska Handelskammaren och Linköpings University, Region Östergötland.

Lundvall, B.Å. (ed.) (1992), Introduction, in National Systems of Innovation Toward a Theory of Innovation an Interactive Learning, London: Pinter Publishers.

Mjärdevi Yearly Report (1996)

North, D.C. (1990) Institutions, Institutional Change and Economic Performance, CUP.

Ohlsson, L., Vinell, L. (1987), Tillväxtens drivkrafter, Industriförbundets Förlag, Stockholm. 
Pronova (1998), http/www.ndk.se/pronova.htm

Saab Årsredovisning 1995

SCB (Statistiska centralbyrån, Statistics Sweden) (1994a), AMPAK 94.

SCB (1994b), Regional Arbetsmarknad Ohlsson/Vinell/Andersson, Årsys 94

SCB (1994c), Industristatistik 1994

SCB (1996a), Statistical yearbook of administrative districts in Sweden 1996.

SCB (1996b), Statistical yearbook of Sweden 1996.

SCB (1996c), Östergötland, fakta och perspektiv, CSB Norrbottenskansliet, Luleå. Stockholm Royal Institute of Technology Acticity Report 1994/95.

\subsection{Interviews}

All interviews were made by phone with the exceptions of Magnus Klofsten and Bo Österberg.

Blomberg, Arne, ALMI företagspartner, 27/11 1996.

Feldskog, Camilla, Ericsson Mobile Communication, 1998

Heijl, Anders, Landstinget i Östergötland (Berzelius Science Park), 9/12 1996. Hull, Anita, Nyföretagarcentrum i Norrköping, 9/12 1996.

Johansson, Sten Gunnar, President (Verkställande direktör), Mjärdevi Science Park AB, 12/12 1996.

Jonsson, Jan, Kommunens Näringslivsbolag i Norrköping, 17/12 1996.

Klofsten, Magnus, CIE/SMIL, 5/12 1996.

Gustafsson, Rutger, ProNova, 10/03/1998

Segerborg, Katharina, President (Verkställande direktör), TeknikbroStiftelsen, 5/12 1996.

Bo Österberg, Innovation Relay Centre/ALMI/(Linköping University?), 17/12 1996. 


\section{Appendix 1-Figures}

Figure 1: Distribution of the Workforce in Five Industrial Sectors, 1994 (\%) (source: SCB, 1994b)
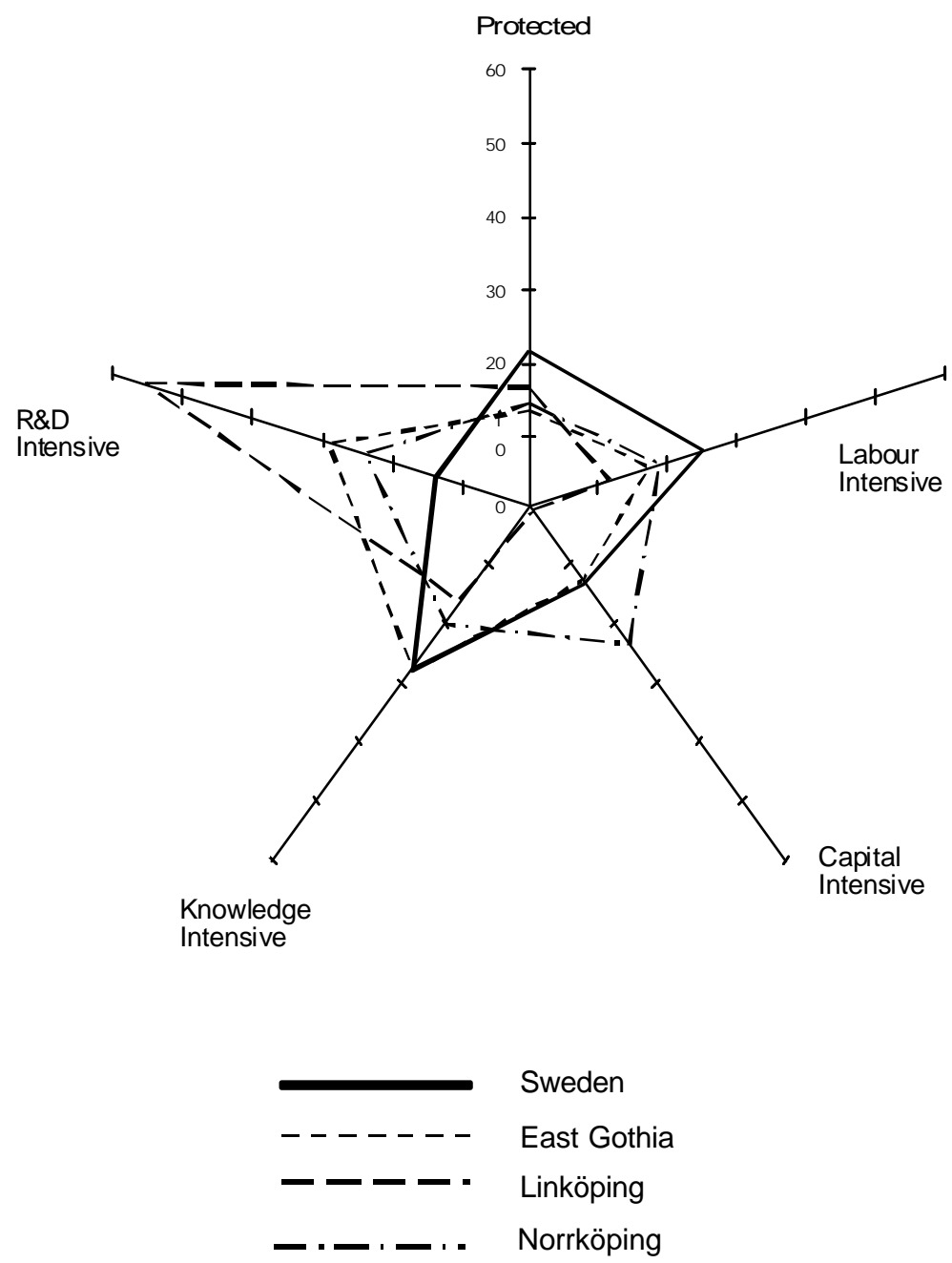
Figure 2: Value Added Distribution in Manufacturing Industry, 1994 (\%) (source: SCB, 1994b)
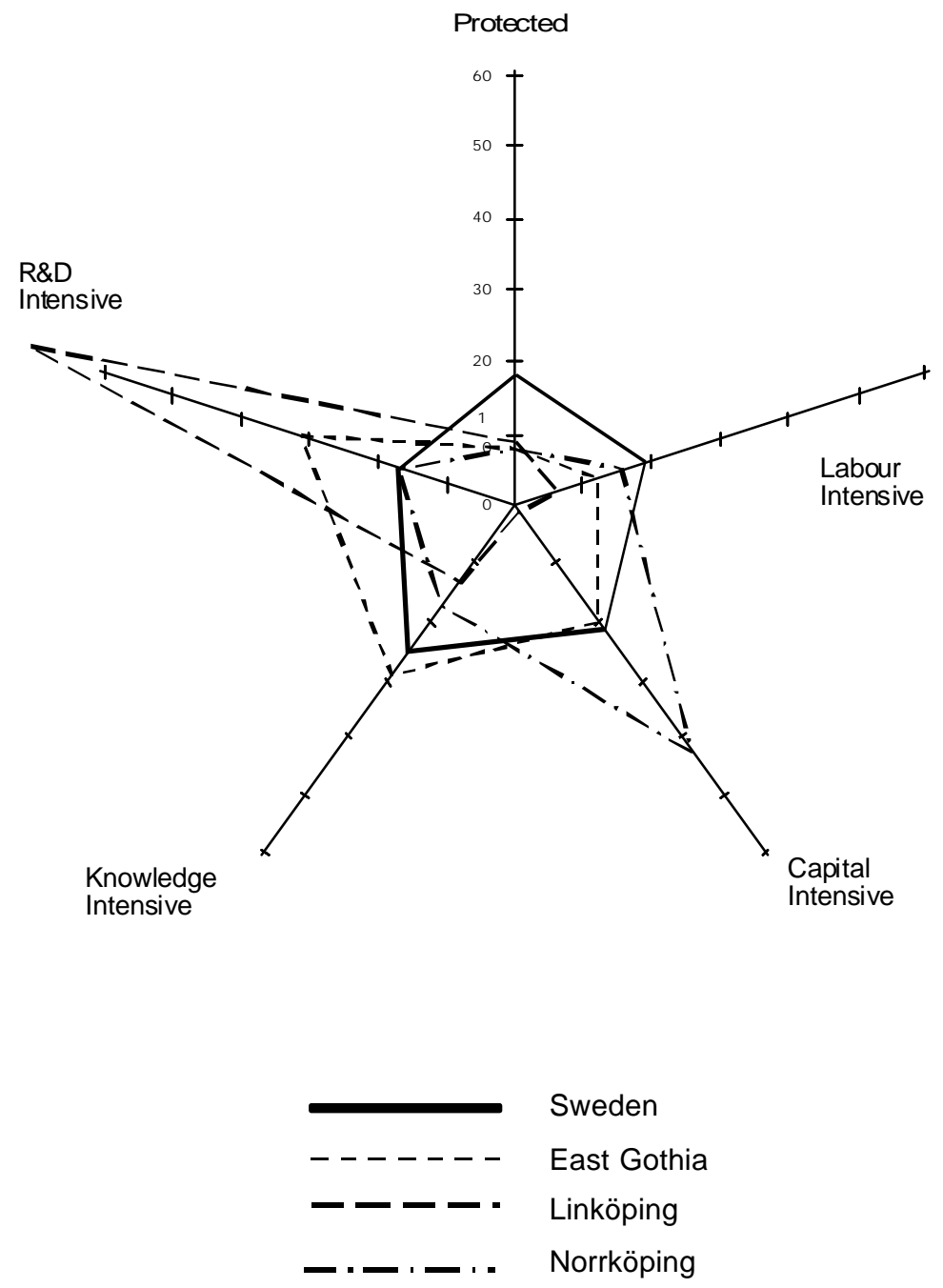
Figure 3: Level of Education in Manufacturing Industry (\%) (source: SCB, 1994b)



Figure 4: Share of High Education Industries in Five Industrial Sectors (\%), 1994 (source: SCB, 1994b).

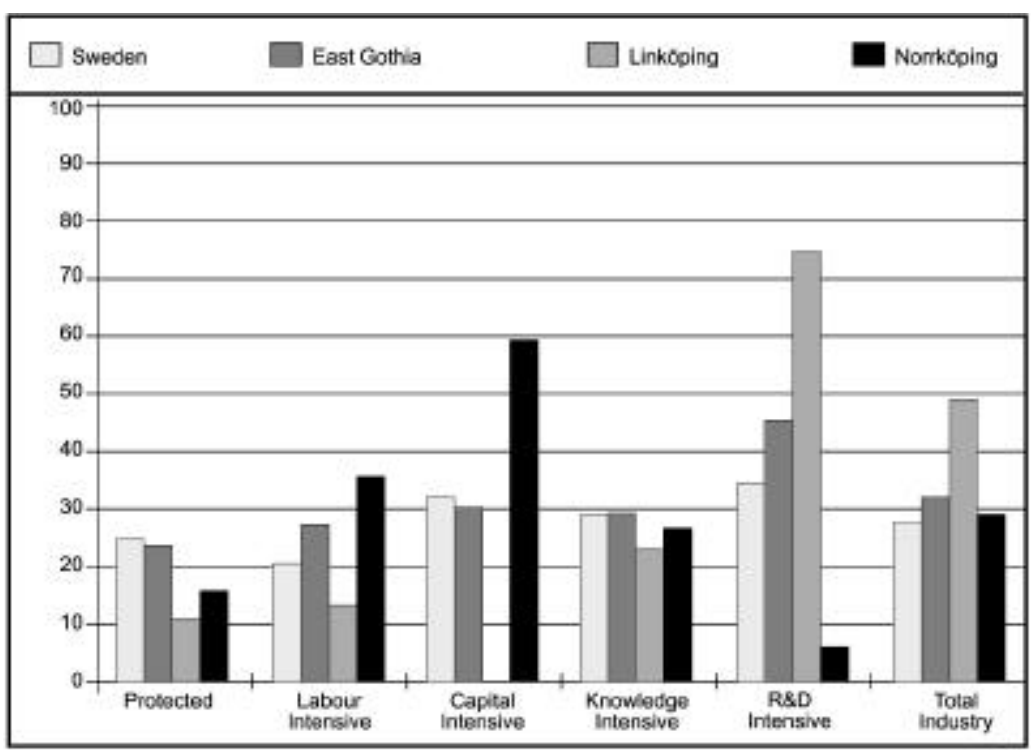


Figure 5: Share of Low Education in Five Industrial Sectors(\%), 1994 (source: SCB, 1994b).

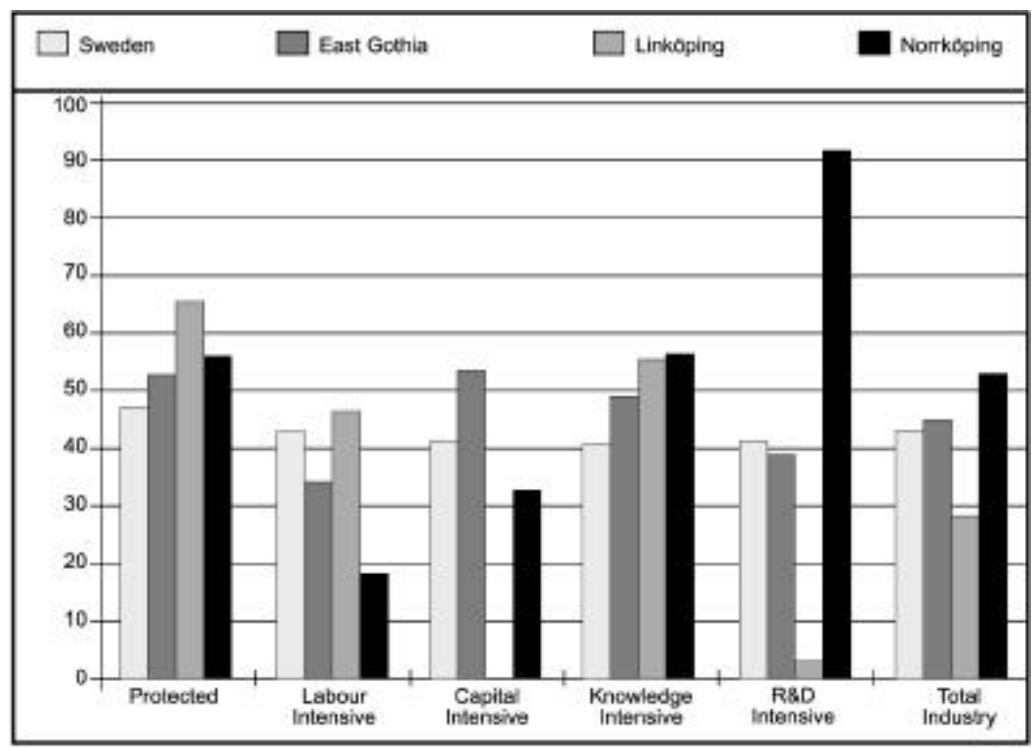

\section{Appendix 2 - Ohlsson/Vinell classification}

The Ohlsson/Vinell classification of industry according to SNI69:

1. Protected sector.

- food products: $3111,3112,3115,3116,3117,3118,3134$

- forestry: 33112, 3312

- building: material: 3692, 3699, 3813

- n.e.c.: $3420,35113,37103,37204,38191$

2. Labour-intensive sector.

- food products: $3113,3114,3119,3121$

- forestry: $33111,33119,34113$

- industrial country competitive: $3214,3320,3412,4319,3551,3559$, $3560,3620,3691,3812,38193,38194,38199,38393,38412,3849$ 
- non-industrial country competitive: $3211,3212,3213,3215,3219$, 32201, 32202, 32203, 32204, 32205, 32209, 3231, 3233, 3240, 3319, $3610,38195,3902,3903,3909$

\section{Capital-intensive sector.}

- food products: $3122,3131,3133,3140$

- forestry: 34111,34112

- petroleum based industry: 3530,3540

- hemical industry: 35111, 35112, 3512 (part of 35111), 3513

4. Knowledge-intensive sector.

- consumer durables: 38291, 3833, 38413, 3843§, 38432, 3844

- investment industry: 3821 (part of 382999), 3822, 38231, 38232, 38241, 38242, 38249, 382991, 382993, 382999, 38391, 38399, 38421

- "insats", consumer goods and other industry: 3521, 3523, 3529, $3811,38192,38259,38392,3852$

- shipping (varvsindustri): 38411

5. Research and development-intensive sector

- electronics based industry:

$38251=$ manufacture of computers

$3832=$ manufacture of teleproducts

$3851=$ manufacture of instruments ${ }^{*}$

- other:

$3522=$ manufacture of medicine

$3831=$ manufacture of electric, motors, generators and electric apparatus for machinery

$38451=$ manufacture of aircraft and motors 
According to SNI92, the following classes are included in the research and development-intensive sector:

- $22140=$ Publishing of sound recordings

- $22310=$ Reproduction of sound recording

- 2320 = Reproduction of video recording

- 22330 = Reproduction of computer media

- $24410=$ Manufacture of basic pharmaceutical products

- 24420 = Manufacture of pharmaceutical preparations

- 24650 = Manufacture of prepared unrecorded media

- $30010=$ Manufacture of office machinery

- $30020=$ Manufacture of computers and other information processing equipment

- $31100=$ Manufacture of electric motors, generators and transformers

- $31610=$ Manufacture of electrical equipment for engines and vehicles n.e.c.

- $31620=$ Manufacture of other electrical equipment n.e.c.

- 32100 = Manufacture of electronic valves and tubes and other electronic components

- 32200 = Manufacture of television and radio transmitters and apparatus for line telephony and line telefigurey

- $32300=$ Manufacture of television and radio receivers, sound or video recording or reproducing apparatus and associated goods

- 33101 = Manufacture of medical and surgical equipment and orthopaedic appliances except artificial teeth, dentures etc.

- 33102 = Manufacture of artificial teeth, dentures, dental plates etc.

- 33200 = Manufacture of instruments and appliances for measuring, checking, testing, navigating and other purposes, except industrial process control equipment 
- $33300=$ Manufacture of industrial process control equipment

- $35300=$ Manufacture of aircraft and spacecraft 


\title{
12 The Role of Culture in Economic and Social Development in Jalisco, México
}

\author{
Óscar Villarreal Fernández \\ Special Adviser for International Recruitment. Human Resources \\ Management - OECD
}

\section{Introduction}

In addressing the role of culture in the economic and social development of a region we will focus on Jalisco as a learning region, examining it from not just one but every angle, so that we can see whether it does in fact qualify as an "intelligent" region, although the criteria for defining a region as such have not yet been fully defined.

The main bibliographical sources used are official reports and statistics by the current State Government, which took office in 1995 . These sources are themselves based on government projects, analyses and reviews at state and federal level and on information supplied by the private sector and universities.

I have also drawn on my own personal knowledge and long experience both as an academic and a professional. The feeling of belonging and cultural identity - whether with reference to "learned" or "popular" culture - has been of enormous help to me in ensuring that this paper is more than just a compilation of events. Furthermore, in this paper, I will consider the notion of culture and the role of a region's culture not as it is primarily understood (and I will attempt to disassociate it from any connotations of "refinement"), but as the set of characteristics that define and identify a place. To speak of culture and regional identity, to me at any rate, is to talk about those aspects of a region that make it what it is, with all that it has and hopes to be.

Lastly, I should make it clear that this paper does not in any way set out to extol militancy or any party line. I will attempt, as far as possible, to steer clear of any ideology and to assess as objectively as possible (although as we 
all know, when we are speaking about people, it is hard not to be subjective) whether Jalisco can be regarded as a learning region.

\section{Definition of "an intelligent" region}

In order to qualify a region as a learning region, we have to determine whether it meets some or all of the following criteria:

1. It must have the human, material and communications infrastructure to generate, maintain and strengthen links and ties among the various stakeholders, society and the outside world.

2. One of its central aims must be the acquisition of knowledge, not only knowledge that is important for employment but knowledge that contributes to self-development, knowledge on a personal, family and social level, for the purpose of greater well-being, which, in turn, contributes to a greater sense of common welfare. In short, knowledge that teaches the value of life-long learning.

3. Its education policies must cover the full spectrum of education from nursery school to university, post-graduate and adult education and must not be confined to purely academic learning.

4. Its public and private sectors must have a clear and real role. I am referring here to the duties of the administration and the involvement and active participation of private sector firms, training institutions, research centres and civil associations.

5. It must actively create production and service businesses in which knowledge is a major component, thus developing human skills and organizational intelligence, creating the right environment for training, creativity and change.

6. It must have a clear common objective, identity and values.

7. It must constantly foster social cohesion and environmental protection.

How well does Jalisco match these criteria? Let us review the main concerns and policies of the state government. 


\section{Some indicators}

Jalisco, a name that is Nahuatl in origin and means "sandy plain", is famous worldwide as the cradle of mariachi music, the charro and tequila.

But that's not all it is renowned for. In fact, Jalisco is one of Mexico's leading states, a position it owes as much to its rich and fertile soils as to its history. It was the seat of feudal lords before the Hispanic conquest and, later, a political and cultural centre of the colonial period; a bastion of independence in the 19th century, it was the scene of the Mexican Revolution at the beginning of the century and the birthplace of great men. Among the great national figures born there were writers such as Juan José Arreola and Juan Rulfo, muralists and artists of the stature of José Clemente Orozco, Dr. Atl and Juan Soriano and eminent musicians such as Pepe Guizar and José Pablo Moncayo.

Located in the west of Mexico, Jalisco is the country's sixth largest state. Covering an area of $80,137 \mathrm{~km}^{2}$, or 4.1 per cent of the surface area of the country, it has $370 \mathrm{~km}$ of coastline. The statistics for 1997 show that it has a population of over 6 million and a population density of 77 per $\mathrm{km}^{2}$.

The state is now divided into 12 regions, comprising 124 municipalities each of which is divided into localidades, "ciudades", "villas", "pueblos", "congregaciones", "ejidos" and "ranchos". The metropolitan area, which comprises Guadalajara (the renowned "perla tapatía" and city of the roses), Zapopan, Tlaquepaque and Tonalá, covers an area of $1,466 \mathrm{~km}^{2}$ and has a population of nearly 3.3 million.

Jalisco is ranked third in Mexico in terms of production and trade as measured by gross domestic product and per capita income, accounting for approximately 7 per cent of the country's GDP. Its main industries are in the services, agricultural, commercial and crafts sectors, followed by manufacturing, transport and communications. The economically active population is employed mainly in the former sectors.

The state has seen tremendous growth in its exports, up by 25 per cent from 1995 to US\$ 7.8 million in 1998. Its share of national exports is estimated at around 6.5 per cent. With almost 800 firms -- 323 of which are in the Guadalajara metropolitan area where industry, services and trade are the main sectors --Jalisco accounts for an estimated 5.4 per cent of total foreign investment in Mexico. The main sources of foreign investment are the United States (58.5 per cent), and Canada (10 per cent), followed by the European Union, headed 
by Spain (nearly 5 per cent), Germany (4 per cent), and the United Kingdom (3 per cent).

The employment index warrants special mention. It has the second highest number of permanent employees registered with the Mexican Social Security Service (IMSS) nationally, and leads the western region in terms of job creation.

The education sector is expanding rapidly, from pre-school education through to university and postgraduate education, with primary school enrolment of almost 1 million, 300,000 lower secondary and 130,000 upper secondary pupils and 85,000 university students. The state has 15 higher education institutes including one university of technology and six nationally and internationally renowned universities (one public and five private): the Universidad de Guadalajara (the second largest in the country, with a 1995 enrolment of 76,380 students on campuses across the state, including 48,000 in the Guadalajara metropolitan area); the Universidad Autónoma de Guadalajara (7,300 students); the Instituto Tecnológico de Estudios Superiores de Occidente (5,000 students), the Universidad del Valle de Atemajac (3,600 students), the Universidad Panamericana (2,400 students) and the Campus Tecnológico de Monterrey (2,500 students). I should mention here that the Universidad Nacional Autónoma de México, the largest in the country and in Latin America, has a student enrolment of more than 350,000.

\section{Identifying priorities, finding solutions}

While Jalisco is certainly one of the leading states in the country, its employment, poverty and crime rates and natural resources and ecological indexes continue to be the central concerns of economic and social policymakers and representatives and senior public authorities at state and national level.

An analysis of the last few years shows that various problems have been experienced at different levels and on different scales: a lag in education, with an average of 6.7 years of schooling, putting the state in 10th place nationally (the Federal District heads the list with an average of 8.9 years); wide discrepancies at regional level in education indicators and rates of employment, production and trade with uneven and sometimes weak participation by the 124 municipalities. The representatives of the municipalities have repeatedly voiced their concern and shown their interest in setting up any 
type of business inside the state - crafts, microbusinesses, assembly plants or other - in order to tackle the problem of unemployment and underemployment head on. It has been estimated that as much as 60 per cent of the economically active population was either without work or underemployed at the end of 1994. Likewise, there had been a marked trend towards centralisation in the Guadalajara metropolitan area, with large influxes of people migrating there from other municipalities adding to employment, housing, health and education problems and adversely affecting the crime and security figures.

Two primary objectives of the work programme prepared by the State Administration to tackle these problems are relevant to us here: achieving a just, efficient, human economy; and, improving the public's quality of life.

For our purposes, these objectives would seem to a large extent to satisfy the conditions listed previously for the definition of a learning region. This is borne out by policies aimed at:

- expanding and improving close, co-operative and efficient relationship among the actors in the productive system;

- strengthening public participation;

- ensuring fair distribution of wealth;

- combating poverty and fostering employment;

- promoting infrastructure as a platform for development;

- guaranteeing human rights;

- encouraging sustainable regional development by balancing the growth and territorial distribution of the population;

- fostering a culture of responsible consumption;

- expanding and improving health and education services;

- ensuring sustainable development;

- encouraging a more caring society;

- strengthening roots, preserving values and traditions.

In other words -- given that the phenomenon of globalisation has not gone unnoticed in the area and that the threats and challenges facing society 
are steadily increasing -- Jalisco is seeking to take its place on the international scene by transforming a once agricultural state into an industrial state in which firms are competitive and there are real synergies between science, industry and technology. This will be achieved, among other things, by tools to encourage investment in line with the special terms and incentives that can be given to firms in these regions. Tools such as skills training and production projects will be key factors in achieving this commitment.

Such ambitious objectives cannot be attained without the proper human and physical infrastructure. Neither would there be any point in undertaking this process without taking into account social development in the broadest sense, in the interests of equal opportunities and living conditions. Education services play a key role and it is hoped that, with improved quality and equity as the goal in this sector, a degree of excellence can be achieved by means of innovative projects, among other things.

In the context of state reform, environmental factors are also relevant. Jalisco's Secretary for the Environment, Natural Resources and Fisheries has set the priorities for the region as ecological land-use planning, air pollution control, the conservation and development of natural resources and natural areas, encouraging consumption of fisheries products, hazardous waste treatment and new attitudes to water use. In this, the role of the private sector, particularly firms that are or will be part of the many industrial corridors, is crucial.

\section{Analysis of findings}

In 1998, as every year, the State Authorities reviewed their achievements in the course of this new era of globalisation and technology that is taking them into the new millennium.

The threats and challenges that the new millennium will bring are becoming steadily clearer but not any easier.

The review showed that the main focus of the government's programme had been decentralisation and support to the regions.

Two important on-going activities were:

1) An ambitious regionalisation plan to decentralise the distribution of 
resources, strengthening the 12 regions. Agreements were reached in 1998 on regionalisation in Jalisco, designed to foster the development of the state through full participation in the decentralised management of government policy, and closer integration of the 124 municipalities. An agreement on the Constitution of a State Sub-Committee for Regional Development was also reached in late 1998.

2) An Economic Development Act for the State of Jalisco was passed in 1995 in order to promote the generation of well-paid jobs, attract investment consistent with the goal of sustainable development and stimulate exports.

The results have been as follows:

Over MN\$ 30 million were granted for the promotion of the economy, mainly to inland areas. This operation benefited over 20 municipalities in 1998 and generated 10,000 new jobs. In addition, special attention was given to promoting the development of new industrial parks through programmes encouraging private investment and strenuous efforts were made to provide financial support for Jalisco's micro-businesses. With its extensive involvement in the electronics, telecommunications and information technology industries, Jalisco is now internationally regarded as Mexico's Silicon Valley. As a result, investment in the State doubled from 1997 to 1998 . Also to be noted are its "Programas de Agrupamientos Empresariales" (business federation programmes), particularly in the footwear, clothing and crafts industries. Jalisco has the largest crafts industry in Latin America and in Mexico in terms of volume, quality and diversity. Loans were granted to over 2,000 craftsmen. It is worth noting that Jalisco's crafts sector accounts for over US\$100 million dollars in exports each year.

Education is the priority in the State's social policy, accounting for nearly half of the budget. The focus has been on decentralising education. In the year prior to the review, a total of 185 facilities were built in 33 municipalities. Some challenges were also set for the year 1998-1999, such as: increasing enrolment; strengthening science teaching by the provision of computing and laboratory equipment; prevention of educational failure from primary school onwards; stepping up of adult education (literacy) projects, education and distance learning at secondary school level and education for indigenous people, with special emphasis on quality via 18 new facilities and the refurbishment of accommodation; strengthening teacher training schools and the academic work of post-graduate institutions; oversight of 2,579 education facilities 
under repair and maintenance; strengthening of public participation in education, etc. Another challenge will be to improve teaching, with greater emphasis on the quality of education, leaving behind the days of traditional methods and shortages of teaching materials.

Regional development also encompasses the cultural domain. In this field, the tourism and culture authorities joined forces to develop the promotion of tourism at regional level. Under a programme to revamp the urban image of tourism destinations, the state was divided into 16 tourism areas, each with their own tourism routes and cultural tours, such as the Volcano Route, the Mariachi, Tequila and Religious Tours and the Haciendas and Country Houses of Jalisco Tour. Special attention was given to the promotion of school, thirdage and conference tourism and national and international campaigns were conducted in close liaison with the private sector. Other helpful tools were the Hundred Cities Programme and the Intermediate Cities Programme which last year benefited more than 20 municipalities, some of which completed the restoration of their historic centres. In 1994 the creation of a sponsorship programme for the historic centre, traditional districts and areas of the city of Guadalajara was approved and work is currently under way on a proposal for a Cultural Development Act, aimed among other things at establishing a statutory instrument in the form of a Cultural Code for the State of Jalisco.

Finally, with regards to the environment, action from both the public sector at federal, state and municipal level and by the private sector is expected to be intensive and will include: the development of natural water features as tourist attractions; air quality monitoring in the Guadalajara metropolitan area; environmental education programmes and the creation of a new "water-use culture"; operation and maintenance of waste-water treatment plants, fire prevention and forestry development.

\section{Regional culture, regional development}

It may be of interest, in this context, to speak of culture in the broadest sense of the word, as the reflection of a community's way of life and its social mores. This approach touches on more than the traditions, heritage, cultural identity, values and roots of a particular area. We can say that the culture of an area is the confluence of its geographical characteristics, the characteristics of its people, its economy and its social activity. This is why I venture to talk about the characteristic "regional culture" of the State. 
The cultural capital of a region consists of its cultural, historical, archaeological, architectural and artistic heritage, both human and material. Indeed, its human capital is part of its cultural capital. This includes values such as its popular culture, religious traditions, folklore, cuisine and, indeed, the environmental and behavioural culture which distinguish it from other areas.

I suggest these aspects because, for our purposes today, Jalisco's society can be characterised, "culturally" speaking, by:

(1). the number of Jaliscans resident abroad - estimated at more than 1 million - who contribute to the economic development of the region by sending part of their earnings to their families. The latter set up small businesses and factories, thus swelling the numbers of family-run micro, small and medium sized enterprises, which as we shall see are typical of the region. Furthermore, this population with the many trips and visits it makes can "infect" others with ways of living and life styles, values and even social identity;

(2). a historically important religious tradition with great social influence in the south of the country; and hence

(3). the characteristics of the family and its role as the most important unit in society.

I think that these are interesting points to mention since Jalisco is one of the first states in Mexico to vote in a right-wing government. The concrete examples of projects and programmes that I will shortly address clearly show the influence of these cultural traits and idiosyncrasies.

In this sense, Jalisco is combining its efforts in the field of culture, tourism and education in order to define and forge an image of the Jaliscan identity, which can be characterised as "a diversified, pluralist society (that) possesses a culture rich in nuances and contrasts, that has drawn on a variety of sources (...) and recreated itself over a bedrock of traditions, habits, customs and values that throws the idiosyncrasy of Jaliscans into more or less sharp relief." These efforts have taken the form of 1) the decentralisation of cultural projects: 2) the maintenance of these projects through legal and administrative measures; 3) the wide provision of centres for artistic expression; 4) support for artists; and 5) the integration of civil society initiatives organised through subsidies which enable them to be self-managing.

Some examples will give a clearer idea of how these objectives have 
been achieved.

\section{Joint public/private sector efforts:}

Starting at the end of the 1970s, in the heart of Guadalajara city, a major project to restore, rebuild and redevelop the historic centre, founded in the 16th and 17th centuries. With the demolition of 11 blocks in a location where the local culture was clearly represented (housing, trade, production) but showing serious signs of dilapidation, the public and private sectors and the public at large worked together to get the Plaza Tapatía project off the ground. This large central square houses much of the historical and architectural heritage of the city: the Government Palace, the Cathedral, the Cabañas Hospice - which has been a World Heritage site since 1997 and now houses the office of the Secretary for Culture - the Plaza de Armas, Plaza de la Bandera, the Degollado Theatre, the Regional Museum, which is now the Music Workshop of the University of Guadalajara, the Secretariat for Tourism, the San Juan de Dios Market and much more. It is a pleasant walk for the residents of the city, domestic and foreign tourists with shade trees, fountains and areas where contemporary artists have contributed major pieces, such as the "Immolation of Quetzalcóatl" or the sculptures at the entrance to the Cabañas Hospice. The construction of this large area was designed so that it also functioned as a shopping area with department stores and boutiques of all types and sizes, restaurants, bars and recreation areas.

It was in 1996 that it became clear that the Plaza Tapatía should be renovated and revitalised in order to pave the way for the city's entry into the new millennium: there are proposals for parking facilities, transport for tours inside the area, total regeneration of the Degollado and Cabañas areas and presentation of the plaza as a popular modern activity and recreation centre for young people. The project had and no doubt still has an important role in creating jobs and since its inception has enabled the regeneration of the city centre and has encouraged the reconstruction not only of great houses and their surroundings but large districts of historic importance both in the metropolitan area (Zapopan, Tlaquepaque and Tonalá) and in smaller cities (San Juan de los Lagos, Lagos de Morena, Puerto Vallarta). 


\section{$\underline{\text { Private sector, family and religious tradition }}$}

The expansion of the private sector, combined with the religious tradition of the region, has been a determining factor in the development of education over the last few years. Indeed, the number of private education institutions from pre-school, primary and secondary education through to preparatory and university levels has been increasing. It is interesting to note the "fundamental role played by religious aspects", mentioned above, as one of the key idiosyncratic factors of Jalisco. The Universidad Autónoma de Guadalajara, founded in 1935, is the oldest private university in Mexico and has its own regional daily newspaper. The Instituto Tecnológico de Estudios Superiores de Occidente was founded in 1957 by the Society of Jesus; the Universidad Panamericana dates back to 1967 and an agreement between the State Government and the Prelature of Opus Dei. The Instituto Tecnológico de Estudios Superiores de Monterrey, founded in 1943 by a group of Mexican employers, opened one of its many campuses in Guadalajara in the early 1990s. All of these institutions offer education programmes that are very competitive with those of the Universidad de Guadalajara (public, independent university) and draw large numbers of students from all over the region and Latin America. They are involved in research and development projects that have been designed in conjunction with the private sector through training programmes and production project start-ups that generate work opportunities for future graduates.

\section{Education and regional identity}

In addition, in liaison with the Secretariat of Public Education as part of the reforms to Article 3 of our Constitution, the State Secretariat for Education provided free textbooks on the geography and history of Jalisco for 3rd grade primary school pupils for 1996. After studying the five chapters and 38 lessons, the pupils are familiar with the 12 regions, their geography, hydrography, climate and history from the first inhabitants before the Conquest, through the colonial period, the Mexican Revolution and Independence, to modern times. At the end of each lesson there is a section containing suggestions for activities to consolidate what pupils have learned, frequent visits to museums in the area or small research projects. 


\section{Local culture: trade and production}

As we have seen, industry in Jalisco consists typically of small and medium-sized manufacturers mainly of textiles, footwear, food and drink, rubber and plastics, furniture, pharmaceuticals and, latterly, high-tech and electronics products. Keen to promote and strengthen development under this heading, another equally important initiative implemented by the State was the creation of industrial parks and complexes - with surface areas ranging from 5 to $100 \mathrm{~km}^{2}$ - throughout the state. Of Jalisco's nearly 800 firms, which account for 5.4 per cent of foreign investment at national level, 281 are in the services sector, 270 in the industry sector and 206 in the commercial sector. There are now 16 industrial parks, areas or corridors, mainly in the Guadalajara metropolitan area, and 16 others are under construction in the interior of the state. Along with the new impetus it has given to industry, the state is also striving to promote a new culture of staff training and environmental protection in which the private sector is playing a key role.

Shopping centres or plazas have taken off in a big way in Jalisco in the last 10 years, particularly in Guadalajara. Since the construction of one of the most well-known shopping plazas in 1968, the Plaza del Sol, there are now more than 20 such centres, which besides boosting trade and generating jobs are places for the young, and not so young, to meet, relax and spend some leisure time, with numerous cafes, bars, restaurants, cinemas, cyber-cafes as well as play and learning areas for children. These programmes are being imitated with great success in all of the medium-sized cities in Jalisco.

Other programmes and projects now under way also warrant mention.

a) The drive to protect the rights of indigenous peoples (5,500 Nahuas in the south, 16,000 Wirákiras in the north), with the creation of the Procuradería para Asuntos Indígenas, in co-operation with the University of Guadalajara, the Secretary for Culture and the Department of Education. Its purpose is to improve development in the areas in which these peoples live, with closer attention to territorial administration, building schools, formulating education programmes and the dissemination of the languages of these peoples.

b) The new regional network of public libraries.

c) The "new-look" State Philharmonic Orchestra and the State Choir 
(ranked second in Mexico), and

d) Advertising and promoting fairs - such as the book fair, the book and culture fair, the international ceramics fair - conferences and awards at international level.

e) New and proposed legislation on the environment, heritage and culture, including the new State Acts on Ecological Balance and Environmental Protection (1989), the Patronage of the Historic Centre and Traditional Districts and Areas of the City of Guadalajara (1994), the Cultural Heritage of Jalisco State and Municipalities (1998) or the proposed legislation on cultural development.

\section{Conclusions}

In conclusion, in this last section I have mentioned some of the characteristics of a learning region. If I have deliberately mentioned the concept of life-long learning, it is because it is implicit in projects to improve the wellbeing of the population whose "aim is to build and create the conditions that enable every individual to develop his or her capacities and abilities to the full (through an effort) directed at the community, family and individual in all of the regions (of the) state."

While we can certainly say that Jalisco indeed exhibits many of the characteristics of a learning region, and moreover has a great influence on its neighbouring states, the following questions nevertheless arise:

1.- Is this enough to classify it as a learning region?

2.- Is a learning region the result of, or an obligatory stage in, the cause and effect relationship that is an inevitable consequence of the globalisation that we are all experiencing?

3.- What methods and strategies characterise these regions?

4.- How do we build a common framework that will be applicable to a specific context and yet respects the concept of "regional culture"?

Let him who has the answer, cast the first stone. 


\section{Bibliography}

-Fryer R.H. (1999): Creating learning Cultures: Next Steps in Achieving the Learning Age. Second Report of the National Advisory Group for Continuing Education and lifelong learning. London.

-Gobierno del Estado de Jalisco (1998) : Cuadernillo ejecutivo sobre La Industria Electrónica y de Telecomunicaciones en Jalisco. Gob. del Edo. de Jalisco.

·H. Ayuntamiento Constitucional de Guadalajara 1998-2000 (1999): Guadalajara Jalisco México. Gob. del Edo. de Jalisco.

.OCDE (1999): Les villes et les régions apprenantes. Paris.

OECD (1997): better understanding Our Cities: The role of urban indicators. Paris.

.OECD (1998): Descentralisation and Local Infrastructure in Mexico. Paris.

.OECD (1998): Integrating Distressed urban Areas. Paris.

.OECD(1997): Regional Competitiveness and Skills. Paris.

.OECD(1998): Regional Development nand Structural Polici in Mexico. Paris.

·Página web de la Cd. de Guadalajara: www.vivegld.com.mx

-Página web de Promoción Comercial de la Cd. de Guadalajara: www.businessgdl.com.mx

·Página web del Gobierno del Estado de Jalisco: www.jalisco.gob.mx

-Página web del Sistema estatal de Información Jalisco del Gobierno del Estado de Jalisco: xxx.jalisco.gob.mx/srias/seijal/index.htlm

Secretaría de Desarrollo económico (1999): The future of electronic JaliscoMexico's High-Tech haven: Jalisco, the Mexican Sillicon Valley. Gob. del Edo. de Jalisco.

-Secretaría de Educación Jalisco (1999): Educación Jalisco. Gob. del Edo. de Jalisco.

SEIJAL (1999): Indicadores económicos de Jalisco. Gob. del Edo. de Jalisco. 
SEIJAL (1999): Infraestructura eléctrica en el Estado de Jalisco. Gob. del Edo. de Jalisco.

.SEIJAL (1999): Infraestructura Jalisco. Gob. del Edo. de Jalisco.

.SEIJAL (1999): Jalisco actual. Gob. del Edo. de Jalisco.

.SEIJAL (1999): Jalisco informa. Gob. del Edo. de Jalisco.

.SEIJAL (1999): Oferta Educativa Jalisco. Gob. del Edo. de Jalisco.

.SEIJAL (1999): Tarifas de Energía Eléctrica en Jalisco. Gob. del Edo. de Jalisco.

.SEIJAL (1999): Situación hidráulica en el Estado de Jalisco. Gob. del Edo. de Jalisco. 
